Portland State University

PDXScholar

Winter 3-24-2014

\title{
Individuals with Intellectual Disabilities in Faith Communities: Perspectives of Catholic Religious Leaders
}

Mazna Patka

Portland State University

Follow this and additional works at: https://pdxscholar.library.pdx.edu/open_access_etds

Part of the Catholic Studies Commons, Civic and Community Engagement Commons, and the Community Psychology Commons

Let us know how access to this document benefits you.

\section{Recommended Citation}

Patka, Mazna, "Individuals with Intellectual Disabilities in Faith Communities: Perspectives of Catholic Religious Leaders" (2014). Dissertations and Theses. Paper 1632.

https://doi.org/10.15760/etd.1631

This Dissertation is brought to you for free and open access. It has been accepted for inclusion in Dissertations and Theses by an authorized administrator of PDXScholar. Please contact us if we can make this document more accessible: pdxscholar@pdx.edu. 
Individuals with Intellectual Disabilities in Faith Communities:

Perspectives of Catholic Religious Leaders

by

Mazna Patka

A dissertation submitted in partial fulfillment of the requirements for the degree of

Doctor of Philosophy

in

Applied Psychology

Dissertation Committee: Eric Mankowski, Chair

Katherine E. McDonald

Greg Townley

Yves Labissiere

Portland State University

2014 
C 2014 Mazna Patka 


\begin{abstract}
Community psychology is concerned with the relationship between individuals and social systems in community contexts, but the field has under-explored the role of religious organizations in the lives of individuals with intellectual disabilities.

Worldwide, most people identify with a religion, and congregations serve as important mediating structure that creates a sense of community and provides linkages between individuals and society. There may be significant benefits to religious participation, including greater life satisfaction, health, and quality of life. Such benefits may be especially important to individuals with intellectual disability who generally experience poorer outcomes. However, we know very little about the inclusion of persons with intellectual disability in faith communities, particularly from the perspective of faith leaders who play pivotal roles in transmitting values and making decisions for their community.
\end{abstract}

The present dissertation aimed to address gaps in knowledge about how religious leaders make meaning of intellectual disabilities and their perspectives toward individuals with intellectual disabilities. Catholic priests, parochial vicars, and deacons were interviewed to address three overarching research questions, viz. (a) What types of experiences, in and outside of faith communities, do religious leaders have with individuals with intellectual disabilities?; (b) What are the beliefs of religious leaders toward the involvement of individuals with intellectual disabilities within faith communities?; and (c) How does religion inform the understanding of intellectual disabilities among religious leaders? 
Participation was limited to religious leaders who are part of the U.S. Roman Catholic Archdiocese in Portland, Oregon. Participation was only sought from religious leaders who are assigned to parishes that either host adaptive liturgies or were identified as having at least one parishioner with developmental disabilities participating in the mainstream mass. A total of 12 religious leaders (pastors, parochial vicars, and deacons) participated in the present study. Semi-structured interviews illuminated the perspectives of religious leaders toward individuals with intellectual disabilities such as the type of involvement individuals with intellectual disabilities are encouraged to engage in within the congregation. Additionally, participants were also asked about how they made meaning of intellectual disabilities.

Using grounded theory analysis, I identified five models of intellectual disability that organize the complex relationships among the focal research questions. These five models include (1) Close to God, (2) Conformity, (3) Unfortunate Innocent Children, (4) Deficient, and (5) Human Diversity. Among the five models, Human Diversity viewed intellectual disability as a natural part of human variation while the rest focused on negative or positive stereotypes of intellectual disabilities. Each model yields a different definitions which results in varying determinations of the needs of people with intellectual disabilities. However, each definition is one dimensional and bound in culture. Most of these models suggest that the construction and categorization of intellectual disability may perpetuate inequality. Additional research is needed to explore the boundaries of models of intellectual disabilities constructed within a religious 
context. The present dissertation is one step in exploring meanings of intellectual disabilities and factors that impact their participation in faith communities 


\section{Table of Contents}

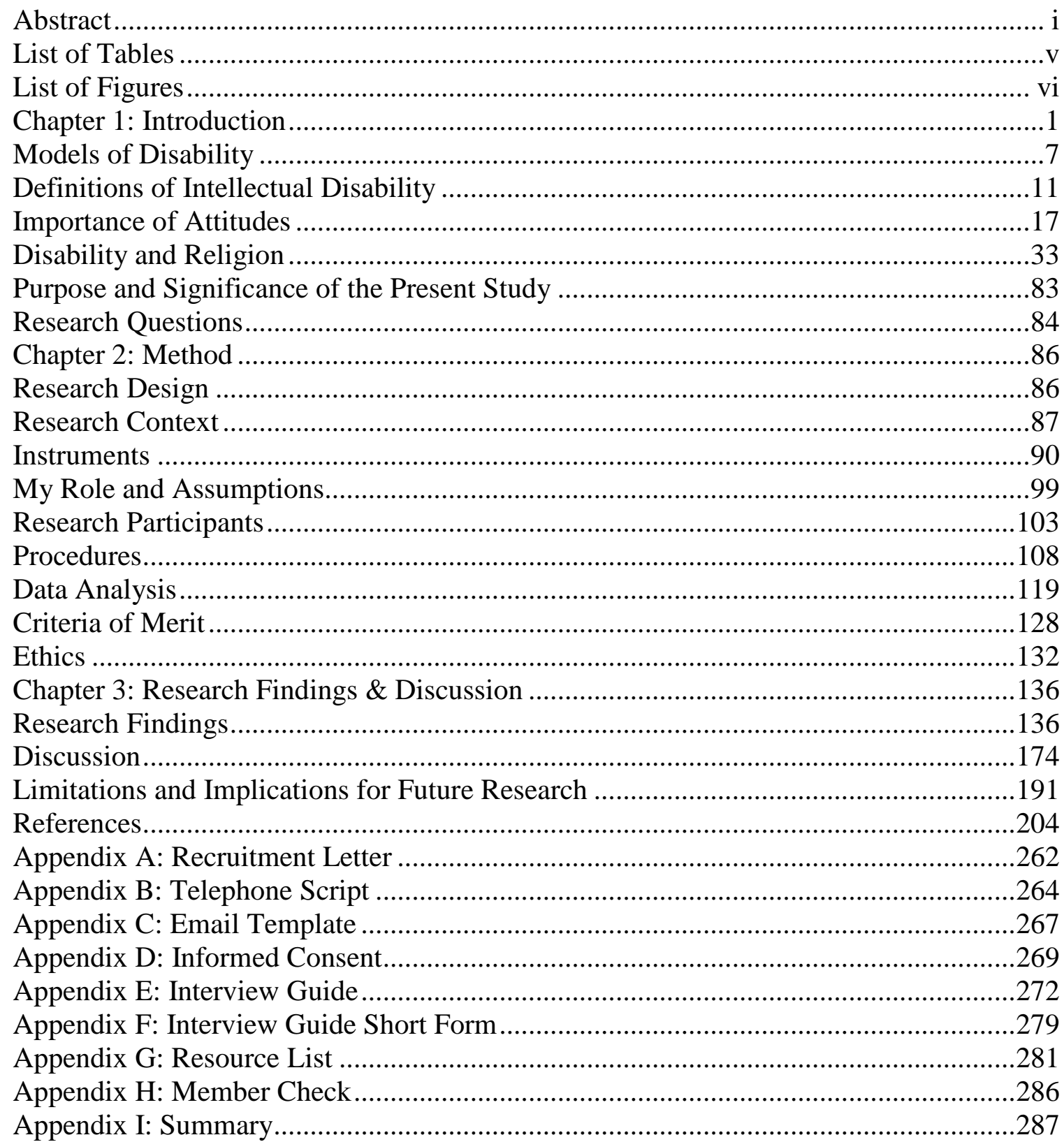




\section{List of Tables}

Table 1. Summary of Results..................................................................................199

Table 2. Similarities and differences among models of intellectual disabilities ............200 


\section{List of Figures}






\section{Chapter 1: Introduction}

Community psychology, since its inception at the Swampscott conference, has emphasized working with individuals and communities within their natural environments (Bennett, Anderson, Cooper, Hassol, Klein, \& Rosenblum, 1966). Working within natural environments involves incorporating culture and context, which allows community psychologists to both further the field's vision and develop a socially responsible agenda for the future (Trickett, 1996). However, the field has under-attended to the role of religion and religious organizations as a source of meaning and strength for individuals and communities. Religion, a form of spiritual expression, provides shared rituals, narratives, symbols, and guidance (Turner, Hatton, Shah, Stansfield, \& Rahim, 2004).

Worldwide, approximately $87 \%$ of the world's population identifies as following a religion [Central Intelligence Agency (CIA) World Factbook, 2008]. Religion is an untapped realm of life many people closely identify with, which community psychologists are only recently beginning to integrate into their work (Hill, 2000; Kloos \& Moore, 2000; Maton \& Wells, 1995). Although religion has received limited attention, research has found that congregations serve as mediating structures. Mediating structures are organizations that provide linkages between personal lives and the broader public sphere of society while also creating a sense of community (SOC; Hughey, Speer,

Peterson, 1999; Pargament, 1997). At the individual level, religious communities have an interest in promoting particular beliefs and behaviors among its members. At small group and organizational levels, many religious organizations create local settings to 
support members, reach out to their local settings, and establish policies that are consistent with their ideology (Levin, 1994). Additionally, the promotion of particular ideologies creates religious movements (Kloos \& Moore, 2000). Thus, a vast audience is presumably receptive to messages that can be drawn from religion.

The field of community psychology has been concerned with the way in which collectives, such as religious groups, satisfy the need for belonging in its members (Sarason, 2001). The sense of belonging or SOC has served as a preventative mechanism to reduce loneliness and isolation while also creating boundaries that both include and exclude segments of society (Newbrough \& Chavis, 1986; Sarason, 2001). Community psychologists as well as other social scientists have found that religious involvement is significantly and positively associated with positive life outcomes such as better physical health (George, Larson, Koenig, \& McCullough, 2000; McCullough, Hoyt, Larson, Koenig, \& Thoresen, 2000), lower alcohol use (Michalak, Trocki, \& Bond, 2007), empowerment (Maton \& Salem, 1995; Speer, Hughley, Gensheimer, \& Adams-Leavitt, 1995), and mental health (Bergin, 1983; Hill \& Pargament, 2003; Maton, 1989; Turner et al., 2004). Moreover, an eight year follow up of more than 20,000 adults representative of the U.S. population found that those attending religious services more than once a week lived about seven years longer than individuals who never attended religious services (Hummer, Rogers, Nam, Ellison, 1999).

Two mechanisms by which religion affects positive outcomes such as physical and mental health include social support and the coherence hypothesis (George et al., 2000). Religious participation may facilitate social support, which in turn has been 
demonstrated to promote health and facilitate recovery from illness (George et al., 2000; Oman \& Thoresen, 2005). Religious participation may also be one of the major contexts in which close social relationships are built outside of nuclear families, and religious organizations explicitly make support part of their organizational mandate (Mattis \& Jagers, 2001; Speer et al., 1995). The coherence hypothesis posits that religion yields positive outcomes such as health promotion by providing a sense of meaning so that people understand their role in the universe and develop the courage and resources to endure life challenges (George et al., 2000).

The participation of individuals with intellectual disabilities within religious communities is unclear (Selway \& Ashman, 1998) because there has not been an extensive study investigating the advantages of membership within faith communities among individuals with intellectual disabilities. For example, in an extensive review of literature on the community participation for adults with intellectual disabilities (Bray \& Gates, 2003), only one study examined integration within church among 11 other community settings (Heller, Miller, \& Factor 1999). In regard to the benefits of religious participation, only one study (Turner et al., 2004) has reported that religious activities and spiritual belief systems were significantly related to life satisfaction, general health, and quality of life for individuals with intellectual disabilities. It is likely that the benefits reported by Turner et al. (2004) and those experienced by the general population extend to individuals with disabilities. With the majority of the world's population identifying with a religion (CIA World Factbook, 2008), it is critical to examine the 
impact of religion on issues relating to individuals with intellectual disabilities to fully address challenges they face in their communities.

In 1998, Selway and Ashman reported that empirical evidence of whether religion foster positive and/or negative attitudes toward people with intellectual disabilities does not exist. Additionally, according to Reinders (2011), academic literature has under-attended to the experience of making meaning of disabilities and its intersection with religion. However, it is known that religion is often used as a source of understanding suffering, death, and differences (Gaventa, 2002). Thus, a religiously bound understanding the meaning making process and perspectives toward individuals with intellectual disabilities within faith communities is needed. Past studies have focused on how parents understand their child's intellectual disabilities (Masood, Turner, \& Baxter, 2007; Mickelson, Wroble, \& Helgesan, 1999) but little information exists on how other groups, such as religious leaders, understand intellectual disabilities.

Further, prior studies have not addressed the understanding of intellectual disabilities among religious leaders or their views toward the participation of individuals with intellectual disabilities in faith communities. In regard to literature concerning individuals with disabilities generally and religion, religious organizations have published policies and statements to promote inclusion rooted within religion texts and resources for various facets of life within faith communities (e.g., Association of Theological Schools, 2008; Cater, 2007; National Council of Churches of Christ, [NCCC] 1995). Similar to policy statements and resource development, studies have discussed and created interventions to promote understanding of people with disabilities 
among seminary students and congregations (Anderson, 2003; Collins \& Ault, 2010; Kleinert, Sharrard, Vallance, Ricketts, \& Favley, 2010), yet only one study (i.e., Butler, Hayley, Ege, \& Allen, 2011) has examined the perceptions of religious leaders toward the benefits and barriers of supporting individuals with disabilities.

Religious leaders are instrumental in moving faith communities toward inclusion of individuals with disabilities within faith communities. Religious leaders have the authority to guide their faith community and therefore are involved in the transmission of values and moral attitudes among congregational members (Lightfoot et al., 2001). Although advocacy for persons with disabilities is often through self advocates and family members, religious leaders have the authority to determine funding to implement changes in floor plans, furniture, updating curriculum, reconfiguring liturgical practices, etc. (R. B. Steele, PhD, personal communication, May 31, 2012). Additionally, religious leaders serve as a form of support for individuals with disabilities and their family and friends to assist in coping with difficult situations (e.g., diagnosis of disability; Johnstone, Glass, \& Oliver, 2007; Pargament, 1997).

Understanding the meaning making process and perceptions of intellectual disabilities among religious leaders through community psychology is a fruitful endeavor. At present, we know that religion is used to promote particular beliefs and behaviors and it can serve a mediating structure. Further, religious involvement is related to positive outcomes and has been used as a source to understand life experiences. For example, recent research has focused on how parents of children with disabilities make meaning of disabilities. However, research has not explored how religious leaders make 
meaning of intellectual disabilities and their perceptions toward the inclusion of individuals with intellectual disabilities within faith communities. The present dissertation intended to examine this very topic. Moreover, the present dissertation sought to integrate organizational theories on leadership styles and organizational culture within the field of community psychology. The results are intended to inform future research aiming to promote the inclusion of individuals with intellectual disabilities in faith communities.

The present dissertation integrates theory and prior research on disability, attitudes, religion, and leadership. Therefore, the first chapter will discuss various models and definitions of disability. The subsequent section seeks to establish the importance of attitudes through presentation of prior research. Additionally, the link between attitudes and the demographics of the respondent and reference group are also presented. The next section discusses the intersection between disability and religion which imparts definitions of inclusion within faith communities, religious responses to disabilities, and the impact of religion on coping, specifically the process of meaning making and attributions. The last section will discuss organizational scholarship including organizational culture and leadership followed by inclusive and exclusionary practices of faith communities. The chapter will conclude with the significance of the present dissertation and research questions of interest. The second chapter will state the method and analysis plan. The last chapter includes a section on the findings, discussion, and limitations and implications of the present study. 


\section{Models of Disability}

Definitions of disability emerge from individual models of disability or a combination of models of disabilities. Models are converted into definitions that link the conceptual model with the real world. The definition makes the abstract model concrete by determining what the researcher should do or observe for measurement (Altman, 2001). For example, if a wheelchair is used as an indicator of the concept of disability, then researchers are likely to ask about the use of wheelchairs to measure disability.

Models help generate an explanation in some way. However, models are not synonymous to theories, as models do not necessitate empirical data. Thus, models are not based upon data collection, but are representations that aid understanding (Llewellyn \& Hogan, 2000). Although models do not accurately depict reality, they do provide multiple perspectives of understanding our phenomenon of interest to generate testable hypotheses.

The traditional medical model of disability views disability as a deficit or trait within an individual (Pledger, 2003). The disability is viewed as a problem within a person caused by disease or another health condition requiring medical intervention to "fix" the individual. The medical model of disability blames the individual for having a disability and is focused on changing the person. Rioux (1997) describes the medical model as the bio-medical approach where it is assumed that disability is caused by a mental or physical condition that can be prevented or ameliorated though medical intervention. Therefore, the condition itself is focused on removing the role of society. Within the bio-medical approach, professionals seek to prevent the disability among the 
general population.

The functional approach to disability, like the medical model, views disability as being within the individual. However, the functional approach seeks to treat functional incapacity through services that assist individuals. Thus, challenges faced by people with disabilities are due to functional incapacity resulting from the individual's disability (Rioux, 1997). The functional approach would utilize programs or services that seek to expand skills that facilitate better functioning within society. Such programs and services seek to help individuals with disabilities live lives that are considered "normal" (Rioux, 1997). The functional approach utilizes ameliorative interventions that may not take into account the contextual factors that impact individuals with disabilities. Additionally, changing individuals to better function within society may operate under the assumption that the program or service is doing what is best for the individual with the disability. However, Rioux (1997) points out that what the program or services wants for the individual may not align with what the individual with the disability wants.

The social model of disability emerged in reaction to the medical model. The social model of disability views disability as a socially constructed phenomenon, and that people with disabilities are oppressed by societal views of normality (Llewellyn \& Hogan, 2000). The social model of disability emphasizes the problem being within society rather than the individual. Similarly, the rights-outcome based approach holds that disability has social causes resulting from the way in which society is organized as a whole (Rioux, 1997). Hence, systemic factors are examined rather then specific environments that limit the participation of particular groups. For example, public 
policies are addressed to promote the participation of individuals with disabilities within society.

The transactional model of disability seeks to understand the environment as interacting with individual's bi-directionally (Llewellyn \& Hogan, 2000). Thus, the behavior of one person impacts and transforms the experience of others in both positive and negative ways. However, the transactional model does not view behaviors as having one cause but rather draws upon multiple variables interacting with one another. Additionally, environments can be modified, reconstructed, and even created, so capacity emerges to the extent that a person is enabled to engage in the environment in which the individual develops (Fawcett, White, Balcazar, \& Suarez-Balcazar, 1994).

The limits model, a less known model, recognizes that there is a need for a more inclusive model. The limits model is not intended to replace other models of disability but rather adds a focus that counters models that focus on deficits. The limits model holds that (1) limits are an unsurprising characteristic of humanity, (2) limits are an intrinsic aspect of humanity, and (3) limits are good or at the very least, not evil. Thus, limits are an unavoidable aspect of being human and are neutral (Creamer, 2009).

I strongly believe that each model of disability provides diverse ways to understand disability and informs the ways in which research and interventions are designed. However, I find myself adhering most to the transactional models of disability. It is important to recognize disability as being a function of both the person and the environment, rather than the individual and environment independently. Due to the diversity among individuals with intellectual disabilities and environments, intrinsic 
(e.g., nature and severity of disability) and contextual (e.g., attitudes of others, the extent to which environments are enabling or disabling, economic issues) factors are critical to understand as simultaneously interacting.

The transactional model recognizes the needs of individuals with intellectual disabilities as being diverse and responsive to social and personal systems. Within community contexts, the attitudes and reactions of individuals are important in determining the ways in which individuals with intellectual disabilities feel about themselves. If social relationships are not positive between people with and without intellectual disabilities, then the interaction may yield in individuals with intellectual disabilities having a negative self-concept (Llewellyn, 1999).

On the other hand, if I were considering the design of an intervention, I would also consider the functional approach to consider accommodations that may facilitate functioning within a setting. Although accommodations may result in the presence of individuals with intellectual disabilities within a setting, it does not mean that people with intellectual disabilities are included. I am aware that each model has its limitations, and I therefore believe that various models must be considered to understand how each may inform my thinking and approach to research.

The models and approaches to disability provide a framework which attributes cause, prevention, and the responsibility of professionals and society as a whole. Each model and approach to disability determines the way in which we understand the lives of people with disabilities. There is nothing inherently wrong with each model, but they become problematic when researchers exclusively adhere to one single model (Rioux, 
1997). However, differences in views yield divergent thinking about disability issues that in turn determine ones research goals. As a result, diverging methods have led to different ways of understanding (Rioux, 1997). However, a model of disability utilizing a religious framework is missing. Research has found that religion is used to make sense of life which can include attributing cause, prevention, and responsibility to disability. As noted above, models are utilized to create definitions of disability, which aids in measurement of disability. Therefore, a model of disability within a religious framework does not exist which may be linked to the absence of religiously based definitions of intellectual disabilities.

\section{Definitions of Intellectual Disability}

Disability is a complicated, multidimensional concept that is embedded within cultures that determine what is viewed to be different or a deviation from what is normative. Therefore, a global definition of disability that fits all circumstances is, in reality, nearly impossible (Altman, 2001). When trying to make sense of the variety of ideas and forms of definitions, it is necessary to take into consideration the structure, orientation, and source of the definition. This also deems necessary to differentiate single purpose statements of definition and theoretical models.

First, it is important to note that the way in which people with disabilities are spoken about is imperative to understand. Self advocates prefer the use of people first language. People first language refers to people first and the disability second. More specifically, people first language describes individuals as "people with Down syndrome" or "students with intellectual disabilities" instead of saying "a Down 
syndrome person" or "an intellectually disabled student." Using the phrase "a person with..." infers that people with disabilities are not defined by their disability and that they have multiple characteristics that make up who they are (Foreman, 2005). Self advocates with intellectual disabilities also support the use of people first language, which is indicative through the accomplishments of organizations like Self Advocates Becoming Empowered (SABE; SABE, n.d.) and the Special Olympics North America (2010). In Oregon, through the work of self advocates and advocates, state law effective on January 1, 2006 requires the use of people first language (SABE, n.d.).

According to the Americans with Disabilities Act (ADA), "disability is defined as a physical or mental impairment that substantially limits one or more major life activities, a person who has a history or record of such an impairment, or a person who is perceived by others as having such an impairment" (para. 2; U.S. Department of Justice, Civil Rights Division, 2012). The ADA does not specifically name every type of disability that falls under its definition of disability, which has been problematic in the past. Prior to the 2008 ADA Amendments Act (ADAAA), plaintiffs with disabilities were required to prove that they have a disability in order to proceed with a discrimination lawsuit (Eichhorn, 1999). According to Eichhorn (1999), determining what constitutes as being major, a life activity, and a substantial limitation was challenging because they rely on relative notions of how people should perform functions. The ADAAA sought to address the shortcomings of ADA by shifting the focus from the threshold of disability to its original intention of developing nondiscriminatory policies. The ADAAA explicitly directs courts and administrative 
agencies to interpret disability broadly and to consider substantial life events without regard to the effects of measures including medication and assistive technology. The ADAAA also provides a list of major life activities, which includes but is not limited to reading, learning, thinking, communicating, and major bodily functions (e.g., bowel, bladder, brain, circulatory, and reproductive functions; DeLisa, Silverstein, \& Thomas, 2011; Long, 2008).

The World Health Organization (WHO; 2012) uses disability as a broad term including impairments, activity limitations, and participation restrictions. Impairment is defined as a problem in body function, and an activity limitation involves difficulties when executing a task or action. Participation restriction involves problems experienced when involved in life situations. WHO, like the United Nations (UN), also states that disability is complex and involves the interaction between a person's body and their environment (UN, 2007; WHO, 2012). According to the UN, disability is the interaction between long-term physical, mental, intellectual, or sensory impairments and ones environment that hinders full and effective participation in society. Moreover, the UN states that its definition is not exhaustive (UN, 2007).

Naming or creating terminology for phenomenon is rooted in the human desire to make sense of our world (Luckasson \& Reeve, 2001). Although, terminology has use, we often see terms appear and disappear based on their perceived usefulness. In the West, multiple labels and definitions have been utilized that are synonymous to intellectual disability. Over the past 200 years, terms have included feebleminded, mental deficiency, mental sub-normality, mentally handicapped, and mental retardation 
(Cegelka \& Prehm, 1982; Luckasson \& Reeve, 2001). According to Luckasson and Reeve (2001), a term should refer to a single entity to allow for consistent application in communication.

Consequently, the way in which the term is defined is important as it explains and establishes boundaries for the term. Luckasson and Reeve (2001) provided 10 questions when considering definitions which include asking whether the definition leads to a respectful understanding of a group while allowing for classification into groups based on meaningful criteria, facilitate record keeping and communication, allow for generalizations about the group, and be consistent with a desired theoretical framework (Luckasson \& Reeve, 2001).

A definition can then give way for the classification of groups within the boundary of the term. Historically, classification was based on a range of IQ scores. Classifications included moron, imbecile, and idiot for the generic term of feebleminded; mild, moderate, and severe for mental subnormality and mental deficiency; and mild, moderate, severe, and profound for the generic term of mental retardation (Cegelka \& Prehm, 1982).

In the West, intelligence testing is still used to identify individuals with intellectual disabilities through measures such as the Wechler Adult Intelligence Test and the Wechler Intelligence Scale for Children (O’Brien, 2001). Alfred Binet developed the first IQ test in 1910, and the test was used to prove that criminals, prostitutes, and alcoholics tended to have intellectual disabilities (Kempton \& Kahn, 1991). Although, the use of intelligence testing has been the subject of controversy, it is still used 
internationally by organizations such as WHO. Test results can vary based on mood, motivation, and fatigue, and the tests show the effects of rehearsal/learning, assume a degree of literacy, and are largely grounded in Western culture (O’Brien, 2001). Environmental factors such as socioeconomic status also impact IQ scores (Turkheimer, Haley, Waldron, D’Onofrio, \& Gottesman, 2003). According to the American Association on Intellectual and Developmental Disabilities (AAIDD; 2010) IQ tests are used to measure intellectual functioning but professionals must consider the individual's typical community life with peers and culture, linguistic diversity, and cultural differences in the way people communicate, move, and behave.

Today, if IQ is used to measure whether an individual has an intellectual disability, the cut-off point employed in most approaches is at two standard deviations below the mean of 100 (i.e., a score of 70; O'Brien, 2001). This is the internationally accepted standard adopted by WHO (O'Brien, 2001) and the Centers for Disease Control and Prevention (CDC; 2012) as a definition for intellectual disabilities. When utilizing IQ testing, intellectual disability is a condition marked by IQ below 70 and utilizes subcategories that include mild (IQ of 70-50), moderate (IQ of 49-35), severe (IQ of 3420), and profound (IQ less than 20; CDC, 2102; O’Brien, 2001)

According to the Diagnostic and Statistical Manual of Mental Disorders, fourth edition, text revision (DSM-IV TR; American Psychiatric Association, 2000), an individual is considered to have an intellectual disability when they have an IQ below 70 , onset before the age of 18 , and concurrent impairments in adaptive functioning (using the standard expected for ones age and cultural group) in at least two of the 
following life domains: communication, self-care, home living, social/interpersonal skills, use of community resources, self-direction, functional academic skills, work, leisure, health, and safety. Similarly, according to AAIDD (2010) intellectual disability originates before the age of 18 and is characterized by significant limitations in both intellectual functioning (i.e., reasoning, learning, problem solving) and adaptive behavior (including a range of everyday social and practical skills). Although AAIDD (2010) holds that the evaluation and classification of intellectual disability is a complex process, it does state that IQ testing is a major tool to measure intellectual functioning, and limited intellectual functioning are marked by IQ scores below or around 70 to 75 .

Although IQ testing is utilized for diagnostic purposes, it should not be employed in isolation when trying to understand an individual's ability. For parents with intellectual disabilities, intelligence tests do not predict parenting skills, which include household organization, warmth, and nurturance (Watkins, 1995). More specifically, Watkins (1995) found that parents with intellectual disabilities often display unexpected strengths in parent-child interactions that cannot be predicted from standardized testing or psychological evaluations.

Similarly, IQ tests are not strong predictors of academic success. In Farrell's (2010) review of studies on IQ testing, he found that the extent to which IQ scores and academic achievement levels correlate is problematic. There is consensus in empirical literature that IQ scores and achievement are not perfectly correlated. In fact, it has been generally found that IQ scores account for up to $50 \%$ of the variance in academic achievement. Thus, IQ tests are unsound predictors of academic achievement (Farrell, 
2010). IQ tests should emphasize a formative role rather than a diagnostic role rooted within the medical model of disability, viewing problems to be centered within the individual being tested.

Throughout history and across cultures, intellectual disabilities, as they are currently called, have always existed (Manion \& Bersani, 1987). However, the label, definition, and method of diagnosis have changed and continue to vary across cultures. Therefore, respondents of the present dissertation were provided with the AAIDD (2010) definition of intellectual disability. Additionally, once the definition was presented, all respondents were told that intellectual disability was once called "mental retardation" for purposes of clarification as the term mental retardation was once widely used. The definition was provided to ensure that both the interviewee and interviewer are referring to the same reference group.

\section{Importance of Attitudes}

Attitudes are beliefs and feelings held by individuals, which tend to be either positive or negative. Hence, attitude is a latent construct in that it is not directly measured. Attitudes are often measured based on inferences based on evaluative responses to the attitude object (Manstead, 1996). Thus, attitudes are subjective states that cannot be observed externally. Attitudes exist within a person's mind. Due to their structural complexity and to the intricate social environmental context in which attitudes are expressed, it is a challenge to assume that attitudes are directly related to behavior. However, attitudes are a contributing cause for behavior, necessitating the importance of its measurement (Antonak \& Livneh, 1988). Social psychologists believe that modifying 
attitudes is the most effective means to bring about change in behaviors (Manstead, 1996). Based on Festinger's (1957) theory of cognitive dissonance, there is a need to maintain consistency between attitudes and behaviors. Thus, if attitudes are modified, there will be a response to modify behaviors in order to reduce dissonance.

Attitudes may predict future behavior. When beliefs are consistent with a new program or policy, they can facilitate the adoption of the change (Klein \& Sorra, 1996). On the other hand, if attitudes are not consistent with a new program or policy, they tend to become sources of resistance (Foster-Fishman \& Keys, 1997). Thus, identifying attitudes embedded within particular contexts including culture allows for a deeper and more accurate explanation and prediction of behaviors. Knowledge of attitudes may then provide a basis for the promotion of change to thereby promote positive attitudes such as the meaningful integration of people with disabilities (Yuker, 1988). For example, if community residents do not accept people with disabilities, they may be excluded from residential and/or from the community life of their residential area.

Individuals with disabilities face societal stigma and negative attitudes. Persistent negative attitudes and social rejection of people with disabilities is evident throughout history and across cultures (Gordon, Feldman, Tantillo, \& Perrone, 2004). Decreasing negative attitudes toward people with disabilities reduces the harm of stigma. Stigma is the degradation of individuals or groups by viewing them as different from the norm and undesirable (Goffman, 1963), and it occurs through a combination of stereotyping, prejudice, and discrimination (Rusch, Angermeter, \& Corrigan, 2005). Stereotypes, which are beliefs, are a means of categorizing information about social groups and they 
often represent collectively agreed upon notions of groups (Hamilton \& Sherman, 1994). According to some models of attitudinal structure, factors other than stereotypes may give rise to prejudice, which include affect and past behavior toward members of a group (Corrigan \& Watson, 2002). Prejudice is defined as an agreement with negative stereotypes about groups of people (Allport, 1954). Prejudice can lead to discrimination, which is a behavioral response that may cause negative consequences for the members of a negatively evaluated group (Crocker, Major \& Steele, 1998). For example, prejudice that yields fear may lead to avoidance, and in a real world setting that may translate into employers not hiring individuals with disabilities (Corrigan \& Watson, 2002).

Of note, models of stigma and prejudice describe the same phenomena but have some differences in focus and emphasis (Phelan, Link \& Dividio, 2008). In their systematic comparison of conceptual models of stigma and prejudice, Phelan et al. (2008) found that stigma models emphasize targets of stigma, especially in terms of stereotypes, identity, and emotions while prejudice models focus more on processes in perpetrators and refers specifically to the perpetrators' attitudes. Similarly, Allport's (1954) work on prejudice emphasized the perpetrator while Goffman's (1963) work focused on the target. Additionally, prejudice is more connected with race and ethnicity in research while research on stigma more commonly focuses on illness or disability (Phelan et al., 2008). Phelan et al. (2008) suggests that prejudice may be narrower in scope in comparison to stigma as it refers to an attitudinal component within the larger process of stigma.

Prejudice and discrimination may be in the form of avoidance, coercion, 
exclusion, segregation, and hostile or aggressive behaviors (Corrigan, Markqitz, Watson, Rowan, \& Kubiak, 2003). In regard to reactions toward people with disabilities, individuals without disabilities often feel awkward, anxious, or sad and may react in a variety of ways to compensate for their discomfort (Cahill \& Eggleson, 1994; Perry, 1996; Susman, 1994; Zola, 1993). These public reactions can, in turn, have an impact on the stigmatized individual's sense of self and full participation in the work and social life of the community (Link, Cullen, Struening, Shrout, \& Dohrenwend, 1989).

In an evaluation of existing measures of stigma toward people with intellectual disabilities, it was found that scales used by intellectual disability researchers focus on attitudes rather than stigma. The scales measuring attitudes concern affective, behavioral, and cognitive aspects rather than stereotypes, prejudice, and discrimination (Werner, Corrigan, Ditchman, \& Sokol, 2012). Werner et al. (2012) note that intellectual disability research focuses on social inclusion, and that some intellectual disability researchers believe that stigma does not provide strategies to challenge prejudice. Werner et al. (2012) believe that stigma and inclusion should be viewed as constructs on the same continuum where anti-stigma initiatives may be a tool to promote inclusion. Additionally, it is suggested that stigma may be less explored because some researchers may believe that individuals with intellectual disabilities do not experience negative repercussions from stigma (Werner et al., 2012).

Based on Goffman's (1963) work, perceptions and reactions toward groups of individuals can profoundly affect the quality of the individual group member's life experience (Green, 2003). The prevalence of mental health problems is higher among 
individuals with intellectual disabilities than individuals without disabilities. Individuals with intellectual disabilities are vulnerable to social deprivation and the experience of failure, which may contribute to the higher levels of mental health problems (Dykens, 1999). Mead (1934) proposed that a mechanism in the development of self-concept is that of becoming an object of oneself by reflecting upon how one is treated by others. Cooley (1956) calls this the looking glass theory because individuals come to see themselves as others see them. Therefore, when individuals are aware that they are stigmatized, their sense of self and well-being are likely threatened. The looking glass theory has been supported in research where studies have established that adults with intellectual disabilities are aware of the prejudice and discrimination they experience (Abbott \& McConkey, 2006; Cooney, Jahoda, Gumley, \& Knott, 2006), as well as stigmatizing social representations of their group (Jahoda \& Markova, 2004). Based on reflection of how adults with intellectual disabilities are treated by significant others and their position in wider society, they struggle to maintain a positive view of themselves with feelings of powerlessness, anger, and frustration (Jahoda \& Markova, 2004).

Alternatively, research has also found that stigmatized individuals, like those with intellectual disabilities (Gibbons, 1985; Stager, Chassin \& Young, 1983) and physical disabilities (Burden \& Parish, 1983), do not have lower self-esteem than the general public (Corrigan \& Watson, 2002). Therefore, the awareness of being stigmatized does not necessarily lead to internalized oppression (Crocker \& Major, 1989). Corrigan and Watson (2002) argue that stigmatized individuals experience psychological reactance where the individual opposes negative evaluations and embraces 
positive self-perceptions. This process is referred to as righteous anger. Righteous anger is a reaction that empowers individuals who change their roles within systems by becoming more active to promote change (Corrigan \& Watson, 2002).

Of note, regardless of the type of disability, individuals with disabilities are usually the focus of prejudicial attitudes and discriminatory behaviors (Goffman, 1963). Yet, it is likely that individuals with intellectual disabilities are more likely to experience the consequences of discrimination due to social rejection and social stigma varying by specific disabilities, creating a hierarchical order (Gordon et al., 2004; Strohmer, Grand \& Purcell, 1984). In studies examining hierarchical attitudes toward disabilities, intellectual disability and psychiatric disability have consistently been cited as the least socially accepted (Gordon et al., 2004; Jones, Gottfried, \& Owens, 1966; Lyons \& Hayes, 1993; Karnilowicz, Sparrow, \& Shinkfield, 1994). Similarly, in a comparison to 11 types of disability populations, individuals were least willing to be friends with individuals with intellectual disabilities (Gordon et al., 2004).

The experience of stigmatization can be buffered by engaging in socially acceptable roles such as being employed (Crocker \& Quinn, 2000). However, the opportunity to engage in socially acceptable roles may not be available. Negative attitudes toward individuals with intellectual disabilities may influence their overall quality of life in areas such as education, employment, housing, and everyday interactions with the general public (Siperstein, Norins, Corbin \& Shriver, 2003). For example, if individuals with intellectual disabilities seek job opportunities, they may face barriers in gaining employment due to discrimination. If individuals with intellectual 
disabilities are unable to engage in their communities through activities such as work, the opportunity to buffer the experience of being stigmatized is reduced and feelings of powerlessness may be perpetuated.

One way to promote the social inclusion of individuals with disabilities has been through laws. Laws dictate behaviors, but they may contradict one's attitudes. The U.S. has specifically adopted legislation that protects individuals with disabilities from various types of discrimination (Block, 2002). This began with the National Council on Disability (NCD), an independent federal agency, that provided the president and congress recommendations regarding policies and laws concerning the lives of Americans with disabilities. In 1986, NCD recommended creating a comprehensive law that prohibited discrimination on the basis of disability. Programs at that time over emphasized income support and under emphasized equal opportunity. Although discrimination was prohibited in educational settings, broader protection was sought that paralleled the Civil Rights Act of 1964. This need led to the collaboration of multiple individuals and organizations including the Arc, TASH, politicians, and self-advocates to create, publicize and advocate for the passage of the ADA (Carey, 2009).

In 1990, the ADA was signed into law and many organizations and settings were forced to consider ways to accommodate individuals with disabilities, who were previously excluded from society. For example, based on Title II, public transportation must be accessible to individuals with disabilities; and based on Title I, it is illegal to discriminate based solely on an individual's disability (ADA of 1990). The ADA applies to both public and private entities, which include but are not limited to schools, 
hospitals, and hotels.

Regrettably, gaps within the law exist. Private clubs and religious entities are exempt from most of the ADA mandates (ADA of 1990, Sec. 12187). Private clubs are organizations that have a highly selective membership process, charge substantial membership fees, and are operated on a nonprofit basis. Section 12187 states, "The provision of this subchapter shall not apply to religious organizations or entities controlled by religious organizations, including places of worship" (ADA of 1990). This means that religious organizations like churches are not legally required to make facility changes to accommodate individuals with disabilities, and they are not required to consider ways in which to minister to individuals with intellectual disabilities.

Furthermore, if a faith community operates a school for both members and nonmembers of the faith community, the school facility is still not legally required to accommodate individuals with disabilities (Americans with Disabilities Act, n.d.). The limitations of the ADA were constitutionally questioned in the case of Posner v. Central Synagogue. From a legal standpoint, religious organizations are exempt from abiding by the ADA to avoid violating the Free Exercise and Establishment Clause of the First Amendment of the U.S. constitution (Posner v. Central Synagogue, 1993).

Laws guide provisions for individuals but laws are not sufficient in and of themselves to shape attitudes toward individuals with disabilities. Thus, governmental actions promote equal opportunities for people with disabilities (e.g., ADA of 1990), but beliefs involving prejudice and stigma continue to influence perceptions toward individuals with disabilities (Marinelli \& Orto, 1999). The impact of negative attitudes 
has significant consequences for both the social and vocational lives of individuals with disabilities even when laws are abided. For example, when examining the interactions between persons with severe intellectual disabilities and their peers without disabilities in an integrated workplace, persons with intellectual disabilities were accepted within the workplace yet few were befriended outside of the work setting (Rusch, Wilson, Hughes, \& Heal, 1991). Ferguson, McDonnell, and Drew (1993) found that workers without disabilities initiated interaction with coworkers without disabilities three times more often than with co-workers with intellectual disabilities. Further, attitudes and behaviors by the nondisabled workers suggested that their views toward their peers with disabilities were not necessarily derogatory but also were not those of equals.

Stigma also has far reaching consequences that extend beyond individuals with disabilities. Stigma by association (also called courtesy stigma; Mehta \& Farina, 1988) affects those who are closely associated with stigmatized individuals (Goffman, 1963). Studies have found that parents of individuals with intellectual disabilities experience stigma (Kearney \& Griffin, 2001; Grey, 2002). Most individuals with intellectual and developmental disabilities continue to live with their families into adulthood (Carter 2013), and parents often serve as caregivers. Thus, family members may become targets for stigma because of their affiliation with stigmatized individuals (Struening et al., 2001). In comparison to mothers without children with intellectual disabilities, mothers of children with intellectual disabilities experience lower well being (Norlin \& Broberg, 2013), social isolation (Griffith, Totsika, Nash, Jones, \& Hastings, 2012), depression (Singer, 2006), and lower marital quality (Floyd \& Zmich, 1991; Kersh, Hedvat, 
Hauder-Cram, \& Warfield, 2006). For example, in one study examining the experience of stigma among mothers of children with Asperger's Syndrome, a mother chose to avoid certain social situations to avoid embarrassment. Other parents learned to adapt to stigma by not letting it upset or anger them (Gill \& Liamputtong, 2011). Thus, family members may develop negative self evaluations and withdraw or conceal their negative status from others (Ali, Hassiotis, Strydom, \& King, 2012).

The study of attitudes is important to understand the social standing of individuals with intellectual disabilities as it affects opportunities to engage in ones community as well as self-perceptions. Of particular importance, attitudes held within faith communities require exploration. Laws that deem discrimination against individuals with disabilities illegal do not apply to religious contexts. Therefore, some religious communities may seek to include individuals with disabilities while others may not, but the absence of a legal requirement to promote inclusion may mean that the experiences of religious communities with individuals with disabilities are unique. Studying how meaning is made of intellectual disabilities and perceptions toward participation will provide insight into beliefs that may serve as barriers to promoting quality of life and inclusion in faith communities.

\section{Participant Demographics and Attitudes.}

Psychological literature has identified several factors that influence attitudes toward many social groups. Attitudes toward people with disabilities depend on an interaction of factors including the participant's gender, education, age, and types of previous contact with people with disabilities (Antonak \& Livneh, 1995; Chubon, 1982; 
Paris, 1993; Yuker, 1994). The following discussion of how respondent demographics are related to attitudes toward individuals with disabilities serves to inform the demographic information collected for all participants.

\section{Gender.}

Prior research has often reported that women hold more positive attitudes toward individuals with disabilities than men (Granello \& Wheaton, 2001; Hunt \& Hunt, 2000; Hunt \& Hunt, 2004; Pace, Shin, \& Rasmussen, 2010; Panek \& Jungers, 2008; Panek \& Smith, 2005; Royal and Roberts, 1987; Werner \& Davidson, 2004; Yuker, 1988). Gender differences are not applicable to the present dissertation because the research participants (i.e. Catholic pastors, parochial vicars, and deacons) are all male. However, the fact that all participants were male may matter. Males may have relationships that are unique, and therefore the results may not generalize to religious denominations that include males, females, and transgendered individuals as religious leaders.

\section{Age.}

Previous studies examining attitudes toward people with disabilities have reported significant relationships between age and attitudes. Among undergraduate students, older students were more likely to hold positive attitudes toward people with physical disabilities (Granello \& Wheaton, 2001). In contrast, within the same study, age did not have a significant effect in attitudes toward people with psychiatric disabilities. Inconsistent findings may possibly be due to limited variance in age, particularly in student samples. Therefore, samples with little variance do not allow for the full exploration of the impact of age on attitudes. However, in a study of attitudes of 
university students toward the sexuality, pregnancy, and midwifery care for women with intellectual disabilities, participants over the age of 25 held more negative attitudes than individuals below the age of 25 (Jones, Binger, McKenzie, Ramcharan, \& Nankervis, 2010). In an Australian study of attitudes toward the sexual rights of people with intellectual disabilities, participants over the age of 60 held less positive attitudes than individuals below the age of 60 (Cuskelly \& Gilmore, 2007). Overall, research indicates that younger individuals hold more positive attitudes than older individuals in regard to attitudes toward individuals with disabilities.

\section{Education and Experience.}

Attitudes toward people with disabilities tend to be positively correlated with increasing years of education (Antonak \& Livneh, 1995). For example, one study found that individuals with higher education levels held positive attitudes toward inclusion of individuals with Down syndrome in school and work settings (Pace, Shin, \& Rasemussen, 2010). Additionally, education accounts for more variance than any other demographic variable (Olkin, 1999; Yuker, 1994).

Knowledge about specific social groups has been investigated as a predictor of attitudes. Specifically, studies have found that increased knowledge about different racial groups (McClelland \& Linnander, 2006; Preston \& Robinson, 1974) and gays and lesbians (Lance, 1992; Riggle, Ellis, \& Crawford, 1996) is related to more positive attitudes toward that group. Information integration theory deals with the concept that a person's attitudes are a reflection of their knowledge and belief about an object. Therefore, it may be possible to alter misconceptions of people with disabilities through 
the introduction of new information. For example, teaching information aimed at changing the understanding of disability from the medical model framework to the social model has contributed in attitude change (Oliver, 1996). Similarly, interventions that aim to increase knowledge about people with disabilities are associated with positive attitudes (Campbell, Gilmore, \& Cuskelly, 2003; Gliner, Baher, \& Weise, 1999; Hunt \& Hunt, 2004). However, prior studies have also found that traditional university information-based courses for pre-service teachers have led to an increase in knowledge but have little impact on attitudes (Forlin, Tait, Carroll \& Jobling, 1999; Hastings, Hewes, Lock, \& Witting, 1996; Tait \& Purdie, 2000). Research has found that the most effective way to alter attitudes through information is with the combination of formal instruction with either structured and direct contact with people with disabilities (Ford, Pugach, \& Otis-Wilborn, 2001; Mayhew, 1994; Rees, Spreen \& Harnadek, 1991) or with simulations or role playing activities that provide experiential learning (Forlin et al., 1999; Pernice \& Lys, 1996). In addition to asking about the level of education participants have completed, all participants in the present study were asked about whether their educational training included knowledge about disabilities and what the training consisted of (e.g. direct contact, information-based learning). According to Allport (1954), contact between social groups may decrease prejudice, although a meta-analysis testing Allport's (1954) hypothesis has found varying degrees of support for intergroup contact where intergroup contact was related to less prejudice (Pettigrew \& Tropp, 2006). However, simply having contact with another group may not always have positive outcomes. 
People form and change their attitudes as they interact with other people. Contact provides a context for the formation of affective and behavioral responses toward a person. Contact is sometimes defined as familiarity, which has been described as knowledge and experience with a particular group that can vary in degree of intensity (Corrigan, 2002). Without direct experience, little emotional and behavioral responding is likely to occur, and attitudes will be based mainly on beliefs (Eagly \& Chaiken, 1993). Yuker (1988) found that the majority of studies using direct assessment methods reported a positive effect for contact. Similarly, American and Taiwanese students with prior contact with people with disabilities expressed more positive attitudes than those without prior contact (Chen, Brodwin, Cardoso \& Chan, 2002). Previous research has also reported that previous contact with persons with disabilities is related to experiencing less discomfort than people without contact (MacLean \& Gannon, 1995), and individuals without disabilities are more willing to help people with disabilities (Menec \& Perry 1998).

When evaluating a stranger with a disability, without any personal attributes, the disability becomes the single characteristic that dominates the evaluation, facilitating the creation of the fundamental negative bias because other important aspects are not considered (Wright, 1991). However, if personal characteristics are provided about the person with a disability, the context will influence the importance of the attributes (Wang, Thomas, Chan \& Cheing, 2003). Thus, if education is valued in a setting, the level of education of the person with the disability will be viewed as a salient factor. The age of the person with the disability may also impact how individuals with disabilities 
are evaluated. Some studies have reported a preference for people with disabilities at a younger age (Wang et al., 2003; Wong, Chan, Da Silva Cardoso, Lam \& Miller, 2004) while others do not (Tsang, Chan \& Chan, 2004). The present dissertation does not provide information that describes individuals with intellectual disabilities. Instead, participants were asked about their experiences with individuals with intellectual disabilities. That is, the focus of this exploratory dissertation is the experiences of participants regardless of the age, gender, etc. of the individuals with intellectual disabilities.

The quality of contact is a critical element in influencing attitudes toward people with disabilities. Generally, when contact takes place in favorable conditions with similar or superior status or if there is cooperation, contact leads to positive attitudes (Greig \& Bell, 2000; Makas, 1993). Corrigan et al. (2001) found that the existence of a positive interaction between the participant and the person with a disability is associated with positive attitudes toward individuals with disabilities. In contrast, situations that place people with disabilities in an inferior role or position is related to negative attitudes (Yuker, 1988). Contact may offer the opportunity to correct negative beliefs or attitudes based on stereotypes and prejudice.

The distinction between the quantity of contact versus the quality of that contact is also an important factor to consider. Research focusing on attitudes toward racial groups has found that the quality of contact, operationalized as the positivity or negativity of the experiences that one has had with members of an out group. Plant and Devine (2003) found that greater quantity of contact with Blacks was unrelated to how 
positive Whites believed future interactions with Blacks would be. They did however find that White participants who reported having more positive experiences with Blacks thought future interactions with Blacks would be more positive. Further, they also has less anticipated anxiety and were less likely to avoid future interactions with Blacks. Thus, it may not be that quantity of contact with outgroup members is related to expectations about future interactions with that outgroup, rather it may be the overall quality of the experience one has with outgroup members that determines outcome expectancies, anxiety, and future interactions with members of the outgroup.

Many studies have examined the quantity of contact (Akrami, Ekehammar, Claesson \& Sonnander, 2006; Hall \& Minnes, 1999; Krajewski \& Flahert, 2000; Yazbeck et al., 2004), quality of contact (Hall \& Minnes, 1999; Nosse \& Gavin, 1991; Palmerton \& Frumkin, 1969), and knowledge (Akrami et al., 2006; Campbell \& Gilmore, 2003; Hunt \& Hunt, 2004; Krajewski \& Flaherty, 2000) as predictors of attitudes toward individuals with intellectual disabilities with mixed results. When examining quality of contact, quantity of contact, and knowledge about individuals with intellectual disabilities, McManus, Feyes, and Saucier (2011) found that all three predictors are interrelated, but quality of contact is an important variable in predicting individuals' attitudes toward individuals with intellectual disabilities. Thus, the quality of previous interactions, not the number of interactions or how much a person knows about intellectual disabilities, determines whether or not an individual will have positive or negative attitudes and behaviors toward individuals with intellectual disabilities. 
Therefore, the present dissertation asked participants who report contact with individuals with intellectual disabilities to describe the type of contact they have had.

\section{Disability and Religion}

Some faith communities boast a strong history of welcoming and including individuals with disabilities. Regrettably, some faith communities, like non-religious organizations, have been less responsive to the call to be more inclusive. As a result, many individuals with disabilities are not welcomed within congregational life. There is a growing body of research that has focused on inclusion and community participation, but few studies have included faith communities as a domain of community life. Therefore, more information on the inclusion of individuals with intellectual disabilities within faith communities is needed.

Understanding the inclusion of individuals with intellectual disabilities within faith communities requires knowledge of other domains related to religion and disability issues such as the way in which religious texts depict or convey information about individuals with disabilities. Within the Christian faith, the Bible may be utilized for guidance and to understand life events. Based on passages within the Bible that relate to disability, intellectual disabilities are not explicitly discussed. However the role of sin in the cause of disability is discussed, as well as conflicting information about whether parental sins result in future generations being punished. The way in which religion views disability is particularly important, because it can impact the meaning and attribution of disabilities. For that reason, the present dissertation aimed to explore the meaning making of intellectual disabilities among religious leaders. Additionally, an 
understanding of leadership within churches will be sought as leadership styles may impact the mission and actions of the congregation. That is, leaders may be open to understanding and implementing the ideas of others (e.g., implementing accommodations) through collaborative decision making processes while some may not be willing to integrate others' ideas.

The following section begins with a brief introduction on the definition of inclusion followed by a discussion of information conveyed about individuals with intellectual disabilities within the Bible. The next section concerns meaning making and attributions, which are embedded within the area of coping. Although prior studies have focused on parental coping, the process of making sense of and attributions to disability may be pertinent to others in understanding disability within their lives.

\section{Inclusion.}

Individuals with developmental disabilities usually have limited access to participation within society and are often regarded as having little to no role in public, private, familial, and domestic life domains (Meekosha \& Dowse, 1997; Bray \& Gates, 2003). More specifically, studies have found that individuals with intellectual disabilities have few friends and even when they are involved in community activities, they still may not meet other people (Bray \& Gates, 2003). As a result, individuals with disabilities experience more social isolation, fewer opportunities to participate in their communities [National Organization on Disability (NOD), 2010; Verdonschot, de Witte, Relchrath, Buntinx \& Curfs, 2009], and less satisfaction when they do participate compared to people without disabilities (NOD, 2000). Thus, individuals with intellectual 
disabilities are not completely included within their communities.

The term inclusion is widely used throughout the field of disability studies (Verdonschot et al., 2009), and no one universal definition is accepted. According to AAIDD (2012), inclusion includes participation in all aspects of life including public activities, programs and settings, and private settings that are open to all members of the public. More specifically, AAIDD (2012) provides examples of inclusion for both children and adults with intellectual disabilities where children should have the opportunity to participate in activities with children without disabilities while adults should have the opportunity to live in a home of their choice and with whom they choose.

In an examination of how experts in the area of inclusion for students with moderate to severe disabilities defined the term inclusion, seven elements of inclusion were addressed. These seven elements include (1) being placed in natural and typical settings, (2) being together with students without disabilities for instruction and leaning, (3) available supports and modifications, (4) endorsement and value for belongingness, equal membership, and acceptance, (5) collaborative integrated services, (6) a systemic philosophy and belief system, and (7) unifying general and special education systems (Ryndak, Jackson, \& Billingsley, 2000). However, according to Ryndak et al. (2000), only the first five elements must be applied for inclusive services and programming. Part of the movement for inclusion within society has been the inclusion or mainstreaming of students with disabilities, which began when United States Congress enacted the Education for All Handicapped Children Act (PL 94-142; U.S. Department 
of Education, n.d.). The Education for All Handicapped Children Act became the Individuals with Disabilities Education Act (IDEA; PL 101-476; U.S. Department of Education, n.d.), which requires free public education in the least restrictive setting. Other macro-level changes have taken place that protect the rights of individuals such as The Developmentally Disabled Assistance and Bill of Rights Act, which in 1976 was followed by independent living centers (U.S. Department of Education, n.d.).

Inclusion within communities is of critical importance because the position of individuals with intellectual disabilities within society requires change. In spite of the attention on inclusion and community participation of individuals with intellectual disabilities, little is known about the actual community participation in different life domains as well as the challenges and successes experienced when participating in community life (Verdonschot et al., 2009) The aim of the present dissertation is to understand the meaning of intellectual disabilities and perceptions toward the participation of individuals with intellectual disabilities to better understand their social position in faith communities.

\section{Christian Responses to Individuals with Disabilities.}

Until recently, the spirituality of people with disabilities has been largely ignored by faith communities, secular social service systems, and educational systems (RogersDulan, 1998; Stolberg, 2008). Neglecting the importance of religious beliefs and experiences in the lives of many individuals with disabilities and their families may imply a view of their innate humanity being incomplete or that of an eternal innocent child (Swinton, 1997). 
For the past four decades, religious leaders and self-advocates have advocated for the creation of a framework for effective ministry with individuals with developmental disabilities. While the church has made increasing efforts to promote equal opportunities for worship and fellowship (e.g., National Council of Churches of Christ, 1995; Block, 2002; Webb-Mitchee, 1994; Wolfensberger, 2001), some Christian leaders criticize the church for its failure to provide clear or adequate teaching that addresses disability issues (Blair \& Blair, 1994; Blair \& Davidson, 1993; Eiesland, 1994). Even though religious scriptures such as the Bible are utilized to understand prescribed beliefs and behaviors, the position of individuals with disabilities is not completely clear.

Jesus Christ lived and ministered during the first century when the Roman culture did not provide a favorable environment for individuals with developmental disabilities. This unfavorable environment can be noted by the inhumane social context in the first century when individuals with developmental disabilities were limited to begging as a means of obtaining basic life essentials. In this context, the gospel repeatedly highlights the compassion of Jesus as he offers restoration of body and spirit to many individuals as a means of proving the truthfulness of his claims regarding God (Byzek, 2000). Expressing compassion through bodily restoration may communicate that individuals with life long disabilities are not bestowed with compassion and therefore are possibly not viewed to be worthy of that compassion.

The Gospel of Luke portrays Jesus as openly accepting individuals who were rejected by society including individuals with developmental disabilities (McReynolds \& Bundy, 2008). More specifically, the Bible states, "Then Jesus said to his host, 'When 
you give a luncheon or dinner, do not invite your friends, your brothers or relatives, or your rich neighbors; if you do, they may invite you back and so you will be repaid. But when you give a banquet, invite the poor, the crippled, the lame, and the blind, you will be blessed. Although they cannot repay you, you will be repaid at the resurrection of the righteous" (Luke 14:12-14; The Holy Bible: New International Version, 2011). The Bible encourages inclusion of individuals with developmental disabilities with the incentive of receiving blessings, but the passage also places individuals with developmental disabilities as recipients of charity. This emphasis of being dependent on others sympathy perpetuates the disenfranchised status of individuals with disabilities. That is, providing food, clothing, and money allow for individuals to survive, but it may not provide the means to become independent.

Additionally, Jesus preached the gospel to all people, regardless of their social position in society (Stein, 1992). For example in Matthew 9:1-8, a man who was paralyzed was forgiven of his sins as a result of his faith in Jesus and he was healed (The Holy Bible: New International Version, 2011). The gospel was preached and forgiveness was given regardless of an individual's disability (Block, 2002; Byzek, 2000). Thus, individuals with and without disabilities are ministered to; but as stated above, healing of ones disability may communicate that individuals with disabilities are not worthy of God's benevolence. Additionally, the link between having ones sins forgiven and being healed may infer that the paralysis is related to ones' sins.

In John 9:1-33 (The Holy Bible: New International Version, 2011), the role of sin is examined in the life of an individual who was blind. The man had been blind since 
birth, and Jesus was questioned to understand who sinned (i.e., the blind man or his parents) to bring about the disability. The concept of sin is rooted in the Old Testament in Exodus 34:6-7 stating, "And he passed in front of Moses proclaiming, "The Lord, the Lord, the compassionate and gracious, slow to answer, and abounding in love and faithfulness, maintaining love to thousands and forgiving wickedness, rebellion and sin. Yet he does not leave the guilty unpunished; he punishes the children and their children for the sin of the fathers to the third and fourth generation" (The Holy Bible: New International Version, 2011). Thus, the revelation of God visiting the sins of parents through their children may be applied to children with disabilities for some (Miles, 2002). For example, children born with disabilities are sometimes linked to a parent's substance abuse. However, Miles (2002) notes that, disability may be linked to its parent's behavior, but it does not mean that God is punishing the child for the parent's behaviors. Also, scriptures relating to disabilities emphasize the healing of people with disabilities to illustrate Christ's divinity, even though Jesus regarded disability to be a natural human experience (Anderson, 2003).

In contrast, Biblical passages such as Jeremiah 31:30 state "Instead, everyone will die for his own sins whoever eats sour grapes - his own teeth will be set on edge" (The Holy Bible: New International Version, 2011). Similarly, Ezekiel 18:20 states, "The soul who sins is the one who will die. The son will not share the guilt of the father, not will the father share the guilt of the son. The righteousness of the righteous man will be credited to him, and the wickedness of the wicked will be charged against him" (The Holy Bible: New International Version, 2011). Thus, Jeremiah 31:30 and Ezekiel 18:20 
indicate considerable variation in the concept of parental sin resulting in punishing the child. Also, in Luke 5:18-26, Jesus heals a paralyzed man and tells him his sins are forgiven (The Holy Bible: New International Version, 2011). This may imply that when individuals are healed, they are also made free from $\sin$. In this case, sin may be a factor in one's disability.

In the case of the blind man, in John 9:1-33, Jesus declares that sin was not the cause of the man's blindness but it was simply the work of God. If disability is not a result of sin, then the passage regarding those committing sin being punished along with their children does not apply to disabilities. According to Miles (2002) Christianity views disability as neutral based on John's gospel (9:1-41). The interpretation of John 9:1-33 (The Holy Bible: New International Version, 2011) conveys that individuals with disabilities are part of the diversity in which God made human beings, which coincides with Reinders' (2011) position on theological views of disability. Some individuals who belong to a faith community have been confronted in their local church by the belief that there must be something wrong with people with disabilities because God does not punish individuals without reason. Others have been confronted by the belief that God must love individuals to be given a special task. This may not only convey that family members of individuals with disabilities are somehow better than others but that individuals with disabilities exist to serve as a challenge for others. Many religious people have been confronted with both beliefs, and Reinders (2011) attributes both to "cheap theology." Cheap theology is based on the assumption that the universe is governed by a moral geometry such that for every bad result there must be a bad cause; 
and reversely, for every good result there must be a good cause. When disability is presumed to be a bad outcome, it is assumed that there must be a bad cause such as disobedience to God, for which individuals are punished with a disability. This is cheap theology because it suggests that there are easy answers to the "why?" question.

Disability has been named a curse, a punishment for sins committed (either by the person with disability or by others), a lack of faith, a sign of imperfection, or a blemish that renders the individual unfit to worship God (Reinders, 2011). Several accounts have reported that this has led to individuals leaving the Christian church completely (Black, 1996; Eiesland, 2002). Among the "positive" responses are those that name disability as a blessing or a special token of God's love, an opportunity for spiritual growth, or as eternal innocent children (Reinders, 2011). Regardless of whether disability is interpreted as being a curse or a blessing, they both assume that disability is a special condition. Special individuals are those who are excluded from mainstream society. Whether responses are positive or negative, viewing disability as a special condition is an instrument of exclusion (Reinders, 2011). According to Reinders (2011), we should not accept the notion that there is meaning in disability in any of the senses in which previous generations of religious people have spoken about. The reason for making this claim is that disability scholars are right in saying that attributing religious meaning to disability, be it either negatively or positively, is putting people with disabilities into a special category.

Hence, the belief that disability equals tragedy is not true. Individuals with disabilities have reclaimed their own agency as human beings. More specifically, people 
with intellectual disabilities have become self-advocates and have established their own organizations such as People First (People First, n.d.). Participating in these organizations, people with intellectual disabilities have expanded their skills as they continue to fight for the right to live their lives and asserting the necessity of being consulted in issues involving individuals with intellectual disabilities (Parmenter, 2001). But this is not always how their lives began. The lives of individuals with intellectual disabilities sometimes begin with the experience of their parents being victims of a tragedy. The experience of tragedy is produced by an ideology called normalcy (Reynolds, 2008). Popular culture advertises "normal" ways of living and when people face a life that does not fit the pattern of what is "normal," they feel their world is falling apart. The experience of tragedy is not a function of disability, but it is a function of being raised in a culture that believes in normalcy (Reinders, 2011). Additionally, many people with disabilities falsify the notion that their lives are tragic, simply because of the fact that, when asked, they will tell you a different story. People with disabilities view themselves as living a life with both potentialities and limitations, more or less like other people. They do not consider themselves to be victims, which is what the imposition of tragedy does (Reinders, 2011).

While most religious traditions address suffering, theological explanations for disabilities are unclear and not clearly answered (Paterson, 1975). The New Testament has been interpreted and reinterpreted on a regular basis for centuries, and the treatment of people with disabilities has varied with these changes (Miles, 2002). Since 400 A.D. various Christian theologians have offered interpretations of disabilities as evidence that 
immortality is inheritable (Miles, 2001). Specifically among Catholics in the United States, the majority $(77 \%)$ believes that there is more than one true way to interpret the teachings of the faith (The Pew Forum on Religion \& Public Life, 2010). Based on the practices of Christian leaders and their congregations, treatment of individuals with disabilities in the past has been both positive and negative (Blanks \& Smith, 2009). Although there is not a clear way in which intellectual disabilities are defined within Christianity, individuals still utilize religion to make meaning. Therefore, the present dissertation took an exploratory approach to develop an understanding of meaning making among religious leaders.

\section{Coping.}

Theological understandings of disability have spilled into the study of coping, which consists of meaning making and attributions. The following section discusses meaning making and attributions as part of the coping literature to inform the way in which individuals may utilize religion to understand disability. Knowing how individuals use religion in the context of disability is important, because religion frames many individuals' responses and behaviors (Grossoehme, Ragsdale, Wooldridge,

Cotton, \& Seid, 2010). Coping exists at the intersection between persons and situations. More specifically, Friedman, Chodoff, Mason, \& Hamburg (1963) described coping as a mechanism to deal with a threat to one's psychological stability and functioning, and according to Lazarus and Folkman (1984), coping is the management of internal and/or external demands that are evaluated as stressful or exceeds ones resources. Thus, coping 
is a transactional process where an exchange exists between persons and their situations within the larger milieu.

The onset of diagnosis of a disability drives family members to make sense of the disability. This leads to families seeking solutions and cures to remedy the disability (Larson, 1998). Medical professionals, in many cases, can provide information about factors that are causally responsible for a disability, and medical science has found ways to combat some diseases such as polio and small pox while some remain incurable (e.g., cerebral palsy, spina bifida, congenital conditions). However, Reinders (2011) argues that people want to understand "why?" and not "how?" Parents may not want to know about the scientific explanation of the cause of their child's disability but they seek to make sense of what is happening. Thus, parents may want to understand why their child has a disability.

Stress resides between person and environment interactions, which leads to the coping process. The person-environment interaction is comprised of stress appraisal, which is the process of how individuals assign meanings of harm, threat, challenge, and locus of stressor to life situations (Groomes \& Leahy, 2002). Four components make up the stress appraisal process, which is used to determine the meaning of situations (Lazarus \& Folkman, 1984). The first component, called primary appraisal, is the extent to which the person appraises the situation as stressful. If a person believes that the situation is not stressful, no coping is employed. If the person perceives the situation to be stressful, the second component of the appraisal process is implemented. The second process concerns the type of stress appraisal. Situations are typically appraised to be 
stressful when the individual perceives harm, threat, or challenge from the situation. The third component is the level of experience with the stressful situation, which involves how often the situation is experienced. Thus, stressful situations become less threatening as familiarity increases and confidence in effective coping mechanisms is learned. The last component of the stress appraisal process is the location of the difficulty or uncertainty in the situation. This involves determining whether the difficulty resides within the individual or an external person or thing (Lazarus \& Folkman, 1984).

The complexity of the coping process has given rise to the development of several models that attempt to describe this process. Notably, an inductively constructed model of how religion is used in the process of meaning making among religious leaders has not been created. An expanded discussion of the meaning making models is beyond the scope of the present dissertation, but a brief outline is provided for the meaning making model followed by discussion of religion in the process of meaning making and attributions.

\section{Meaning Making Model.}

People typically believe that they have control over their own lives and that they are good people and that bad things do not happen to good people (Janoff-Bulman \& Frantz, 1997). Therefore, when adverse circumstances arise, individuals must adjust. However, circumstances that are not amenable to active problem solving can only be resolved by transforming the meaning of the circumstance. Park and Folkman (1997) integrated the work of numerous coping and meaning theorists (Greenberg, 1995;

Rothbaum, Weisz, \& Snyder, 1982; Taylor, 1983) into a meaning making model of 
coping. This model takes into account the multiple sources to make meaning which include one's surrounding culture (e.g., parents, media) and personal experiences (Baumeister, 1991; Singer \& Salovey, 1991).

Meaning making refers to the process of coming to see the situation in a different way and reviewing and reforming one's beliefs and goals in order to regain consistency among them. Stress and trauma theories emphasize that distress arises when something occurs that violates a person's beliefs (Janoff-Bulman, 1989; Park \& Folkman, 1997) which can raise questions about the purpose of life and injustice in the world (Lazarus, 1993). When individuals encounter stressful events, they appraise the meaning of the event (e.g., What happened?) and then determine the extent to which this appraised meaning differs from their own (Park \& Folkman, 1997).

\section{Religious Coping \& Meaning Making.}

Religious coping is an important focus for community psychology research because it is a naturally occurring process that is common among a large proportion of the U.S. population (Smith, Pargament, Brant, Oliver, 2000). Religion is a personal and social resource that is readily available from one's culture, particularly their family and subculture, but larger cultural and religious institutions also provide support and structure within which individuals conduct themselves and to which they turn to times of crisis (Maton, Dodgen, Domingo, \& Larson, 2005; Pargament \& Maton, 2000). These institutions reinforce and facilitate the application of religious meaning systems when individuals are coping within stressful situations. Individual applications of religious meaning systems in understanding and dealing with stressful situations, supports and 
reinforces the societal provision of these larger structures. Individuals create and maintain these institutions, and their needs and desires thereby shape them.

Religious coping can be passive (i.e., a person turns their problems over to God) or active (i.e., increase in prayer or religious rituals). Three types of positive religious coping mechanisms have been suggested which include: (1) spiritual religious support (Johnstone, Glass, \& Oliver, 2007; Pargament, 1997), (2) clergy and congregational support (Johnstone et al., 2007; Pargament, 1997), and (3) benevolent religious reframing (Pargament, 1997). Spiritual religious support occurs when individuals perceive that they have the support of a higher power (i.e., they trust that God would not let anything bad happen to them) and/or that they will receive guidance from God (i.e., God will show them how to deal with the situation). Clergy and congregation support occurs when individuals turn to religious leaders (e.g., priests, pastor, ministers, rabbis, imams) to assist them in coping with difficult situations. Benevolent religious reframing is a cognitive reframing to attribute negative life events to karma or to the will of God (i.e., acceptance that God will work with them in their difficult time for a specific reason), making it easier for them to accept their fate. Pargament and Brant (1998) reported on negative forms of religious coping that can adversely affect the ability of individuals to cope with a disability including discontent with God or one's congregation and negative religious reframing. Being discontent with God or one's congregation is where individuals may feel that God has abandoned them. Negative religious reframing is where individuals believe that their disability is a reflection of negative karma or of God's punishment. 
The extent to which religion is involved in the coping process is largely predicated on the extent to which religion is part of one's orienting system. Religion is far more likely to be used in the coping of those for whom religion is a highly salient aspect of their understanding of self and world than in the coping of those who are less religious (Pakenham, 2008; Pargament, 1997). The nature of the event also determines the likelihood of religious involvement. If the stressful event is one that cannot be solved such as illness or death, meaning making efforts become central (Mattlin, Wethington, \& Kessler, 1990), and religion may help to restore beliefs that the world is a safe, predictable, fair, and controllable (Dull \& Skokan, 1995; Pargament, 1997). Thus, beliefs and practices connected to a higher power provide individuals with a sense of control when immediate personal control is lacking or insufficient (Smith et al., 2000).

The same event can be viewed differently depending on one's specific views, including their religious beliefs. For many people, religion serves as a lens through which reality is perceived and interpreted (McIntosh, 1995); yet it also provides options for understanding the meaning of an event, including the notions that there is a larger plan, that events are not random, and that personal growth can arise from struggle (Furnham \& Brown, 1992; Marshall et al., 2003). Some individuals believe that God would not harm them or bestow upon them more than they could handle, whereas others may believe that God is trying to communicate something important through the event, or that the event is a punishment from God (Furnham \& Brown, 1992). For example, some hospice caregivers appraised their situation as part of God's plan or as a way to gain strength or understanding from God, while others viewed their situation as a 
punishment from God (Mickley, Pargament, Brandt, \& Hipp, 1998). Parents may also interpret children's disabilities as punishment for their own misdeeds (Glover \& Blankenship, 2007) and therefore they feel significant shame or guilt. Of note, research has not found religious denominational differences in regard to family adjustment to a child with a disability (Rogers-Dulan \& Blancher, 1995; Weisner, Beizer \& Stolze, 1991).

Few studies have explicitly examined the links between religion, meaning making, and adjustment (Park, 2005), but of the disability research that does exist, there has been a focus on parents and disability service providers as research participants. Parents have used religion to make meaning of their child's cystic fibrosis diagnosis by imagining God as active, benevolent, and an interventionist and subsequently found hope in their beliefs, felt supported by God, and related religion to their motivation to adhere to their child's treatment plan (Grossoehme et al., 2010). More specifically, parents who used religion as a source of hope believed that God placed them in the situation that they would be able to handle. Parents also believed that God would reunite them with their child in an afterlife in which the child does not have a disability. Similarly, Skinner, Bailey, Correa, and Rodriguez (1999) found that $71 \%$ of Latino mothers viewed their child with a disability as a gift from God who found them worthy of the responsibility of raising a child with a disability or wanting them to grow from the experience. Notably, research on religious coping in families with children with disabilities has involved mothers (Mahoney \& Tarakeshwar, 2005). 
To my knowledge, research on the meaning making process for disabilities among religious leaders does not exist. However, prior research has found that clergy and congregation supports are positive coping mechanisms whereby religious leaders have the opportunity to provide individuals with spiritual support and guidance. Having the authority to guide individuals, families, and communities necessitates the understanding of intellectual disabilities and attitudes toward individuals with intellectual disabilities on the part of religious leaders. Although religious leaders may not experience the coping process as parents and caregivers do, they still may engage in a process of utilizing their theology to inform their understanding of people with intellectual disabilities as well at their attitudes.

\section{Attributions.}

Religion offers adherents information to understand and make sense of what happens by providing a framework for evaluating daily events (Baumeister, 1991). Attributions involve the understanding of why an event occurred and is part of the coping and meaning making process (Park \& Folkman, 1997). Searching for and finding a reason why an event occurred and who or what is responsible for its occurrence helps people make sense of their experiences. Searching for explanations is important to family and friends of individuals with disabilities, and individuals often seek understanding through religion (Gaventa, 2002; Selway \& Ashman, 1998). The answer for the cause of a disability is usually in terms of divine origin or personal responsibility.

Weiner's (1979) attribution theory provides a useful framework and theoretical basis for understanding people's attitudes and behaviors toward individuals with 
disabilities by focusing on beliefs about the causation of the disability. According to attribution theory (Weiner, 1979), causal explanations influence ones adjustment and expectations to the phenomenon being understood. Attribution theory is based on the assumption that individuals search for causal understanding of everyday events, and therefore seek the causes of disability.

When encountering someone with a disability, people often question why one outcome occurred and not another. Such encounters lead to emotional responses, which in turn affect behavior (Weiner, 1986, 1993). When a person is viewed as being responsible for or having control of a negative condition, they are more likely to elicit anger from others (Schmidt \& Weiner, 1988; Weiner, Perry, \& Magnusson, 1988). In contrast, individuals who are not believed to be responsible for a negative condition are pitied. This disparity offers a partial explanation for why attitudes vary toward people with different types of disabilities. For example, in assessing hiring biases, individuals whose disability was attributed to an external cause were more likely to be hired in comparison to individuals whose disability was attributed to an internal cause in vignettes (Bordieri \& Drehmer, 1986; Stone \& Sawatzki, 1980). Similarly, people with Down syndrome were evaluated more positively than those whose intellectual disability was self-inflicted (e.g., brain damage caused by drinking cleaning fluid; Panek \& Jungers, 2008).

Attributions of disability are important to understand because they may impact the relationship people have with individuals with disabilities. Historically, around the world, individuals with disabilities have been understood and treated as being either a 
blessing or a curse. The Azand tribe has viewed people with disabilities as a blessing and has shown love for them. On the other hand, some groups, such as the Jukun of Sudan, have proclaimed disability to be a curse, and they have left people with individuals with intellectual disabilities to die (Selway \& Ashman, 1998). Thus, attributions may predict the ways in which individuals with disabilities are treated.

In the United States, parents commonly rated genetic inheritance (25\%), God's will (20.5\%), medical problems during pregnancy or birth (11.4\%), medical problems/unspecific (11.4\%) and something the parent did or did not do $(9.1 \%$; percentages can exceed $100 \%$ because parents could report multiple cases) as causes. Additionally, parents reporting God's will as a cause also reported less positive parentchild relationships (Masood et al., 2007). Similarly, Mickelson et al. (1999) found that American parents of children with Down syndrome and autism most frequently attributed the disability to a genetic fluke followed by fate or God's will.

Although initial attributions may be made following an event, a search for more acceptable reasons for the event's occurrence in the months following is common (Davis, Nolen-Hoeksema, \& Larson, 1998). Religion can be involved in reappraisals, or changes in situational meaning, by offering additional possibilities for causal attributions and by illuminating other aspects of the situation. Theoretically, reappraisals can be either positive or negative, and the motivation to reduce stress generally leads to placing stressful situations in more positive contexts by giving them a meaning that is consistent with one's global beliefs and goals. People often make reattributions that help to alleviate their initial distress (Park \& Folkman, 1997). For example, individuals may 
initially feel that God neglected them or caused the event. Over time, people often come to see the stressful event as the will of a loving or purposeful God (Spilka, Hood, Hunsberger \& Goruch, 2003). Religion offers multiple avenues for making positive reattributions, and is frequently invoked in the search for a more acceptable reason as to why an event occurred than what one may have originally made.

\section{Causes of Intellectual Disabilities}

Intellectual disability is not a disease to be cured, and all of its causes are unknown. Thus, the absence of knowledge on how one comes to have an intellectual disability elicits feelings and behaviors of wanting to understand and make sense of intellectual disabilities. Therefore, individuals may engage in the coping and meaning making processes, which includes determining the cause of intellectual disabilities.

All of the causes of intellectual disabilities are not known, but it can be caused by conditions that impact development before, during, or after birth. Before birth, a child may develop Down syndrome which is a chromosomal disorder where the twenty first chromosome set is a triplet instead of a pair. During pregnancy, the use of alcohol and drugs can cause intellectual disabilities. At the time of birth, difficulties in the birthing process such as oxygen deprivation or brain injuries can cause intellectual disabilities. After birth, injuries to the head and environmental toxins (e.g., lead) can lead to intellectual disabilities. Additionally, malnutrition and under-stimulation of children can result in brain damage causing intellectual disabilities (AAIDD, 2010). 
Knowing how religious leaders use religion in the meaning making process of intellectual disabilities is important since religion may fame their responses and behaviors. Therefore, all participants, Catholic religious leaders, will be asked to share how their theology informs their process of making meaning of intellectual disability as well as their perspectives on the participation of individuals with intellectual disabilities in their congregation.

\section{Church as a Community Organization.}

Organizations in which in individuals study, work, and pursue shared interests are primary settings in the lives of most individuals, and are therefore a concern for community psychologists (Bond, 1999). Keys and Frank (1987) called on community psychologists to consider ways in which community psychology can contribute from the study of organizations, and they suggested that community psychology offers a unique focus on well-being in organizational contexts. However, organizational constructs and theories are not widely utilized by community psychologists. In a review of articles published in American Journal of Community Psychology and Journal of Community Psychology from 1988 to 2000 , less than $4 \%$ of articles focused on organizations or workplace issues. Even after the publication of the 1987 special issue of American Journal of Community Psychology there was a slight decrease in publications on organizational themes. Of the articles that did publish on organizational themes, only two utilized organizational theories of which were dated (Boyd \& Angelique, 2002). Similarly, Zimmerman (2000) noted that there have been few studies that examine the organizational characteristics of community settings that make them empowering for 
members. Clearly, community psychologists have not incorporated organizational scholarship within the field.

Understanding organizations is of particular importance to the present dissertation because it can inform ways in which organizational contexts support diversity. For example, elements of organizational settings considered important for promoting diversity include an explicit value for diversity among members, tolerance for ambiguity (Bond, 1995), and opportunities for cooperative exchanges (Kelly, Azelton, Burzette, \& Mock, 1994). To be effective in promoting active collaboration across diverse groups, it is important that organizations value resources that diverse groups offer, recognize diversity within groups, and actively support team work (Bond \& Keys, 1993; Foster-Fishman \& Keys, 1997). Of the community psychology literature that examines organizational culture, there is a primary focus on empowerment (e.g. Bond \& Keys, 1993; Foster-Fishman \& Keys, 1997; Maton, 2008; Maton \& Salem, 1995). Therefore, theories of organizational studies are integrated within the present dissertation.

Organizational culture has varying definitions. Foster-Fishman \& Keys (1997) utilized Schein's (1985) definition, which is a shared meaning system that guides member behaviors, thinking, perceptions, and feelings. Schein's (1992) updated definition stated that organizational culture is made up of shared assumptions that a group learns through problem solving and have worked well enough to be taught to new members as a way to think and feel. Bond (1999) defines organizational culture as values, beliefs, and shared meanings, which result from experience and interactions over 
time. Another definition states that organizational climate and culture are the shared perceptions of employees (Mumford, Scott, Gaddis \& Strange, 2002; Zohar \& TenneGazit, 2008) of the organization's policies, procedures, and practices as well as behaviors that are rewarded and supported (Schneider, Gunnarson, \& Niles-Jolly, 1994). Thus, organizational culture generally concerns shared meanings and assumptions that guide attitudes and behaviors transmitted through policies and/or practices, and based on aforementioned definitions, the construction of an organization's climate is made up of components that leaders have substantial control and influence over (Mumford et al., 2002).

Leaders provide direction and facilitate processes that enable organizations to achieve their goals and objectives (Grojean, Resick, Dickson, \& Smith, 2004). Leaders have the responsibility to institute standards of ethical conduct and moral values that guide the behaviors of its followers. This is done directly through policies, but it is also done indirectly through the leaders actions, which influence the perceptions of followers. When the leaders behaviors are viewed as normative, they become ingrained within the organization's culture. Thus, leadership may be an antecedent of the organization's culture (Dragoni, 2005). For example, in Litwin and Stringer's (1968) classic study, three simulated organizations with different leadership styles yielded climate changes over time in ways that were consistent with the leadership style. Therefore, leaders have the power to change the culture of organizations (Schein, 1992). The power leaders possess within organizations may be of particular importance for the present dissertation considering the impact religious leaders have on whether individuals with intellectual 
disabilities participate in faith communities and if they do participate, the extent of participation.

In regard to examining leadership, there are differences between for-profit and non-profit organizations, which make it inappropriate to assume that research and findings in for-profit contexts apply to non-profit contexts (Westhead \& Cowling, 1998). This difference may be due to differences in vision, mission, and motives where earnings drive for-profit organizations and non-profits are driven by their social mission (Quarter \& Richmond, 2001; Wooten, Coker \& Elmore, 2003). Additionally, non-profit organizations rely heavily on volunteer management and support (Wooten et al., 2003). Thus, differences in organizations suggest that leadership differs based on the type of organization (Quarter \& Richmond, 2001). However, the ways in which leadership may differ based on the type of organization is not completely known, because leadership research has been neglected in the study of non-profit organizations (Hollister, 1993). Additionally, McMurray, Pirola-Merlo, Sarros, \& Islam (2010) argue that it would be incorrect to assume that research findings in nonprofit contexts such as education apply to church based contexts, so researchers should examine different types of non-profit organizations to understand varying leadership styles based on specific contexts.

Within the community psychology literature, contexts and leaders that support diversity are those that actively acknowledge and legitimize differences. Interdependence is one way to support diversity within organizational cultures because it acknowledges and values differences, which is necessary to create settings that support meaningful inclusion of marginalized group members (Bond, 1999). For example, co- 
empowerment underscores the importance of interdependency to bring groups with diverging agendas together. When working with community groups, Bond and Keys (1993) used the term co-empowerment to describe the process in which groups with differing agendas equally shaped the direction of an organization. When coempowerment does exist, it is often a process where groups move in and out of empowerment depending on the topic without pressuring the groups to abate their differences. This involves recognizing and balancing similarities and differences between groups to sustain an interdependent relationship. The culture of interdependence also requires the connection between groups be reciprocal and sustained over time where there is a continued sharing of goals and valuing of each member or group's unique contributions (Bond, 1999).

Interdependence and empowerment are important for organizational contexts, but power structures also matter. However, the power structure of the organization, the distribution of power among members, and the relative power of individuals within broader society can serve to privilege one group over another. For example, Gruber and Trickett (1987) found that the process of empowerment among parents, students and teachers in a school was inadvertently hindered by the power and knowledge teachers possess. The program itself revealed the paradox of empowerment where institutional structures put teachers, parents, and students in a position to empower one another while simultaneously undermining the act of empowerment. The process of empowerment was undermined by the fact that there were inequities in power based on each groups' position derived from institutions outside of the school setting. Similarly, Serrano- 
Garcia's (1984) research on empowerment in Puerto Rico was hindered due to marcolevel barriers of power sharing. In a Catholic parish community in New York City, the dynamics among groups within the church also reflected what they were like outside of the church environment. For example, older immigrants who were also the elite of the Chinese community maintain superiority while newer immigrants worked as unskilled or semiskilled labor in the businesses of the older immigrants. The economic relationship between the groups made it difficult for the members to relate as equals. Additionally, the church had a council, which served as a gatekeeper for service opportunities that was limited to those who spent years volunteering. While the newer immigrants worked long hours and had less time to volunteer than the older immigrants, the newer immigrants had less access to high status positions in the church. As a result, the council focused the church's attention on the needs of its older members (Borg, 2006)

The preference for and attraction to others who are perceived to be more like oneself may hamper cultures that value diversity (Bond, 1999). According to the similarity-attraction paradigm (Byrne, 1971), similarity between individuals on several dimensions, such as demographic characteristics, is related to interpersonal attraction (Linden, Wayne, \& Stilwell, 1993). Most people prefer to work with others who are like them in terms of age, gender, education, and social status (Tsui, Eagan, \& O'Reilly, 1992). Thus, there is a preference for homogenous work groups. Homogenous work groups tend to be more familiar, predictable, and comfortable which is related to higher cohesion and lower turnover (Jackson \& Ruderman, 1995; Meglino, Ravlin, \& Adkins, 1991; Schein, 1990). Additionally, demographic similarities are suggested to increase 
affect, attraction (Meglino, Ravlin, \& Adkins, 1989), and trust (Mayer, Davis,

Schoorman, 1995). Increased affect, attraction, and trust in turn are associated with a leader's tendency to invite group members to participate (Schriesheim, Neider,

Scandura, \& Tepper, 1992; Yukl, 2006; Yukl \& Fu, 1999). Demographic dissimilarity is associated with differences in attitudes and values and low communication between the leader and the member (Burns \& Otte, 1999; Epitropaki \& Martin, 1999; Tsui \& O’Reilly, 1989). Bond (1999) describes homogenous work settings as those that adopt a dominant story, which has its own meanings and behaviors. Settings that adopt the dominant story may not allow for variety based on the experiences of members with differing expectations, resources, or values.

However, it has been suggested that the effect of demographic dissimilarity varies as a function of the interaction between the leader and member (Bauer \& Green, 1996; Mayer et al., 1995). Early in relationships between leaders and members, each individual possesses little information about one another so demographic characteristics are salient. As time passes, leaders begin to evaluate members based on performance rather than relying on stereotypes (Dienesch \& Linden, 1986; Somech, 2003). However, faith communities excluding individuals with intellectual disabilities may be due to the similarity-attraction paradigm, but congregations may not have the opportunity to move beyond stereotypical evaluations of individuals with intellectual disabilities without any contact.

One study within the community psychology literature examined leadership within a church setting, and the results of study yielded leadership qualities that support 
empowerment. However, within the organizational literature, multiple types of leadership styles exist which include transformational, transactional, and laissez-faire (Bass, 1997; Hunt, 1999). Since 1990, the majority of studies on leadership have focused on transformation leadership (Judge \& Piccolo, 2004).

In a case study examining how community settings help members enhance psychological empowerment in three community settings, one of which was a nondenominational Christian church led by lay ministers, leaders exhibited four qualities (Maton \& Salem, 1995). Maton and Salem (1995) defined leadership as the qualities of specific individuals with formal or informal responsibilities for a setting that can contribute to empowerment. In all three community settings, leadership was inspirational (motivational and inspiring), talented (clear vision of what to accomplish with a record of achieving goals), shared (roles are shared and open to new leaders emerging), and committed to the setting and members' growth. Additionally, the leaders encouraged full participation of its members in domains such as decision-making.

Within the organizational literature, Burns (1978) developed the initial concepts of transformative and transactional leadership styles. Transformational leadership involves establishing oneself as a role model by gaining the trust and confidence of followers. Similarly, Bass (1990) defined transformation leadership as the process in which leaders inspire followers to prioritize the good of their group over their own selfinterest. By doing so, transformational leaders engage in empowering behaviors that create positive emotions in followers (Dasborough \& Ashkanasy, 2002), and enhance well being and life satisfaction (Ryan \& Deci, 2000). In comparison, transactional 
leadership is a process of exchange between leaders and followers. Transactional leadership involves clarifying subordinate responsibilities, rewarding subordinates for meting goals, and correcting them for failing to meet goals (Eagly, Johannesen-Schmidt, van Engen, 2003). Last, the laissez-faire style is characterized by the failure to take responsibility to manage such as being absent and uninvolved (Eagly et al., 2003).

Transformation leadership works to help both leaders and followers to achieve greater motivation and satisfaction. The skills required are concerned with establishing a long-term vision, empowering people, coaching, and challenging the culture to change. In transformation leadership, the power of the leader comes from creating mutual trust and openness (Gillespie \& Mann, 2004). Such leaders create more opportunities for sharing and clarifying perceptions (Kozlowski \& Doherty, 1989) and offer better articulation of tasks (Kirkpatrick \& Locke, 1996), all of which should provide group members with better information for assessing what is prioritized, valued, and supported, promoting the development of shared cognitions, hence a stronger climate (Zohar \& Tenne-Gazit, 2008).

Four dimensions underlie transformational leadership (Barbuto, 1997; Bass, 1997; Bass \& Steidlmeier, 1999; Tracey \& Hinkin, 1998), which include the following: (1) charismatic leadership/idealized influence, (2) inspirational motivation, (3) individualized consideration, and (4) intellectual stimulation. Charismatic leadership occurs when the leader provides a vision and sense of mission while also gaining the trust of its followers. Inspirational motivation involves inspiring followers to accept challenging goals, providing meaning for engaging in shared goals, and encouraging 
team spirit through optimism and enthusiasm. Individualized consideration involves recognizing individual uniqueness, current needs of individuals, and providing coaching and mentoring opportunities. Last, intellectual stimulation involves the leader encouraging followers to approach problems in new ways and to question ways of doing things.

Transactional leaders help followers identify what must be done to accomplish desired goals, which involves daily exchanges between leaders and subordinates. Transactional leadership is built upon reciprocity and depends on a hierarchy and the ability to work through the mode of exchange. It requires leadership skills such as the ability to obtain results, to control through structures and process, to solve problems, and to work within the structures and boundaries of the organization (McMurray et al., 2010).

Transactional leadership consists of three dimensions (Bass, 1997; Bass \& Steidlmeier, 1999; Tepper \& Percy, 1994) which are (1) contingent rewards or reinforcement, (2) active management-by-exception, and (3) passive management-by exception. First, contingent rewards or reinforcement involves the leader using rewards and promises to motivate followers to achieve expected levels of performance. Active management-by-exception involves the leader monitoring the performance of followers and taking corrective action when problems occur. Passive management-by exception involves leaders waiting for problems to become severe before taking corrective action.

Bass (1999) argues that transformational leaders emphasize the development of autonomy and empowerment among its followers (Dvir, Eden, Avolio, \& Shamir, 2002). 
By doing so, transformational leaders enhance their followers' capacity to think independently, develop new ideas, and question rules (Bass \& Avolio, 1999). Transformational leadership, in comparison to transactional and laissez-faire leadership, is also associated with other positive effects within organizations, including follower motivation, satisfaction, and performance (Judge \& Piccolo, 2004; Lowe, Kroeck, \& Sivasubramaniam, 1996). Additionally, performance among diverse work groups is high when transformational leadership is high (Keaney \& Gerbery, 2009). Overall, prior research indicates that transformational leadership is associated with better outcomes in the workplace, but it is not clear whether such results would extend to religious communities.

In a review of leadership publications, the vast majority the research has measured leadership through quantitative methods. Among the approximate $33 \%$ of articles employing qualitative methods, about half utilized content analyses that converted data allowing for quantitative analyses (Lowe \& Gardner, 2000). There have been articles that argue for the use of qualitative methods to understand leadership (Parry, 1998) because it allows for greater attention to the ways in which leaders and styles of leadership interact with specific contexts (Bryman, 2004; Parry, 1998). Organizational literature has utilized qualitative methods to understand leadership in underexplored areas such as e-leadership (Brown \& Gioia, 2000) and environmental leadership (Dyck, 1994; Flannery \& May, 1994). Therefore, the examination of leadership with faith communities utilizing qualitative methods may be most appropriate to allow for an understanding of leadership specific to faith communities. 


\section{Church Leadership}

Each church turns to God and its pastor for guidance. Numerous studies have demonstrated that millions of Americans who have mental health needs, approximately 4 out of 10, seek assistance from clergy (Weaver et al., 1997). Reliance on clergy is not unusual given their accessibility (Weaver, Revilla, \& Koenig, 2002). For example, women who attend church on a regular basis described having a supportive relationship with clergy where they have the opportunity to seek guidance at any time (Brodsky, 2000). One review of prior studies found that clergy spend $15 \%$ of their working time in pastoral counseling (Weaver, 1995). Even though clergy are called upon more frequently than most professionals to work with people with disabilities (Anderson, 2003), most pastors start their ministry without any experience with individuals with disabilities (Poston \& Turnbull, 2004; Shogren \& Rye, 2005).

Of note, religious leaders such as pastors do not always have the sole responsibility to control internal functioning in their church. Some churches employee a staff member to aid in church administration. However, one study found that less than $3 \%$ of churches employ a staff member who is responsible for church administration (Duncan \& Stocks, 2003). Therefore, religious leaders often have the responsibility to manage the church internally.

Seminaries, current pastors, and researchers need to address faith inclusion for persons with disabilities in the systemic preparation of future ministers (Kleinert et al., 2010; McNair, 2007). The U.S. Catholic Bishops Pastoral Statement on People with Disabilities from 1978 called upon leaders and general members of the church to educate 
themselves to understand the contributions individuals with disabilities can make to the Church's spiritual life. The U.S. Pastoral Statement on People with Disabilities from 1978 also calls for a change in both attitudes and behaviors toward individuals with disabilities to recognize what they can offer the church by through full participation. The pastoral statement even goes to the extent of stating that the Christian community must understand the needs of individuals to make appropriate adaptations to promote active participation (United States Conference of Catholic Bishops, 1978). Similarly, the 2008 Association of Theological Schools' Policy Statement on Disability and Theological Education called upon schools to include students with disabilities while also pointing out that interaction with individuals with disabilities will cultivate the capacity of leaders to respond in ministry, teaching, and congregational settings (Association of Theological Schools, 2008). However, there is still little representation in theological curriculum to equip clergy with knowledge about disabilities (Anderson, 2003).

Graduate schools of theology have limited experience with both the study of disability and the presence of individuals with disabilities in their training as students (Anderson, 2003; Association of Theological Schools, 2008). This impairs the practice of ministry for seminarians (students studying in a seminary) and the churches that they will serve. Including the human experience of disability in theological education and practical ministry might alleviate the faith community's struggle to serve families with individuals with disabilities (Creamer, 2003). Of note, Anderson (2003) points out that knowledge of disabilities is not as important as having direct relationships with people with disabilities, to view them as human beings and members of faith communities. 
Limited education on disability issues may not only exclude individuals with disabilities, but it may also promote inaccurate information about them. The way scripture is interpreted and the by the religious leader will impact ministry. As a result, a community of faith that views disability as God's punishment for sin will likely reinforce this belief among congregational members. Such beliefs may lead to practices described by Reynolds (2012) where individuals with disabilities are pressured to attend religious services to be healed. The individual with a disability is called to stand in front of everyone during the service for healing but is made into a spectacle when healing does not occur.

Research on the attitudes and experiences of religious leaders working with individuals with disabilities is limited. In a study examining the perceptions of benefits and barriers of including older adults with chronic illnesses held by church leaders found that the religious leaders did not possess the skills to identify chronic illnesses and associated needs. Church leaders also identified that working with the needs of older adult with chronic illnesses requires additional time, and the time of volunteers is limited. Financial limitations were also discussed where religious leaders questioned how much money it would require to provide services (Butler et al., 2011). Realistically, all accommodations do not have to be implemented immediately. For example, congregations can integrate accommodations that are of little or no cost and then slowly integrate accommodations with higher costs (Gaventa, 2001/2; McIntire, 2001/2).

Although little is known about the attitudes and experiences of religious leaders with individuals with disabilities in their congregations, research does suggest that faith 
communities are failing to meet the needs of individuals with disabilities and their families. A national survey of American Presbyterian pastors indicated that almost 30\% were aware of members of their congregations who were unable to fully participate because the facilities were not easily accessible (Presbyterian Panel, 2004). An American Congregational Life Survey reported that only $10 \%$ of faith communities offered some form of care for people with disabilities (Woolever \& Bruce, 2002). Focus group discussions involving parents of children with disabilities revealed that many families felt unwelcome and lacked the supports necessary to fully participate in worship of related activities (Poston \& Turnbull, 2004). As a result of the limited support and inclusion offered by faith communities, some parents may not call upon their religious leaders for help when their family member is diagnosed with a disability. Coulthard and Fitzgerald (1999) found that social withdrawal from faith communities was highest at the time of a child's diagnosis, and $22 \%$ of families did not tell their clergy about the diagnosis.

Children and adults who do attend religious services may find that other aspects of full or meaningful participation within the larger religious community remain inaccessible. Riordan and Vasa (1991) reported that 44\% of clergy surveyed reported that religious education was not available to individuals with disabilities. Exclusion of individuals with disabilities is not limited to religious education, but social events in religious contexts as well. Orsmond, Krauss, and Seltzer (2004) reported that only 11\% of youth and adults with autism attend social events in religious settings more than once per month. 
Despite the lack of education on disability issues and how to meaningfully include individuals with disabilities within theological curriculum, people of faith are called to regard people with disabilities as integral parts of their community and that every member should be viewed as indispensable (Carter, 2007). However, religious leaders and organizations intending to promote inclusion may also perpetuate misunderstandings of disability. The U.S. Catholic Bishops Pastoral Statement on People with Disabilities states that the church is committed to "...understanding of both the pain and the potential of our neighbors who are blind, deaf, mentally retarded, emotionally impaired, who have special learning problems, or who suffer from single or multiple physical handicaps - all those whom disability may set apart" (United States Conference of Catholic Bishops, 1978, para 1). Such statements lead members of the faith community to believe that there is pain and suffering associated with disability, which may lead some to feel pity or view individuals with disabilities as recipients of charity.

Historically, individuals with disabilities have been viewed as recipients of charity in settings that are segregated from community life. In the fourth and fifth centuries, Christian hospice care and for individuals with disabilities were created (Nelson, 1983). Individuals with developmental disabilities were believed to require religious healing in areas away from larger society (Webb-Mitchell, 1994;

Scheerenberger, 1983). Later in the early Roman era and into the Middle Ages, Pope Leo $\mathrm{X}$ used individuals with developmental disabilities as a form of entertainment where guests were encouraged to laugh at and play cruel jokes upon individuals with disabilities (Scheerenberger, 1983). 
During the Protestant Reformation, personal responsibility was emphasized and those who were unable to display a significant degree of self-sufficiency were devalued (MacMillan, 1982). The fifteenth and sixteenth centuries were also characterized by some groups struggling to attain social needs resulting from poverty, famine, and class divisions (Nelson, 1983). Martin Luther, a Christian leader during the Protestant Reformation fostered questionable attitudes toward individuals with disabilities. Luther helped people with disabilities, but he had inconsistent views on the nature of disabilities. He often questioned the degree of personhood of those who had congenital disabilities (Miles, 2001). Luther also suggested that individuals with intellectual disabilities are possessed by demons (Anderson, 2003; Webb-Mitchell, 1994). At the time, Luther's views were not uncommon within the Catholic Church. The Catholic Church attempted to treat individuals with intellectual disabilities, and when they did not improve with medications, they were labeled as being possessed by demons (Scheerenberger, 1983).

In the U.S., the state has primarily provided services for individuals with developmental disabilities rather than churches (Webb-Mitchell, 1994). The U.S., for many years, institutionalized individuals with disabilities. For over 200 years, persistent reports of physical, emotional, and sexual abuse of residents were recorded (Vitello \& Soskin, 1985). Individuals with developmental disabilities wanted to move from institutions to community living (Block, 2002), and the disability movement in the 1960's demanded human rights for individuals with disabilities. Early efforts to establish a means by which individuals with developmental disabilities could have access to all 
aspects of society are generally based on legal mandates established by the U.S. government, which excludes church involvement in the process or the mandates (Block, 2002). Some churches may intentionally exclude individuals with disabilities, but it is more likely that the lack of awareness and training among church leaders has hindered the progress of inclusion of individuals with disabilities within faith communities.

At present, limited information exists on the perceptions and experiences of religious leaders and individuals with disabilities. However, there is an increasing number of studies on individuals with intellectual disabilities sharing their experiences with faith communities (e.g., Franklin, Yoon, Acuff \& Johnstone, 2008; Irvine \& Lupart, 2006; Shogren \& Rye, 2005; Swinton \& Poweries, 2004; Turner et al., 2004; Vogel, Polloway \& Smith, 2006).

\section{Inclusion and Exclusion in Religious Communities.}

Most Americans associate themselves with a congregational community (Dudley \& Roozen, 2001). Thus, it would be expected that involvement of individuals with disabilities is similar, but numerous surveys reveal that individuals with disabilities are involved in faith communities less often than individuals without disabilities (Carter, 2007). For example, Orsmond et al. (2004) found minimal participation rates for autistic adolescents and young adults in religious activities where $30.6 \%$ did not attend religious services at least once a week, and nearly half (44.3\%) participated in religious services less than once a year. Studies have examined the faith and spirituality among individuals with disabilities and have found that religion is important in their lives. For example, in interviews about faith or religious identity, the majority of individuals with intellectual 
disabilities reported faith and/or religion played a major role in their lives (Franklin et al., 2008; Irvine \& Lupart, 2006; Turner et al., 2004; Vogel et al., 2006). Additionally, Shogren and Rye (2005) report that the majority of individuals with intellectual disabilities interviewed identified prayer and religion as important parts of their lives. These results are consistent with the 2004 Harris poll conclusion that religious faith is equally important to adults with and without disabilities. That is, $84 \%$ of adults with disabilities and $84 \%$ of adults without disabilities rated their religious faith to be "somewhat important" or "very important" (NOD, 2004). While religion is important in the lives of people with intellectual disabilities, ways in which to promote inclusion within congregational communities is necessary.

In order to understand membership within religious communities, discussion of literature of inclusion and exclusionary practices within religious communities must be prefaced with research on the psychological sense of community. Psychological sense of community is concept representing a positive relationship to a community consisting of four parts: (1) membership, (2) influence, (3) integration and fulfillment of mutual needs, and (4) shared emotional connection (McMillan \& Chavis, 1986). According to McMillan and Chavis (1986) membership refers to the boundary criteria that establishes who is part of the in and out groups while also providing emotional and physical safety associated with a sense of belonging and support. The component of influence is a bidirectional process where the community influences the individual and vice versa. Integration and fulfillment of needs is a reinforcement of the community's cohesion where community success and values contribute to individuals feeling that their needs 
are being met. Last, shared emotional connection come about through a shared history, positive experiences, spiritual bond, and meaningful bonding experiences among members. When there is a strong positive SOC with religious communities, the members are likely to experience congregational support (Brodsky, 2000).

However, a tension exists between the values of SOC and human diversity (Townley, Kloos, Green, \& Franco, 2011) where belonging can be overvalued at the expense of the diversity that makes up one's personhood. Although individuals represent multiple communities as defined by factors such as interests, ethnicity, and gender (Okazaki \& Saw, 2011), SOC tends to value uniformity. Townley et al. (2011) reviewed international research on SOC and found that SOC is related to high group homogeneity. For example, when assessing SOC among individuals with mental illness, individuals living with others with mental illness reported greater levels of SOC than individuals who lived in communities with individuals who do not necessarily have mental illness (Townley et al., 2011). Thus, the value of SOC may hinder the inclusion of individuals with intellectual disabilities within organizations such as churches.

The lack of SOC at the psychological level (i.e., psychological sense of community, PSOC) and therefore an absence of protective factors, is associated with less positive outcomes for both individuals and communities (McMillan \& Chavis, 1986; Chavis \& Wandersman, 1990). However, it is also possible that the lack of positive SOC may be defined as negative PSOC, which can be associated with positive outcomes for some individuals. For example, individuals who experience negative PSOC may find that religious communities are not sources of positive feelings and support due prior 
experiences with the religious community. Brodsky (2000) found that negative experiences with churches among a group of women reflected issues that exist within the larger community that the church is located in. Thus, religion may be assumed to be stress-buffering, but it is not always the case in stressful communities. Church membership in a stressful community may be as stressful as membership in the larger community (Maton, 1989). These findings may apply to the lives of individuals with intellectual disabilities where congregational attitudes and behaviors replicate that of society at large. As a result, individuals with intellectual disabilities may identify as a member of their religious community, but due to barriers, such as attitudes, PSOC may be negative.

Barriers identified within faith communities parallel those found in larger society. Examination of these obstacles can guide research and practice specific to the field of faith community inclusion. According to the 2000 NOD/Harris Survey on Community Participation, people with slight or moderate disabilities more commonly cite lack of time, lack of income, and lack of awareness of activities as explanations for not participating more in their communities. Lack of awareness and lack of income are also commonly cited among individuals with severe disabilities. For people with severe disabilities, lack of encouragement from community organizations was by far the most common barrier to participation.

Research studies investigating the barriers to inclusion specific to communities of faith are emerging (see Stookey, 2003; Vogel et al., 2006; Christensen \& Weil, 2007). Children and adults with developmental disabilities who wish to be included in a faith 
community encounter a variety of barriers to full participation. Obstacles including architectural barriers, attitudes, communication (e.g., for individuals who use signing or who have no formal communication system), programming (e.g., lack of individualized supports in on going educational and religious programs), and liturgy (e.g., narrow interpretations of how to participate in sacred rituals) within congregations present a variety of challenges to individuals with disabilities (Carter, 2007; Collins \& Ault, 2010; LaRocque \& Eigenbrood, 2005; Vogel et al., 2006). For example, LaRocque and Eigenbrood (2005) reported that most of the faith communities that they surveyed (including Christian, Jewish, and Muslim congregations) were just in the initial phases of planning for inclusion of members with significant disabilities.

Some congregations have promoted inclusion through physical access of buildings. However, advocates believe that physical access such as ramps are not enough. Building ramps, automated doors, and designated parking spaces do little to fully welcome individuals with disabilities. Barriers to full inclusion may also include sight and sound, language, and listening (Carter, 2007). The ways in which worship is presented and information is shared may be inaccessible to certain segments of the populations, and the level at which information is presented may present challenges in understanding for some members. According to Swinton (2002), some congregations offer additional supports such as large print materials, Braille texts, and sign language interpreters, but rarely consult with individuals with disabilities to better meet their needs. Although the idea that people with disabilities can contribute to their communities is new to some church members (Fette, 2011; Young 2009), failing to take into account 
the perspectives of people with intellectual disabilities when designing these supports put us at risk of doing things to people with intellectual disabilities instead of with them (Shogren \& Rye, 2005).

In some circumstances, congregational leaders have been unwilling to make adaptations or alterations to long held traditions for individuals who are unable to participate. Leaders of religious institutions frequently assume that inclusion would be expensive and therefore not possible (Christensen \& Wiel, 2007). Others placed blame on the individuals with disabilities, claiming that few people has taken advantage of the inclusive services offered. On the other hand, many congregations believe there is not a need for accommodations because they do not have a member with a disability (Collins \& Ault, 2010; Schultz, 2012). Realistically, it is likely that individuals with disabilities do not participate in congregational communities because there are no accommodations. Notably, implementing ideas for inclusion costs very little (Gaventa, 2001/2; McIntire, 2001/2), and all inclusion does not have to occur at once. On the other hand, congregations that are larger and well resourced may have accessible facilities but segregate their programs (e.g., special classes, group seating during worship), inhibiting the opportunity for friendships to develop among members with and without disabilities (Collins \& Ault, 2010).

Attitudinal barriers and feelings of uncertainty and fear among religious leaders about including people with disabilities is a common reaction, which has also led to exclusion (Perkins; 2001/2002). Webb-Mitchell (1994) reported that religious leaders commonly ask families to find alternative communities due to their own lack of 
confidence in their ability to care for families with a member with a disability. In other instances, leaders were comfortable ministering to but not ministering with individuals with disabilities (Carter, 2007). Thus, children and adults with disabilities are seen as objects of paternalism to be cared for in a segregated manner.

Additionally, individuals with disabilities have been excluded due to communication barriers. Children with disabilities are denied access to religious rites and rituals (Jocober, 2007; Vogel et al., 2006). For example, children with autism and intellectual disabilities were not allowed to be baptized or receive communion because of their inability to communicate understanding in a way that was acceptable to the church leader (Vogel et al, 2006). According to Gaventa (2005), Americans equate faith and cognitive ability, presuming that faith is not important to individuals with disabilities because of an inability to grasp complex doctrines, even though typically developing members of congregations do not always understand the true theological meaning of liturgical traditions. Additionally, religious leaders deem it appropriate to question the understanding of people without disabilities but not individuals with disabilities (Swinton, 2001). Thus, when communication barriers exist, religious leaders may not make an effort to understand people with disabilities by asking questions and building communication. However, some theologians suggest that it is impossible to determine eligibility and that in many cases true understanding is not necessary to participate (Vogel et al., 2006).

When understanding the inclusion or exclusion of individuals with intellectual disabilities within religious communities, it is possible for an individual to be physically 
included while not actually feeling like they belong (Swinton \& Powries, 2004).

Research has documented reports of why individuals with intellectual disabilities dislike attending church. Reasons included a dislike for the atmosphere and the lack of help from others (Turner et al., 2004). For example, a man with intellectual disability attended church for three months and no one spoke to him. Similarly, a woman with intellectual disabilities attended mass to create friendships. Within the church, she found a level of friendship but she was never invited to activities outside of the church, which she longed for (Swinton \& Powries, 2004). An earlier study concluded that almost half of young adults with intellectual disabilities attend church services, and only $14 \%$ participated in other congregational activities, such as youth groups or choirs (Kregel, Wehman, Seyfarth, \& Marshall, 1986). Thus, churches provide support in and outside of church services, which may serve as an indirect benefit from congregational membership (Brodsky, 2000).

Inclusive ministries are one of the highest priorities for families who want to be part of a faith community (Bolduc, 2001). Nonetheless, many families experience barriers and are discouraged to participate within their faith communities. According to Bolduc (2001) an inclusive environment can be both facilitated and impeded by individual attitudes within existing faith communities. Positive and negative aspects of inclusion and the success of inclusion are directly related to attitudes of those involved within the community (Breeding, Hood, \& Whitworth, 2006).

Many people with disabilities and their family members feel that the messages communicated in their places of worship are inconsistent with their own experiences of 
disability (Eiesland \& Saliers, 1998). Both members and leaders of faith groups sometimes come to faulty conclusions about the causes and implications of disabilities. For instance, researchers have highlighted presumed links between disability and parental sin, lack of faith, and divine rejection (Abrams, 1998; Covey, 2005). For example, a mother who gave birth to a child with Down syndrome received cards of sympathy rather than support from members of her church (Collins \& Ault, 2010).

Like many parents, parents of children with disabilities seek acknowledgement and acceptance of their child and family (Poston \& Turnbull, 2004; Speraw, 2006; Tam \& Poon, 2008). Parents long to be included and hope their child will have friends (Jacober, 2007). As parents bring their child with a disability into a church, reactions by the congregations are sometimes extreme. Some churches have told parents to educate their own children or to look elsewhere for religious education (Amado \& Simon, 2001/2; Speraw, 2006). The support and sense of community that congregational life can offer becomes non-existent for many parents who have a child with a disability (Coulthard \& Fitzgerald, 1999; Jacober, 2007). Among parents of autistic children, only $5 \%$ reported seeking help from their church, frequently citing that having a child with autism isolated them from their faith community (Coulthard \& Fitzgerald, 1999). Consequently, some families have reported seeking different congregations when they do not feel accepted in their current church while others forego religious membership entirely (Todis \& Singer, 1991).

In regard to social support from religious leaders, many parents have reported discontent with their clergy. Among parents of autistics, only $7 \%$ reported that their faith 
leader had been helpful at the time of diagnosis while in another study of moderately to very religious parents, $30 \%$ reported dissatisfaction with their clergy and church members (Tarakeshwar \& Pargament, 2001). Dissatisfaction with the support parents receive from religious leaders may in part be related to theological barriers. Theological barriers, created through interpretations of scripture or religious tradition in a way that links disability with uncleanness, sin, or anything less than human, exist within congregations (Vogel et al., 2006). The development and acceptance of images of God within Christian theology has been deeply impacted by two factors which are as follows: (1) most influential theologians, historically and contemporarily, have been individuals without disabilities and have assumed an able-bodied framework as the norm; and (2) the church has been overly influenced by the values and assumptions that emerge from dominant cultures, particularly in the West (Swinton, 2011). Mainstream constructions of human experiences and developing images of God mean that disability can only be perceived as an abnormality, which cannot reflect the true image of God. According to Swinton (2011) if individuals with disabilities are not seen to represent God's image, they may be assumed to be the product of sin. Additionally, segregationalist views of individuals with disabilities being recipients of charity and objects of pity (Rose, 1997; Swinton, 2011) and oppressive readings of healing miracles have ostracized individuals with disabilities within faith communities (Swinton, 2011).

Recently, however, religious institutions and spiritual communities are beginning to understand that individuals with intellectual disabilities have spiritual lives and religious needs that are quite similar to the needs of individuals without disabilities 
(Swinton, 1997; Yong, 2007). Many studies have focused specifically on church attendance of individuals with disabilities (Irvine \& Lupart, 2006; Jacober, 2007; Turner et al., 2004). In 2000, McNair and Smith reported that $52 \%$ of individuals with intellectual disabilities reported attending church in a particular week. In 2004, Turner et al. found that 19 of $29(66 \%)$ individuals with intellectual disabilities belonged to a church. In 2005, Shogren and Rye found that $76 \%$ of individuals with intellectual disabilities went to church with church attendance being the highest reported community activity. Furthermore, in a survey of teachers of students with intellectual disabilities, participation in faith community activities (e.g., youth groups, social events) represented the most frequently named opportunity for inclusion for students outside of school (Kleinert et al., 2007). In another study, students with intellectual disabilities, multiple disabilities, and autistics participated in church youth groups at about the same rate as students with disabilities across all special education categories (Wagner, Cadwallader \& Marder, 2003). These findings may suggest that faith related activities are a potential source of friendships, support, and community inclusion for students with disabilities. However, defining inclusion as being physically present in locations is problematic. In recognizing that individuals with disabilities may physically attend church, they may not be fully included. Thus, the distinction between inclusive practices and an inclusive community is of critical importance. Inclusive practices refer to the policies, procedures, or structures of programs that encourage or make possible the participation of people with disabilities into the ongoing activities of the congregation. For example, an inclusive practice may be that the congregation has made a decision to provide 
religious education to children and adults with disabilities within an existing Sunday school program rather than offer a segregated class specifically for individuals with intellectual disabilities (Collins \& Ault, 2010). Policies are important and central to the process of inclusion, but while laws can change structures for inclusion, it cannot create belonging (Swinton, 2012). Vanier (1998) describes belonging as being part of a common humanity.

An inclusive community, which creates belonging, goes deeper and involves the beliefs of the persons in the congregation. In an inclusive community the overall philosophy of the congregation is one of acceptance of differences among people, awareness of disability issues, a willingness to solve problems, and a commitment to include all people into the life of the congregation regardless of their labels or differences. Inclusive practices may be implemented in the church but an inclusive community may not be present. It is likely that if a community does not have an inclusive philosophy, inclusive practices will not be effective or will not be maintained (Collins \& Ault, 2010). Therefore, the emphasis should be on creating a SOC, because integration goes not have a direct relationship with the number of times a location is frequented (Cummins \& Lau, 2003). Physical exposure is a necessary but not sufficient condition to create a positive SOC. For example, in an observation of people with severe and profound intellectual disabilities during trips to their community, the average proportion of time each person spent in contact with a member of the public was about 2\% (Saxby, Thomas, Felce, \& de Kock, 1986). 
Friendship development depends on the opportunity to interact with others, appropriate social and interpersonal skills, and the ability to initiate and sustain a relationship (Gordon et al., 2004). Inclusive communities can nurture friendships, which are reciprocal and include a sharing of resources (e.g., time support; Lutfiyya, 1991). Thus, participation in faith communities may have a positive impact on social relationships, personal friendships, and one's sense of belonging (Gleeson, 2002).

The way in which community participation is defined is of critical importance because physical presence within a setting is vastly different from involvement and relationship building within a setting. Based on differences found in prior research, the present dissertation asked participants about the type of relationship they have with individuals with intellectual disabilities which may include physical presence within their congregation and/or ways in which individuals with intellectual disabilities are involved within the setting.

\section{Purpose and Significance of the Present Study}

For individuals with disabilities, participation within a community in which relationships can be developed is important (Harlan-Simmons, Holtz, Todd, \& Mooney, 2001), and faith communities can be a key part of community life (Amado, DeGrande, Boice, \& Hutcheson, 2011). Participation within a religious community has potential physical and mental health benefits for adults with developmental disabilities (Turner et al., 2004). Further, inclusion within a religious community provides persons with disabilities a method to gain independence, meaningful social inclusion, and valued social roles (Turner et al., 2004). 
Statements published by religious organizations have been created to promote the inclusion of individuals with intellectual disabilities. However, no known empirical study exists on the examination of religious leaders' beliefs and attitudes toward individuals with intellectual disabilities. The significant leadership role of religious leaders affects thousands of individuals in the United States as they communicate political, religious, and social issues (Cohall \& Cooper, 2010) making it imperative that the perceptions of these leaders be known to explore their understanding of individuals with intellectual disabilities. The present dissertation intended to address the knowledge gap of religious leaders beliefs, and attitudes through qualitative inquiry. More specifically, this dissertation explored how religion informs the meaning of intellectual disabilities and attitudes toward individuals with intellectual disabilities among Catholic religious leaders. Additionally, all participants will be asked about demographic variables (e.g., age, level of education completed) as well as information on the nature and type of their disability training (if any), characteristics of their congregation (e.g., as decision making bodies), and leadership styles. By exploring ways in which religion informs understandings of intellectual disabilities and practices that include and exclude individuals with intellectual disabilities may help improve understanding of how community psychologists may work within the context of religious communities.

\section{Research Questions}

Legislative mandates have been instrumental in providing some degree of accessibility for individuals with disabilities in various domains of community life. However, political leaders have been reluctant to require that churches meet any of these 
accessibility guidelines due to stipulations in the First Amendment. For example, religious organizations are exempt from abiding by the ADA mandates (ADA of 1990, Sec. 12187). As a result, many barriers for inclusion remain for individuals with intellectual disabilities participating in church communities. Structural barriers are important, but according to prior studies, attitudinal barriers are significant (Carter, 2007).

The present dissertation aimed to understand how religious leaders make meaning of intellectual disabilities and perceptions toward the inclusion of individuals with intellectual disabilities within congregations. The overarching research questions the present dissertation will explore are (1) What types of experiences, in and outside of faith communities, do religious leaders have with individuals with intellectual disabilities?; (2) What are the beliefs of religious leaders toward the involvement of individuals with intellectual disabilities within faith communities?; and (3) How does religion inform the understanding of intellectual disabilities among religious leaders? At present, no existing theory addresses my research question. Therefore, a goal of the present dissertation was to develop a model inductively. In this way, the current dissertation contributes to addressing the lack of theory in the literature. Further, integrating religion into our understanding of disability issues will allow for culturally relevant applications for our knowledge base. Resulting knowledge may be utilized as instruments of social change, which begins with first exploring the impact of religion on communities and individuals. 


\section{Chapter 2: Method}

\section{Research Design}

The present dissertation aimed to address gaps in knowledge about how religious leaders make meaning of intellectual disabilities and their perspectives toward individuals with intellectual disabilities. To seek understanding of perspectives within the context of faith communities, a qualitative approach is particularly applicable. Qualitative methods seek to explore rather than verify (Ambert, Adler, Adler, \& Detzner, 1995), allowing for the exploration of perspectives within the under explored context of faith communities. Qualitative research aims to understand individuals in their natural environment in an attempt to make sense and meaning of the phenomenon based on the way individuals interpret their lived experiences.

Utilizing the qualitative method of semi-structured individual interviews, I gained a detailed picture of perspectives among religious leaders toward the participation of individuals with intellectual disabilities in faith communities as well as how religious leaders make meaning of intellectual disabilities. The interview questions illuminated what I wanted to know about the perspectives of religious leaders toward individuals with intellectual disabilities such as the type of involvement individuals with intellectual disabilities are encouraged to engage in within the congregation. Additionally, the present dissertation also sought to understand the process of making meaning of intellectual disabilities. Notably, semi-structured interviews do not require interviewers to utilize a series of identical questions (Smith, 1995). Therefore, I had the opportunity to generate questions throughout the interview process such as exploring participant 
experiences with and attitudes toward adaptive liturgies. As a result, the interviews were guided by a series of themes, which aimed to ensure all relevant topic areas from the interview guide were discussed in each interview.

The present dissertation utilized an inductive model to understand the meaning of intellectual disabilities and perceptions toward the participation of individuals with intellectual disabilities among religious leaders. Grounded theory is an analytic tool where theory emerges from the data. Grounded theory is inductively derived through systematic data collection and analysis of the data. More specifically, the data collection, analysis, and theory have a reciprocal relationship where data is analyzed after each data collection point to inform future data collection in order to clarify emerging theoretical relationships (Corbin \& Strauss, 1990; Parry, 1994). A description of the process I engaged in is detailed within the Data Collection and Data Analysis sections.

As a way to build upon my sensitivity and understanding of the context, I engaged in participant-observations to compliment my methodology of semi-structured interviews with grounded theory. Participant-observation is the observation of a context that is carried out while the researcher physically and socially is part of the context (Atkinson \& Hammersley, 1994). Researchers engage in participant observation to learn what life is like within a context while also complementing other forms of research.

\section{Research Context}

To understand the status of individuals with intellectual disabilities within a religious context, religious leaders were asked to participate in the present dissertation. More specifically, participation was limited to religious leaders who are part of the U.S. 
Roman Catholic Archdiocese in Portland, Oregon. The Catholic Church was specifically chosen rather than including all Christian churches due to possible denominational differences. Additionally, the Catholic Archdiocese in Portland has an Office for People with Disabilities, and through this office there has been an intentional effort to include individuals with disabilities. For example, a training program is offered for deacons concerning disability related issues within the Catholic community. Based, in part, on the work of the Office for People with Disabilities, many Catholic religious leaders were able to discuss their first-hand experiences with people with intellectual disabilities thereby allowing me to understand the perspectives of Catholic religious leaders.

The Archdiocese of Portland in Oregon serves as a leading resource for congregations of multiple denominations and faith organizations, particularly its Office for People with Disabilities (D. Coughlin, personal communication, May 22, 2012). The Archdiocese of Portland in Oregon has an Office for People with Disabilities whose mission it is to create churches that are inclusive attitudinally, architecturally, educationally, liturgically, and socially (Archdiocese of Portland in Oregon; n.d.). Additionally, the Archdiocese of Portland in Oregon (n.d.) may be unique from other faith communities, because they offer numerous services that promote the inclusion of individuals with disabilities, some of which include pastoral support to individuals with disabilities and their families, assistance to parishes to increase access and inclusion, ministry training on pastoral ministry with individuals with disabilities, and adaptive liturgies for people with developmental disabilities. In comparison to other denominations, it may be more likely that Catholic religious leaders have more contact 
with individuals with intellectual disabilities based on its local efforts in including all individuals with disabilities. However, according to the Director of the Office for People with Disabilities at the Archdiocese of Portland, Dorothy Coughlin, not all Oregon Catholic churches are involved in creating inclusive ministries (D. Coughlin, personal communication, May 22, 2012).

Among Christian denominations, the Office for People with Disabilities within the U.S. Roman Catholic Archdiocese is unique. The Episcopal Diocese of Oregon (Diocese of Oregon, 2011) has a deaf ministry in Monmouth, Oregon and a Parish Nurses/Health Ministries (focusing on care for people with disabilities), but it does not specifically concern inclusion of people with disabilities other than people who are deaf. Offices for other denominations, such as the Central Pacific Conference of the United Church of Christ (2010) and the Oregon-Idaho Conference of the United Methodist Church (2010), have ethnic ministries and gay/lesbian/bisexual/transgender working groups but none specifically concern disability. Outside of Oregon, multiple efforts are currently in place to promote inclusion of individuals with intellectual disabilities in faith communities such as the United Methodist Committee on DisAbility Ministries in New York (2013), Willow Creek Community Church in Illinois (Willow Creek Association, n.d.), and the Bethlehem Baptist Churches in Minnesota (2013). Nationally, organizations like the National Catholic Partnership on Disability (n.d.) and the National Collaborative on Disability, Religion, and Inclusive Spiritual Supports (Center for Community Inclusion and Disability Studies, n.d.) work to promote inclusion of people with various types of disabilities within faith communities across the United States. 


\section{Instruments}

Interview Schedule. A semi-structured interview guide (Appendix E) was developed for use in all individual interviews. The interview guide served as a model during the interview to make sure that all relevant topics were covered (Patton, 2002). The creation of the interview guide required thinking about what I thought and hoped the interview would cover. It also enabled thinking about challenges that I may encounter in terms of question wording or sensitive areas and how these challenges might be handled during the interview process (Smith, 1995).

The interview schedule was created utilizing Smith's (1995) guidelines, which consists of four steps. First, I considered the broad themes and question areas I wanted the interview to cover, which were generated while considering prior literature. Based on prior research, I considered where gaps in knowledge exist. A growing body of literature on the community participation of individuals with intellectual disabilities exists, but it is limited in the domain of religious participation. Of the studies that do focus on religious participation, participant samples have heavily relied on parents and disability service providers. These studies have focused on coping where religion has been used to inform the meaning making process and experiences of exclusion within congregations. The narrow focus on parents and disability service providers led me to consider the possible sources of religious beliefs as well as gatekeepers within religious communities. Therefore, I chose to focus specifically on the views of religious leaders to contribute to our knowledge of an under-explored perspective. The broad question areas I generated included how one's theology informs meanings of intellectual disabilities, experiences 
with individuals with intellectual disabilities, and perspectives about the participation of individuals with intellectual disabilities within faith communities. Additionally, I asked participants about their training on disability issues and leadership.

Next, the order in which questions are asked is important. Funneling was employed where the interview began with broad questions followed by more specific questions (Smith, 1995). For example, participants were first asked to describe their role in the church and their experiences with individuals with intellectual disabilities followed by their beliefs about the participation of individuals with intellectual disabilities.

The next step concerned generating questions related to each broader area. For example, for the larger theme of experiences with individuals with intellectual disabilities, participants were asked about the context in which their experiences have taken place, the relationship between the individual with intellectual disabilities and the participant, and the nature of the contact (e.g., spiritual guidance). The last step Smith (1995) suggested is to consider possible probes and prompts to follow from answers that might be given to some of the questions. Probes are used to increase the richness and depth of response and to give cues to the interviewee about the level of response that is desired. According to Patton (2002), probes should be conversational and offered in a natural style and voice. There are three types of probes, and one type asks interviewees about the who, what, where, why, when, and how of experience. Elaboration probes are another type that encourages continued talking. A nonverbal elaboration probe can be a gentle nod of one's head in positive reinforcement, but overenthusiastic nodding may be 
perceived as endorsement of the content of a response or as a cue to stop talking because the interviewer has already understood what the respondent has to say. A verbal elaboration probe can include asking "Would you elaborate on that?" or "Can you say more about that?" Clarification probes are used when more information is needed such as contextual information or a restatement of the answer (Patton, 2002). A clarification probe may ask, "I am not sure I understand what you mean by that. Would you elaborate?" As a reminder for myself, probes were integrated into the interview guide (Appendix E) for convenient retrieval during the interview.

A short form of the interview guide (Appendix F) was created to share with participants. The short form included the introduction, definition of intellectual disabilities, and interview questions. Information such as the probes were not included within the short form of the interview guide.

Process feedback was integrated within the interview. As the interviewer, I was responsible for communicating what information is sought, how the interview is flowing, and what kinds of feedback are appropriate and helpful to maintain the flow of communication (Patton, 2002). For example, midway through the interview, I checked to see how the interviewee felt about the interview process by asking "We are about halfway through the interview now. I think it is going very well and you are providing important information. How is the process going for you?" All participants expressed that the process was going well for them, and some participants then asked me how I felt about the process. When asked, I reiterated that the interview was going well and that they were providing valuable information. For some interviews, process feedback was 
utilized too early in the interview, because some participants had more to share in response to questions in the second half of the interview guide. Additionally, as the interview proceeded, some participants remembered information toward the end of the interview so, they referred to questions and responses discussed earlier in the interview.

Before moving on to the demographic questions, the interviews closed by providing interviewees the opportunity to have a final say. Before I asked participants demographic questions, I stated, "I do not have any more questions for part 1," and then I asked, "Is there anything you would like to add?" (Patton, 2002, p. 379). Most participants did not have anything to add when asked this question. However, I did provide a resource list upon the completion of the interview. Most participants looked through the list and found organizations that they have worked with in the past. In such instances, participating religious leaders briefly shared their experiences with the $\operatorname{organization}(\mathrm{s})$.

The interview guide was altered throughout the research process. First, after the first three interviews, I noticed that individuals were not clear about the difference between intellectual disabilities and psychiatric disability. Therefore, the interview guide (Appendix E), including the short form (Appendix F), stated, "Intellectual disabilities are not the same as mental illness. Schizophrenia and bipolar are types of mental illness." Of note, the term "mental illness" was used instead of psychiatric disability because participants used the term "mental illness" and participants did not know the meaning of the term psychiatric disability. During the fifth interview, I began to learn more about adaptive liturgies, which included discussions about creating adaptive liturgies as well as 
the attitudes of participants hosting an adaptive liturgy at their parish. Therefore, subsequent interviewees were asked about their experiences with adaptive liturgies as well as their attitudes toward adaptive liturgies. Last, some participants were not clear when I asked, "What resources does the Catholic church use in shaping its understanding of intellectual disabilities?" In such cases, I asked participants to imagine someone, such as a parent of a child with intellectual disabilities or a general member of the parish, asking the interviewee to help them understand intellectual disabilities. Then I asked them to consider which Catholic resources they utilize and share to help individuals understand intellectual disabilities.

Although I added questions to the interview guide as I completed interviews, I did not return to prior interviewees to ask new questions. My dissertation proposal and my application to the Human Subjects Research Review Committee only included contacting participants for the initial interview and member check. Additionally, the semi-structured interview process involves interview questions developing throughout the research process. Therefore, seeking out prior interviewees could simply yield more questions leading to multiple interviews with each participant. Given that data collection took place approximately one to five months before individuals were transferred to other parishes, multiple face-to-face interviews may not have been possible.

Field notes. Field notes in qualitative research are a record of what has been seen and heard by the researcher (Maykut \& Morehouse, 1994). Field notes were recorded throughout the research process (e.g., recruitment, participant observation, interviews) and they were written down immediately after engaging in each research activity. All 
field notes were recorded in narrative form of what occurred in chronological order including people's actions and interactions including intrusions (e.g., phone calls).

All field notes were dated while also recording important information such as where the occurrence took place, who was present, what the setting was like, and what activities took place (Patton, 2002). Additionally, during the interview process, nonverbal interactions that the voice recorder cannot document were recorded. Thus, field notes were used to provide information about nonverbal communications that took place. For example, one participant was only able to meet with me for one hour, so toward the end of the interview I noticed that he continuously looked at a clock in the room. My interpretations and insights were also recorded, and they were clearly separated from my observations. More specifically, I documented my observations in chronological order first and then I wrote my interpretations at the end of the field notes or in the margins of my paper. Field notes also aided the analysis where I wrote memos and noted topics to follow up on (Lincoln \& Guba, 1985; Maykut \& Morehouse, 1994; Patton, 2002). When I wrote my interpretations of each interview, I also documented how I felt during the process of the interview. During my first four interviews, I particularly found that I was nervous and relied heavily on the interview guide. Therefore, I specifically made notes to follow up on topics of discussion not explicitly stated in my interview guide.

I have two sets of field notes, which include process field notes (e.g., recruitment strategies, chronological description of each interview) and participant observation field notes (e.g., notes recorded after each participant observation in a parish, see Ecological 
Identity). The process field notes were recorded every time I worked on my dissertation, excluding the participant observations. For example, after each individual interview, I wrote field notes about what happened when I first arrived at each parish until the point where contact ceased with anyone from the parish setting. Thus, my field notes were not limited to information gathered when the audio recording took place. For example, when the audio recorder was turned off at the end of the interview, some participants and I talked about disability related issues. In conversation, a few participants remembered information about their experiences that they did not share when the audio recorder was turned on. The information shared during this time was documented in my field notes. Therefore, I treated field notes as a data source. Utilizing field notes as a data source meant that I could not document information that participants explicitly stated not to be part of my data. For example, I did not record field notes for the time when one participant, during the interview, asked to have the audio recorder turned off. The participant did not want his responses, while the recorder was off, to be included in my data. Additionally, I did record information shared by parish staff who were not participants in the study. Based on the mutual decision made among my dissertation committee co-chairs and myself, information shared by a parish staff member who did not consent to participate in the interview was not included as a data source. Only information from consenting participants was used as a data source. The informed consent process provides information to participants about how data is used. Therefore, an individual sharing information without having gone through the informed consent process may not know how the data will be used and disseminated. 


\section{Ecological Identity}

Community psychology stresses the importance of viewing communities ecologically by seeking an understanding of how individuals, roles, organizations, and events are interrelated (Kelly, 1971; Trickett, 1996). Trickett (1984) calls this environmental reconnaissance, which serves to sharpen questions relevant to the phenomenon embedded within its environment. This requires researchers placing themselves within social settings and being willing to grow (Kelly, 1971). As a way to place myself within the setting of Catholic churches and build upon my identity in relation to the community, I have engaged in participant-observations.

Participant observation, also called fieldwork, is where researchers enter preexisting settings and attempt to gather data unobtrusively about a group or social process (Cieurzo \& Keitel, 1999). Participant observation provides the opportunity to understand, firsthand, the experience of participating within the context of interest, because it requires researchers to immerse themselves into a context both physically and socially (Cieurzo \& Keitel, 1999).

Prior to the data collection process, I engaged in 14 participant observations at 11 parishes. The parishes in which I engaged in participant observation were linguistically and ethnically diverse and included adaptive liturgies. I engaged in two participant observations at three parishes, which included weekday mass. The participant observation continued during data collection, and some of the parishes I observed were those of participating religious leaders. 
The church is a focal setting for faith communities, and its purpose is for individuals to come together to worship God. Therefore, participant observations took place at Catholic churches during a religious service. Observations within the church were intended to provide me the opportunity to understand and be sensitive to the cultural context of Catholic churches in Oregon. More specifically, I focused on questions posed by Trickett (1984) that aid in the environmental reconnaissance process. These questions included asking what opportunities there were for lay participation (e.g., greeter at entrance) and who currently participants (with respect to readily apparent characteristics). Such questions helped me document the ways in which participation is defined and supported within the Catholic community.

Since I participated within the setting, I did not record field notes while I was in the field. Immediately after I left the setting, I recorded in chronological order what I observed, followed by my reactions to the events. When recording what I observed, I recorded information on all the events that took place, a description of the physical setting, who was present, and interactions. The documentation served as a record of my experience for future reference when considering the environment of the Catholic churches in Oregon.

By engaging in participant observations, I learned that each parish has its own unique personality. For example, I attended two adaptive liturgies at separate churches. At one church, volunteers with disabilities acted out the gospel and in some cases others provided support so that individuals could engage in various roles. Then the homily was tied into sports and the pastor engaged with parishioners throughout mass. However, 
another parish was structured where people without disabilities engaging in roles available to parishioners and the mass was simplified to promote understanding for people with disabilities. It is important to note that the differences I noted may not be accurate of parish life. More specifically, of the parishes that I engaged in participant observation twice, I noticed that the individuals engaging in roles such as greeters and Eucharistic ministers changed. One church even had a bulletin posted a calendar that listed various roles along with parishioners who volunteered for the role. Therefore, participant observations helped me further my understanding of the Catholic mass script and identifying roles available to parishioners. However, my specific experiences in regard to who participants may not reflect what typically occurs.

\section{My Role and Assumptions}

Methodologists have engaged in an epistemological debate about the nature of reality and knowledge, which has centered on the competing paradigms with one using of quantitative methods to generate and test hypothetical generalizations while the other uses qualitative approaches to inductively and holistically understand human experiences and constructed meanings in context specific settings (Patton, 2002). According to Morgan (2013) and Patton (2000), a pragmatic approach to research allows one to favor methodological appropriateness, which recognizes that different methods are appropriate for different situations. The paradigm (or worldview) with which I identify most with for the present dissertation is the qualitative, inductive, and context specific understanding of human experience and constructed meanings. It is assumed that the perspectives of others are meaningful, knowable, and able to be made explicit (Patton, 2002); thus, the 
present dissertation sought to understand the process of meaning making of intellectual disabilities and perspectives about the inclusion of individuals with intellectual disabilities in congregations among religious leaders.

Qualitative research is not value free and, as the researcher, I am an instrument of the study (Cieurzo \& Keitel, 1999; Lincoln \& Guba, 1985). The researcher and participants mutually construct data. Therefore, the research data was filtered through my perceptions, personality, and experiences, requiring an explicit articulation of my assumptions about the phenomena under investigation (Griffin, 1996; Kiddler \& Fine 1997).

Although no standard exists in regard to how much to share about my involvement and status throughout the research process (Merrick, 1999), I have chosen to share my relationship to research involving individuals with intellectual disabilities and faith communities. One aspect of my personal life that has direct relevance to the proposed dissertation is that I have worked with individuals with intellectual disabilities for over 15 years. I started to volunteer at an orphanage in Karachi, Pakistan run by a Christian church. As I spent time with these individuals, I learned they were socially excluded from society and were abandoned as children. Regardless of whether the individual was Muslim, Hindu, or Christian, their families and community members expressed that they were unwanted because normative belief dictated they were possessed by demons or were proof of their parents' sin. Within both the Muslim and Christian communities, I have witnessed blessings in hopes to cure disabilities such as intellectual disabilities. For example, in some Catholic churches outside of the U.S., 
individuals with disabilities have been asked to stand in front of a congregation while individuals pray for them to be cured. Intellectual disabilities being attributed to a demonic possession, past sins of an individual's parents, and a curable disease have influenced my interest in empirically pursuing how religion impacts beliefs about the nature and cause of intellectual disabilities and how that in turn impacts how individuals with intellectual disabilities are included.

Although I do not have a relationship with my research participants, I have attended Catholic Church services since 2003 in various locations. I have attended mass in Oregon. My relationship with religious leaders in Oregon, prior to data collection, has never gone beyond greeting individuals (e.g., saying hello, sharing my name, where I am from). During the Fall of 2012, I started to engage in participant observations to further develop my understanding and sensitivity for the cultural context of Oregon's Catholic churches (Goodley, 1999).

Additionally, my experience as a Muslim with a disability also has relevance to the proposed dissertation. As a Muslim woman who is hard of hearing, my family expected that I did not tell others that I have a disability. They feared the social isolation I would experience. Because I learned I must conceal my hearing loss, I struggled to participate fully. Thus, I was physically present in various community settings, but I had minimal involvement in actively being involved by taking on tasks or engaging with my peers. As a result, I navigated through life as an observer, lacking communication with others, and speaking at a bare minimum when faced with barriers. Through my own 
experience, I strongly believe that physical presence in a setting does not constitute inclusion or participation.

Importantly, my experience is likely very different from individuals with intellectual disabilities, requiring me to recognize the danger in "representing the Other" (Griffin, 1996, p.186). According to Griffin (1996), researchers must explicitly state their motive for conducting research and how it contributes to social change. Individuals with intellectual disabilities have faced exclusion from multiple community domains, but a growing body of research has begun to examine and promote community inclusion. However, this body of literature has paid little attention to religious participation. Through my own experiences within Muslim and Catholic communities and religious based organizations serving individuals with intellectual disabilities, I have had the opportunity to observe the social benefits of religious participation. Therefore, I strongly believe that for all individuals who identify with a religion or want to identify with one should be welcomed and included meaningfully. Additionally, religious leaders may serve as decision makers that lead to practices that may include or exclude individuals with intellectual disabilities. Being in a position of power while also balancing the needs of its congregation, religious leaders may provide insight in exploring inclusive and exclusionary practices. It is my hope that the results of this study will yield information on the successful ways in which individuals with intellectual disabilities are included within congregations as well as barriers to participation for future interventions and research to address. 
My experiences and academic work have shaped my interest in understanding how individuals with intellectual disabilities are perceived within faith communities and how it impacts their inclusion and participation. Throughout the research process, I intend to question how my own background and concerns affect the project in various stages.

\section{Research Participants}

The present section utilizes data shared by research participants about their parish and themselves. During the course of the semi-structured interview, research participants were asked to describe their parish. I asked about specific information such as the number of paid staff and volunteers and the linguistic, racial and ethnic makeup of parishioners. Participating religious leaders were also asked to describe their leadership role which focused on their day-to-day responsibilities.

Parish demographics. A total of 12 religious leaders participated in the present dissertation and they represent seven parishes. All participants were asked how many individuals are paid staff members within their parish. Of the participants who were from the same parish, discrepancies were found. For example, one participant stated having 20 paid staff while an individual from the same parish said there were 24 . Roughly, there was a range of 2 to 24 paid staff and the average was 9.58 paid staff based on the numbers provided. Two participants also discussed having paid staff with disabilities, including intellectual disabilities, in their parish.

All participants reported having numerous volunteers, and again there were discrepancies among religious leaders within the same parish. For example, one 
participant stated having 18 volunteers while another participant from the same parish stated having 85 to 90 volunteers. Except for the parish reporting 18 or 85 to 90 volunteers, most parishes reported having about 150 to 600 volunteers per year. This number includes individuals who may have only volunteered at one parish event.

Participating religious leaders also described their parishioners along various dimensions including, but not limited to, the types of disabilities represented, racial and ethnic diversity, and socioeconomic status. All parishes had parishioners with disabilities and multiple disabilities were represented at each parish. Participating religious leaders described experiences with individuals with multiple disabilities. Among the seven parishes representing the sample of participants, individuals with physical disabilities were most common and present in six parishes and individuals with intellectual disabilities and psychiatric disabilities were present in five parishes. Parishioners with hearing disabilities (present in two parishes), autistic individuals (present in two parishes), people with addictions (present in one parish), and individuals with visual disabilities (present in one parish) were relatively less common. Of note, the types of disabilities represented may not be completely valid. The majority of individuals with intellectual disabilities display mild symptoms of intellectual disability and are therefore at risk for having their symptoms unrecognized or misattributed. Additionally, little is known about the ability to recognize intellectual disability among people who are not disability professionals (Scior, Potts, \& Furnham, 2012).

Parishioners were also diverse in other regards such as age. All religious leaders described a large proportion of their parishioners being older in age and retired. Six of 
the seven parishes also stated having families with children of a variety of ages. All parishes also have racial and ethnic diversity with Latino, African, and Asian communities represented among parishioners. The participating religious leaders also described the socioeconomic status and education levels of their parishioners. Three participating religious leaders described having parishioners who primarily are of lower socioeconomic status. All other participants described their parishioners as being educated and representing middle and upper socioeconomic statuses.

Participant demographics. Twelve Catholic religious leaders were interviewed for the present study. Of the 12 participants, five were pastors, four were parochial vicars, and three were deacons. The leadership structure within Catholic faith communities is unique. Every diocese (a geographical area) is under the supervision of a bishop, and the bishop appoints ordained priests to be the pastor of a parish. A parish is a geographic area with boundaries for which religious leaders are responsible. Hence, a parish is a subpart of a diocese. The pastor's role is to speak in Christ's name to that community, and the pastor is responsible legally in the state of Oregon and by Church law for their parish. Additionally, a pastor's workweek is 72 hours per week, which is established by cannon law [law governing the Catholic church]. One individual described his role as pastor to the "the CEO [chief executive officer] of a fairly large organization."

The position of the parochial vicar was generally described as being "second in command." According to Cannon Law, a parochial vicar is under the authority of the pastor and assists in various functions. In the event that that a parish does not have a 
pastor or if the pastor is not available, the parochial vicar assumes the governance of the parish temporarily. These duties can involve, but are not limited to, preaching and decision-making (Code of Cannon Law, n.d.).

There are two types of deacons within the Catholic church. Permanent (or married) deacons are individuals who are ordained, but are not in the process of becoming a priest. Once a person is ordained, they are consecrated or given ministerial or priestly authority. Lay religious leaders are not ordained. A permanent deacon can be married. There are also deacons who are seminarians becoming priests. The last year of training for priesthood involves being a deacon. The participating deacons in the present study were permanent deacons. Deacons can perform many roles such as baptisms, witness marriages, and gravesite services, but there are roles deacons are not allowed to engage in such as presiding at mass and hearing confession.

All 12 participants were Caucasian and two identified as being part of nonCaucasian ethnic groups. The average age of participating religious leaders was 58.5 years of age and age ranged from the late 20 s to the late 70 s. In regard to the time in which participating religious leaders have been in their current position, there was a range of 6 months to 29 years. On average, pastors were in their roles for 3.7 years, 1.38 years for parochial vicars, and 5.67 years for deacons. The majority of participating religious leaders had prior roles within the Catholic church in roles such as, but not limited to, being a religious leader in another parish or working in youth ministry. Three individuals had work experience in secular organizations. 
All participating religious leaders completed at least one Master degree. Of the most common Master degrees among participating religious leaders, three (25\%) studied in the area of Theology, three (25\%) in the area of Divinity, two (16.67\%) in Liturgical Studies, and two (16.67\%) in Pastoral Ministry. Three (25\%) participating religious leaders also completed Masters degrees in areas not relating to religion such as the social sciences. In regard to disability training within participating religious leader's religious education, five $(41.67 \%)$ did not have any disability related training. One of the five (20\%) individuals without disability training stated having the opportunity in seminary, but he chose not to get involved. Among participating religious leaders, four $(33.33 \%)$ stated that there was some acknowledgement or reference to disability in their seminary training. Additionally, two $(16.67 \%)$ had practicums during their seminary training in settings that served a broad range of people with disabilities. Further, two participating religious leaders $(16.67 \%)$ had practicums in settings that were specific to people with intellectual disabilities, and one (8.33\%) worked with people with intellectual disabilities. Last, one participating religious leader (8.33\%) discussed having disability specific training post-ordination at the priest convocation that focused on diversity within the Catholic church.

Additionally, one participating religious leader had direct engagement with mass held in Spanish. Other religious leaders reported having limited or no contact with mass held in Spanish. More specifically, those with limited experience were currently or formerly in parishes that held a Spanish mass, but they did not take part in the mass. 


\section{Procedures}

Sampling. According to the Archdiocese of Portland in Oregon (n.d.), there are 39 parishes and 83 religious leaders in Portland, Oregon. These religious leaders include pastors, parochial vicars, and deacons. The Archdiocese of Portland in Oregon (n.d.) website lists the address, phone numbers, and names of religious leaders for access.

Non-probabilistic sampling is appropriate for many qualitative designs (Patton, 2002), and it was employed for the present dissertation. Grounded theorists utilize theoretical sampling, which is a type of purposeful sampling. The goal of theoretical sampling is to collect data from individuals who can provide relevant information for the generation of theory (Glaser \& Strauss, 2010). It was assumed that it would be most useful to seek participation of religious leaders based in parishes that have some form of contact with individuals with disabilities. Therefore, participation was only sought from religious leaders who are assigned to parishes that either host adaptive liturgies or were identified as having at least one parishioner with developmental disabilities participating in the mainstream mass (as determined by the Director of the Office for People with Disabilities at the Archdiocese of Portland in Oregon).

Dorothy Coughlin, the director for the Office for People with Disabilities at the Archdiocese of Portland in Oregon identified the three parishes that host adaptive liturgies and 23 parishes that have at least one parishioner with developmental disabilities. The Office for People with Disabilities works directly with religious leaders and parishioners, so the parishes were identified based on disability specific experiences of the Office for People with Disabilities. Adaptive liturgies are akin to mainstream 
Sunday mass, but they provide accommodations such as accessible spaces, listening devices, and rhythmic instruments (for those who cannot sing). Adaptive liturgies are not exclusively for people with disabilities, but it seeks to create an environment for both people with and without disabilities to worship God. Therefore, adaptive liturgies do not sacrifice elements of mass (D. Coughlin, personal communication, October 3, 2012). Of the three parishes with adaptive liturgies, two have adaptive liturgies fully implemented and one is in the early stages of implementation. Participation was sought from Catholic religious leaders regardless of the type of contact they may have with individuals with intellectual disabilities. Thus, the sample was heterogeneous and represents a range of experiences.

The process of theoretical sampling starts with a partial framework based on general concepts and the researcher continues to ask who should be sampled next and its theoretical purpose (Glaser \& Strauss, 2010). In the process of sampling, I began to sample from the 23 parishes known to have the involvement of individuals with developmental disabilities and these 23 parishes had 43 religious leaders. Then I sampled from parishes that host adaptive liturgy, which had eight religious leaders. I first wanted to make sure that I sampled at least three participants from parishes that do not host adaptive liturgies, and then I continued to schedule interviews based on my participants' schedules. The decision to start sampling from parishes that do not have adapted liturgy was so that early interviews did not reflect any premature bias of questions or analysis due to limited variability in the sample. 
Generally, steps for recruitment involved sending a recruitment letter (Appendix A), informed consent document (Appendix D), and the short form of the interview guide (Appendix F) through postal mail. Then I initiated contact with potential participants by calling them at their parish. I utilized a telephone script (Appendix B) as a guide to ensure I share the purpose of my study, why I am contacting them, what participation would entail, and answer any questions individuals may have. If I was asked by potential participants or parish staff to contact individuals through email, I utilized an email template (Appendix C) that paralleled the telephone script. When I connected with potential participants through telephone or email, I asked if they would like to meet faceto-face to discuss the study more. Participants who expressed interest in participating chose to schedule a time for the interview.

More specifically, all individuals recruited received a recruitment letter (Appendix A), informed consent document (Appendix D), and the short form of the interview guide (Appendix F). The recruitment letter introduced who I am, why I am engaged in this research, why I am contacting them, and that I would contact them within a week by telephone. The recruitment letter also stated that if they do choose to participate in the interview, I would ask them to sign the informed consent document (Appendix D). Excluding the two individuals who contacted me before I contacted them, I made a maximum of three phone calls and two emails. Of the two individuals who initiated contact with me upon receiving the recruitment letter, one called me to set up a time to meet face-to-face. The other individual sent me his signed informed consent document and emailed me about setting up a time to meet face-to-face for the interview. 
I made the initial phone call with the other participants one week after the letter was mailed to solicit participation. For the telephone calls, I utilized a telephone script (Appendix B) and for emails, I utilized an email template (Appendix C) that paralleled the telephone script. The telephone script and email template conveyed who I am, the purpose of my contacting them, and what is involved in participation. I also stated that I could meet with the potential participant face-to-face. Over the telephone, I asked individuals about their availability, and in email communications, I provided a list of dates I could meet with the individual. If individuals did not respond after the three phone calls and two emails, I ceased recruitment efforts. Of note, my initial plan was to make contact with potential participants through the telephone. When I contacted parishes to speak with the potential participant, parish staff and potential participants sometimes suggested I email the information I wish to convey through the telephone.

I engaged in recruitment of participants at three different times. To determine which parishes I would sample first, I assigned each parish (not including parishes with adaptive liturgy) a number, and I used randomizer.org to provide a random list of five numbers between 1 through 23. The six parishes yielded 10 religious leaders (i.e., seven pastors, one parochial vicar, two deacons). Six of the $10(60 \%)$ initially selected religious leaders agreed to participate in the present study. Of the four individuals who did not participate, one person expressed he did not want to participate, another person said his work required heavy travel and would only be able to participate in a telephone interview, and two individuals were unreachable by phone and/or email. The option to conduct a telephone interview was not pursued. Telephone interviews were not part of 
my proposed research and telephone interviews present challenges that will impede upon the quality of the data (e.g., absence of facial expressions, quality of phone call; Smith, 1995).

Then I recruited individuals from parishes that host adaptive liturgies. Of the eight religious leaders at the three parishes, five participated (62.5\%). Two individuals were unreachable by phone and email. One individual said he did not have time to meet with me, and I explained that I was willing to be flexible with scheduling a time that may work in the future. The individual expressed not wanting to schedule a date to meet with me in the future.

Once I scheduled eleven interviews, I sought participation from three parishes of the remaining 17 parishes that have at least one individual with developmental disabilities. Again, randomizer.org was utilized to determine which three parishes would be sampled. I mailed the recruitment letter, informed consent document, and the short form of the interview guide to six religious leaders from three parishes, but recruitment was only followed up with four religious leaders.

Among the three parishes I last recruited from, one had four religious leaders. I first contacted the pastor of the parish who said he would consider participation and contact me a month later. Next, I spoke with the parochial vicar who was interested in participating, so we scheduled a time to meet. When I arrived at his parish on the date and time we agreed upon, I was told the parochial vicar was out of the state. The pastor asked to speak with me and explained that the parish does not concern itself with people with disabilities, it is the responsibility of the parent(s) of individuals with intellectual 
disabilities to deal with them, and that the others in the parish are not interested in my study. Therefore, the two religious leaders who had not been contacted through telephone were not pursued for recruitment.

Of the four individuals called and emailed from parishes that have at least one parishioner with developmental disabilities, only one individual participated. Of the three that did not participate, one stated he was not interested in participating while the remaining two were unattainable through telephone and email.

In qualitative inquiry, there are no rules for sample size. Sample size depends on what the researcher wants to know, the purpose of the inquiry, what will have credibility, and what can be done with available time and resources (Patton, 2002). Lincoln and Guba (1985) recommend sampling to the point of redundancy. This means that sampling is terminated when new information is no longer emerging (Cutcliffe, 2000; Guest, Bunce, \& Johnson, 2006; Patton, 2002). Thus, qualitative researchers continue to collect data until they find that nothing new about the phenomena of interest is emerging. Patton (2002) recommends sampling designs specify minimum samples based on expected coverage of the phenomenon given the purpose of the study. Some researchers have suggested approximate numbers of sample sizes. For example, Morse (1994) recommends 30 to 50 participants for grounded theory studies, whereas Creswell (1998) recommends a sample of 20 to 30 for a grounded theory study. These sample sizes are provided as guidance, and they do not provide empirical arguments as to why they suggest specific ranges. Guest, Bunce, and Johnson (2006) systematically examined the degree of data saturation and variability over the course of their analysis with interviews 
from Ghana and Nigeria. After analyzing six interviews, they found that the basic elements for meta-categories were present. After 12 interviews, they found that $92 \%$ of their codes were developed for the Ghanaian interviews and $88 \%$ of codes for both countries.

In consultation with the co-chairs of my dissertation committee and based on my preliminary data analysis (see data collection procedures and data analysis sections), I chose to stop data collection once I completed 12 interviews. I recruited a total of 24 individuals; therefore, my response rate was 50\%. In other words, my preliminary analysis allowed me to determine that I was not collecting new information.

In summary, 16 religious leaders from parishes with member with developmental disabilities were recruited and 7 individuals participated. Eight religious leaders were recruited from parishes that host adaptive liturgies and five participated. The total sample size for the present dissertation was 12 and included five pastors, four parochial vicars, and three deacons. Figure 1 displays a summary of the recruitment effort.

All participants were Caucasian and two individuals identified with nonEuropean ethnic groups. Participant ages ranged from 28 to 79 years of age and the average age was 58.5 years. All participants completed at least one Masters degree while two completed three Masters degrees. The most common Masters degrees were in theology $(n=3)$, and divinity $(n=3)$.

The range of the time served in the participants' current position was from 6 months to 15 years. Deacons were in their current role for an average of 5.67 years, parochial vicars for an average of 1.38 years, and pastors for an average of 3.7 years. 
The previous role of almost all participants was within the Catholic church. Pastors and parochial vicars tended to be religious leaders at another parish while deacons were in roles such as youth ministers. Of the seven parishes represented, three parishes only had one participating religious leader. The range of paid staff at the parishes of participating religious leaders was from 2 to 24 with an average of 9.58 individuals. Additional information about the participating religious leaders and their parish is provided in the Results section.

Data collection. All face-to-face meetings were scheduled through telephone or email exchanges (see Research Participants). I told participants that they could choose the meeting location, which could include their parish or an office at Portland State University. One interview took place at Portland State University while the remainder of interviews took place at the participant's parish. At the face-to-face meeting, all participants were provided the same informed consent document that was mailed to them. I first asked individuals if they had a chance to read the document. If they did not read it, I gave them time to read it. Then, I asked all participants if they have any questions. A few participants wanted to know if I would share their information or identify their parish in publications or with the Archdiocese in Portland. I said I would not share any identifying information, and that only my research advisers and myself have access to their information. I briefly shared the purpose of my study and I reminded participants that they could skip questions or stop participating at any time. Once all questions were asked, I retained the signed copy of the informed consent document and the participant was offered an unsigned copy for their records. 
Once informed consent was obtained, participation in the interview began and the digital voice recorder was turned on. The use of a digital voice recorder allowed me to concentrate on how the interview is proceeding and where to go next rather than writing down what the interviewee was saying (Smith, 1995). Rather than taking notes of what participants said, I took notes for the purpose of helping me formulate new questions as the interview progressed. While the voice recording provided a record of what was said, it is not a complete interview (Lincoln \& Guba, 1985). Non-verbal behaviors are excluded from voice recordings, and the recording went through a process of interpretation from me, the transcriber.

All of the participants allowed audio recording of the interview. Once the voice recorder was turned on, all participants were offered the short form of the interview guide (Appendix F). During the interview, I took notes of topics I wanted to follow up on or probe participant responses. When the interview was complete, I provided each participant a resource list (Appendix G) that listed local and national resources concerning disability within a Christian context.

Based on the audio recordings, interviews ranged from about 39 - 95 minutes and the average duration was 68 minutes. The audio recording began once the informed consent process was complete. At the end of the interview, participants were asked if they would like to share any other information, and once they completed their answer, I told them I would turn the recorder off. The recording time does not accurately convey the duration in which information was gathered. For example, one participant walked me to the exit when the interview was complete. At this time, he was also looking through 
the resource list. He recognized one of the organizations and described an experience he had with individuals with intellectual disabilities within the organization. The information gathered was recorded in my field notes. Similarly, another participant was interviewed for two hours, but the audio recorder was turned off, by request of the participants, for parts of the interview. The information shared when the audio recorder was turned off was not used as data because the participant did not want to publically share information that was specific to his parishioners, which may identify the parishioner and/or participating religious leader.

When I completed each interview, I recorded field notes as soon as possible and the interview was transcribed. For the transcription process, I first only listened to the audio recording. Then I listened to the audio recording while typing out each word stated and sounds like sighs and pauses. Next, I reviewed the transcript while listening to the audio recording to ensure the transcript was accurate (Poland, 1995). Throughout the transcription process, I did not edit the verbatim accounts including alterations to sentence structure.

Notably, qualitative research, particularly grounded theory, necessitates the overlapping of data collection and analysis. Upon the completion of each interview transcription, analysis took take place to inform future interviews. A detailed discussion of the analysis process is discussed in the Data Analysis section.

\section{Pilot of Research Procedures}

Piloting the research materials can reveal weaknesses or problems with the research design and materials. Therefore, I piloted the procedures with one graduate 
student peer and two individuals working at the Archdiocese of Portland. Of the individuals working at the Archdiocese of Portland, one individual is the director of Life, Justice, and Peace and the other is the director of Hispanic Ministries. I began the piloting process by sharing the initial letter religious leaders received followed by an enactment of my telephone script. Then, during our face-to-face meeting, I went through the process of gaining informed consent, answering questions, and then the interview began. At the end of the process, I sought feedback to determine whether changes are required, and I reviewed the audio recording of the pilot to identify weaknesses I need to address.

Based on my discussion with my pilot participants and my review of the audio recordings of the pilot interviews, I made changes to the interview guide. I altered two questions, which were not clear to my pilot participants. Additionally, the order of two questions was altered to aid in probing. For example, I initially planned to ask, "How would you describe your faith community?" toward the end of the interview. I chose to place it as the second question so I can probe about specific sub-communities within the parish. For example, one pilot participant described differences between the Latino and Caucasian communities. Knowing the make-up of the parish early on allowed me to ask about possible differences within the parish based on factors such as race and ethnicity. While I was conducting the pilot interviews, my application for the Portland State University Human Subjects Research Review Committee was under review. Therefore, I submitted a modification request, which were accepted, to the Portland State University Human Subjects Research Review Committee. 
Although I did not test whether the alternations worked better than what I initially planned, none of my research participants expressed confusion about the questions altered. Additionally, based on the responses I received, there was no indication that my questions lacked clarity. I speculate that the movement of the question about the participant's parishioners created the opportunity for me to probe specific information shared by participating religious leaders. Asking about parishioners at the end of the interview may not have allowed me the time to go through every question to understand differences in parishioner sub-groups and the process would likely be fatiguing for participants.

\section{Data Analysis}

Data from this study were analyzed utilizing a grounded theory approach. The primary purpose of grounded theory is to generate explanatory models of social processes that are grounded in data (Strauss \& Corbin, 1994). Explanatory models are developed through the technique of constant comparison, which involves identifying patterns and relationships within the data. Thus, models or mini-theories emerge from the data. Models, unlike theories, are incomplete and tentative descriptions of phenomena (Llewellyn \& Hogan, 2000). Generally, models of disability are intended to be frameworks to understand the cause(s) of disability and its associated implications (Altman, 2001). Thus, models of disability describe the disability as well as different intervention approaches. However, no single model provides the best or most comprehensive intervention approach. The models of intellectual disabilities, developed within the present dissertation, intend to represent reality but the models do not duplicate 
reality. The models of intellectual disabilities intend to help organize the complex relationships among how meaning is made of intellectual disabilities, experiences with persons with intellectual disabilities, and attitudes toward the participation of individuals with intellectual disabilities in faith communities. Notably, each model of intellectual disability is a representation of people who ascribe to a set of ideas. Thus, each participating religious leader represented a single voice. Each participant was compared with other research participant voices to determine boundaries for models. Each model of disability discussed within the Research Findings section is made up of a distinct group of leaders that were grouped together to exemplify each model. Therefore, comments from one participating religious leader cannot support multiple models.

The first two research questions exploring the types of experiences religious leaders have with individuals with intellectual disabilities and the perspectives of religious leaders toward the involvement of individuals with intellectual disabilities involved yielded a description of participant experiences and perspectives while the process of how meaning is made of intellectual disabilities took a grounded theory approach. Grounded theory is a research method that allows for theory construction from the data, and it involves simultaneous data collection and analysis (Charmaz, 2011). When considering versions of grounded theory, this dissertation utilizes a constructivist grounded theory approach. Thus, the approach utilized in the present dissertation moves away from the more positivistic versions of grounded theory presented by Glasser (1987) and Strauss and Corbin (1998; Charmaz, 2006; Denzin \& Lincoln, 2005). For example, Strauss and Corbin (1998) explicitly aimed for verification 
in grounded theory and drew upon objectivist assumptions rooted in positivism.

Constructivist grounded theory is not rule bound but rather offers flexible guidelines to adapt them to studies (Charmaz, 2006). Therefore, the way in which the guidelines are used is not neutral. The present dissertation utilizes a constructivist grounded theory approach.

In its purist form, explanations and theories that yield from a grounded theory approach are derived from the dataset itself rather than from a researcher's prior knowledge. According to the Glaserian position, literature reviews are conducted when grounded theory is nearly done during the write up phase (Glaser, 1998). In contrast, Strauss and Corbin (1998) expect researchers to be familiar with the literature in their field. Glaser's (1998) position assumes researchers randomly pick a topic, but as a student, I have studied a specialty and developed research interests. To stay abreast within my field, I am expected to keep up-to-date within my field of study. Therefore, it is not possible for me to stay away from the literature. Furthermore, preparing the literature review enabled me to frame my study and determine where current gaps in knowledge exist. Thus, this knowledge has allowed me to create a research design that develops new knowledge and goes beyond existing literature.

Of importance, the way in which I utilized existing knowledge must be made explicit (Hallberg, 2010; McCallin, 2006). First, the literature review within this dissertation is intended to meet academic purposes that demonstrate my knowledge about the phenomena and methods for study. As I created the literature review, I thought through the issues to develop a cautious attitude about the literature. Therefore, 
throughout the research process, I maintained theoretical sensitivity through constant comparison (e.g., incidents to concepts, concept to concept). Charmaz (2003) defined sensitizing concepts as those that help organize and understand the overall phenomena. Additionally, I am aware of the possibility that my preexisting knowledge likely has influenced me (Suddaby, 2006), but I have not tested hypotheses based on existing knowledge.

For the analysis, all field notes were typed and all interviews were transcribed verbatim. The analysis began upon completing my first interview to direct subsequent interviews. The overlapping of data collection and analysis allowed me to consider questions to follow up on with future participants (Corbin \& Strauss, 1990). Once each interview was complete, I recorded field notes, completed the transcription process, and then I begin the first stage of analysis. Emerging concepts informed how I changed my interview guide. As stated earlier in the Instruments section, after the third interview, I stated that intellectual disability is not mental illness and then I provided examples of categories within mental illness (e.g., bipolar). Based on my knowledge, empirical literature on adaptive liturgies does not exist, so I initially did not include too many questions on the topic. However, as I went through multiple interviews, I started to ask more questions about adaptive liturgies that I had not considered in the development of this dissertation. I asked questions such as "In your experience, who has advocated for inclusion of people with intellectual disabilities in your faith community?," "Have you ever attended an adaptive liturgy?," and "What are your thoughts on integrating parts of the adaptive liturgy into mainstream mass?" Thus, the data collection and analysis 
processes were iterative. Therefore, multiple stages within the analysis phase were operating at multiple times to provide continuous development (Glaser \& Strauss, 2010).

First, I started with one transcript and read it over multiple times (Smith, 1995). One side of the margin was used to note down anything interesting or preliminary interpretations (Smith, 1995). For example, this helped me identify, early in the interview process that some individuals differentiated between counseling and spiritual direction while others did not. Therefore, I asked participants about their involvement in both spiritual direction and counseling. The other margin was used to identify emerging theme titles, which is called open coding (Charmaz, 2011; Glaser \& Strauss, 2010). Open coding asks what each line of data means to identify, name, and categorize data. I used line-by-line coding to look for what is happening in the data and labeling it with short terms. Importantly, while coding for a category, I compared it with previous incidents in the category to develop the theoretical properties of the categories (Glaser \& Strauss, 2010).

Upon completing the first coding of each transcript, I recorded memos to document the initial coding process (Glaster \& Strauss, 2010). Memos, or extended notes, were written to record each code, its properties, and comparisons between codes and categories (Charmaz, 2011). This process allowed me to document conflicts during the coding process (Glaser \& Strauss, 2010). Then, as codes began to develop from the transcripts, I started to code my field notes.

I followed the next step prescribed by Glaser and Strauss (2010), which was to integrate categories and their properties. During this stage, each category and 
subcategory was defined and comparisons continued. However, instead of comparing incidents within the data, category properties were compared to determine which cluster together and which differ (Charmaz, 2011; Glasser \& Strauss, 2010; Smith, 1995). During this process, I found that I did have redundant codes that needed to be further examined for differences or collapsed into one code. For example, initially, I believed I had redundant codes about beliefs regarding the purpose individuals with intellectual disabilities serve in the lives of others (e.g., family, community members). By re-reading the data and refining codes and corresponding definitions, I was able to better distinguish differences. The integration of categories and their properties yielded a codebook (Appendix $\mathbf{J}$ ) that accounts for interrelationships among categories to describe the phenomena. This process involved integrating categories where each core code had multiple mid-level codes, and the mid-level codes often had lower level codes. I went through multiple iterations to examine which structures captured my data and focused on my research questions. For example, when participating religious leaders discussed which and how resources were used to understand and address disability issues, I continually pieced apart and put together information so that I separated the types of resources sought as well as the ways in which resources were utilized. Throughout the process, I took notes on larger core codes that I saw as possibly emerging from the codes. I retained a list of my ideas in my memos as I continued to work with the data. Utilizing the Dedoose 4.5.95 web application, I engaged in selective coding once my core categories emerged. The core categories represent five models of disability (i.e., Close to God, Conformity, Unfortunate Innocent Children, Deficient, and Human 
Diversity), which are fully discussed in the Research Findings section. I returned to my notes on possible core categories, to determine my next steps, and I found that my possible core codes had similarities. For example, I initially paired the code Unfortunate Innocent Children with Paternalism. As I worked with the data further by re-reading codes and working through the selective coding process, I found that paternalism was not an accurate description of the data but Unfortunate Innocent Children was. This process involved defining both paternalism and what it means to be unfortunate, innocent, and childlike. Participants described the terms unfortunate, innocent, and child-like. Initially, I thought it might be best to group the three definitions together under paternalism. Paternalism is defined as the practice of restricting freedom of a subordinate group and assumes restricting freedom is in the best interest of the subordinate group (Merriam-Webster, 2013). I compared the definitions and then examined the boundaries of my codes to determine which label fit best as well as how I may need to alter boundaries. Engaging in peer debriefing also aided in making decisions about code boundaries and labels. My final decision to use the label Unfortunate Innocent Children was based on recognizing that participant definitions of the terms unfortunate, innocent, and child-like did not fit within the boundary of paternalism. In order to create a label for paternalism, I would need lower level codes that focused on limiting autonomy for the good of people with intellectual disabilities or behaviors that went against the will of people with intellectual disabilities. Similarly, I also considered how the Deficiency model differed from the Medical model of disability as well as how the Close to God model differed from the supercrip stereotype. Thus, the 
goal was to create core categories that accurately represented the data to understand the relationship between beliefs about the nature and cause of intellectual disabilities and attitudes toward the presence and participation of individuals with intellectual disabilities in faith communities. Five core categories emerged which are the five models of intellectual disabilities (presented in detail in the Findings section).

Once the core categories were determined, the data was selectively coded with the core categories guiding the selective coding. Selective coding involved returning to the transcripts to identify the instances that fall under each category and subcategory. The selective coding process also involved going over field notes and interview transcripts, which were already coded once at an earlier stage (Glasser \& Strauss, 2010). The end of this process yielded core categories to explain the phenomena of interest. The final core categories represent models of intellectual disability that capture information addressing the study's three research questions. The core categories or models represent beliefs about the nature and cause of intellectual disability and associated behaviors and attitudes toward people with intellectual disabilities in faith communities. The structure of each model is not identical. The models vary due the semi-structured approach to data collection. For example, the Deficiency model discussed the cause of intellectual disabilities. However, the remaining four models do not include information about the cause of intellectual disability because the participants steered the conversation to which resources they would utilize to understand intellectual disability issues.

The process of grounded theory analysis is cyclical. As a result, categories were added, altered, or removed as new data emerged. If new categories emerged in 
subsequent interviews, they were tested against earlier transcripts. Although the data collection and data analysis overlap, data analysis continued once data collection was complete. As discussed earlier, member checks were completed once a preliminary summary of my results was complete. All participants had the opportunity to express their views, which was documented to inform my interpretations.

Demographic information shared during the interviews (e.g., time in current position, level of education completed) was utilized to describe the participating religious leaders and their parish in the Methods section. Demographic information, such as training on disability issues were also coded utilizing grounded theory, as described above. Thus, all information shared (i.e., demographic information, experiences with individuals with intellectual disabilities, perspectives toward the participation of individuals with intellectual disabilities in faith communities and beliefs about the meaning of intellectual disabilities) was utilized to create models of intellectual disabilities.

The findings and discussion sections are presented as separate sections. It is important that I recognize that I am an instrument in the study. The data is filtered through me where I shaped the data through my own experiences and expertise (Stein \& Mankowski, 2004). For example, I drew upon my own subjectivity to make meaning of what my research participants have shared and I made decisions about which pieces of information are pertinent to my research questions. Thus, I first present the voices of participants through each model and then my interpretations are presented in the discussion section. 


\section{Criteria of Merit}

Qualitative researchers utilize criteria of merit that parallel quantitative researcher's use of reliability and validity (Lincoln \& Guba, 1985). I integrated steps within the methods of the present study to bolster the merit of my findings. One way in which I addressed the criteria of transferability is by providing thick descriptions of the data, research processes, and the conclusions I drew based upon the data. The thick descriptions intend to provide sufficient information for others to draw conclusions and evaluate the conclusions I draw from the data. According to Lincoln and Guba (1985), transferability is the responsibility of others wanting to transfer my research findings to another situation or population. For example, researchers may seek to transfer my research findings to religious leaders of other denominations or lay religious leaders. Therefore, I aimed to present sufficient descriptive data and information on the research processes to allow for comparison.

The criterion of credibility is where researchers seek to establish confidence in findings from the data. I took part in prolonged engagement where sufficient time was invested for observation, triangulation, peer debriefing, and member checks. Qualitative researchers increase the worth of their findings by decreasing the distance between themselves and the informants, which can be achieved through prolonged engagement (Krefting, 1991; Lincoln \& Guba, 1985). I have engaged in prolonged observation through participant observation of church service, and I engaged in individual interviews that provide participants time to fully provide their responses. For example, interviews lasted about one to two hours. I used triangulation to gain a rich understanding of the 
complex phenomena being studied. Triangulation is a strategy to converge multiple perspectives for mutual confirmation (Denzin \& Lincoln, 2005; Lincoln \& Guba, 1985). I utilized investigator triangulation, which is part of the analysis, and it therefore does not concern data sources. I engaged in investigator triangulation by regularly consulting with my research adviser and graduate student peers regarding my findings. More specifically, investigator triangulation was built into the analysis where I shared descriptions and experiences of my dissertation with others for their feedback. For example, after my third and fifth interviews, I sought out peer feedback on my probes and general interview style. I also received feedback on my fifth interview from my adviser, Katherine McDonald. During the analysis stage, I have also continued to engage in investigator triangulation. For the analysis, I shared my line-by-line codes, super codes, and multiple drafts of my coding framework with a peer for feedback and discussion.

The accuracy of descriptions and interpretations were intended to be addressed through member checks. I utilized member checks upon completing all interviews. Once all interviews were completed, I mailed a letter (Appendix H) with a summary of my findings. One week after I sent the letter, I called each of my participants to find out their opinion of the summary. For example, I asked participants if the summary leaves anything out that they feel is important.

Of the 12 participating religious leaders, two individuals did not respond to two phone calls and two emails. Six participating religious leaders were not longer at the parish they were affiliated with at the time of data collection, but I was able to contact 
three through email. One individual emailed me and said he did not have any comments but he will use the summary to think about how he will approach inclusion at his new parish. I responded to the email asking for information on how he might use the summary, but I did not receive a response. One parish staff member provided the email address of one participating religious leader who was no longer at the parish. I emailed the individual twice, but I did not receive a response. Another individual who was no longer at the parish they were associated with at the time of data collection stated that the tension between having an adaptive liturgy and an integrated mainstream mass stood out, and he stated that there are advantages and weaknesses with either approach. He also stated that based on the wide disparity in understanding of the needs and abilities of persons with intellectual disabilities, education on disability issues for religious leaders is needed.

Among those who were still at the parish they were associated with at the time of data collection, one said he would email me his response, but he never emailed. I emailed him twice to follow up, but I did not receive a response. One individual stated he did not have any comments, but he thanked me for including him in my research. The other individual stated that the wide range of responses were surprising and reading the summary made him think that he needs to attend the adaptive liturgy. He also said that it would be good for religious leaders to be trained on disability issues that involved attending adaptive liturgies. One individual contacted me through the telephone and he said he was disappointment in the results indicating exclusionary attitudes and believes that a lot of work still needs to be done within faith communities in regard to disability 
issues. In summary, three individuals provided a response to my questions, one stated not having any comments, and the remaining eight participants did not respond to multiple telephone calls and emails.

The purpose of the member check was to document the disagreements and consider why a disagreement exists and what may account for it. Due to the way in which the Catholic church is structured and realities of a job, transfers within the church, sabbaticals, and retirement are to be expected. One participating religious leader shared that it was a busy time of year as religious leaders were transitioning into new settings and those currently within the setting were helping with transitioning individuals. This likely account for the extremely low response rate for the member check, but it provides a learning opportunity for future research with religious leaders, which is expanded on in the Discussion section.

Another practice to satisfy the criteria of credibility is negative case analysis. During the analysis, I checked on the quality of categories and explanations through negative case analysis. As I developed explanations of my phenomena through grounded theory, the explanations became stronger when more data confirmed it. However, if new data refuted the explanation, I revised the explanation. Then, I continued to use new data to test the explanation until there were no more negative cases to account for (Kidder, 1981). The goal of the negative case analysis will be to yield robust explanations.

Dependability, another criteria of merit, can be established through an inquiry audit (Lincoln \& Guba, 1985). I have left an audit trail, which involves maintaining extensive documentation of records. The audit trail includes raw data (e.g., written notes, 
audio files), data reduction and analysis products (e.g., field notes, summaries), data reconstruction and synthesis products (e.g., structure of categories, findings and interpretations), and process notes (e.g., implementation of methods).

\section{Ethics}

Upon completing and successfully passing my dissertation proposal, I submitted an application to the Portland State University Human Subjects Research Review Committee to gain approval for data collection. Modifications were submitted upon completing the pilot, and the Human Subjects Research Review Committee approved the application.

Research utilizing semi-structured interviews requires that research participants are protected. Throughout the process of developing and implementing my dissertation, I have considered and integrated ethical requirements to ensure participants are protected. Further, throughout the research process, I remained cognizant of and acknowledged important ethical considerations.

The process of informed consent required that I provide research participants with sufficient information about the research so that they can make informed decisions regarding participation. The process of informed consent took place prior to beginning the semi-structured interview. However, due to the fact that the interview was semistructured, allowing for emergence of topics I may not have planned, it is not possible to provide specific statements about what participants would have experienced. Therefore, information about the general topic of the research was shared as well as other information including that participation is voluntary and that participants may stop 
participating at any time. I went over the informed consent document with each participant and I answered any questions they had. Once the participant agreed to participate and signed the informed consent document, I provided them with an additional copy of the informed consent document.

Confidentiality of all participants has been protected. The digital voice recordings for all interviews were transferred to the Portland State University secure (i.e., H:) Home Folder. An electronic document that links participant numbers (used in transcripts) and participant names is kept on the Portland State University secure Home Folder and the document is password protected. The only printed document that lists participant names is the informed consent document. The informed consent documents, during data collection, were kept in a locked filing drawer in Katherine McDonald's graduate students' office, which is always locked. With permission from Portland State University's Human Subjects Research Review Committee, the informed consent documents were moved to a locked cabinet at Mazna Patka's office at Governors State University. All interviews and corresponding field notes refer to the participant with a unique identifying number.

My dissertation proposal stated that I would utilize pseudonyms to replace participant names. Although I will be omitting identifying information such as parish name, I have chosen to omit the use of within person tracking in my results. The data shared by participants is contextually specific to where linking what an individual participant says throughout the results section may identify the participant. 
Additionally, all participants were informed that the data would be disseminated. Therefore, I sought their consent to have their words published. Prior to disseminating the results of the study, a member check was completed to protect the credibility of the data descriptions.

Additionally, there was minimal risk involved in the present study. The probability of harm or discomfort anticipated was not greater than what participants experience in daily life. For example, participants may consider their views on inclusion when encountering people with disabilities, and individuals with disabilities and family members may seek council and support from religious leaders to understand disability within the context of their faith.

A direct benefit of participating in interviews for some participants may be that it was empowering. Sharing one's story and being able to influence others is powerful (Rappaport, 1995). Based on previous literature, the dominant cultural narrative has been communicated through the perspectives of parents of individuals with disabilities and disability service providers, and the views of others have been under-explored. Therefore, an alternative story may serve as a resource to inform and influence our understanding of the participation of individuals with intellectual disabilities within religious communities in a unique way. Based on my observation of the interview process, I did not notice expressions on the part of individuals that would indicate participation being empowering. Although I did not notice an outward expression of the participant feeling empowered, participants may have found the experience to be empowering. Additionally, all participants received a resource list consisting of 
organizations, websites, and books that concern the integration of individuals with intellectual disabilities in faith communities. Participants may have experienced indirect benefits. For example, the results of the study may inform the Archdiocese and its Office for People with Disabilities about the challenges parishes are experiencing to inform future interventions. Similarly, the results may also help the Archdiocese understand the strategies that religious leaders and their parishes have utilized to promote the participation of individuals with intellectual disabilities. 


\section{Chapter 3: Research Findings \& Discussion}

The present study aimed to understand the meaning making process and perspectives of Catholic religious leaders toward the participation of individuals with intellectual disabilities in faith communities through the development of grounded theory. Specifically, this study addresses three overarching research questions which include: (1) What types of experiences, in and outside of faith communities, do religious leaders have with individuals with intellectual disabilities?; (2) What are the perspectives of religious leaders toward the involvement of individuals with intellectual disabilities within faith communities?; and (3) How does religion inform the understanding of intellectual disabilities among religious leaders?

The present chapter adheres to the traditional dissertation format of distinctly separating the results and discussion sections. Therefore, each model is presented with participant voices, and my interpretation of the models is discussed in the discussion section.

\section{Research Findings}

The grounded theory analysis yielded five core categories representing models of intellectual disabilities. Each model captures data addressing all three research questions to describe multidimensional aspects of intellectual disability issues in faith communities (see Table 1). Of note, in grounded theory, categories are raised to a conceptual level of analysis (Charmaz, 2006), which evolve around a storyline. Within the present context the abstract categories that were created from lower level categories are identified as models of intellectual disability, which are intended to be the storyline for the sets of 
categories. Thus, models of intellectual disability are conceptual frameworks that provide insight into how disability is defined. The present dissertation helps to widen our perspective, through models representing the experiences, perceptions, and meaning making of intellectual disabilities, to better understand disability issues. The data from the present study yielded five models which include (1) Close to God, (2) Conformity, (3) Unfortunate Innocent Children, (4) Deficient, and (5) Human Diversity.

Throughout the analysis process, patterns were explored and examined to determine how to present the present findings. During the analysis process, I continually examined how the voice of each participating religious leader was similar and different. Throughout the process, I found that most participating religious leaders viewed people with intellectual disabilities as having a purpose. When I worked further with the data, I explored ways in which participating religious leaders were similar and different in regard to their understanding of intellectual disabilities. It should be noted that I first looked at how intellectual disability was defined and understood because it was most apparent to me at the time. Although research participants were asked how they made meaning of intellectual disabilities, some conveyed their understanding of intellectual disabilities throughout their interview. For example, the participating religious leader making up the Human Diversity model viewed intellectual disabilities as being natural. The other 11 participating religious leaders utilized a deficit model, and their interviews were examined to determine similarities and differences. A process of constantly comparing the data took place. This process did not take place only when looking at the understanding of intellectual disabilities. The process started with the understanding of 
intellectual disabilities but the method of constantly comparing data and its emerging codes and variables took place throughout the analysis process. Notably, there are similarities among the models such as the language used to describe people with intellectual disabilities and attitudes toward participation within mainstream settings of faith communities. While the models focus on the attributes that make each model unique, similarities among models are also explored.

Table 2 broadly displays similarities and differences among the models of intellectual disability. It is important to note that Table 2, in comparison to the Findings section is simplistic. For example, similarities and differences are displayed in regard to whether participating religious leaders support participation in mainstream mass and/or adaptive liturgy. According to Table 2, participating religious leaders within the Close to God and Unfortunate Innocent Children models both support participating in mainstream mass. However, the Close to God model supports participation in mainstream settings because people with intellectual disabilities are viewed to be part of the Catholic community. On the other hand, one participating religious leader in the Unfortunate Innocent Children model supported participation in the mainstream mass due to the resources required to create a separate setting for people with disabilities.

\section{Close to God}

The experiences and beliefs of four religious leaders made up the Close to God model. Within this model, participating religious leaders viewed people with intellectual disabilities as possessing extraordinary skills and having a close relationship with God. Participating religious leaders also believed that people with intellectual disabilities have 
a purpose, which is to be present to their faith communities to exemplify their relationship with God and their disability. Participating religious leaders generally supported inclusion of people with intellectual disabilities within the mainstream mass. Additionally, they have experience with individuals with intellectual disabilities engaging as volunteers and Eucharistic ministers while also receiving Holy Communion.

This model focuses on viewing people with intellectual disabilities as possessing exceptional skill or knowledge and being closer to God than people without intellectual disabilities. More specifically, participating religious leaders adhered to the savant syndrome which is a label used to describe people with developmental disabilities who possess skills at a level believed to be inconsistent with their intellectual functioning. When describing a person with whom a participating religious leader had a relationship with, he emphasized the person with intellectual disability having the ability to memorize information like local bus systems and schedules by saying:

“I mean, he can get on a bus and go anywhere...it's just, it's almost savant. You know, I don't even know if that would be accurate, but yeah it's amazing how he's managed to do that or in a relatively short period of time."

People with intellectual disabilities were also described as having the ability to understanding God in a way that people without intellectual disabilities do not. Participating religious leaders described people with intellectual disabilities as possessing a visceral understanding of religion where their relationship with God is inherently part of their being rather than a relationship that is built through experience and religious observances. 
When describing experiences with individuals with intellectual disabilities, some research participants discussed their experiences with L'Arche in various parts of the United States. L'Arche is an international faith-based community of individuals with and without intellectual and developmental disabilities with homes and support networks in various parts of the world. L'Arche is rooted in the Roman Catholic tradition, but its communities today are inter-religious and accept people of all faiths (L'Arche USA, 2013). When discussing experiences with the L'Arche community, one participating religious leader said:

“' Cause I think people in the L'Arche, I think they had a deeper, you know, they I mean they didn't have all this, you know don't have all the prejudice...it's just a very kind of raw simple approach to it."

Similarly, another participating religious leader said, "There is a real grace in their lives and a power in their lives. They understand a lot more than we do because they're open." Another participating religious leader described the approach of individuals with intellectual disabilities toward religious life as being "more divine in a sense." Common to these sentiments is the focus on individuals with intellectual disabilities possessing inherent qualities that are unique from others without intellectual disabilities. These unique qualities were discussed within a religious context that placed people with intellectual disabilities as being closer to God because they have an understanding or connection that was viewed to be specific to people with intellectual disabilities. 
One participating religious leader within the Close to God model described people with intellectual disabilities as suffering by saying "he suffered from an intellectual disability." The label of suffering was not exclusive to people with intellectual disabilities, but the participating religious leader believed that individuals with intellectual disabilities suffered from the experience of loneliness and isolation. The participating religious leader also described homeless individuals as suffering from factors such as social isolation and poverty.

Moreover, participating religious leaders within this model believed that people with intellectual disabilities have a purpose. The purpose of individuals with intellectual disabilities is to impact members of the general congregation through their presence within faith communities. In particular, participating religious leaders believed it was important for people without disabilities to see how people with intellectual disabilities live and interact within the parish. According to participating religious leaders, individuals with intellectual disabilities being present to the community involves making visible their differences, including both the disability and their relationship with God. For example, one participating religious leader said:

"For them to be an instrument of grace in the community by simply being present, I have found that's just been incredibly powerful. To let people be exposed to people's honesty. To be able to see life in sometimes articulated in the simple expressions, that is a powerful gift for a community. So to make sure that people are visible and honored and a part of a family, and not separated out from the family, because family is also us.” 
According to the Close to God model, individuals with intellectual disabilities are not believed to be gifts from God. One participating religious leader explained that people with intellectual disabilities should not be viewed as gifts from God because they are not perfect. God is believed to be perfect. Thus, individuals with intellectual disabilities may possess qualities that bring them closer to God and religious life but they are not God-like. For example, one participating religious leader stated:

“I don't assign, because there is no blame, and I also, I don't want to be arrogant and just enough to say it's a gift to be disabled...I'm not one of those people to say you've been given a gift to be given this illness, this cross to carry. I don't speak in that language."

Although people with intellectual disabilities are viewed to be closer to God, intellectual disability is not a divine present or punishment. Thus, even though people with intellectual disabilities have a purpose to serve within their community, intellectual disabilities are not dichotomized as being either a gift or punishment from God.

When considering causes of intellectual disabilities within this model, one participating religious leader expressed that he was not concerned with the cause because intellectual disabilities cannot be cured nor do they need to be. The participating religious leader's focus was on building community because he believes that loneliness and social isolation are the problems requiring attention.

Individuals adhering to the Close to God model also worked with people with intellectual disabilities in ways that are unique from other models. Participating religious leaders within this model have utilized secular resources to educate themselves on 
disability issues. For example, one participating religious leader sought out funding for his parish to be trained by a professional on how to best serve the needs of people with disabilities. Hence, the religious leaders made an intentional effort to learn about disability issues and aimed to include people with disabilities within parish life.

Participating religious leaders within the Close to God model also discussed how family members, particularly parents, are a resource in helping parish staff understand what needs to be done to include people with intellectual disabilities. For example, one participating religious leader said:

"So far it's been really a no brainer, very easy to do, because typically the families...know more than we do and what the needs are, and so it's basically just plugging ourselves in with the needs."

One participating religious leader stated that if the parents are unsure of what needs to be done, to promote inclusion, the parish has contacted the Archdiocese of Portland in Oregon to learn what can be done to ensure people with intellectual disabilities are included within the parish.

One participating religious leader led mass in Spanish. This participating religious leader adhered to the Close to God model because he expressed similar attitudes to other participants within the model. The participating religious leader who had experience with a Latino congregation found that Latinos accepted people with intellectual disabilities. According to the participating religious leader, acceptance was defined as being okay with an individual with intellectual disabilities calling out and moving around during mass. Based on the experience of this one participating religious leader, parishioners 
attending mass held in English generally experienced fear when initially attending mass with people with intellectual disabilities.

Participating religious leaders within the Close to God model have reacted to negative attitudes toward people with disabilities among parishioners by raising awareness. For example, one parish's mission explicitly focuses on the inclusion of marginalized groups. Additionally, one participating religious leader held retreats to help educate people about marginalized groups. Three participating religious leaders raised awareness during mass and through local Catholic media sources (e.g., bulletins, blogs).

When considering action on the part of religious leaders in reaction to parishioner complaints about the presence of individuals with intellectual disabilities, participating religious leaders within the Close to God model were comfortable making decisions without parishioner support. For example, when describing an experience with a parishioner who felt uncomfortable with people with disabilities at mass, one participating religious leader said, "We're not going to change things because somebody feels uncomfortable. There are other places. We are what we are. And intentionally, deliberately." However, decisions made by religious leaders where they do not have the full support of their parishioners were typically limited to issues the religious leader finds important. For participating religious leaders in the Close to God model, inclusion of individuals with intellectual disabilities was described to be important. Other areas of importance for participating religious leaders within this model included creating community and working with people with addictions and those experiencing poverty. For 
other decisions, religious leaders described working with their parish council and parish staff for input on what needs to done and how plans should be implemented.

In regard to participation within parish life, all participating religious leaders within the Close to God model were proponents for inclusion within mainstream mass rather than having a segregated mass for people with disabilities. One participating religious leader believe that a parish is made up a diverse community, which includes people with disabilities. However, if people with disabilities are in segregated settings within the parish, the participating religious leader believed that the experience and relationship parishioners have with God would be hindered. Segregation within a faith community would create an artificial environment, because it does not accurately reflect Catholics. When describing his opinion toward inclusion within mainstream mass, he said:

"For the people who want to be exclusionary...it doesn't make pastoral sense to me, because how can I speak, how can I ever be effective...unless they're [people who want to be exclusionary] there to share the word with them [persons with intellectual disabilities], to share sacraments with them [people with intellectual disabilities], how can we expect them [people who want to be exclusionary] to have that moment and that relationship with God in order to experience that desire to know God better... I prefer to be inclusionary in that way... so as far as I'm concerned, if they're there, they're teachable. They're there for a reason." However, one participating religious leader who had knowledge of adaptive liturgies acknowledged that segregated settings may be important for families with 
individuals with disabilities, but his knowledge of the reasons is limited to what he knows of the experiences of parents of children with disabilities. He recognized the stigma parents of children with disabilities experience, but he is unsure if there is a correct decision about whether segregated liturgies should exist. The participating religious leader described what he learned from parents of children with disabilities:

"Families of those people you know with intellectual disabilities and other disabilities, they have told me that you have no idea of how hard it is on us to sit in a regular mass when they feel like they're being judged or the person with the disability themselves can't handle crowds. So it's like if we don't do this [adaptive liturgy], you know for a lot of those families it's pretty much the one mass they go to...so I'm conflicted here."

Participating religious leaders within the Close to God model also had experience with individuals with intellectual disabilities participating in parish life as volunteers, Eucharistic ministers, and receiving communion. Participation in such roles was initiated both by religious leaders and parishioners with intellectual disabilities. Participating religious leaders also recognized the diversity in experience and ability where they stated, "They can do whatever they want to do if they articulate it and we can ask them to do things that they would be able to do." Another participating religious leader said, "In worship, in the learning process, in volunteering, and service, uh, just the same way anybody else would be but at their chosen level."

Participating religious leaders also made accommodations for people with intellectual disabilities to participate. One participating religious leader gave communion 
to a person with intellectual disabilities who was not part of his parish boundaries, because no other priest in the area would give the man with intellectual disability communion. The participating religious leader described the experience as such:

"The mother came to me and this gentleman he suffered from an intellectual disability. We were the same age at the time, and he said to me that she had tried to bring him to almost every Catholic parish in the [city] area, and no priest would give him communion. And so I said to her, you know, that's no problem. We'll work together."

When individuals with intellectual disabilities initiated participation or were asked to engage in a role, participating religious leaders discussed engaging in training or mentoring to teach people with intellectual disabilities about the role. Roles like pouring juice after mass may require support through a mentor for persons with intellectual disabilities, but that mentorship is not offered to people without disabilities. On the other hand, training for roles in sacraments like a Eucharistic minister was provided to all parishioners regardless of whether they have a disability.

Participating religious leaders also discussed accommodations in terms of communication. One participating religious leader discussed his experiences with a parishioner with intellectual disabilities who is active in multiple ways within the parish. When working with the individual with intellectual disabilities, the participating religious leader avoided abstract concepts and explained information in ways that are more concrete. Another participating religious leader has done mass for multiple L'Arche 
communities and acknowledged the importance of communicating information in a way that is helpful. He described his approach as follows:

"My general approach is that I never want to impose my agenda on them [L'Arche communities]. You know, often times that I, I go to a lot of parishes over the course of a year and so often they'll go 'how do you do mass, father?' It's the wrong question for me. I say, 'no, how do you do it? I'm here to help you pray, and you've been doing it.' But some guys they go 'well, okay, I'm gonna show them the right way.' Uhhh, no. [laughing]. You know, it's how do they, how does that local community do it, including how does the local, how does the L'Arche community do it?"

Overall, participating religious leaders adhering to the Close to God model viewed people with intellectual disabilities has having extraordinary qualities that made them closer to God in terms of understanding and connecting with God. Those ascribing to this model also believed that individuals "suffer" from their intellectual disabilities and their purpose in life is to be present to those without disabilities. The Close to God model posits that the presence of individuals with intellectual disabilities exposes people without intellectual disabilities to the diversity that exists within life. Another unique aspect of participating religious leaders within this model is that when faced with the negative attitudes of parishioners toward people with intellectual disabilities, they have made the decision to go against the wishes of parishioners without disabilities by including people with intellectual disabilities within parish life. 
Conformity. The model of Conformity comprises the beliefs and experiences of two participating religious leaders. Those adhering to the model of Conformity believe it is essential for people with intellectual disabilities to conform to what is viewed to be the norm and/or desired socially in order to successfully participate within faith communities. Participating religious leaders described the norm to be accommodations that suit individuals without disabilities and a high level of education. Within this model, systems of support, such as accommodations, are not a plausible option to facilitate participation. Therefore, if a person with intellectual disabilities cannot function within the present context of the parish, participation is barred. The rationale for exclusion is that participating religious leaders do not have the time to serve individuals with intellectual disabilities and that persons with intellectual disabilities are not a priority within the church.

Similar to the Close to God model, participating religious leaders did not use people first language. Participating religious leaders described persons with intellectual disabilities as "handicapped person" and "Down syndrome" person. One participating religious leader also made a statement, where people without intellectual disabilities were labeled as "normal," which infers that people with intellectual disabilities are not normal: "So we had all normal kids and [name of person with intellectual disabilities]."

Both participating religious leaders reported having relationships with individuals with disabilities. One participating religious leader believed his child has a developmental disability, but he chose not to seek a diagnosis or council from a professional working in the area of disability. He expressed feeling frustrated with his child for spending time 
alone and not taking initiative in activities. He also described relatives who are parents of children with disabilities experiencing social isolation and that he anticipates his son with a possible disability living with him for the long term. The other participating religious leader had a friendship with a couple that have a daughter with intellectual disability.

When describing ones leadership role within the parish, one religious leader expressed that his authority is influenced by the needs and wants of his parishioners without disabilities. He specifically said, "I have immense power, yet my powers, authority, and they're limited by what the people give me... and what they allow." Thus, participating religious leaders within this model may be more likely to be influenced by the preferences of parishioners. The other participating religious leader explicitly stated that his leadership role in no way concerned people with intellectual disabilities. When describing a former parishioner with intellectual disabilities, he shared at that the former parishioner used public transportation and needed help getting to the bus stop. The participating religious leader said:

"I didn't have the time or energy or ability to do much for her. I didn't...the priest wants certain things done, and helping somebody to the bus and getting in, you know that's not part of it."

In fact, when discussing priorities of the parish, participating religious leaders believed that disability issues were not important. One religious leaders expressed lacking the time and skills required to work with people with disabilities, and both participating religious leaders did not have an interest in disability issues. For example, one 
participating religious leader openly expressed that he had no interest in working with people with disabilities within his parish when he stated the following:

“It's like there's so much to do here and uh, I hope not too many people with wheelchairs come here where we have to deal with it, you know? And in a sense, you know what's what I'm saying, who's going to take, who's going to deal with that one, you know?"

Although one participating religious leader acknowledged that the Bishop chose to maintain the Office for People with Disabilities, participating religious leaders also believed that disability issues were not a priority within the larger Catholic church. One participating religious leader stated that the larger Catholic church has more important issues to concern itself. One issue mentioned was the Archdiocese of Portland filing bankruptcy in 2004 as a result of the financial strain it experienced from the multi-million dollar sex abuse lawsuits. A participating religious leader also stated that the relatively small population of people with disabilities deems disability issues to not be of concern. Instead, one participating religious leader believed that the church focuses on working with the Latino community due to its size within the Catholic faith community.

Generally, the two participating religious leaders, within the Conformity model, were concerned about parishioners pursuing lawsuits. For example, one parishioner said, "These days, such a litigious society, trying to keep us out of trouble, keeping people from falling, and then having some disability because they've fallen." One participating religious leader said that the fear of a lawsuit has been grounds for barring participation for people with disabilities because they are viewed to be at higher risk for injury. 
Therefore, if an individual is unable to perform a role given the structure of the parish, individuals are denied participation. More specifically, an example was shared where an individual who was blind had a desire to participate in a role that involved climbing stairs. The participating religious leader did not believe the man who was blind would be able to climb the stairs without injuring himself. Moreover, the religious leader would not consider creating accommodations where the actions required of the role are relocated or allowing a person to walk with the man who was blind.

Related to the example above, both participating religious leaders within the Conformity model did not view the parish to be a flexible or malleable setting. They believed that individuals have to fit in to the environment, because the environment would not be changed for people with intellectual disabilities. Thus, participating religious leaders within the Conformity model were unwilling to create accommodations for parishioners with disabilities.

In regard to the nature of intellectual disabilities, the Conformity model adheres to the belief that people with intellectual disabilities lack complexity, which can include the capability of reason, self-awareness, and self-determination. These attributes define personhood and the absence of the attributes may imply people with intellectual disabilities are not fully human beings. More specifically, according to this belief, people with intellectual disabilities do not experience worry or negative emotions and are easy to please. For example, one participating religious leader said: 
"He was always happy. You know, if the Oregon Ducks won that day, he was really happy... he was simple, life was simple, some of the other kids, normal kids they got stressed out by work and stuff like that."

Similar to the Close to God model, Participating religious leaders also believed that people with intellectual disabilities have a purpose in life. However, the way in which participants described the purpose of individuals with intellectual disabilities within the Conformity model was different from that articulated in the Close to God model. One participating religious leader believed that children with intellectual disabilities are born to teach their parents and siblings how to love. He also stated that having a parishioner with a disability also provide the community the opportunity to love and view their lives differently. For example, the participating religious leader said:

"So these handicapped people, God places there...to give us an opportunity ...to expand our hearts and to hear another's journey and to look through their eyes and that might be a very saving grace actually, if they actually do that. 'Cause if we just stay within ourselves, and selfish, you know that's kind of the definition of hell, is to be with yourself forever."

One participating religious leader within the Conformity model reported having disability related training. His training involved one visit to a state institution for people with intellectual and developmental disabilities. Further, one participating religious leader stated that there is a shortage of priests and therefore serving as a mentee and learning through the experiences of other priests is not readily available. However, the participating religious leader stated, if he needed to learn about disability issues, he 
would seek help from university professors in his geographic area as well as state and county organizations engaging in disability specific work.

Notably, preferences based on ethnicity and socioeconomic status were also expressed by both religious leaders when considering parishioner groups. For example, one participating religious leader expressed a liking for Asians in comparison to Latinos. The participating religious leader said:

“They're [Asians] very um, they do well in computers, you know they're not like the Hispanic community where you know, fixing up uh hotel beds...doing those service things. But they tend to do well in computers and those kinds of things...they're so kind and gracious, so like I said before, when I'm with them, you know heaven's gonna be like this."

Similarly, the other participating religious leader expressed a preference for people of high socioeconomic status. He described himself as being "lucky" to be preaching to a group where $75 \%$ of parishioners have graduate degrees and access to resources that others do not have. When reflecting on his experience, the participating religious leader said, "You know, I can use big words and they understand. So it's kind of fun preaching."

Faith communities being an environment for intellectuals was important for both participating religious leaders. Both participating religious leaders opposed integration of people with intellectual disabilities within mainstream mass. The belief held by participating religious leaders is that communication would be a barrier for people with intellectual disabilities. For example, one participating religious leader said, "The 
environment is too intellectual for them, they would need a translator. [laughing] Like you see for the deaf or something like that." It was also stated that people with intellectual disabilities would be unable to participate given the fast pace environment of the church and the presumed inability to follow along with the different parts of mass on the part of people with intellectual disabilities. Thus, people with intellectual disabilities are devalued because they do not conform to what is expected from mainstream society. More specifically, a participating religious leader said:

"Normal people are just going so fast, things that we do that I feel that they're probably left to the side. Um, unless somebody can slow down and say hello to them...I guess an extended sense they're not productive, you know, what good are they? They're in the aisle, they're in the way."

When participating religious leaders encounter people with intellectual disabilities, they typically refer them to others. For example, one participating religious leader explained that a woman contacted by telephone because she wanted to advocate for people with disabilities in the parish. During the phone conversations, the participating religious leader listened to what the woman had to say, but he did not consider a possible role for her within his parish. The participating religious leader said he would refer her to the Office for People with Disabilities at the Archdiocese if she called again, because he is not an expert in disability issues. The participating religious leader also believed that for people with intellectual disabilities to participate within the parish, they would require an advocate without a disability. The participating religious leader believed that people with intellectual disabilities are not effective in 
communicating their needs and wants. This may be related to learned helplessness where the needs and wants of persons with intellectual disabilities have been ignored. More specifically, the participating religious leader said:

"I'm thinking um, the ones that are not handicapped can yell louder or get in your face and the, maybe they've just learned uh, you know they're kind of just pushed to the side unless you have, I guess unless you have a special advocate for them in the parish."

In contrast, one participating religious leader chose to hire a person with Down syndrome to work in the parish. The decision to hire the person with Down syndrome was based on the participating religious leader's relationship with the parents of the employee. Furthermore, when describing the employee with Down syndrome, she was described as being more like people without disabilities. When describing the employee, the participating religious leader said:

"She's very bright, and has her own little apartment she takes care of. And she takes care of her accounts and all that...does her own shopping."

The decision to hire the person with Down syndrome came about when the mother of the employee, a friend of the participating religious leader, shared that the woman with Down syndrome needed a job. At this get-together with the mother of a woman with Down syndrome, the participating religious leader offered the woman with Down syndrome a job. The participating religious leader asked the mother to communicate the job offer to her daughter. Of note, the participating religious leader explicitly expressed a preference for people with Down syndrome versus other types of 
intellectual disabilities. When discussing people with intellectual disabilities within his parish, the participating religious leader said, “...Down syndrome type have been easier people."

Both participating religious leaders making up the Conformity model had experiences with adults with intellectual disabilities within their parish. They believed that parishioners must initiate participation within the life of the parish. For example, if a position as a greeter is available to parishioners, participating religious leaders within the Conformity model expect parishioners to indicate that they would like to participate. Participating religious leaders in this model would not ask specific individuals if they wanted to participate as a greeter. One participating religious leader stated, "I can't be calling people to say why didn't you call me. They have to have initiative."

If parishioners with disabilities initiate participation, eligibility must be determined. If a person with intellectual disabilities wanted to be a Eucharistic minister, they would have to meet with the staff person in charge of religious formation. The staff person would determine whether the individual understands that Eucharistic ministers do not simply give out bread and wine but instead the bread and wine represent the blood and body of Christ. In one example shared by a participating religious leader, a person with physical and intellectual disabilities wanted to participate in a role during mass. The participating religious leader was unwilling to use accommodations that would allow for the parishioner to partake in the role. Both participating religious leaders expressed that participation within the life of the parish is okay only if they conform to the environment. Thus, making alterations to the context was not acceptable. One participating religious 
leader described it by stating, "So like mainstreaming people in classrooms or school or something. Uh. I think it's great, you know if they're not totally disruptive, you know." When describing the experiences of prohibiting participation within the parish to two individuals with disabilities, a participating religious leader described the individuals as being aggressive and angry about issues concerning their rights, in his view, inappropriate behavior in this setting.

Lastly, although participating religious leaders had contact with people with intellectual disabilities, they described their relationship to be limited. One participating religious leader knew that parishioners with disabilities are present within his parish but he does not connect with them. For example, he said:

"I see them in wheelchairs or that, but I tend, you know I say hi...I kind of also walk by because there's people that are walking and you know I'm working with them...it makes me think...well they're in a wheelchair, should I know anything more than that? [laughing] That kind of thing."

The participating religious leader also expressed feeling uncomfortable in the presence of people with disabilities. He expressed not knowing what to do or how to interact with people with disabilities. More specifically, he stated:

"Yeah, we have our coffee and donuts...[name of person with disability] goes down there quite a bit...when people see someone that's uh, in a wheelchair or whatever, there's sort of a uncomfortableness. You don't know what to do, what to say.” 
He also acknowledged that although he is trained as a minister, he is like any other person without disability when in the presence of people with disabilities. This participating religious leader chooses to interact with his friends who are not individuals with disabilities. When describing his reaction in a setting with people with disabilities, the participating religious leader said:

"I'm a minister but at coffee and donuts, as human beings are, they kind of know who their friends are, so most every Sunday they're sitting with the same friends, you know."

In summary, participating religious leaders adhering to the Conformity model believe that people with intellectual disabilities should only participate within the life of the parish if they can within the existing context of the parish. Additionally, the Conformity model also expresses a preference for certain groups of individuals perceived as more desirable. The Conformity model does not view disability issues to be important within parish life and therefore, accommodations are not considered for implementation to include people with disabilities. However, when a person is accepted within the parish environment, acceptance may be contingent upon how well the individual with intellectual disabilities conforms to what is expected of them within mainstream society.

Unfortunate innocent children. The model of Unfortunate Innocent Children is comprised of the experiences and beliefs of two participating religious leaders. Participating religious leaders within this model view people with intellectual disabilities to be innocent and to be children in adult bodies. People without intellectual disabilities were described to be fortunate when compared with people with intellectual disabilities. 
This model also posits that people with intellectual disabilities are meant to serve some unspecified purpose for their families.

Within this model, people first language was not consistently utilized. Participating religious leaders used descriptors such as "handicap folk." One participating religious leader did use people first language when saying "people who are dumb." According to the Unfortunate Innocent Children model, people with intellectual disabilities are perceived to be ill fated or unfortunate and incapable of wrongdoing due to limited development.

When comparing people with and without intellectual disabilities, people without intellectual disabilities where described as being fortunate thereby denoting that people with intellectual disabilities are ill-fated and unfortunate. When describing an experience where a participating religious leader worked with youth visiting people with severe disabilities (including people with intellectual disabilities), he described the disability related work he engages in as follows:

"They'd [youth without disabilities] just go thinking about how fortunate they are, and their life, and how thankful they are for being there to help those people... so I have quite a bit of experience with the change in the personality of these youngsters as they interacted with the less fortunate folks."

In addition to being unfortunate, people with intellectual disabilities were also viewed as innocent children. Generally, participating religious leaders believed that people with intellectual disabilities cease development in childhood and therefore are not capable of malice. For example, one participating religious leader said "And these people 
even though they were adults, mentally they were still children." Hence, people with intellectual disabilities are viewed to be incapable of committing sin because they do not have evil will. Relatedly, one participating religious leader questioned the participation of individuals with intellectual disabilities in the sacrament of penance. Although the participating religious leader questioned the ability of individuals with intellectual disabilities to sin, he did hear a woman with intellectual disabilities' confession and gave her absolution. When discussing the participation of a person with intellectual disabilities in the sacrament of penance, he described his opinion and experience as follows:

"My heart goes out to them 'cause I think there's such an innocence in this person that I don't know how much of this is a sin, but I give them absolution...no, she doesn't understand that it's a sin or she thinks it's a sin because she's there in confession. I don't know myself if that is really a sin for her...just because of the innocence of the person."

Participating religious leaders adhering to the Unfortunate Innocent Children model also believed that people with intellectual disabilities were born to serve a purpose. Here, participating religious leaders believed that children with intellectual disabilities were born into families that require some form of help. Families who provide love and assistance to their family member with intellectual disability will eventually be rewarded in some way. The participating religious leader did not specify the nature of the reward. One participating religious leader stated, "He may not be or she may not be the perfect human being, but that child will change you, if you just keep loving that child and helping that child." 
In regard to the presence of people with intellectual disabilities within the life of the parish, one participating religious leader believed that there should not be an adaptive liturgy due to the amount of time and effort involved in preparing for the Sunday Eucharist. However, this participating religious leader was not aware of the Office for People with Disabilities at the Archdiocese of Portland and the adaptive liturgies held in Oregon.

When considering the participation of people with intellectual disabilities within faith communities, one participating religious leader believed that people with intellectual disabilities do not need to be included in sacraments and other aspects of their faith community. He believed that there are specific roles for different segments of society such as the role of priests being limited to males. The participating religious leader also stated that priesthood would not be appropriate for an individual with intellectual disabilities due of the responsibilities priests have to parishioners. The participating religious leader stated:

"I don't think we need to promote inclusion in that specific area [sacraments] that you know, it may not be for people with disabilities...so inclusion doesn't mean that everyone needs to have access to everything, you know because that's not true of the world either [laughing], you know."

Additionally, with regard to creating physical accommodations, the participating religious leader believed that the physical structure of the church trumped the needs of people requiring structural changes for accommodations. More specifically, he was opposed to the idea of having to create a structural change when he stated, "It's not an 
option to modify that or build a ramp or anything, because we cannot change the façade

of the church because the church is so old." The participating religious leader stressed the importance of preserving older churches. Similar to the Conformity model, the religious leader believed that people with disabilities should change so that they fit into the environment of the parish.

One participating religious leader discussed how he interacts with people with intellectual disabilities. He described communication to be frustrating when he has difficulty understanding people with intellectual disabilities. However, he stated that being patient and present are important as well as the willingness to hug and express love toward people with intellectual disabilities.

Both participating religious leaders believed that people with intellectual disabilities should not be left alone. One participating religious leader said that he would not leave a person with intellectual disabilities alone in any setting because they require help while the other participating religious leader was concerned about protecting all individuals in the environment. The participating religious leader expressed concern about people without intellectual disabilities taking advantage of people with intellectual disabilities and therefore felt a need to protect them. He also expressed needing to protect the way in which people with intellectual disabilities interact with others. For example, when the participating religious leader worked with youth, he announced impromptu breaks to remove the person with intellectual disabilities from the given environment to communicate one-on-one when he sensed something might be wrong. 
The Unfortunate Innocent Children model views individuals with intellectual disabilities as unfavored eternal children who have limited development and an inability to commit sin. The purpose of people with intellectual disabilities is believed to provide help to families of children with intellectual disabilities, which is received in exchange for love and help. Additionally, promoting inclusion within the parish life may not be necessary within the model because inclusion in all aspects of parish life is believed to be unnecessary. Thus, there may be specific roles that are viewed to be appropriate for people with intellectual disabilities but not others. Factors such as the level of responsibility involved in a position are considered to determine whether person with intellectual disabilities should participate in a particular role.

Deficiency. The fourth model, Deficiency, represents the experiences and beliefs of three participating religious leaders. The Deficiency model posits that people with intellectual disabilities are defective or incomplete and require fixing. However, intellectual disabilities are not viewed to be a curse or punishment. There was also a belief that religious healings are possible for various people including those with intellectual disabilities, but all people with intellectual disabilities undergoing a healing may not be cured.

Like the previous three models, participating religious leaders within the Deficiency model used phrases such as "she's intellectually impaired," and "those who are disabled." Of the participating religious leaders within the Deficiency model, one participating religious leader had extensive contact with people with intellectual disabilities. This individual worked with people with a variety of disabilities within his 
faith community, and some of those people had intellectual disabilities. The other participating religious leader also had extensive contact with youth with intellectual disabilities, but this contact took place in a prior role serving people both in and outside of the Catholic faith community. Lastly, one participating religious leader had limited contact with individuals with intellectual disabilities. For the participating religious leader with limited contact, three individuals with intellectual disabilities once attended the participating religious leader's parish, but he did not build close relationships with the parishioners.

The Deficiency model views intellectual disabilities to be deficient or lacking but not inferior or unfavorable to God. Moreover, it is believed that individuals with disabilities should seek to fix their disability. One participating religious leader believed that people seek God to fix them and make them better. Although two participating religious leaders believed in the possibility of intellectual disabilities being healed, they also stated that the spiritual aspect of one's life is more important than a person's body or mind. One participating religious leader explained his view of disability needing to be fixed as follows:

"People talk about differently abled, well, or the argument about the deaf who you know there are some people in the deaf community who oppose cochlear implants. If I were deaf, I'd kill to get one of those things...it's better to be able to hear than not to hear. Now that doesn't mean that people who don't have hearing who either never had it or who lose it, you know are bad people or that they are 
sinners or that they are inferior in some way. But it's better to hear than not to be able to hear. Uh, it's better to see than not to be able to see."

Participating religious leaders did explain that intellectual disabilities are "not necessarily a curse" but it could be a result of various factors including those that may not be understood by scientists or faith leaders. Two of the three religious leaders did state that people with intellectual disabilities may be more blessed than people without disabilities. One of the participating religious leaders stated that individuals with intellectual disabilities may be more blessed because they need God's blessings more than people without intellectual disabilities. Thus, because people with intellectual disabilities are viewed to be deficient, they require additional blessings from God.

Two participating religious leaders also shared their beliefs about religious healings. One participating religious leader explained that he believed that Jesus had the power to heal people. More specifically, he stated that negative emotions or well-being could impact individuals physically, which may result in a disability. The participating religious leader also questioned whether the way in which people live their lives determines whether a person develops a disability. For example, he questioned whether people develop dementia because they did not live a happy and free life. The participating religious leader also provided the following example:

"I know there is a lot of scientific evidence that forgiveness makes a huge difference in a person's physical bodily health...maybe the person was so bound by his resentment that it caused a physical ailment that causes paralysis." 
When discussing healing, the other participating religious leader shared that he has engaged in healings. The healing involved praying with people seeking healing of some aspect. For example, healing can be done to divinely remove paralysis or cancer. However, he is cautious about the healing process, because people are not always healed in ways that are visible to human beings. For example, a person may be emotionally healed through a process over time but they may not be physically healed immediately. In cases where an individual is not healed, the two religious leaders stated that they did not have a way of knowing why the healing process was not successful.

An inconsistency within the Deficiency model is that participating religious leaders had differing views on whether people with intellectual disabilities should participate within a segregated setting like the adaptive liturgy or if they should participate in the mainstream mass. Two participating religious leaders believed that people with intellectual disabilities should participate in both settings. Although they believed that people with disabilities are deficient in some way, disability status is not a primary concern in the context of religious worship. For example, if an adaptive liturgy is offered once a month in a community, individuals should be welcome to attend it in addition to participating within the mainstream mass for the remainder of the month. According to one participating religious leader, at the adaptive liturgy, priests can preach in a way that allows them to connect with people with intellectual disabilities. For example, when preaching to people with disabilities, one participating religious leader connects the gospel to day-to-day activities or interests (e.g., sports) that are popular within the parish. The adaptive liturgy also provided opportunities for the participating 
religious leader to connect with parishioners with disabilities and encourage participation in various ways (e.g., bringing up the gifts, communion, Eucharistic minister). Thus, parishes should be inclusive settings where diverse people worship together while also having occasional gatherings to address the needs of specific groups. One participating religious leader described it as follows:

"Theologically the ideal community is an inclusive community where people are there because they want to be and they choose to be there and that their strengths or weaknesses or abilities or disabilities maybe are irrelevant, what their ethnic background, gender, or any of these things would be secondary. The primary purpose is to gather...I think that's true with people with intellectual disabilities as well as any other kinds of things, they should be able to be comfortable in, you know, the mainstream nine o'clock mass at their local parish, but at the same time there is something to be said for having liturgies on occasion that address the specific kinds of experiences that people in that category might have as opposed to people in another. I think the idea would be to integrate the community so that everybody feels a part of the community."

Of note, the above quote was stated by an individual who supported people with intellectual disabilities having their needs met through inclusive mainstream settings and segregated spaces while also supporting and engaging in religious healings for people with disabilities, including people with intellectual disabilities. Additionally, the two participating religious leaders advocating for both segregated and mainstream settings for people with intellectual disabilities did not recall experiences where parishioners reacted 
negatively to people with intellectual disabilities participating in mainstream mass.

However, if parishioners were to find the participation of an individual with intellectual disabilities to be problematic, both participating religious leaders said that they would want to talk to the person to discuss what they believed to be a fear of people with intellectual disabilities.

One participating religious leader was a proponent for the participation of individuals with intellectual disabilities within segregated settings. Although the participating religious leader has never attended an adaptive liturgy nor does he know individuals with disabilities involved in it, he believed that people with disabilities attending the adaptive liturgy would not be interested in participating in the mainstream mass. He also believed that the level of intellect required for attendance within mainstream mass would require people without disabilities to invest time and energy to accommodate people with intellectual disabilities. In the opinion of the participating religious leader, parishioners do not want to make that extra effort considering all of the other things people have happening in their lives (e.g., work, family). The participating religious leader, who has not attended an adaptive liturgy nor does he know individuals with disabilities attending the adaptive liturgy, said:

"The people that we have coming to the adaptive mass, some of them are so handicapped enough where they would not want to do that...the adaptive mass is a safer group, small number of people, and they just feel at ease there."

The participating religious leader also said that the adaptive liturgy was started in reaction to parents of children with disabilities sharing their experiences. The 
participating religious leader described parents of children with disabilities as feeling stigmatized because their children may call out during mass or do things differently. In response to behaviors that did not conform to the schema of Catholic mass, parishioners without disabilities were not accepting of people with disabilities and their families.

The Deficiency model holds that people with intellectual disabilities do have an issue or challenge that should be fixed. When considering interventions, medical science and religious healings were discussed as possible ways of removing disabilities. Although participating religious leaders believed that was something inherently wrong within people with intellectual disabilities, two of the three participating religious leaders advocated for the participation of individuals with intellectual disabilities in segregated and mainstream settings, because both settlings can serve the needs of people with intellectual disabilities. On the other hand, one participating religious leader was opposed to integration within the mainstream mass due to the belief that individuals with intellectual disabilities would not understand what was taking place and that accommodations would require excessive resources from individuals within the mainstream mass.

Human Diversity. Lastly, the fifth model is called Human Diversity, which is comprised of the experiences and beliefs of one participating religious leader. Unlike the four previous models, the participating religious leader in the Human Diversity model most often employed people first language. He also used the phrase "typically developing" individuals when making comparisons with autistic individuals. 
The participating religious leader grew up with a relative with an intellectual disability and the relative was an integrated and active member of the family. He viewed disabilities to be a natural part of human diversity, which is similar to differences one would see among a group of people without disabilities. The participating religious leader described it as follows:

"Just as we get used to in any society...there are many characters that you know, the guy who is always negative about whatever you do or whatever the process is, the guy that's judgmental, or the woman that's angry...so these are just other characters that are unique to the community."

In regard to making sense of intellectual disabilities or understanding disability issues, the participating religious leader believes that people doing adaptive liturgy, lay people working in the area of disability, and people with disabilities are the best resources. He also stated that he would not utilize the Bible to understand intellectual disabilities, because intellectual disabilities were not recognized in first century Palestine. The discussion of demons within a person within a religious context, according to the participating religious leader, could be a variety of things such as psychiatric disabilities. He also stressed the importance of understanding the context in which the Bible was written, which is a time when individuals who were not viewed to be typical in some way were assumed to be sinners. At that time, the Bible documents instances where Jesus expresses his acceptance and love for people who are different. Thus, the participating religious leader believed it is important to prevent discrimination. 
The participating religious leader believed that both segregated and integrated mainstream settings should be available to people with intellectual disabilities. His stance was similar to that expressed by the participating religious leaders who supported both settings within the Deficiency model. The participating religious leader adhering to the Human Diversity model believed that people and groups go through various stages in life and some of those stages might require safe settings for people of a particular group like the adapted liturgy. Therefore, one setting is not better than the other, but it serves a function depending on where a person may be given the context of their life.

In the experience of the participating religious leader, having both settings is important because different stakeholder groups may have their own preferences. For example, based on the experience of the participating religious leader within this model, adults with intellectual disabilities as well as other disabilities chose to attend and participate within the mainstream mass while parents of individuals with intellectual disabilities advocated for segregated settings. Parents expressed feeling stigmatized and unwelcome within the mainstream mass. Therefore, religious leaders may feel the need to address the needs of multiple groups involved.

When considering the participation of individuals with intellectual disabilities within the life of the parish, the participating religious leader representing the Human Diversity model believed that individuals must have a desire for the role, instead of being tested on their knowledge of theology or the specific role. However, finding a fit between individuals and roles within the faith community is also important because the participating religious leader would not want to have a person with an intellectual 
disability attempt engaging in a role they were unable to fully participate in. For example, he would not ask someone with cerebral palsy to hold a cup of wine unless he knew they could hold a cup.

When working with people with intellectual disabilities, the participating religious leader believed that it is important to be open to unexpected experiences, which may require getting accustomed to over time. Additionally, when communicating with individuals with intellectual disabilities, the participating religious leader described how he goes about it:

"Stop, slow down, and engage, explain yourself and then re-explain yourself when that explanation didn't work. And then finally move to story telling or even simple diagrams or whatever you need to do to help the individual."

Furthermore, the participating religious leader also engaged in larger scale accommodations for people with intellectual disabilities. In one instance, a woman with an intellectual disability wanted to receive first communion but was not comfortable with people outside of her family and she did not like water. The participating religious leader worked with the woman's family to hold the first communion at a private location where the woman's brother was used as a proxy for the process of first communion. Thus, the brother went through the actions for his sister, and then an eyedropper was used to place a drop of water on her head.

Overall, the Human Diversity model views disability to be akin to the natural variety in human beings along dimensions such as race and ethnicity. The model focuses on including people with intellectual disabilities in ways that they want to be included 
and utilizing accommodations when needed. The model also recognizes that multiple stakeholders exist when working with people with disabilities with varying needs as well as the recognition that people with disabilities have diverse needs. Therefore, the model supports having people with intellectual disabilities in both mainstream mass as well as segregated settings that are tailored for people with disabilities.

An exploration of the attitudes and beliefs about the meaning of intellectual disabilities among religious leaders yielded five unique models of intellectual disability which include: (1) Close to God, (2) Conformity, (3) Unfortunate Innocent Children, (4) Deficient, and (5) Human Diversity. The models represent the ways in which participating religious leaders described the inherent nature of people with intellectual disabilities, their purpose in life, possible causes of intellectual disability, resources utilized and actions taken on the part of religious leaders when working with people with intellectual disabilities, as well as beliefs about the ways in which people with intellectual disabilities should be present and participate in faith communities.

\section{Discussion}

This dissertation aimed to understand the perspectives of Catholic religious leaders toward the participation of individuals with intellectual disabilities in faith communities as well as how Catholic religious leaders make meaning of intellectual disabilities. More specifically, Catholic priests, parochial vicars, and deacons were interviewed to address three overarching research questions, viz. (1) What types of experiences, in and outside of faith communities, do religious leaders have with individuals with intellectual disabilities?; (2) What are the beliefs of religious leaders 
toward the involvement of individuals with intellectual disabilities within faith communities?; and (3) How does religion inform the understanding of intellectual disabilities among religious leaders? Through grounded theory procedures and analysis, five models of intellectual disability were created to understand how meaning is made of intellectual disabilities. Each model organizes the multidimensional aspects of disability issues within faith communities that address all three research questions. The five resulting models include (1) Close to God, (2) Conformity, (3) Unfortunate Innocent Children, (4) Deficient, and (5) Human Diversity.

Generally, participating religious leaders in the Close to God model believed that people with intellectual disabilities have a relationship to God that is closer than the relationship people without intellectual disabilities have with God. The Conformity model involves beliefs about people with intellectual disabilities needing to conform and adjust to parish environments rather than altering environments. Additionally, participating religious leaders in the Conformity model expressed not being interested in disability issues. The Unfortunate Innocent Children model posits that individuals with intellectual disabilities are children in adult bodies, and the Deficient model holds that people with intellectual disabilities are incomplete and require fixing through means like religious healing. Lastly, the participating religious leader in the Human Diversity model believed that creating a person-environment fit was important and participation should be supported in both segregated and mainstream settings (see Table 2 for more defining features for each model). 
The development of the five models of intellectual disability is intended to begin to explore gaps in knowledge, namely the participation of individuals with intellectual disabilities in faith communities and perspectives of faith leaders toward people with intellectual disabilities. The exploratory nature of the present dissertation serves as a first step to further deepen our understanding about the position of people with intellectual disabilities in Catholic faith communities to propose and implement changes, as needed, so that Catholics with intellectual disabilities are involved and participating in ways that they choose.

It is important to note that the shift in terminology from mental retardation to intellectual disabilities is within our recent past. It was only in 2007 that the American Association on Mental Retardation changed its name to the American Association on Intellectual and Developmental Disabilities (AAIDD; Prabhala, 2006). Additionally, disability related language is dynamic where terms have had relatively short term use (e.g., mental deficiency was changed to mental retardation in the 1970s; Foreman, 2005).

Most participating religious leaders in the present study utilized outdated terminology. More specifically, participating religious leaders, excluding the one in the Human Diversity model, did not employ people-first language. Participating religious leaders in these four models also described their understanding of intellectual disabilities and their views toward people with intellectual disabilities in ways that indicate that people with intellectual disabilities are viewed as their disability and not as full human beings. This language is also associated with the medical model, which places people with disabilities in stigmatizing categories thereby allowing the general public to view 
people with disabilities as their disability category (e.g., the disabled). Since the 1970s, people with disabilities have emphasized using people first language. However, utilization of terminology that is rooted in the medical model may be because it may require time for individuals outside of the disability community to learn about the language preferred by people with intellectual disabilities. However, given that the people first movement started in 1974 (39 years ago), the lack of awareness about people first language may indicate society's disregard for disability issues. Alternatively, variation in terminology may relate to the lack of uniformity in preference for labels within the disability community.

More recently there has been a movement toward using the phrase "disabled individuals" because it is argued that people first language assumes a disability is undesirable (Bersani, 1996). For example, Bersani (1996) stated that individuals identifying as "disabled people" implies that they are proud of their disability. Bersani (1996) calls this "disability first language" because self advocates identifying as disabled people compliment the people first movement. Disability communities, like the autistic community refer to "disability first language" as "identity first language." This is similar to the way in which other groups identify as "African American" or "Catholic" (Brown, 2013). Ultimately, people should self-label as they deem appropriate, but whether an individual uses people first language or disability first language, they want their human rights protected and to be integrated members within society.

The Close to God, Conformity, Unfortunate Innocent Children, and Deficient models all are deficit based because they focus on the weaknesses of individuals. Thus, 
these aforementioned models parallel the medical model of disability. These deficit based models do not view society as having a responsibility to accommodate people with intellectual disabilities. Instead, people with intellectual disabilities must adapt themselves to existing circumstances. For example, the Deficient model holds that people with intellectual disabilities are deficient and incomplete. Deficit based models create a need to provide interventions that fix people with intellectual disabilities. However, there are ways in which the Deficit model aligned with the model of Human Diversity (Table 2). Specifically, two participating religious leaders within the Deficit model supported inclusion of individuals with intellectual disabilities within both mainstream mass and adaptive liturgy. Similar to the Human Diversity model, two individuals within the Deficit model believed that adaptive liturgy can serve purposes specific to the disability community, but ultimately mainstream mass should be inclusive. Therefore, people with intellectual disabilities should participate in the mainstream mass while also having the opportunity to engage in the adaptive liturgy. The inconsistency within the Deficient model may be unique given that models of disability define disability and its relationship to how society react to people with disabilities given a particular model of disability. This inconsistency indicates that models of intellectual disability may be similar on certain dimensions such as the way in which people with intellectual disabilities should be included in faith communities.

In comparison to the deficit based model, it may be beneficial to utilize a personenvironment fit model (Thompson, Wehmeyer, \& Hughes, 2010) or ecological model (Satariano, 2006), which better aligns with the Human Diversity model. The Human 
Diversity model, like person-environment fit models, recognizes the gap between individual capacity and the environment. Thus, there is a focus on the strengths of people with intellectual disabilities. Understanding that a gap exists can then promote focus on how to close the gap to promote meaningful participation of individuals with intellectual disabilities in settings such as faith communities (Thompson et al., 2010).

When considering ways in which the Human Diversity model can be utilized as an exemplar, it may be useful to view attitudes and experiences as varying on continuums across multiple dimensions. In which case, there should be an effort to shift perspectives across multiple dimensions of attitudes toward people with intellectual disabilities and participation of people with intellectual disabilities. However, the point of intervention must take place at the intersection between an individual's capacity and the resources of a social and physical environment. For example, the participating religious leader in the model of Human Diversity recognized that capacity was low given the way in which people communicate in the parish. Therefore, when communication barriers exist, reexplaining oneself, story telling, and simple diagrams were utilized to bolter the environmental press. With deficit-based models like the Conformity model, attitudinal shifts to viewing physical environments to be malleable is necessary to shift settings to promote participation. However, awareness to shift social and physical contexts may require more efforts within the Catholic church. More specifically, solutions should be identified and initiated by Catholic religious leaders working with offices and agencies for people with disabilities within both the faith community and secular environment. 
Contact with people with intellectual disabilities is one dimension in which participating religious leaders varied. One participant within the Conformity model had contact with people with intellectual disabilities during his seminary training. He once visited a state institution for people with intellectual and developmental disabilities. The visit took place many years ago, so the participant did not remember what the purpose of the visit was. This participant being part of the Conformity model utilized a deficit perspective. Social contact theory provides a framework to understand contact between people with and without intellectual disabilities (Allport, 1954). The type of contact people have with individuals with intellectual disabilities is important. If the visit was intended to be a service learning opportunity, seminary educators should consider how such opportunities are structured. Service learning where students without disabilities provide a service to individuals with disabilities can reinforce common stereotypes (Gent \& Gurecka, 2001). Therefore, seminary professors, like teachers, should be encouraged to design service learning opportunities or fieldwork where individuals without disabilities work with people with disabilities. Equal partnerships where problems are solved together can facilitate the opportunity to both communicate and connect for people with and without disabilities (Gent \& Gurek, 2001; Greig \& Bell, 2000; Makas, 1993). Moreover, the quality of contact between people with and without disabilities contributes to the determination of whether individuals hold positive or negative attitudes toward people with disabilities (McManus et al., 2011). For example, the participating religious leader within the Human Diversity model described having a relative with intellectual disability who was a close and active member of the family. Based on the information 
provided, it may be that the participating religious leader had both high quality and quantity contact which may relate to his attitudes toward people with intellectual disabilities. Thus, the contact (e.g., communication, connection) must be positive between people with and without disabilities. However, according to McManus, Feyes, ad Saucier (2011) the quality of contact is most important which may be illuminated through the case where a participant in the Conformity model described having a child with an undiagnosed disability while expressing feeling frustrated and his observations of the social isolation parents of people with disabilities experience.

Notably, most participating religious leaders in the present study did not have disability specific training during their religious education which reflects current literature reporting that seminaries offer limited or no coursework or field experiences addressing disability issues (Anderson, 2003; Association of Theological Schools, 2008; Carter, 2013). Moreover, the Pastoral Statement of U.S. Catholic Bishops on People with Disabilities calls upon religious leaders to educate themselves to understand the contributions individuals with disabilities can make in faith communities (United States Conference of Catholic Bishops, 1978). This places the responsibility of learning about disabilities issues upon religious leaders rather than seminaries. As participants in the Conformity model discussed, religious leaders do not have time to learn about and address disability issues. Thus, if the Catholic church is invested in disability issues, it should consider disability training, so that individuals are not responsible for seeking training independently. Importantly, cultural competence, a process of understanding the importance of social and cultural influences on beliefs and behaviors (Betancourt, Green, 
Carrollo \& Ananeh-Firempong, 2003), is a life-long process rather than a discrete endpoint. (Tervalon \& Murray-Garcia, 1998; Minkler \& Wallerstein, 2008). In recognizing this limitation, religious leaders should be trained to be open to different ways of thinking about issues and addressing them as well as critical reflection where individuals examine their own biases (Tervalon \& Murray-Garcia, 1998). The Catholic community embodies these characteristics at the diocesan level through the Office of Life, Justice and Peace where diversity in thinking and experiences are valued.

Notably, one participating religious leader adhering to the Close to God model described a Latino congregation being accepting of people with disabilities. Past research has not explored attitudes among Latinos generally, but researchers have explored attitudes among Mexicans, a segment of the Latino population. Traditionally, Mexicans, have viewed people with disabilities as punishments from God for their wrongdoing or sin (Glover \& Blankenship, 2007). However, more recent research has found that Latinos mothers view their children with disabilities as gifts from God (Glover \& Blankenship, 2007; Skinner et al., 1999). It may be that there has been a shift among some Latinos where negative responses to disability are now becoming "positive". Although both types of responses interpret disability is a special condition (Reinders, 2011), "positive" responses may have benefits such as varying levels of inclusion.

Multiple stereotypes of individuals with intellectual disabilities exist and the use and perpetuation of such stereotypes are present in the models of disability found in the present dissertation. One common stereotype of individuals with intellectual disabilities is that they are like children throughout their lives, regardless of age (Kliewer \& Drake, 
1998). The assumption that individuals with intellectual disabilities are like children was present in the Unfortunate Innocent Children model. One participant described people with intellectual disabilities as being children in the bodies of adults. This stereotype promotes beliefs about people with intellectual disabilities being helpless and dependent on individuals without disabilities. A more concrete example of this would be the belief that individuals with intellectual disabilities cannot live independently because they require life-long care from their family and society. Within faith communities, this may translate into people without disabilities making decisions concerning people with disabilities where people with disabilities are not only excluded from decision making but their concerns, needs, and wants are not accounted for.

The Deficient model most aligned with the stereotype of people with intellectual disabilities needing to be fixed (Remen, 1996; Snow, 1998). According to Gent and Gurecka (2001), this stereotype is rooted in societal inequality where those in power (e.g., service providers, religious leaders) have the expertise to fix or change people while those being fixed (e.g., service recipients) are incompetent and ignorant. For example, charity that fixes some challenge a person is facing bestows unequal status on recipients. This devaluation of individuals with disabilities is part of an institutionalized structure where a dominant group seeks to deliver services with the goal of changing people to fit the norm (Rappaport, 1977). Relatedly, there may be a link between the belief about the cause of intellectual disability and the cure for intellectual disability. The dimensions of cause and cures were only discussed within the Close to God and Deficient models. A participating religious leader in the Close to God model specifically expressed that he 
was not concerned with the cause of intellectual disability because a cure is not needed.

On the other hand, participating religious leaders in the Deficient model did not explicitly make links between the cause and cure of intellectual disability. It is not clear how participating religious leaders would link the relationship between the cause and cure of intellectual disability.

Within the Conformity model, the Down syndrome stereotype was present, which involves beliefs about people with Down syndrome being exceptionally happy and friendly (Watt, Johnson, \& Virji-Babul, 2010). Within the Conformity model, one participating religious leader hired a person with Down syndrome, which may indicate that the stereotypes attributed to people with Down syndrome may mean they are perceived to fit into the parish setting without having to make changes within the parish. Alternatively, the decision to hire the person with Down syndrome may have been a function of being friends with the employee's parents. Based on prior research (Crocker \& Quinn, 2000), the act of employing a person with an intellectual disability may buffer stigmatization. The person with Down syndrome would be engaging in a social acceptable role (e.g., employee; Crocker \& Quinn, 2000), but the buffering of stigmatization may depend on the degree to which the employee interacts with others and/or makes friendships within the workplace (Ferguson et al., 1993).

When considering what inclusion may look like for people with intellectual disabilities, there generally were mixed responses. Like academic literature on disability issues, there was no accepted universal definition of what inclusion should look like (Ryndaket et al., 2000; Verdonschot et al., 2009). The Close to God, Deficient, and 
Human Diversity models supported inclusion in both the adaptive liturgy and mainstream mass. In the Close to God and Deficient models, participants specifically discussed parents of individuals with intellectual disabilities wanting segregated settings. Based on what participating religious leaders shared about the experiences of parents, they may be experiencing the courtesy stigma (Goffman, 1963; Mehta \& Farina, 1988). Prior research has reported that mothers of children with intellectual disabilities experience social isolation (Griffith et al., 2012) and lower well being in comparison to mothers with children without disabilities (Norlin \& Bioberg, 2013). It is not clear if participation in segregated settings is a result of these outcomes or vice versa.

It is possible that experiences of social isolation and lower well being may be buffered by participation in segregated settings. For example, Townley et al. (2011; 2013) found that high SOC is associated with homogeneity, which may mean that individuals attending the adaptive liturgy experience belonging. Thus, adaptive liturgies may serve as a "safe space" made up of people with disabilities to share and discuss their unique identities, struggles, and ideals for individual, communal, and societal change. Notably, the association between SOC and homogeneity does not mean that individuals with high SOC value homogenous communities generally, but homogeneity is a characteristic of high SOC. Moreover, the participating religious leader representing the Human Diversity model discussed adaptive liturgies serving as a safe space to address issues specific to the disability community. For example, safe spaces within the lesbian, gay, bisexual, transgendered literature has found that safe spaces provide minorities a place to discuss their identities and interests to mobilize a group for social change 
(McBride, 2001). On the other hand, homogenous groups may exhibit little tolerance for diversity (Humphrey, 2000) where belonging is overvalued at the expense of diversity (Townley et al., 2013). Therefore, balancing participation in both segregated safe spaces and mainstream settings is critical for the disability community to consider.

Of note, one participating religious leader within the Deficient model stated that the adaptive liturgy was created in reaction to parents of children with disabilities sharing their experiences. According to the Director at the Office for People with Disabilities at the Archdiocese of Portland in Oregon, the adaptive liturgy was created when the Archdiocese found out that parents of autistic children were not attending church. The autistic children required specific accommodations like small group settings. The families did not report feeling stigmatized but rather their autistic child was not comfortable, for disability related reasons, in the mainstream mass environment. The adaptive liturgy was intended to provide accommodations for families who stopped attending church, but the Archdiocese of Portland in Oregon welcomed all people with and without disabilities. Therefore, accommodations for people with disabilities generally were implemented. Thus, views of the process of creating adaptive liturgy differed (D. Coughlin, personal communication, June 6, 2013).

Participants in the Conformity model discussed the presence and attempted participation of individuals with intellectual disabilities in mainstream mass. Participation was specifically denied because the participating religious leader did not believe the individuals would be able to perform certain tasks and implementing accommodations was not a plausible option for the participating religious leader. Thus, no emphasis was 
placed upon identifying how to include people with intellectual disabilities. The participating religious leader did not want to allow a man who was blind to walk with a companion. Prior research has found that companions for individuals with developmental disabilities in faith communities have been an effective tool to promote participation (Minton \& Dodder, 2003).

Furthermore, another way in which a participant in the Conformity model excludes people with intellectual disabilities is by having parish staff assess the individual with intellectual disability's understanding of the role. Determining whether individuals with intellectual disabilities can participate in religious rituals or observances may depend on one's interpretation. According to Swinton (2001), it is not appropriate to ask questions of people with intellectual disabilities when those same questions are not asked to people without disabilities and are actively participating in religious services. Such behaviors (testing for eligibility) deem people with intellectual disabilities unfit to worship God. Thus, religious leaders should be encouraged to consider whether an individual expresses having a desire to participate, which was discussed by the participating representing the Human Diversity model.

Literature that discusses common models of disability, like Rioux's (1997) piece, explains that there is nothing inherently wrong with the medical, functional, and social models of disability. Instead, problems arise with models of disability when adhering exclusively to one single model. While I believe that the medical model may be beneficial in a medical setting where diagnosis intends to connect individuals to services, I argue that such statements would not apply to all of the models created in the present 
study given the context of participation in faith communities. Multiple models that resulted from the present study, excluding Human Diversity, are rooted in negative stereotypes with a strong focus on the supposed deficits of persons with intellectual disabilities. Thus, they are similar to the medical model because they focus on deficits, but faith communities do not require diagnoses to promote participation of individuals with disabilities. Little, if any, emphasis is placed on the strengths of people with intellectual disability or the context in which people are situated. Moreover, the real world implications of the models presented here should be taken seriously. When parishioners view a leaders' behavior toward persons with intellectual disabilities to be normative, this behavior becomes integrated within the organizational culture (Dragoni, 2005). Religious leaders play a pivotal role in shaping the attitudes and behaviors of their followers, so addressing negative attitudes among leaders is critical. For people with disabilities and their families, negative attitudes among leaders are likely to translate to exclusion from one's religious community. Moreover, shaping negative attitudes and behaviors among parishioners may translate into other life domains, which may perpetuate exclusion in contexts outside of one's religious community.

Models with features comprising the Human Diversity should be promoted within faith communities. Human Diversity aligns with the transactional model of disability, which focuses on the continual interplay between persons and the environment (Llewellyn \& Hogan, 2000). There is a tendency to view disability as static, as seen through the other models identified in this research. The Human Diversity model focuses on the need for practices that build competence in both environments and individuals, 
because competence does not solely reside within individuals. Thus, communities must be competent to work with diverse groups, like the disability community. For example, Human Diversity posits that churches need to be open and flexible for unexpected experiences that may take time to get used to. This also aligns with prior research reporting that organizational contexts that support diversity have a tolerance for ambiguity (Bond, 1995)

More broadly, my personal stance is rooted within the field of community psychology. Based on Lewin's conceptualization of person-environment fit, Kelly (1971) envisioned the field working to improve environments rather than focusing on individualized solutions. Thus, community psychologists respect human diversity by promoting the right to be different and not focusing on changing people to fit into the dominant culture (Rappaport, 1977). Thus, models of disability that view causes and solutions of a problem residing within an individual actually ignore contextual factors that impact the problem. Deficit based models like the medical model do not utilize an ecological framework because they focus on the individual experiencing the disability. Models of disability should concern the needs and abilities of individuals as well as the resources and opportunities provided by environments. Examining people and their environments in congruence with one another yields a more holistic perspective of social problems. Thus, problems do not arise from the person or environment separately. Interventions within faith communities should involve examining personenvironment fit with focus on both the person and the environment. If focus is placed on the context alone, faith communities may create inclusive environments where people 
with intellectual disabilities are physically present but are not socially integrated in an environment that fosters friendships. Thus, simply changing the physical environment of a social setting without considering its impact on social interaction may not alter the ways in which people with intellectual disabilities participate within settings. However, first order changes may need to take place. For example, physical access to parishes for people with intellectual disabilities is required for them to participate within the life of the parish. Thus, promoting attendance may be a first step toward meaningful inclusion. Once people with intellectual disabilities are present, then second order changes can be explored to determine which roles people with intellectual disabilities want to engage in. Then the environment can be examined to create a person environment fit. The onset of such changes toward inclusion may need to come from within faith communities, particularly self-advocates and faith leaders. Self-advocates who choose to be part of faith communities can work to create awareness and identify ways in which they want to be included. It is my belief that a movement led by self-advocates in partnership with faith leaders and other groups within faith communities can work together to transform faith communities. Faith leaders have the opportunity to transmit their values and goals to their congregation. Furthermore, given the exploratory nature of the present study, prior to implementing interventions within faith communities, future action researchers need to explore the experiences of people with intellectual disabilities, their families, and general members of faith communities, as well as how all groups make meaning of intellectual disability. 
Religious leaders are a group of people who, in part, represent the Catholic community. The ways in which religious leaders view and understand intellectual disabilities may convey to parishioners who is and is not valued within their community. For Catholics with intellectual disabilities, negative attitudes may isolate them or even result in no longer attending church or joining another church. If the Catholic community chooses to be an inclusive community, it may consider partnering with people with intellectual disabilities, family members of people with intellectual disabilities, and general members of the parish to create accommodations or interventions that allow people with intellectual disabilities to participate at their chosen level.

\section{Limitations and Implications for Future Research}

The present dissertation has limitations that have important implications for future research. First, the present dissertation only included one perspective on the inclusion of individuals with intellectual disabilities within Catholic congregations. The participant group matters, because they may provide a unique perspective (Lincoln \& Guba, 1985). The inclusion of only one perspective -- Catholic pastors, parochial vicars, and deacons -is a limitation. More specifically, the participants within my dissertation are likely unique in that I first sought participants who have individuals with developmental disabilities within their faith community. Therefore, the participants may unique because they have allowed people with intellectual disabilities within their parish. Although, there may be parishes with parishioners with intellectual and developmental disabilities that may not be known to those outside of the parish. Additionally, unlike other groups (e.g., general members of faith communities), religious leaders go through specific theological training. 
To more fully account for the complexity of interactions within faith communities, other perspectives should be sought in future studies. These perspectives may include individuals with intellectual disabilities, family members of individuals with intellectual disabilities, church administration, and lay religious leaders. More specifically, the perspectives of individuals with intellectual disabilities may provide information on the importance of their faith and how it relates to their faith community (e.g., local church, religious leaders), desired roles within the community, and what and how they would like things like processes changed. Future research should assess the perspectives of diverse groups involved within faith communities to further strengthen our understanding of inclusion within faith communities.

Examining the perspective of other groups within faith communities, particularly individuals with intellectual disabilities can help better discern strategies of change. Based on my value for the person-environment fit and the knowledge gained through the present study, I believe that faith leaders should be trained on disability issues within their diversity training. Accommodations made for ethnic groups like Latinos, which include the integration of Spanish or Spanish only mass as well as cultural practices rooted within the Latino community should also be implemented for the disability community. However, I believe that this movement needs to be led by self-advocates so that changes are focused on what people with intellectual disabilities want. Collaboration between people with intellectual disabilities and faith leaders could help determine specific accommodations. Self-advocates and faith leaders would likely be in a better position to negotiate how to implement accommodations. For example, if faith leaders are 
concerned about preserving the façade of a church while at the same time physical changes are required to create an accommodating space, the two groups would need to work together to address this challenge of competing values. For example, there may be elements of the interior of a church that would allow for physical changes like an elevator.

As stated earlier, models are not intended to be complete and fully representative of the phenomena being described. Therefore, models help generate explanations, but they do not constitute an explanation. For the present dissertation, the limitations of models are important to note because some models are made up of a small sub-sample. The Conformity and Unfortunate Innocent Children models were each created through the experiences of two participating religious leaders while the Human Diversity model was made through the experience of only one participating religious leader. Thus, if sampling for the present dissertation continued, it is possible that the boundaries and definitions of each model would have been more refined with additional data. Further developing the boundaries and definitions of each model may yield better developed models. The inconsistencies within models, such as the differences in opinions about whether individuals with intellectual disabilities should participate in segregated or mainstream settings in the Deficiency model, may be related to the extent to which the models were developed. There may be unique differences among participants within the Deficiency where additional data may indicate that the model should be separated into two models. Markedly, inconsistencies among behaviors and attitudes may actually describe attitudes toward participation. Thus, individuals who believe individuals with 
intellectual disabilities require fixing may include people who both support participation in mainstream and segregated studies while other only support participation in segregated settings. Also, if sampling did continue, the models may still not be complete. For example, no single model of disability has the ability to describe and explain every aspect of the disability experience (Tate \& Pledger, 2003). Thus, every model focuses on a limited number of aspects of disability while ignoring other facets.

However, the present findings may transfer to other communities of faith (e.g., other Christian denominations, Islam, etc.). Faith communities are unique because they are not required to adhere to the ADA. Settings like public spaces (e.g., schools) may have more awareness of disability issues simply because of legal obligations. Furthermore, ADA may create settings that allow people with intellectual disabilities to be present where that option may not be available in faith communities. Thus, inhabitants of public spaces may have different types and levels of contact with people with intellectual disabilities than those in faith communities. However, as discussed above, the models developed in the present study are similar to existing models in multiple ways.

Furthermore, other sampling limitations are present within the present dissertation. As described in the methods section, of the 10 individuals who were at parishes with adapted liturgies, $60 \%(\mathrm{n}=6)$ chose to participate and of the 17 individuals recruited to participate, approximately $35 \%(\mathrm{n}=6)$ chose to participate in the present dissertation. Although the present dissertation aimed to present detailed descriptions of the data so that readers have enough information to judge the relevance and applicability of the findings to other settings, transferability may be limited. Future researchers should 
consider alternative forms of recruitment. Some potential participants were not reached through telephone calls or email. Researchers may want to consider alternative forms of communication such as contacting parish staff (e.g., secretaries) to find out which form of communications are best for religious leaders. In the present study, some religious leaders and parish staff stated that email contact is preferred. Some participants also stated that they were busy during the time of recruitment and member checks. During recruitment and member checks, individuals mentioned that they were busy with new religious leaders starting at their parish.

Also related to sampling as a limitation, the present grounded theory does not satisfy all of the requirements for theory building (i.e., conceptual development, operationalization, confirmation/disconfirmation, application, and continuous refinement, Lynham 2002). For example, the process of confirmation or disconfirmation in the present study was limited to because the present sample and setting were narrow. Aspects of theory building like confirmation may need to extend beyond the present dissertation. Thus, the resulting storylines are not identified as theories.

In regarding to sampling, future research may consider recruiting first from parishes that are not involved in transitioning religious leaders. Alternatively, the time of each in which data collection takes place may be important. In Oregon, the transfers were taking place on July 1, 2013 for some individuals. Some individuals stated that June was a busy time because religious leaders were preparing to move while the Fall months involved a process of transitioning religious leaders new to the parish. Researchers may consider collecting data at various times during the year. 
Another limitation may be a function of face-to-face individual interviews.

Participants may feel the need to respond in socially desirable ways or they may omit information they do not feel comfortable sharing. During the research process, I did not notice any evidence of social desirability possibly being a challenge within the present dissertation. One way in which I hoped to reduce social desirability is by ensuring all participants that their responses would be kept confidential. I also had the opportunity to practice the interview for the present dissertation during the pilot of my procedures, which allowed me to reflect on ways in which I can decrease my influence on the direction of interviews. Additionally, I have had the opportunity to engage in face-to-face structured interviews for my thesis, which provided first-hand experience in collecting data through interviews.

There may be unique ways in which my own experiences, values, and perspectives impacted the findings and analysis of the present dissertation. For example, I engaged in the present dissertation with knowledge of the intellectual disability literature and pre-existing models of disability. Although I made a conscious effort not to test hypothesis based on my pre-existing knowledge. However, I did utilize pre-existing knowledge to describe the data such. More specifically, I identified models that utilized a deficit-based approach that is similar to the medical model.

Markedly, models are useful for disability researchers because they aid in the exploration of real world problems (Llewellyn \& Hogan, 2000). In the present dissertation, the models created and described are intended to help disability researchers evaluate the influence of the context of Catholic faith communities and religious leaders 
to understand the underexplored area of the participation of individuals with intellectual disabilities in faith communities. More specifically, the models may aid in the generation of hypotheses. For example, scale development based on the present may help understand whether similar attitudes exist among a larger sample of religious leader as well as lay leaders and parishioners within faith communities.

\section{Conclusion}

Disability is a social construction (Fine \& Asch, 1988). The models of intellectual disability aim to define what intellectual disabilities are. Each model yields a different definitions which results in varying determinations of the needs of people with intellectual disabilities. However, each definition is one dimensional and bound in culture. Additional research is needed to explore the boundaries of models of intellectual disabilities. The present dissertation is one step in exploring meanings of intellectual disabilities and factors that impact their participation in faith communities. The limitations should be carefully considered as the results are not meant to be generalizable but rather a representation of what some of the diversity in attitudes may look like. These findings should be used as a starting point for future research. Once we understand the social constructions of intellectual disabilities, we can then start to challenge the constructions to promote acceptance of differences, improve access to resources, and decrease disparities between people with and without intellectual disabilities. 
Figure 1. Participant Flow Diagram

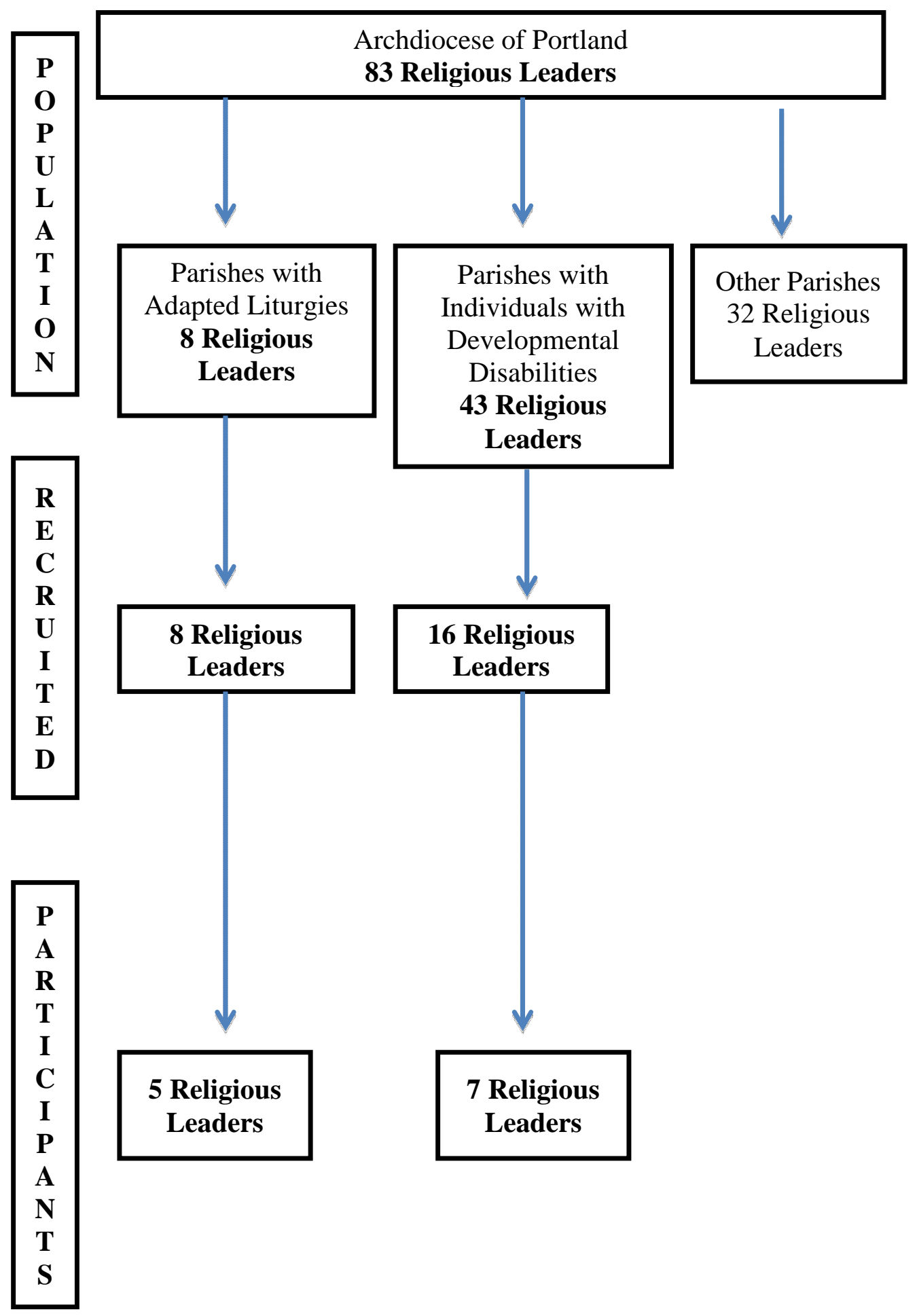


Table 1. Summary of Results

\begin{tabular}{|c|c|c|c|c|c|}
\hline & Close to God & Conformity & $\begin{array}{c}\text { Unfortunate } \\
\text { Innocent Children }\end{array}$ & Deficient & Human Diversity \\
\hline \multicolumn{6}{|l|}{ Research Question } \\
\hline $\begin{array}{l}\text { Experiences with } \\
\text { Individuals with } \\
\text { Intellectual Disabilities }\end{array}$ & $\begin{array}{l}\text {-Resources Utilized: } \\
\text { Secular, family } \\
\text { members, Archdiocese } \\
\text {-Participation of } \\
\text { people with } \\
\text { intellectual disabilities } \\
\text { as volunteers, } \\
\text { Eucharistic ministers }\end{array}$ & $\begin{array}{l}\text {-Frustrated with } \\
\text { child presumed to } \\
\text { have a disability } \\
\text {-Needs of people } \\
\text { with disabilities } \\
\text { are not a priority }\end{array}$ & $\begin{array}{l}\text {-Concerned about } \\
\text { protection and } \\
\text { safety } \\
\text {-Unwilling to make } \\
\text { changes to the } \\
\text { structure of the } \\
\text { building }\end{array}$ & $\begin{array}{l}\text {-Varying levels of } \\
\text { contact }\end{array}$ & $\begin{array}{l}\text {-Grew up with a relative } \\
\text { with intellectual disability } \\
\text {-Experience with large } \\
\text { scale accommodations }\end{array}$ \\
\hline $\begin{array}{l}\text { Perspectives Toward } \\
\text { the Involvement of } \\
\text { Individuals with } \\
\text { Intellectual Disabilities }\end{array}$ & $\begin{array}{l}\text {-Advocated for } \\
\text { inclusion in } \\
\text { mainstream mass } \\
\text { regardless of } \\
\text { parishioner reactions } \\
\text {-Exception: } \\
\text { Segregated settings by } \\
\text { family request }\end{array}$ & $\begin{array}{l}\text {-Not interested in } \\
\text { disability issues } \\
\text {-Eligibility must } \\
\text { be determined for } \\
\text { roles like } \\
\text { Eucharistic } \\
\text { minister } \\
\text {-Require } \\
\text { advocates } \\
\text { without } \\
\text { disabilities }\end{array}$ & $\begin{array}{l}\text {-People with } \\
\text { intellectual } \\
\text { disabilities do not } \\
\text { need to participate } \\
\text { in everything } \\
\text {-Mainstream mass } \\
\text { preferred due to } \\
\text { resources }\end{array}$ & $\begin{array}{l}\text {-Varying views on } \\
\text { participation } \\
\text {-Proponents for both } \\
\text { mainstream and } \\
\text { segregated settings } \\
\text { being available } \\
\text {-Proponent for } \\
\text { segregated settings } \\
\text { only }\end{array}$ & $\begin{array}{l}\text {-Support participation in } \\
\text { segregated and } \\
\text { mainstream settings } \\
\text {-Individuals must have a } \\
\text { desire for a role } \\
\text {-Create person- } \\
\text { environment fit }\end{array}$ \\
\hline $\begin{array}{l}\text { Understanding of } \\
\text { Intellectual Disabilities }\end{array}$ & $\begin{array}{l}\text {-Exceptional skill } \\
\text { - Close relationship } \\
\text { with God } \\
\text {-Presence powerful for } \\
\text { parishioners without } \\
\text { disabilities }\end{array}$ & $\begin{array}{l}\text {-Lack complexity } \\
\text {-Purpose to teach } \\
\text { one's family and } \\
\text { community how } \\
\text { to love }\end{array}$ & $\begin{array}{l}\text {-Unfortunate } \\
\text {-Innocent } \\
\text {-Children in adult } \\
\text { bodies } \\
\text {-Born into families } \\
\text { that require some } \\
\text { form of help }\end{array}$ & $\begin{array}{l}\text {-Defective } \\
\text {-Incomplete } \\
\text {-Need to be fixed } \\
\text {-Religious healing }\end{array}$ & $\begin{array}{l}\text {-Part of natural human } \\
\text { differences } \\
\text {-May be more blessed } \\
\text { than people without } \\
\text { intellectual disabilities }\end{array}$ \\
\hline
\end{tabular}


Table 2. Similarities and differences among models of intellectual disability

\begin{tabular}{|c|c|c|c|c|c|}
\hline & Close to God & Conformity & $\begin{array}{c}\text { Unfortunate } \\
\text { Innocent Children }\end{array}$ & Deficient & Human Diversity \\
\hline $\begin{array}{l}\text { Participating } \\
\text { Religious Leaders }\end{array}$ & 4 & 2 & 2 & 3 & 1 \\
\hline Language & Not people first & Not people first & Not people first & Not people first & People First \\
\hline $\begin{array}{l}\text { Relationship with } \\
\text { People with } \\
\text { Disabilities }\end{array}$ & $\begin{array}{l}\text { Parish, relative with } \\
\text { intellectual } \\
\text { disability, L'Arche }\end{array}$ & $\begin{array}{l}\text { Child with possible } \\
\text { developmental } \\
\text { disability, friend with } \\
\text { child with intellectual } \\
\text { disability, Employee } \\
\text { with Down syndrome }\end{array}$ & Parish & $\begin{array}{l}\text { Contact in and } \\
\text { outside of parish }\end{array}$ & $\begin{array}{l}\text { Parish, relative with } \\
\text { intellectual disability }\end{array}$ \\
\hline $\begin{array}{l}\text { Qualities of People } \\
\text { with Intellectual } \\
\text { Disabilities }\end{array}$ & $\begin{array}{l}\text { Closer relationship } \\
\text { to God than people } \\
\text { without intellectual } \\
\text { disabilities }\end{array}$ & $\begin{array}{c}\text { Simple, lack } \\
\text { complexity, people } \\
\text { with Down syndrome } \\
\text { are easier to work } \\
\text { with }\end{array}$ & $\begin{array}{l}\text { External children, } \\
\text { incapable of } \\
\text { wrongdoing, } \\
\text { unfortunate in } \\
\text { comparison to } \\
\text { people without } \\
\text { intellectual } \\
\text { disabilities, need to } \\
\text { be protected }\end{array}$ & $\begin{array}{l}\text { Deficient, need to } \\
\text { be fixed, may be } \\
\text { more blessed than } \\
\text { people without } \\
\text { intellectual } \\
\text { disabilities }\end{array}$ & $\begin{array}{l}\text { Natural part of human } \\
\text { diversity, have unique } \\
\text { characteristics like } \\
\text { people without } \\
\text { intellectual disabilities }\end{array}$ \\
\hline
\end{tabular}




\begin{tabular}{|c|c|c|c|c|c|}
\hline Purpose & $\begin{array}{l}\text { Exemplify } \\
\text { relationship with } \\
\text { God }\end{array}$ & $\begin{array}{l}\text { To teach parents and } \\
\text { siblings how to love, } \\
\text { provide community } \\
\text { opportunity to love } \\
\text { and see life } \\
\text { differently }\end{array}$ & $\begin{array}{l}\text { Born to families } \\
\text { that require help }\end{array}$ & & \\
\hline Cause & $\begin{array}{l}\text { Not concerned with } \\
\text { cause }\end{array}$ & & & $\begin{array}{l}\text { Cause may not be } \\
\text { understood by faith } \\
\text { leaders or scientists, } \\
\text { may result from } \\
\text { negative emotions } \\
\text { or well-being }\end{array}$ & \\
\hline Cure & Not needed & & & Religious healings & \\
\hline Secular Resources & $\begin{array}{l}\text { Sought funding for } \\
\text { disability training, } \\
\text { parents of people } \\
\text { with disabilities }\end{array}$ & & & & $\begin{array}{c}\text { People with } \\
\text { disabilities, disability } \\
\text { professionals, religious } \\
\text { leaders involved in } \\
\text { adaptive liturgy }\end{array}$ \\
\hline Religious Resources & $\begin{array}{c}\text { Archdiocese } \\
\text { contacted after } \\
\text { secular resources are } \\
\text { used }\end{array}$ & $\begin{array}{l}\text { Refer people with } \\
\text { disabilities or people } \\
\text { interested in } \\
\text { disability issues to } \\
\text { the Archdiocese }\end{array}$ & & & $\begin{array}{l}\text { Would not use Bible } \\
\text { because intellectual } \\
\text { disability was not } \\
\text { recognized in first } \\
\text { century Palestine }\end{array}$ \\
\hline $\begin{array}{l}\text { Disability Awareness } \\
\text { in Parish }\end{array}$ & $\begin{array}{l}\text { Mission statement, } \\
\text { retreats, Catholic } \\
\text { media }\end{array}$ & $\begin{array}{l}\text { Not concerned with } \\
\text { people with } \\
\text { intellectual } \\
\text { disabilities }\end{array}$ & & & \\
\hline
\end{tabular}




\begin{tabular}{|c|c|c|c|c|c|}
\hline $\begin{array}{l}\text { Preferred Setting for } \\
\text { People with } \\
\text { Intellectual } \\
\text { Disabilities }\end{array}$ & $\begin{array}{l}\text { Mainstream mass } \\
\qquad(\mathrm{n}=3)\end{array}$ & $\begin{array}{l}\text { Adaptive liturgy } \\
\qquad(\mathrm{n}=2)\end{array}$ & $\begin{array}{l}\text { Mainstream mass } \\
(\mathrm{n}=1) \text {, adaptive } \\
\text { liturgy }(\mathrm{n}=1)\end{array}$ & $\begin{array}{l}\text { Both settings }(\mathrm{n}=2) \\
\text { adaptive liturgy } \\
\qquad(\mathrm{n}=1)\end{array}$ & Both settings $(\mathrm{n}=1)$ \\
\hline $\begin{array}{l}\text { Exceptions relating to } \\
\text { setting participation }\end{array}$ & $\begin{array}{l}\text { One acknowledged } \\
\text { that adaptive liturgy } \\
\text { may be preferred by } \\
\text { parents of people } \\
\text { with intellectual } \\
\text { disabilities }\end{array}$ & & & & \\
\hline $\begin{array}{l}\text { Who Should Initiate } \\
\text { Participation }\end{array}$ & $\begin{array}{l}\text { Religious leaders } \\
\text { and people with } \\
\text { intellectual } \\
\text { disabilities }\end{array}$ & $\begin{array}{l}\text { People with } \\
\text { intellectual } \\
\text { disabilities }\end{array}$ & & $\begin{array}{l}\text { Religious leaders } \\
\text { and people with } \\
\text { intellectual } \\
\text { disabilities }\end{array}$ & $\begin{array}{c}\text { People with } \\
\text { intellectual disabilities }\end{array}$ \\
\hline $\begin{array}{l}\text { Roles of People with } \\
\text { Intellectual } \\
\text { Disabilities }\end{array}$ & $\begin{array}{l}\text { Volunteers, } \\
\text { Eucharistic } \\
\text { ministers, } \\
\text { communion }\end{array}$ & $\begin{array}{l}\text { Employee with } \\
\text { Down syndrome, } \\
\text { eligibility must be } \\
\text { determined for } \\
\text { participation }\end{array}$ & Confession & $\begin{array}{c}\text { Communion, } \\
\text { Eucharistic minister }\end{array}$ & $\begin{array}{l}\text { Accommodations and } \\
\text { a person-environment } \\
\text { fit is sought when } \\
\text { individuals with } \\
\text { intellectual disabilities } \\
\text { express a desire for } \\
\text { participation }\end{array}$ \\
\hline
\end{tabular}




\begin{tabular}{|l|c|c|c|c|c|}
\hline & Accommodations & $\begin{array}{c}\text { Mentorship, concrete } \\
\text { language }\end{array}$ & $\begin{array}{c}\text { Individuals are } \\
\text { expected to fit into } \\
\text { the parish setting, } \\
\text { Accommodations are } \\
\text { not created }\end{array}$ & $\begin{array}{c}\text { Structural changes } \\
\text { to the church } \\
\text { building are not } \\
\text { acceptable }\end{array}$ & $\begin{array}{c}\text { Engaged in large scale } \\
\text { accommodations, } \\
\text { willing to work with } \\
\text { individuals and } \\
\text { families to create } \\
\text { accommodations }\end{array}$ \\
\hline
\end{tabular}




\section{References}

Abbott, S. \& McConkey, R. (2006). The barriers to social inclusion as perceived by people with intellectual disabilities. Journal of Intellectual Disabilities, 10, 275287.

Abrams, J. (1998). Judaism and disability: Portrays in ancient texts from the Tanach through the Bavli. Washington, DC: Gallaudet University Press.

Akrami, N., Ekehammar, B., Claesson, M. \& Sonnander, K. (2006). Classic and modern prejudice: Attitudes toward people with disabilities. Research in Developmental Disabilities, 27, 605-617.

Allport, G.W. (1954) The nature of prejudice. Reading, MA: Addison Wesley.

Ali, A., Hassiotis, A., Strydom, A., King, M. (2012). Self stigma in people with intellectual disabiltiies and courtesy stigma in family carers: A systematic review. Research in Developmental Disabilities, 33, 2122-2140.

Altman, B.M. (2001). Disability definitions, models, classification schemes, and applications. In G.L. Albrecht, K.D. Seelman, \& Bury, M. (Eds.), Handbook of disability studies (pp. 97-122). Thousand Oaks, CA: Sage Publications.

Amado, A., DeGrande, M., Boice, C., \& Hutcheson, S. (2011). Impact of two national congregational programs on the social inclusion of individuals with intellectual/developmental disabilities. Minneapolis, MN: University of Minnesota, Institute on Community Integration.

Amado, A. \& Simon, S. (2001/2, Fall/Winter). Congregational roles in community inclusion across the lifespan. Impact, 14(3), 6-7. 
Ambert, A., Adler, P.A., Adler, P., \& Detzner, D.F. (1995). Understanding and evaluating qualitative research. Journal of Marriage and Family, 57(4), 879-893.

American Association on Intellectual and Developmental Disabilities (AAIDD; 2010). Intellectual disability: Definitions, classification, and system of supports (11th Ed.). Washington, DC: American Association on Intellectual and Developmental Disabilities.

American Association on Intellectual and Developmental Disabilities (AAIDD; 2012). Inclusion. Retrieved from http://aaidd.org/content_161.cfm?navID=31

American Psychiatric Association (2000). Diagnostic and statistical manual of mental disorders $\left(4^{\text {th }}\right.$ ed., text rev.). Washington, DC: American Psychiatric Association. Americans with Disabilities Act of 1990, Pub L. No. 101-336, 104 Stat. 328 (1990).

Americans with Disabilities Act (n.d.) ADA title III technical assistant manual: Covering public accommodations and commercial facilities. Retrieved from http://www.ada.gov/taman3.html

Anderson, R. (2003). Infusing the graduate theological curriculum with education about disability: Addressing the human experience of disability in the theological context. Theological Education, 39(1), 131-153.

Antonak, R.F. \& Levneh, H. (1988). The measurement of attitudes toward people with disabilities: Methods, psychometrics and scales. Charles C Thomas publisher, Springfield, IL. 
Antonak, R.F. \& Livneh, H. (1995). Direct and indirect methods to measure attitudes toward persons with disabilities, with an exegesis of the error-choice method. Rehabilitation Psychology, 40, 3-24.

Archdiocese of Portland in Oregon (n.d.). Parishes - Portland, OR. Retrieved from http://www.archpdx.org/parishes/portland.html

Association of Theological Schools (2008). Policy statements: Disability and theological education. Retrieved from http://www.ats.edu/about/Documents/08ATSPolicyStatements.pdf Association of University Centers on Disabilities. (2011). Portrayal of people with disabilities. Retrieved from http://www.aucd.org/template/page.cfm?id=605

Atkinson, P. \& Hammersley, M. (1994) Ethnography and participant observation. In N.K. Denzin \& Y.S. Lincoln (Eds.), Handbook of qualitative research (pp. 248261). Thousand Oaks, CA: Sage Publications.

Barbuto, J.E. (1997). Taking the charisma out of transformational leadership. Journal of Social Behavior and Personality, 1293), 689-690.

Bass, M.B. (1990). From transformational to transactional leadership: Learning to share the vision. Organizational Dynamics, 18(3), 19-36.

Bass, M.B. (1997). Does the transactional-transformational leadership paradigm transcend organizational and national boundaries? American Psychologist, 52(2), 130-139. 
Bass, M.B. (1999) Two decades of research and development in transformation leadership. European Journal of Work and Organizational Psychology, 8(1), 932.

Bass, M.B. \& Avolio, B.J. (1999). Training full range leadership: A resource guide for training with the $M L Q$. Redwood City, CA: Mind Garden.

Bass, M.B. \& Steidlmeier, P. (1999) Ethics, character, and authentic transformational leadership behavior. Leadership Quarterly, 10(2), 181-217.

Baumeister, R.F. (1991). Meanings of life. New York, NY: Guilford Press.

Bauer, T.N. \& Green, S.G. (1996). Development of leader-member exchange: A longitudinal test. Academy of Management Journal, 30, 1538-1568.

Behr, S.K. \& Murphy, D.L. (1993). The role of perceptions in cognitive adaptation to disability. In A.P. Turnbull, D.L. Murphy, J.M. Patterson, J.G. Marquis, S.K. Behr \& M.J. Blue-Banning, Cognitive coping, families, and disability (pp.151164). Baltimore, MD:Paul H. Brookes Publishing Co.

Bennett, C.C., Anderson, L.S., Cooper, S., Hassol, L., Klein, D.C., \& Rosenblum, G. (1966). Community psychology: A report of the Boston conference on the education of psychologists for community mental health. Boston: Boston University Press.

Bennett, T., Deluca, D., \& Allen, R. (1995). Religion and children with disabilities. Journal of Religion and Health, 34(4), 301-312.

Bergin, A.E. (1983). Religiosity and mental health: A critical reevaluation and metaanalysis. Professional Psychology: Research and Practice, 14(2), 170-184. 
Bersani, H. (1996). Leadership in developmental disabilities: Where we've been, where we are, and where we're going. In G. Dybwad \& H. Bersani (Eds.), New voices: Self-advocacy by people with disabilities (pp. 258-269). Cambridge, MA: Brookline Books.

Batancourt, J.R., Green, A.R., Carrillo, J.E., \& Ananeh-Firempong, O. (2003). Defining cultural competence: A practical framework for addressing racial/ethnic disparities in heath and health care. Public Health Reports, 118, 293-302.

Bethlehem Baptist Church (2013). Disability ministry. Retrieved from http://www.hopeingod.org/ministries/family/disability-ministry

Black, K. (1996). A healing homiletic: Preaching and disability. Nashville, TN: Abingdon Press.

Blair, W.A. \& Blair, D.D. (1994). Ministry to persons with disabilities: Can we do better? Journal of Religion in Disability and Rehabilitation, 1, 1-9.

Blair, W.A. \& Davidson, D. (1993). To the glory of God: Hesed, hospitality and disabilities. In L.H. Merrick (Ed.), And show steadfast love: A theological look at grace, hospitality, disabilities, and the church (45-65). Louisville, KY: Presbyterian Church.

Blanks, A.B. \& Smith, J.D. (2009). Multiculturalism, religion, and disability: Implications for special education practitioners. Education and Training in Developmental Disabilities, 44(3), 295-303.

Block, P. (2002). Sexuality, parenthood, and cognitive disability in Brazil. Sexuality and Disability, 20(1), 7-28. 
Bolduc, K.D. (2001). A place called acceptance: Ministry with families of children with disabilities. Louisville, KY: Bridge Resources.

Bond, M. (1999). Gender, race, and class in organizational contexts. American Journal of Community Psychology, 27(3), 327-356.

Bond, M.A. (1995). Prevention and the ecology of sexual harassment: Creating empowering climates. Prevention in Human Services, 12(2), 147-173.

Bond, M.A. \& Keys, C.B. (1993). Empowerment, diversity, and collaboration: Promoting synergy on community boards. American Journal of Community Psychology, 21, 37-58.

Bordieri, J. \& Dremer, D. (1986). Hiring decisions for disabled workers: Looking at the cause. Journal of Applied Social Psychology, 16, 197-208.

Borg, M.B. (2006). Engaging diversity's underbelly: A story from an immigrant parish community. American Journal of Community Psychology, 37(3/4), 191-201.

Bowker, L.H. (1988). Religious victims and their religious leaders: Services delivered to one thousand battered women by the clergy. In A.L. Horton \& J.A. Williamson (Eds.), Abuse and religion: When praying isn't enough (pp. 229-234). Lexington, KY: Lexington Books.

Boyce, G., Behl, D., Mortensen, L. \& Akers, J. (1991). Child characteristics, family demographics and family processes: Their effects on the stress experienced by families of children with disabilities. Counseling Psychology Quarterly, 4, 273288. 
Boyd, N.M. \& Angelique, H. (2002). Rekindling the discourse: Organization studies in community psychology. Journal of Community Psychology, 30(4), 325-348.

Bray, A. \& Gates, S. (2003). Community participation for adults with intellectual disability. Retrieved from http://www.nhc.govt.nz

Breeding, M., Kennamer, D. \& Whitworth, J.E. (2006). Let all children come to me: A practical guide including children with disabilities in your church ministries. Colorado Springs, CO: Cook Communications Ministries.

Brodsky, A.E. (2000). The role of religion in the lives of resilient urban, African American, single mothers. Journal of Community Psychology, 28(2), 199-219.

Brown, L. (2013). Identity first language. Retrieved from http://autisticadvocacy.org/identity-first-language/

Brown, M.E. \& Gioia, D.A. (2002). Making things click: Distributive leadership in an online division of an offline organization. Leadership Quarterly, 13(4), 397-420.

Bryman, A. (2004). Qualitative research on leadership: A critical but appreciative review. Leadership Quarterly, 15, 729-769.

Burden, P.R. \& Parish, T.S. (1983). Exceptional and normal children's descriptions of themselves. Education, 104, 204-205.

Burns, J.M. (1978). Leadership. New York, NY: Harper and Row.

Burns, J.Z. \& Otte, F.L. (1999). Implications of leader-member exchange theory and research for human resource development research. Human Resource Development Quarterly, 10, 225-247. 
Butler, D.C., Hayley, P.P., Ege, M.A., \& Allen, R.S. (2011). Religious leaders' perceptions regarding benefits of and barriers to organized religious support in providing care to older adults with chronic illness. Clinical Gerontologist, 34, $237-250$.

Byrne, B. (2013) Hidden contradictions and conditionality: Conceptualization of inclusive education in international human rights law. Disability \& Society, $28(2), 232-244$.

Byrne, D. (1971). The attraction paradigm. New York, NY: Academic Press.

Byzek, J. (2000). Jesus and the paralytic, the blind and the lame: A sermon. Retrieved from http://www.ragged-edge-mag.com/1100/1100cft1.htm

Cahill, S. \& Eggleston, R. (1994). Managing emotions in public: The case of wheelchair users. Social Psychology Quarterly, 57, 300-312.

Campbell, J., Gillmore, L., \& Cuskelly, M. (2003). Changing student teachers' attitudes towards disability and inclusion. Journal of Intellectual \& Developmental Disability, 28(4), 379-379.

Carey, A.C. (2009). On the margins of citizenship: Intellectual disability and civil rights in twentieth-century America. Philadelphia, PA: Temple University Press.

Carter, E.W. (2007). Including people with disabilities in faith communities: A guide for service providers, families, and congregations. Baltimore: MD: Paul H. Brookes.

Carter, E.W. (2013). Supporting inclusion and flourishing in the religious and spiritual lives of people with intellectual and developmental disabilities. Inclusion, 1(1), $64-75$. 
Cegelka, P.T. \& Prehm, H.J. (1982). Mental retardation: From categories to people. Columbus, OH: Merrill.

Center for Community Inclusion and Disability Studies (n.d.). Community engagement: Projects and initiatives - National Collaborative on disability, religion, and inclusive spiritual supports. Retrieved from http://ccids.umaine.edu/researchprojects/collaborative/

Centers for Disease Control and Prevention (2012). Official MADDSP and MADDS surveillance case definitions. Retrieved from http://www.cdc.gov/ncbddd/developmentaldisabilities/MADDSP.html

Central Pacific Conference of the United Church of Christ (2010). Ministry Teams. Retrieved from http://cpcucc.org/ministry_teams.html

Central Intelligence Agency (CIA) World Factbook (2008). Religions. Retrieved from https://www.cia.gov/library/publications/the-world-factbook/fields/2122.html

Charmaz, K. (2003). Grounded theory: Objectivist and constructivist methods. In N.K. Denzin \& Y.S. Lincoln (Eds.), Strategies for qualitative inquiry (pp. 249-291). Thousand Oaks, CA: Sage.

Charmaz, K. (2011). A constructivist grounded theory analysis of losing and regaining a valued self. In K. Charmaz, L.M. McMullen, R. Josselson, R. Anderson, \& E. McSpadden (Eds.), Five ways of doing qualitative analysis: Phenomenological psychology, grounded theory, discourse analysis, narrative research, and intuitive inquiry (pp. 165-203). New York, NY: Guilford Press. 
Chavis, D.M. \& Wandersman, A. (1990). Sense of community in the urban environment: A catalyst for participation and community development. American Journal of Community Psychology, 18, 55-81.

Chen, R.K., Brodwin, M.G., Cardoso, E. \& Chan, F. (2002). Attitudes toward people with disabilities in the social context of dating and marriage: A comparison of American, Taiwanese, and Singaporean college students. Journal of Rehabilitation, 68(4), 5-11.

Christensen, S. \& Weil, M. (2007). From invisibility to visibility in: Community program ignited change in awareness and attitudes toward Jews with disabilities. Journal of Jewish Communal Service, 82(1/2), 105-112.

Chubon, R.A. (1982). An analysis of research dealing with the attitudes of professionals toward disability. Journal of Rehabilitation, 48(1), 25-30.

Cieurzo, C. \& Keitel, M.A. (1999). Ethics in qualitative research. In M. Kopala \& L.A. Suzuki (Eds.). Using qualitative methods in psychology, pp.63-75. Thousand Oaks, CA: Sage.

Code of Cannon Law (n.d.). Parishes, pastors, and parochial vicars. Retrieved from http://www.vatican.va/archive/ENG1104/_P1U.HTM

Cohall, K.G. \& Cooper, B.S. (2010). Educating American Baptist pastors: A national survey of church leaders. Journal of Research on Christian Eduacation, 19(1), 27-55. 
Collins, B.C. \& Ault, M.J. (2010). Including persons with disabilities in the religious community: Program models implemented by two churches. Journal of Religion, Disability, \& Health, 14, 113-131.

Conway, K. (1986). Coping with the stress of medical problems among Black and White elderly. International Journal of Aging and Human Development, 21, 39-48.

Cooley, C.A. (1956). Human nature and the social order. New York, NY: Free Press.

Cooney, G. Jahoda, A., Gumley, A., \& Knott, F. (2006). Young people with intellectual disabilities attending mainstream and segregated schooling: Perceived stigma, social comparison and future aspirations. Journal of Intellectual Disability Research, 50, 432-444.

Corbin, J. \& Strauss, A. (1990). Grounded theory research: Procedures, canons, and evaluative criteria. Zeitschrift fur Soziologic, 19(6), 418-427.

Corrigan, P., Markowitz, F.E., Watson, A., Rowan, D., \& Kubiak, M.A. (2003). An attribution model of public discrimination towards persons with mental illness. Journal of Health and Social Behavior, 44(2), 162-179.

Corrigan, P.W. (2002). Empowerment and serious mental illness: Treatment parternships and community opportunities. Psychiatry Quarterly, 73(3), 217-228.

Corrigan, P.W. \& Watson, A.C. (2002). The paradox of self-stigma and mental illness. American Psychological Association, 9(1), 35-53.

Corrigan, P.W., River, L.P., Lundin, R.K., Penn, D.L., Uphoff-Wasowski, K., Campion, J., Mathisen, J., Gagnon, C., Bergman, M., Goldstein, H. \& Kubiak, M. (2001). 
Three strategies for changing attributions about severe mental illness.

Schizophrenia Bulletin, 27(2), 187-195.

Coulthard, P. \& Fitzgerald, M. (1999). In God we trust? Organized religion and personal beliefs as resources and coping strategies, and their implications for health in parents with a child on the autism spectrum. Mental Health, Religion, and Culture, 2(1), 19-33.

Covey, H.C. (2005). Western Christianity's two historical treatments of people with disabilities or mental illness. Social Science Journal, 42(1), 107-114.

Creamer, D. (2009). Disability and Christian theology embodied limits and constructive possibilities. New York, NY: Oxford University Press, Inc.

Creswell, J. (1998). Qualitative inquiry and research design: Choosing among five traditions. Thousand Oaks, CA: Sage.

Crocker, J. \& Quinn, D.M. (2000). Social stigma and the self meaning, situations and self esteem. In Social Psychology and Stigma (eds. T.F. Heatherton, R.E. Klede, R.M. Hebl, \& J.G. Hull). Guildford Press, New York, NY.

Crocker, J. \& Major, B. (1989). Social stigma and self-esteem: The self-protective properties of stigma. Psychological Review, 96, 608-630.

Crocker, J., Major, B., \& Steele, C. (1998). Social stigma. In D.T. Gilbert, Fiske, S.T., \& Lindzey, G. (Eds.) The handbook of social psychology (4 ${ }^{\text {th }}$ ed.), (pp.504-553). New York, NY: McGraw Hill. 
Cummins, R.A. \& Lau, A.L. (2003). Community integration or community exposure? A review and discussion in relation to people with an intellectual disability. Journal of Applied Research in Intellectual Disabilities, 16, 145-157.

Cuskelly, M. \& Gilmore, L. (2007). Attitudes to sexuality questionnaire (Individuals with an intellectual disability): Scale development and community norms. Journal of Intellectual and Developmental Disability, 32(3), 214-221.

Cutcliffe, J.R. (2000). Methodological issues in grounded theory. Journal of Advanced Nursing, 31(6), 1476-1484.

Dasborough, M.T. \& Ashkanasy, N.M. (2002). Emotion and attribution of intentionality in leader-member relationships. Leadership Quarterly, 13, 615-634.

Davis, C.G., Nolen-Hoeksema, S., \& Larson, J. (1998). Making sense of loss and benefiting from the experience: Two construals of meaning. Journal of Personality and Social Psychology, 75, 561-574.

Dedoose, Version 4.5.95, web application for managing analyzing, and presenting qualitative and mixed method data (2013) Los Angles, CA: SocioCultural Research Consultants, LLC.

Delisa, J., Silverstein, R. \& Thomas, P. (2011). More implications of the 2008 amendments to the Americans with Disabilities Act: Influencing institutional policies, practices, and procedures. Academic Medicine, 86(6), 677-679.

Denzin, N.K. \& Lincoln, Y.S. (2005). The sage handbook of qualitative research. Thousand Oaks, CA: Sage. 
Dienesch, R.M. \& Linden, R.C. (1986). Leader-member exchange model of leadership: A critique and further development. Academy of Management Review, 11, 618634.

Diocese of Oregon (2011). Commissions \& Ministries Index. Retrieved from http://www.episcopaldioceseoregon.org/node/18

Dragoni, L. (2005). Understanding the emergence of state goal-orientation in organizational work groups: The role of leadership and multilevel climate perceptions. Journal of Applied Psychology, 90, 1084-1095.

Dudley, C.S. \& Roozen, D.A. (2001). Faith communities today: A report on religion in the United State today. Retrieved from: http://faithcommunitiestoday.org/sites/all/themes/factzen4/files/Final\%20FACTr pt.pdf

Dull, V.T. \& Skokan, L.A. (1995). A cognitive model of religion's influence on health. Journal of Social Issues, 51, 49-64.

Duncan, J.B. \& Stocks, M.H. (2003). The understanding of internal control principles by pastors. Nonprofit Management \& Leadership, 14(2), 213-225.

Dvir, T., Eden, D., Avoilio, B.J., \& Shamir, B. (2002). Impact of transformational leadership on follower development and performance: A field experiment. The Academy of Management Journal, 45(4), 735-744.

Dyck, B. (1994). From airy-fairy tales to concrete realities: The case of shared framing. Leadership Quarterly, 5, 227-246. 
Dykens, E.M. (1999). Personality-motivation: New ties to psychopathology, etiology and intervention. In E. Zigler \& D. Bennett-Gates (Eds.) Personality Development in Individuals with Mental Retardation. Cambridge: Cambridge University Press.

Eagly, A.H. \& Chaiken, S. (1993). The psychology of attitudes. Fort Worth, TX: Hartcourt Brace Jovanovich College Publishers.

Eagly, A.H., Johannesen-Schmidt, M.C. \& van Engen, M.L. (2003). Transformational, transactional, and laissez-faire leadership styles: A meta-analysis comparing women and men. Psychological Bulletin, 129(4), 569-591.

Eichhorn, L. (1999). Major litigation activities regarding major life activities: The failure of the "disability" definition in the Americans with Disabilities Act of 1990. North Carolina Law Review, 77(4), 1405.

Eiesland, N.L. (1994). The disabled God: Toward a liberatory theology of disability. Nashville, TN: Abingdon Press.

Eiseland, N.L. \& Saliers, D.E. (1998). Human disability and the service of God: Reassessing religious practice. Nashville, TN: Abingdon Press.

Emmons, R.A. (1999). The psychology of ultimate concerns. New York, NY: Guilford Press.

Emmons, R.A. (2005). Striving for the sacred: Personal goals, life meaning and religion. Journal of Social Issues, 61(4), 731-745. 
Epitropaki, O. \& Martin, R. (1999). The impact of relational demography on the quality of leader-member exchanges and employee' work attitudes and well-being. Journal of Occupational and Organizational Psychology, 72, 237-240.

Exline, J.J. \& Rose, E. (2005). Religious and spiritual struggles. In R.F. Paloutzian \& C.L. Park (Eds) Handbook of the Psychology of Religion and Spirituality (pp. 315-330). New York, NY: Guilford Press.

Farrell, P. (2010). School psychology: Learning lessons from history and moving forward. School Psychology International, 31(6), 581-598.

Fawcett, S.R., White, G.W., Balcazar, F.E. \& Suarez-Balcazar, Y. (1994). A contextualbehavioral model of empowerment: Case studies involving people with physical disabilities. American Journal of Community Psychology, 22(4), 471-496.

Ferguson, B., McDonnell, J. \& Drew, C. (1993). Type and frequency of social interactions among workers with and without mental retardation. American Journal on Mental Retardation, 97, 530-540.

Festinger, L. (1957). A theory of cognitive dissonance. Stanford, CA: Stanford University Press.

Fine, M. \& Asch, A. (1988). Disability beyond stigma: Social interaction, discrimination, and activism. Journal of Social Issues, 44, 3-21.

Flannery, B.L. \& May, D.R. (1994). Prominent factors influencing environmental activities: Applications of the environmental leadership model (ELM). Leadership Quarterly, 5, 201-221. 
Floyd, F.J. \& Zmich, D.E. (1991). Marriage and the parenting partnership: Perceptions and interaction of parents with mentally retarded and typically developing children. Child Development, 62, 1434-1448.

Ford, A., Pugash, M.A., \& Otis-Wilborn, A. (2001). Preparing general educators to work well with students who have disabilities: What's reasonable at the preservice level? Learning Disability Quarterly, 24(4), 275-285.

Foreman, P. (2005). Language and disability. Journal of Intellectual \& Developmental Disability, 30(1), 57-59.

Forlin, C., Tait, K., Carroll, A., \& Jobling, A., (1999). Teacher education for diversity. Queensland Journal of Educational Research, 15(2), 207-225.

Foster-Fishman, P.G. \& Keys, C.B. (1997). The person/environment dynamics of employee empowerment: An organizational culture analysis. American Journal of Community Psychology, 25(3), 345-369.

Franklin, K., Yoon, D., Acuff, M., \& Johnstone, B. (2008). Relationships among religiousness, spirituality, and health for individuals with spinal cord injury. Top Spinal Cord Injury Rehabilitation, 14(2), 76-81.

Freedman, B.H., Kalb, L.G., Zablotsky, B. \& Stuart, E.A. (2012). Relationship status among parents of children with autism spectrum disorders: A population-based study. Journal of Autism and Developmental Disorders, 42, 539-548.

Friedman, S.B., Chodoff, P., Mason, J.W. \& Hamburg, D.A. (1963). Behavioral observations on parents anticipating the death of a child. Pediatrics, 32, 610-625. 
Furnham, A. \& Brown, L.B. (1992). Theodicy: A neglected aspect of the psychology of religion. The International Journal for the Psychology of Religion, 2, 37-45.

Gaventa, B. (2001/2). You are not alone! Resources for inclusive ministries and spiritual supports. Impact, 14(3), 8-9.

Gaventa, W. (2002). Dimensions of faith and congregational ministries with persons with developmental disabilities and their families. New Brunswick, NJ: The Boggs Center-UAP.

Gaventa, W. (2005). A place for all of me and all of us: Rekindling the spirit in services and supports. Mental Retardation, 43(1), 48-54.

Gaventa, W. \& Carter, E.W. (2012). Spirituality: From rights to relationships. TASH Connections, 38(1) 5-6.

Gent, P.J. \& Gurecka, L.E. (2001). Service learning: A disservice to people with disabilities? Michigan Journal of Community Service Learning, 8(1), 36-43.

George, L.K., Larson, D.B., Koenig, H.G., \& McCullough, M.E. (2000). Spirituality and health: What we know, what we need to know. Journal of Social and Clinical Psychology, 19(1), 102-116.

Gibbons, F.X. (1985). The social psychology of mental retardation: What's in a label? In S.S. Brehm, S.M. Kassin, \& F.X. Gibbons (Eds.), Development and social psychology (pp. 249-270). New York, NY: Oxford University Press.

Gilbert, K.R. (1989). Interactive grief and coping in the marital dyad. Death Studies, $13(6), 605-626$. 
Gill, J. \& Liamputtong, P. (2011). Being the mother of a child with Asperger's Syndrome: Women's experiences of stigma. Health Care for Women International, 32, 708-722.

Gillespie, N.A. \& Mann, L. (2004). Transformational leadership and shared values: The building blocks of trust. Journal of Managerial Psychology, 19(6), 588-607.

Glaser, B.G. (1998). Doing grounded theory. Mill Valley, CA: Sociology Press.

Glaser, B. \& Strauss, A. (2010). The discovery of grounded theory: Strategies for qualitative research. Piscataway, CA: Aldine Transaction.

Gleeson, T. (2002). Incorporating spiritual supports into residential services. Impact, 14(3), 30-31.

Gliner, J.A., Haber, E. \& Weise, J. (1999). Use of controlled vignettes in evaluation: Does type of response method make a difference? Evaluation and Program Planning, 22, 313-322.

Glover, N.M \& Blankenship, C.J. (2007). Mexican and Mexican Americans' beliefs about God in relation to disability. Journal of Rehabilitation, 73(4), 41-50.

Goffman, E. (1963). Stigma: Notes on the management of spoiled identity. Englewood Cliffs, NJ: Prentice Hall.

Goodley, D. (1999). Disability research and the "research template": Reflections on grounded subjectivity in ethnographic research. Qualitative Inquiry, 5(1), 24-46.

Gordon, P.A., Feldman, D., Tantillo, J.C., \& Perrone, K. (2004). Attitudes regarding interpersonal relationships with persons with mental illness and mental retardation. Journal of Rehabilitation, 70(1), 50-56. 
PERSPECTIVES OF RELIGIOUS LEADERS

Grand, S.A., Bernier, J.E., \& Strohmer, D.C. (1982). Attitudes toward disabled persons as a function of social context and specific disability. Rehabilitation Psychology, 27(3), 165-174.

Granello, D.H. \& Wheaton, J.E. (2001). Attitudes toward persons with physical disabilities and mental illness. Journal of Applied Rehabilitation Counseling, $32(3), 9-16$.

Green, S.E. (2003). "What do you mean 'what's wrong with her?"”: Stigma and the lives of families of children with disabilities. Social Science \& Medicine, 57, 13611374.

Greenberg, M.A. (1995). Cognitive processing of traumas: The role of intrusive thoughts and reappraisals. Journal of Applied Social Psychology, 25, 1262-1296.

Greig, T.C. \& Bell, M.D. (2000). Work to reduce stigma. American Psychologist, 55(9), 1068-1069.

Griffin, C. (1996). 'See whose face it wears': Difference, otherness and power. Feminism \& Psychology, 6(2), 185-191.

Griffin, M.M., Kane, L.W., Taylor, C., Francis, S.H., \& Hodapp, R.M. (2012). Characteristics of inclusive faith communities: A preliminary survey of inclusive practices in the United States. Journal of Applied Research in Intellectual Disabilities, 25, 383-391.

Griffith, G.M., Totsika, V., Nash, S., Jones, R.S.P., Hastings, R.P. (2012). "We are all there silently coping." The hidden experiences of parents of adults with 
PERSPECTIVES OF RELIGIOUS LEADERS

Aspergers syndrome. Journal of Intellectual \& Developmental Disability, 37(3), $237-247$.

Grojean, M.W., Resick, C.J., Dickson, M.W. \& Smith, D.B. (2004). Leaders, values, and organizational climate: Examining leadership strategies for establishing an organizational climate regarding ethics. Journal of Business Ethics, 55(3), 223241.

Groomes, D.A.G. \& Leahy, M.J. (2002). The relationships among the stress appraisal process, coping disposition, and level of acceptance of disability. Rehabilitation Counseling Bulletin, 46(1), 15-24.

Grossoehme, D.H., Ragsdale, J., Cotton, S., \& Seid, M. (2010). We can handle this: Parents' use of religion in the first year following their child's diagnosis with cystic fibrosis. Journal of Health Care Chaplaincy, 16, 95-108.

Groves, R.M., Fowler, F.J., Couper, M.P., Lepkowski, J.M., Singer, E., \& Tourangeau, R. (2009). Survey methodology. Hoboken, NJ: John Wiley \& Sons.

Gruber, J. \& Trickett, E.J. (1987). Can we empower others? The paradox of empowerment in the governing of an alternative public school. American Journal of Community Psychology, 15(3), 353-371.

Guest, G., Bunce, A., \& Johnson, L. (2006). How many interviews are enough? An experiment with data saturation and variability. Field Methods, 18(1), 59-82.

Hall, H. \& Minnes, P. (1999). Attitudes toward persons with Down syndrome: The impact of television. Journal of Development and Physical Disabilities, 11, 6176. 
PERSPECTIVES OF RELIGIOUS LEADERS

Hallberg, L.R.-M. (2010). Some thoughts about the literature review in grounded theory studies. International Journal of Qualitative Studies on Health and Well-being, 5, 1.

Hamilton, D.L. \& Sherman, J.W. (1994). Stereotypes. In R.S. Wyer \& T.K. Srull (Eds.), Handbook of social cognition, Vol 1: Basic processes (2 $2^{\text {nd }}$ ed., pp. 1-68). Hillsdale, NJ: Erlbaum.

Harlan-Simmons, J.E., Holtz, P., Todd, J. \& Mooney, M.F. (2001). Building social relationships through valued roles: Three old adults and the community membership project. Mental Retardation, 39(3), 171-180.

Hastings, R.P., Hewes, A., Lock, S., \& Witting, A. (1996). Do special educational needs courses have any time on student teachers' perceptions of children with severe learning difficulties? British Journal of Special Education, 23(3), 139-144.

Heller, T., Miller, A.B., \& Factor, A. (1999). Autonomy in residential facilities and community functioning of adults with mental retardation. Mental Retardation, $37(6), 449-57$.

Henry, D. Keys, C., Jopp, D., \& Balcazar, F. (1996). The community living attitudes sale, mental retardation form: Development and psychometric properties. Mental Retardation, 34(3), 149-158.

Hill, J. (2000). A rationale for the integration of spirituality into community psychology. Journal of Community Psychology, 28(2), 139-149. 
Hill, P.C. \& Pargament, K.I. (2003). Advances in the conceptualization and measurement of religion and spirituality: Implications for physical and mental health research. American Psychologist, 58(1), 64-74.

Hollister, R.M. (1993). Developing a research agenda for nonprofit management. In D.R. Young, R.M. Hollister, \& V.A. Hodkinson (Eds.). Governing leading and managing nonprofit organizations: New insights from research and practices. San Francisco, CA: Jossey-Bass.

Horner-Johnson, W., Keys, C., Henry, D., Yamaki, K., Oi, F., Watanabe, K., Shimada, H., \& Fugjimura, I. (2002). Attitudes of Japanese students toward people with intellectual disability. Journal of Intellectual Disability Research, 46(5), 365378.

Hughey, J., Speer, P.W., \& Peterson, A. (1999). Sense of community in community organizations: Structure and evidence of validity. Journal of Community Psychology, 27(1), 97-113.

Hummer, R.A., Rogers, R.G., Nam, C.B. \& Ellison, C.G. (1999). Religious involvement and U.S. adult mortality. Demography, 36, 273-285.

Humphrey, J.C. (2000). Cracks in the feminist mirror? Feminist Review, 66(1), 95-130.

Hunt, B. \& Hunt, C.S. (2000). Attitudes toward people with disabilities: A comparison of undergraduate rehabilitation and business majors. Rehabilitation Education, $14(3), 269-283$. 
PERSPECTIVES OF RELIGIOUS LEADERS

Hunt, C.S. \& Hunt, B. (2004). Changing attitudes toward people with intellectual disabilities: Experimenting with an educational intervention. Journal of Managerial Issues, 16, 226-280.

Hunt, J.G. (1999). Transformational/charismatic leadership's transformation of the field: An historical essay. Leadership Quarterly, 10, 129-144.

Irvine, A. \& Lupart, J. (2006). Social supports in inclusive settings: An essential component to community living. Developmental Disabilities Bulletin, 34(1/2), $107-126$.

Jackson, S.E. \& Ruderman, M.N. (1995). Diversity in work teams: Research paradigms for a changing workplace. Washington, DC: American Psychological Association.

Jacober, A. (2007). Ostensibly welcome: Exploratory research on the youth ministry experiences of families of teenagers with disabilities. Journal of Youth Ministry, $6(1), 67-92$.

Jahoda, A. \& Markova, I. (2004). Coping with social stigma: People with intellectual disabilities moving from institutions and family home. Journal of Intellectual Disability Research, 48, 719-729.

Janoff-Bulman, R. (1989). Assumptive worlds and the stress of traumatic events: Applications of the schema construct. Social Cognition, 7, 113-136.

Janoff-Bulman, R. \& Frantz, C.M. (1997). The impact of trauma on meaning: From meaningless world to meaningful life. In M.Power \& C.R. Brewin (Eds.), The 
PERSPECTIVES OF RELIGIOUS LEADERS

transformation of meaning in psychological therapies (pp.91-106). New York, NY: Wiley.

Johnstone, B., Glass, B.A., \& Oliver, R.E. (2007). Religion and disability: Clinical, research and training considerations for rehabilitation professionals. Disability and Rehabilitation, 29(15), 1153-1163.

Jones, L.K., Binger, T.E., McKenzie, C.R., Ramcharan, P. \& Nankervis, K. (2010). Sexuality, pregnancy, and midwifery care for women with intellectual disabilities: A pilot study on attitudes of university students. Contemporary Nurse, 35(1), 47-57.

Jones, R.L., Gottfried, N.W., \& Owens, A. (1966). The social distance of the exceptional: A study at the higher level. Exceptional Children, 32, 551-556.

Judge, T.A. \& Piccolo, R.F. (2004). Transformational and transactional leadership: A meta-analytic test of their relative validity. Journal of Applied Psychology, 89, $755-768$.

Karnilowics, W., Sparrow, W.A., \& Shinkfield, A.J. (1994). High school students' attitudes toward performing social behaviors with mentally retarded and physically disabled peers. Journal of Social Behavior and Personality, 9(5), $65-$ 80.

Karoly, P. (1999). A goal systems self-regulatory perspective on personality, psychopathology, and change. Review of General Psychology, 3, 264-291. 
Kearney, E. \& Gerbert, D. (2009). Managing diversity and enhancing team outcomes: The promise of transformational leadership. Journal of Applied Psychology, 94(1), 77-89.

Kelly (1971) Qualities for the community psychologist. American Psychologist, 26, 897903.

Kelly, J.G., Azelton, S., Burzette, R., \& Mock, L. (1994). Creating social settings for diversity: An ecological thesis. In T. Trickett, D. Birman, \& R. Watts (Eds.). Human diversity: Perspectives on people in context (pp. 424-451). San Francisco, CA: Jossey-Bass.

Kempton, W. \& Kahn, E. (1991). Sexuality and people with intellectual disabilities: A historical perspective. Sexuality and Disability, 9(2), 93-111.

Kersh, J. Hedvat, T.T., Hauder-Cram, P. \& Warfield, M.E. (2006). The contribution of marital quality to the well-being of parents of children with developmental disabilities. Journal of Intellectual Disability Research, 50, 883-893.

Keys, C.B. \& Frank, S. (1987) Community psychology and the study of organizations: A reciprocal relationship. American Journal of Community Psychology, 15, 239251.

Kidder, L. (1981). Qualitative research and quasi-experimental frameworks. In B. Brewer \& B. Collins (Eds.), Scientific inquiry and the social sciences (pp. 226256). San Francisco, CA: Jossey-Bass. 
Kiddler, L.H. \& Fine, M. (1997). Qualitative inquiry in psychology: A radical tradition. In D. Fox \& I. Prilleltensky (Eds.), Critical psychology: An introduction (pp. 3450). London: Sage.

Kirkpatrick, S.A. \& Locke, E.A. (1996). Direct and indirect effects of three core charismatic leadership components on performance and attitudes. Journal of Applied Psychology, 81, 36-51.

Klein, K.J. \& Sorra, J.S. (1996). The challenge of innovation implementation. Academy of Management Review, 21(4), 1055-1080.

Kleinert, H., Miracle, S., \& Sheppard-Jones, K. (2007). Including students with moderate and severe intellectual disabilities in school extracurricular and community recreation activities. Intellectual and Developmental Disabilities, 45(1), 46-55.

Kleinert, H.L., Sharrard, D., Vallance, M., Ricketts, E. \& Farley, J. (2010). Teaching seminary students about faith inclusion for individuals with developmental disabilities: The role of family mentorships. Journal of Religion, Disability \& Health, 14, 6-27.

Kleiwer, C. \& Drake, S. (1998). Disability, eugenics, and the current ideology of segregation: A modern moral tale. Disability \& Society, 13(1), 95-111.

Klinger, E. (1998). The search for meaning in evolutionary perspective and its clinical implications. In P.T.P. Wong \& P.S. Fry (Eds.), The human quest for meaning (p. 27-50). Mahwah, NJ: Erlbaum. 
Kloos, B. \& Moore, T. (2000). The prospect and purpose of locating community research and action in religious settings. Journal of Community Psychology, 28(2), 119-137.

Kozlowski, S.W. \& Doherty, M.L. (1989). Integration of climate and leadership: Examination of a neglected issue. Journal of Applied Psychology, 74, 546-553.

Krajewski, J. \& Flaherty, T. (2000). Attitudes of high school students toward individuals with mental retardation. Mental Retardation, 38, 154-162.

Krefting, L. (1991). Rigor in qualitative research: The assessment of trustworthiness. American Journal of Occupational Therapy, 45(3), 214-222.

Kregel, J., Wehman, P., Seyfarth, J. \& Marshall, K. (1986). Community integration of young adults with mental retardation: Transition from school to adulthood. Education and Training of the Mentally Retarded, 21, 35-42.

L'Arche USA (2013). Spirituality. Retrieved from http://www.larcheusa.org/who-weare/spirituality/

LaGrand, L. (1985). College student loss and response. New Directions for Student Services, 31, 15-28.

Lance, L.M. (1992). Changes in homophobic views as related to interaction with gay persons: A study in the reduction of tensions. International Journal of Group Tensions, 22, 291-299.

LaRocque, M. \& Eigenbrood, R. (2005). Community access: A survey of congregational accessibility for people with disabilities. Journal of Religion, Disability and Health, 9, 55-66. 
Larson, E. (1998). Reframing the meaning of disability to families: The embrace of paradox. Social Science \& Medicine, 47(7), 865-875.

Lazarus, R.S. (1993). Coping theory and research: Past, present, and future. Psychosomatic Medicine, 55, 234-237.

Lazarus, R.S. \& Folkman, S. (1984). Stress, appraisal, and coping. New York, NY: Springer.

Lehrer, E.L. \& Chriswick, C.U. (1993). Religion as a determinant of marital stability. Demography, 30, 385-404.

Levin, J.S. (1994). Religion and health: Is there an association, is it valid, and is it causal? Social Science and Medicine, 38, 1475-1482.

Lightfoot, M., Rotheram-Borus, Towns, B., Cline, T.R., Webber, D., Murphy, D.A., \& Tsai, L.F. (2001). Religious groups as diffusers of HIV antibody testing and prevention messages. Journal of Community Psychology, 29(4), 459-472.

Lincoln, Y.S. \& Guba, E.G. (1985). Naturalistic inquiry. Beverly Hills, CA: Sage.

Linden, R.C., Wayne, S.J., \& Stilwell, D. (1993). A longitudinal study on the early development of leader-member exchange. Journal of Applied Psychology, 78, $662-674$.

Link, B., Cullen, F., Struening, E., Shrout, P., \& Dohrenwend, B. (1989). A modified labeling theory approach to mental disorders. American Sociological Review, 54, 400-423.

Litwin, G.H. \& Stringer, R.A. (1968). Motivation and organizational climate. Boston, MA: Harvard University. 
Llewllyn, A. \& Hogan, K. (2000). The use and abuse of models of disability. Disability \& Society, 15(1), 157-165.

Long, A.B. (2008). Introducing the new and improved Americans with Disabilities Act: Assessing the ADA Amendments Act of 2008. Northwestern University Law Review, 103, 217-229.

Lowe, K.B. \& Gardner, W.L. (2000). Ten years of the Leadership Quarterly: Contributions and challenges for the future. Leadership Quarterly, 11, 459-514.

Lowe, K.B., Kroeck, K.G., \& Sivasubramaniam, N. (1996). Effectiveness correlates of transformational and transactional leadership: A meta-analytic review of the MLQ literature. Leadership Quarterly, 7, 385-425.

Luckasson, R. \& Reeve, A. (2001). Naming, defining, and classifying in mental retardation. Mental Retardation, 39(1), 47-52.

Lutfiyya, Z.M. (1991). "A feeling of being connected": Friendships between people with and without learning difficulties. Disability, Handicap, \& Society, 6, 233-245.

Lyons, M. \& Hayes, R. (1993). Student perceptions of persons with psychiatric and other disorders. American Journal of Occupational Therapy, 47, 541-548.

Mackelprang, R.W. \& Salsgiver, R.O. (1999). Disability: A diversity model approach in human service practice. Pacific Grove, CA: Brooks Cole Publishing.

MacLean, D. \& Gannon, P.M. (1995). Measuring attitudes toward disability: The interaction with disabled persons scale revisited. Journal of Social Behavior and Personality, 10, 791-806. 
PERSPECTIVES OF RELIGIOUS LEADERS

MacMillan, D.L. (1982). Mental retardation in school and society. Boston, MA: Little Brown and Co.

Mahoney, A. \& Tarakeshwar, N. (2005) In R.F. Paloutzian \& C.L. Park (Eds) Handbook of the Psychology of Religion and Spirituality (pp. 177-197). New York, NY: Guilford Press.

Makas, E. (1993). Getting in touch: The relationship between contact and attitudes toward people with disabilities. In M.C. Nagler (Ed.), Perspectives on disability, ( $2^{\text {nd }}$ ed.), (pp. 121-136). Palo Alto, CA: Health Markets Research.

Manion, M. L. \& Bersani, H.A. (1987). Mental retardation as a Western sociological construct: A cross-cultural analysis. Disability \& Society, 2(3), 231-245.

Manstead, A.S.R. (1996). Attitudes and behavior. In G.R. Semin \& K. Fledler, Applied social psychology (3-29). London: Sage.

Marinelli, R.P. \& Orto, A.E.D. (1999). The psychological and social impact of disability $\left(4^{\text {th }} e d\right)$. New York, NY: Springer.

Marshall, E.S., Olsen, S.F., Mandleco, B.L., Dyches, T.T., Allred, K.W., \& Sansom, N. (2003). This is a spiritual experience: Perceptions of Latter-Day Saint families living with a child with disabilities. Qualitative Health Research, 13, 57-76.

Masood, A.F., Turner, L.A., \& Baxter, A. (2007). Causal attributions and parental attitudes toward children with disabilities in the United States and Pakistan. Council for Exceptional Children, 73(4), 475-487. 
Mattis, J.S. \& Jagers, R.J. (2001). A relational framework for the study of religiosity and spirituality in the lives of African Americans. Journal of Community Psychology, 29(5), 519-539.

Maton, K.I. (1989). Community settings as buffers of life stress? Highly supportive churches, mutual help groups, and senior centers. American Journal of Community Psychology, 17(2), 203-232.

Maton, K.I. (2008). Empowering community settings: Agents of individual development, community betterment, and positive social change. American Journal of Community Psychology, 41, 4-21.

Maton, K.I. \& Salem, D.A. (1995). Organizational characteristics of empowering community settings: A multiple case study approach. American Journal of Community Psychology, 23(5), 626-631.

Maton, K.I. \& Wells, E.A. (1995). Religion as a community resource for well-being: Prevention, healing, and empowerment pathways. Journal of Social Issues, 51(2), 177-193.

Maton, K.I., Dodgen, D., Domingo, M.R.S., \& Larson, D.B. (2005). Religion as a meaning system: Policy implications for the new millennium. Journal of Social Issues, 61(4), 847-867.

Maton, K.I. \& Salem, D.A. (1995). Organizational characteristics of empowering community settings: A multiple case study approach. American Journal of Community Psychology, 23(5), 631-657. 
PERSPECTIVES OF RELIGIOUS LEADERS

Mattlin, J.A., Wethington, E., \& Kessler, R. (1990). Situational determinants of coping and coping effectiveness. Journal of Health and Social Behavior, 31, 103-122.

Mayer, R.C., Davis, J.H., \& Schoorman, F.D. (1995). An integrative model of organizational trust. Academy of Management Review, 20, 709-734.

Mayhew, J. (1994). Are preservice general educators being adequately prepared for inclusion? In D. Montgomery (Ed.), Rural parternships: Working together. Austin, TX: American Council on Rural Special Education.

Maykut, P. \& Morehouse, R. (1994). Beginning qualitative research: A philosophic and practical guide. London: Falmer Press.

McBride, A. (2001). Gender democracy in trade unions. Aldershot: Ashgate.

McCallin, A. (2006). Grappling with the literature in grounded theory study. The Grounded Theory Review, 15(2/3), 11-28.

McClelland, K. \& Linnander, E. (2006). The role of contact and information in racial attitude change among White college students. Social Inquiry, 76, 81-115.

McCullough, M.E., Hoyt, W.T., Larson, D.B., Koenig, H.G., \& Thoresen, C. (2000). Religious involvement and mortality: A meta-analytic review. Health Psychology, 19, 211-222.

McDonald, K., Keys, C. \& Henry, D. (2008). The gatekeepers of science: Attitudes toward the research participation of adults with intellectual disabilities. The American Journal on Mental Retardation, 113, 466-478.

McIntire, J. (2001/2). Respecting the urge to join. Impact, 14(3), 4-5. 
PERSPECTIVES OF RELIGIOUS LEADERS

McIntosh, D.N. (1995). Religion-as-schema, with implications for the relation between religion and coping. The International Journal for the Psychology of Religion, 5, 1-16.

McManus, J.L., Feyes, K.J. \& Saucier, D.A. (2011). Contact and knowledge as predictors of attitudes toward individuals with intellectual disabilities. Journal of Social and Personal Relationships, 28(5), 579-590.

McMillan, D.W. \& Chavis, D.M. (1986). Sense of community: A definition and theory. Journal of Community Psychology, 14(1), 6-23.

McMurry, A.J., Pirola-Merlo, A., Sarros, J.C., Islam, M.M. (2010). Leadership, climate, psychological capital, commitment, and wellbeing in a non-profit organization. Leadership \& Organization Development Journal, 31(5), 436-457.

McNair, J. (2007). Christian social constructions of disability. Journal of Religion, Disability \& Health, 11(3), 51-64.

McNair, J. \& Smith, H. (2000). Church attendance of adults with developmental disabilities. Education and Training in Mental Retardation and Developmental Disabilities, 35(2), 222-225.

McReynolds, K. \& Bundy, S. (2008). Luke and a theology of suffering and disability.

McVilly, K.R. \& Rawlinson, R.B. (1998). Quality of life issues in the development and valuation of services for people with intellectual disabilities. Journal of Intellectual and Developmental Disability, 25, 19-31.

Mead, G.H. (1934) Mind, self, and society: From the standpoint of asocial behaviorist. Edited by C.W. Morris. Chicago, IL: University of Chicago Press. 
Meekosha, H. \& Dowse, L. (1997). Enabling citizenship: Gender, disability, and citizenship in Australia. Feminist Review, 57, 49-72.

Meglino, B.M., Ravlin, E.C., \& Adkins, C.L. (1989). A work values approach to corporate culture: A field test of the value congruence process and its relationship to individual outcomes. Journal of Applied Psychology, 74, 424-432.

Meglino, B.M., Ravlin, E.C., \& Adkins, C.L. (1991). Value congruence and satisfaction with a leader: An examination of the role of interaction. Human Relations, 44, 481-495.

Menec, V.H. \& Perry, R.P. (1998). Reactions to stigmas among Canadian students: Testing attribution-affect-help judgment model. Journal of Social Psychology, $138,443-453$.

Merriam, S.B. (2009). Qualitative research: A guide to design and implementation. San Francisco, CA: Jossey-Bass.

Merrick, E. (1999). "Like chewing gravel”: On the experience of analyzing qualitative research findings using a feminist epistemology. Psychology of Women Quarterly, 23, 47-57.

Metha, S. \& Farina, A. (1988). Associative stigma: Perceptions of the difficulties of college-aged children of stigmatized fathers. Journal of Social Clinical Psychology, 7, 192-202.

Michael, S.T. \& Snyder, C.R. (2005). Getting unstuck: The roles of hope, finding meaning, and rumination in the adjustment to bereavement among college students. Death Studies, 29(5), 435-458. 
PERSPECTIVES OF RELIGIOUS LEADERS

Michalak, L., Trocki, K., \& Bond, J. (2007). Religion and alcohol in the U.S. national alcohol survey: How important is religion for abstention and drinking? Drug and Alcohol Dependence, 87(2-3), 268-280.

Michie, M. \& Skinner, D. (2010). Narrating disability, narrating religious practice: Reconciliation and fragile X syndrome. Intellectual and Developmental Disabilities, 48(2), 99-11.

Mickelson, K. Wroble, M., \& Helgeson, V.S. (1999). “Why my child?”: Parental attributions for children's special needs. Journal of Applied Social Psychology, 29, 1263-1292.

Mickley, J.R., Pargament, K.I., Brandt, C.R., \& Hipp, K.M. (1998). God and the search for meaning among hospice caregivers. Hospice Journal, 13, 1-18.

Miles, M. (2001). Martin Luther and childhood disability in $16^{\text {th }}$ century Germany: What did he write? What did he say? Journal of Religion, Disability, \& Health, 5(4), 536.

Miles, M. (2002). Some influences of religions on attitudes towards disabilities and people with disabilities. Journal of Religion, Disability, \& Health, 6(2/3), 117 129.

Minkler, M. \& Wallerstein, N. (2008). Community-based participatory research for health: From process to outcome. San Francisco, CA: Jossey-Bass.

Minton, C.A. \& Dodder, R.A. (2003). Participation in religious services by people with developmental disabilities. Mental Retardation, 41(6), 430-439. 
Morgan, D.L. (2013). Integrating qualitative and quantitative methods: A pragmatic approach. Thousand Oaks, CA: Sage.

Morse, J. (1994). Designing funded qualitative research. In N. Denzin \& Y. Lincoln, Handbook for qualitative research. Thousand Oaks, CA: Sage.

Mumford, M.D., Scott, G.M., Gaddis, D. \& Strange, J.M. (2002). Leading creative people: Orchestrating expertise and relationships. Leadership Quarterly, 13, 705750.

National Catholic Partnership on Disability (n.d.). How NCPD serves. Retrieved from http://www.ncpd.org/about/serve http://www.ncpd.org/about/serve

National Council of Churches of Christ (NCCC; 1995). NCCC policy statement on disabilities, the body of Christ, and the wholeness of society. New York: NY: National Council of Churches of Christ Committee on Disabilities.

National Organization on Disability (NOD; 2000). 2000 N.O.D. /Harris survey of community participation. Retrieved from http://nod.org/what_we_do/research/surveys/harris/

National Organization on Disability (NOD, 2004). 2004 National Organization on Disabiliy/Harris survey of Americans with disabilities. Retrieved from http://nod.org/what_we_do/research/surveys/harris/

National Organization on Disability (NOD; 2010). 2010 GAP survey of Americans with disabilities. Retrieved from http://www.2010disabilitysurveys.org/indexold.html 
Nelson, E. (1983). The local church as a resource for persons with mental retardation living in the community: A study of the emerging roles and service patterns. Dissertation Abstract International.

Newbrough, J.R. \& Chavis, D.M. (1986). Psychological sense of community, I:

Foreward. Journal of Community Psychology, 14, 3-5.

Norlin, D. \& Broberg, M. (2013). Parents of children with and without intellectual disability: Couple relationship and individual well-being. Journal of Intellectual Disability Research, 57(6), 552-566.

Nosse, L.J. \& Gavin, K.J. (1991). Influence of direct contact on college students' attitude toward adults with mental handicaps. College Student Journal, 25, 201206.

O’Brien, G. (2001). Defining learning disability: What place does intelligence testing have now? Developmental Medicine \& Child Neurology, 43, 570-573.

Okazaki, S. \& Saw, A. (2011). Culture in Asian American community psychology: Beyond the East-West binary. American Journal of Community Psychology, 47, 144-156.

Oliver, M. (1996). Understanding disability: From theory to practice. Basingstoke: Houndsmills Macmillan.

Olkin, R. (1999). What psychotherapists should know about disability. New York, NY: Guilford Press. 
Oman, D. \& Thoresen, C.E. (2005). Do religion and spirituality influence health? In R.F. Paloutzian \& C.L. Park (Eds.) Handbook of the Psychology of Religion and Spirituality (pp. 435-459). New York, NY: Guilford Press.

Oregon-Idaho Conference of the United Methodist Church (2010). Ministries. Retrieved from http://www.umoi.org/pages/detail/9

Orsmond, G., Krauss, M. \& Seltzer, M. (2004). Peer relationships and social and recreational activities among adolescents and adults with autism. Journal of Autism and Developmental Disabilities, 34, 245-256.

Pace, J.E., Shin, M. \& Rasmussen, S.A. (2010). Understanding attitudes toward people with Down syndrome. American Journal of Medical Genetics, 152A, 2185-2192.

Pakenham, K.I. (2008). Making sense of illness or disability: The nature of sense making in multiple sclerosis (MS). Journal of Health Psychology, 13(1), 93-105.

Pakenham, K.I., Sofronoff, K. \& Samios, C. (2004). Finding meaning in parenting a child with Asperger syndrome: Correlates of sense making and benefit finding. Research in Developmental Disabilities, 25(3), 245-264.

Palmerton, K.E. \& Frumkin, R.M. (1969). Contact with disabled persons and intensity of counselors' attitudes. Perceptual and Motor Skills, 28, 434.

Panek, P.E. \& Jungers, M.K. (2008). Effects of age, gender, and causality on perceptions of persons with mental retardation. Research in Developmental Disabilities, 29, $125-132$.

Panek, P.E. \& Smith, J.L. (2005). Assessment of terms to describe mental retardation. Research in Developmental Disabilities, 26, 565-576. 
Pargament, K.I. (1990). God help me: Toward a theoretical framework of coping for the psychology of religion. Research in the Social Scientific Study of Religion, 2, $195-224$.

Pargament, K.I. (1997). The psychology of religion and coping: Theory, research, practice. New York, NY: Guilford Publications.

Pargament, K.I \& Brant, C. (1998). Religion and coping. In H.G. Koenig (Ed.), Handbook of religion and mental health (pp.112-129). New York, NY: Academic Press.

Pargament, K.I., Koenig, H.G., Tarakeshwar, N. \& Hahn, J. (2001). Religion struggle as a predictor of morality among medically ill elderly patients. Archives, 161, 18811885.

Pargament, K.I. \& Maton, K.I. (2000). Religion in American life: A community psychology perspective. In J. Rappaport \& E. Seidman (Eds.), Handbook of community psychology, (pp. 495-518). New York, NY: Plenum Publishers.

Paris, M.J. (1993). Attitudes of medicine students and health-care professionals toward people with disabilities. Archives of Psychical Medicine and Rehabilitation, $74(8), 818-825$.

Park, C.L. (2005) Religion and meaning. In R.F. Paloutzian \& C.L. Park (Eds) Handbook of the Psychology of Religion and Spirituality (pp. 295-314). New York, NY: Guilford Press.

Park, C.L. \& Cohen, L.H. (1993). Religious and nonreligious coping with the death of a friend. Cognitive Therapy and Research, 17, 561-577. 
Park, C.L. \& Folkman, S. (1997). Meaning in the context of stress and coping. General Review of Psychology, 1, 115-144.

Parkes, C.M. (1996). Bereavement: Studies of grief in adult life ( $3^{\text {rd }}$ ed.). London, England: Routledge.

Parmenter, T.R. (2001). The contribution of science in facilitating the inclusion of people with intellectual disability into the community. Journal of Intellectual Disability Research, 45(3), 183-193.

Parry, K.W. (1994). Grounded theory and social process: A new direction for leadership research. Leadership Quarterly, 9(1), 85-105.

Parry, K.W. (1998). Process: A new direction for leadership research. Leadership Quarterly, 9(1), 85-105.

Paterson, G.W. (1975). Helping your handicapped child. Minneapolis, MN: Augsberg Publishing House.

Patton, M.Q. (2002) Qualitative research \& evaluation methods ( $3^{\text {rd }}$ ed.). Thousand Oaks, CA: Sage Publications.

People First (n.d.). People first. Retrieved from http://peoplefirstltd.com/

Pernice, R. \& Lys, K. (1996). Interventions for attitude change towards people with disabilities: How successful are they? International Journal of Rehabilitation Research, 19, 171-174.

Perry, J. (1996). Writing the self: Exploring the stigma of hearing impairment. Sociological Spectrum, 16, 239-261. 
Pettigrew, T.F. \& Tropp, L.R. (2006). A meta-analytic test of intergroup contact theory. Journal of Personality and Social Psychology, 90, 751-783.

The Pew Forum on Religion \& Public Life (2010). U.S. religious landscape survey. Retrieved from http://www.religions.pewforum.org/reports/

Phelan, J.C., Link, B.G., \& Dovidio, J.F. (2008). Stigma and prejudice: One animal or two? Social Science \& Medicine, 67, 358-367.

Plant, E.A. \& Devine, P.G. (2003). The antecedents and implications of intergroup anxiety. Personality and Social Psychology Bulletin, 29, 790-801.

Pledger, C. (2003). Discourse on disability and rehabilitation issues: Opportunities for psychology. American Psychologist, 58(4), 279-284.

Poland, B.D. (1995). Transcription quality as an aspect of rigor in qualitative research. Qualitative Inquiry, 1(3), 290-310.

Poston, D.J. \& Turnbull, A.P. (2004) Role of spirituality and religion in family quality of life for families of children with disabilities. Education and Training in Developmental Disabilities, 39, 95-108.

Posner v. Central Synagogue N.Y. 93 Civ. 2448 (1993).

Prabhala, A. (2006, November 29). World's oldest organization on intellectual disability has a progressive new name. Retrieved from http://www.msaaidd.org/PR120061129.htm

Preston, J.D. \& Robinson, J.W. (1974). On modification of interracial interaction. American Sociological Review, 39, 283-285. 
Quarter, J. \& Richmond, B.J. (2001). Accounting for social value in nonprofits and forprofits. Nonprofit Management and Leadership, 12, 75-85.

Rappaport, J. (1977). Community psychology: Values, research and action. New York: Holt, Rinehart \& Winston.

Rappaport, J. (1995). Empowering meets narrative: Listening to stories and creating settings. American Journal of Community Psychology, 23(5), 795-807.

Rees, L.M., Spreen, O., \& Harnadek, M. (1991). Do attitudes toward persons with handicaps really shift over time? Comparison between 1975 and 1988. Mental Retardation, 29(2), 81-86.

Reinders, H.S. (2011). Is there meaning in disability? Or is it the wrong question? Journal of Religion, Disability \& Health, 15, 57-71.

Reynolds, T.E. (2008). Vulnerable communion: A theology of disability and hospitality. Ada, MI: Brazos Press.

Reynolds, T.E. (2012). Theology and disability: Changing the conversation. Journal of Religion, Disability, \& Health, 16, 33-48.

Riggle, E.D.B., Ellis, A.L., \& Crawford, A.M. (1996). The impact of "media contact" on attitudes toward gay men. Journal of Homosexuality, 31, 55-69.

Riordan, J. \& Vasa, S.F. (1991). Accommodations for and participation of persons with disabilities in religious practice. Education and Training in Mental Retardation, $24,653-655$.

Rioux, M.H. (1997). Disability: The place of judgment in a world of fact. Journal of Intellectual Disability Research, 41(2), 102-111. 
Rogers-Dulan, J. (1998). Religious connectedness among urban African American families who have a child with disabilities. Mental Retardation, 36, 91-103.

Rogers-Dulan, J. \& Blacer, J. (1995). African American families, religion, and disability: A conceptual framework. Mental Retardation, 33, 226-238.

Rose, A. (1997). Who causes the blind to see: Disability and quality of religious life. Disability \& Society, 12, 395-405.

Rothbaum, F., Weisz, J.R., \& Snyder, S.S. (1982). Changing the world and changing the self: A two-process model of perceived control. Journal of Personality and Social Psychology, 42, 5-37.

Royal, G. \& Roberts, M. (1987). Students' perceptions of and attitudes toward disabilities: A comparison to twenty conditions. Journal of Clinical Child Psychology, 16, 122-132.

Rusch, F.R., Wilson, P.G., Hughes, C. \& Heal, L.W. (1991). Descriptive analysis of interactions between co-workers and supported employees. Mental Retardation, 29(4), 207-212.

Rusch, N., Angermeyer, M.C. \& Corrigan, P.W. (2005). Mental illness stigma: Concepts, consequences, and initiatives to reduce stigma. European Psychiatry, $20,529-539$.

Ryan, R.M. \& Deci, E.L. (2000). Self-determination theory and the facilitation of intrinsic motivation, social development, and wellbeing. American Psychologist, $55,68-78$. 
Ryndak, D.L., Jackson, L. \& Billingsley, F. (2000). Defining school inclusion for students with moderate to severe disabilities: What do experts say? Exceptionality, 8(2), 101-116.

Sarason, S.B. (2001). Concepts of spirituality and community psychology. Journal of Community Psychology, 29(5), 599-604.

Satariano, W.A. (2006). Epidemiology of aging: An ecological approach. Sudbury, MA: Jones and Bartlett Publishers.

Saxby, H., Thomas, M., Felce, D., \& de Kock, U. (1986). The use of shops, café, and public houses by severely and profoundly mentally handicapped adults. British Journal of Mental Subnormality, 32, 69-81.

Scheerenberger, R.C. (1983). A history of mental retardation. Baltimore, MD: P.H. Brookes Publishing Company.

Schein, E. (1985). Organizational culture and leadership. San Francisco, CA: JosseyBass.

Schein, E. (1990). Organizational culture. American Psychologist, 45, 109-119.

Schein, E. (1992). Organizational culture and leadership, $2^{\text {nd }}$ ed. San Francisco, CA: Jossey-Bass.

Schmidt, G. \& Weiner, B. (1988). An attribution-affect-action theory of behavior: Replications of judgments of help-giving. Personality and Social Psychology Bulletin, 14, 610-621.

Schneider, B., Gunnarson, S.K., \& Niles-Jolly, K. (1994). Creating the climate and culture of success. Organizational Dynamics, 23, 17-29. 
Schriesheim, C.A., Neider, L.L., Scandura, T.A. \& Tepper, B.J. (1992). Development and preliminary validation of a new scale (LMX-6) to measure leader-member exchange in organizations. Educational and Psychological Measurement, 52, $135-147$.

Schultz, C.Y. (2012). The church and other body parts: Closing the gap between the church and people with disabilities. Journal of Religion, Disability, \& Health, 16, $191-205$.

Scior, K., Kan, K., McLoughlin, A. \& Sheridan, J. (2010). Public attitudes toward people with intellectual disabilities: A cross-cultural study. Intellectual and Developmental Disabilities, 48(4), 278-289.

Scior, K., Potts, H.W., Furnham, A.F. (2013). Awareness of schizophrenia and intellectual disability and stigma across ethnic groups in the UK. Psychiatry Research, 208(2), 125-130.

Self Advocates Becoming Empowered (SABE, n.d.). People First Language. Retrieved from http://www.sabeusa.org/user_storage/File/sabeusa/People\%2520First\%2520Lang uage\%2520Manual.pdf

Selway, D. \& Ashman, A.F. (1998). Disability, religion and health: A literature review in search of the spiritual dimensions of disability. Disability \& Society, 13(3), 429-439.

Serrano-Garcia, I. (1984). The illusion of empowerment: Community development within a colonial context. Prevention in Human Services, 3, 173-2000. 
Shogren, K. \& Rye, M. (2005). Religion and individuals with intellectual disabilities: An exploratory study of self-reported perspectives. Journal of Religion, Disability, and Health, 9(1), 29-53.

Silberman, I. (2005). Religion as a meaning system: Implications for the new millennium. Journal of Social Issues, 61(4), 641-663.

Singer, G.H.S. (2006). Meta-analysis of comparative studies of depression in mothers of children with and without developmental disabilities. American Journal on Mental Retardation, 3, 155-169.

Singer, P. (1995). Practical ethics ( $2^{\text {nd }}$ ed.). Cambridge, MA: Cambridge University Press.

Singer, J.L. \& Salovey, P. (1991). Organized knowledge structures and personality: Person schemas, self schemas, prototypes, and scripts. In M. Horowitz (Ed.), Person schemas and maladaptive interpersonal patterns (pp. 33-79). Chicago: University of Chicago Press.

Siperstein, G.N., Norins, J., Corbins, S.B. \& Shriver, T. (2003). Multinational study of attitudes toward individuals with intellectual disabilities: General findings and calls to action. A Special Olympics Report. Washington, DC: Special Olympics, Inc.

Skinner, D., Bailey, D., Correa, V. \& Rodriguez, P. (1999). Narrating self and disability: Latino mothers' construction of meanings via-a-vis their children with special needs. Exceptional Child, 65, 481-495. 
Smith, B.W., Pargament, K.I., Brant, C. \& Oliver, J.M. (2000). Noah revisited:

Religious coping by church members and the impact of the 1993 Midwest flood. Journal of Community Psychology, 28(2), 169-186.

Smith, J.A. (1995). Semi-structured interviewing and qualitative analysis. In J.A. Smith, R. Harre, and L. Van Langenhove (Eds.) Rethinking Methods in Psychology (pp. 9-26). Thousand Oaks, CA: Sage.

Snow, K. (1998). To ensure inclusion, community, and freedom for people with disabilities, we must use people first language. TASH Newsletter, 24(10) 14-16.

Somech, A. (2003). Relationships of participative leadership with relational demography variables: A multi-level perspective. Journal of Organizational Behavior, 24, 1003-1018.

Special Olympics North America (2010). Rosa’s law. Retrieved from http://www.specialolympics.org/Regions/north-america/News-andStories/Stories/Rosa-s-Law.aspx

Speer, P.W., Hughley, J., Gensheimer, L.K. \& Adams-Leavitt, W. (1995). Organizing for power: A comparative case study. Journal of Community Psychology, 23, 57 73.

Speraw, S. (2006). Spiritual experiences of parents and caregivers who have children with disabilities or special needs. Issues in Mental Health Nursing, 27, 213-230.

Spilka, B. Hood, R.W., Hunsberger, B. \& Goruch, R. (2003). The psychology of religion: An empirical approach ( $3^{\text {rd }}$ ed.). New York, NY: Guilford Press. 
Stolberg, T.L. (2008). Attending to the spiritual through the teaching of science: A study of pre-service primary teachers' attitudes. International Journal of Children's Spirituality, 13, 171-180.

Stone, C.I. \& Sawatzki, B. (1980). Hiring bias and the disabled interviewee: Effects of manipulating work history and disability information of the disabled job applicant. Journal of Vocational Behavior, 16, 96-104.

Stookey, L.H. (2003). Inclusiveness as hospitality in worship settings. Journal of Religion, Disability \& Health, 7(3), 95-102.

Strauss, A.L. \& Corbin, J. (1998). Basics of qualitative research: Techniques and procedures for developing grounded theory. Thousand Oaks, CA: Sage.

Strohmer, D.C., Grand, S.A., \& Purcell, M.J. (1984). Attitudes toward persons with a disability: An examination of demographic factors, social context, and specific disability. Rehabilitation Psychology, 29(3), 131-145.

Struening, E.L., Perlick, D.A., Link, B.G., Hellman, F., Herman, D., \& Sirey, J. (2001). Stigma as a barrier to recovery: The extent to which caregivers believe most people devalue consumers and their families. Psychiatric Services, 52(12), 1633 1638.

Suddaby, R. (2006). From the editors: What grounded theory is not. Academy of Management Journal, 49(4), 633-642.

Susman, J. (1994). Disability, stigma, and deviance. Social Science \& Medicine, 38, 1522. 
Swinton, J. (1997). Restoring the image: Spirituality, faith, and cognitive disability. Journal of Religion \& Health, 36, 21-28.

Swinton, J. (2001). Building a church for strangers. Journal of Religion, Disability, and Health, 4(4), 25-63.

Swinton, J. (2011). Who is the God we worship? Theologies of disability; Challenges and new possibilities. International Journal of Practical Theology, 14(2), 273307.

Swinton, J. \& Powrie, E. (2004). Why are we here? Understanding the spiritual lives of people with learning disabilities. London, UK: Mental Health Foundation.

Tait, K. \& Purdie, N. (2000). Attitudes toward disability: Teacher education for inclusive environments in an Australian university. International Journal of Disability, Development, and Education, 47(1), 25-38.

Tam, C. \& Poon, V. (2008). Developing a support group for families with children with disabilities in a Canadian Chinese church community. Journal of Pastoral Care \& Counseling, 62(2), 343-351.

Tarakeshwar, N. \& Pargament, K.I. (2001). Religious coping in families of children with autism. Focus on Autism and other Developmental Disabilities, 16(4), 247-260.

Tate, D.G. \& Pledger, D.C. (2003). An integrative conceptual framework of disability: New directions for research. American Psychologist, 58, 289-295.

Taylor, S.E. (1983). Adjustment to threatening events: A theory of cognitive adaptation. American Psychologist, 38, 1161-1173. 
Tepper, B.J. \& Percy, P.M. (1994). Structural validity of the multifactor leadership questionnaire. Educational \& Psychological Measurement, 54(3), 734-745.

Tervalon, M. \& Murray-Garcia, J. (1998). Cultural humility versus cultural competence: A critical distinction in defining physician training outcomes in multicultural education. Journal of Health Care for the Poor and Underserved, 9(2), 117-125.

Thompson, J.R., Wehmeyer, M.L., \& Hughes, C. (2010). Mind the gap! Implications of a person-environment fit model of intellectual disability for students, educators, and school. Exceptionality: A Special Education Journal, 18(4), 168-181.

Thompson, S.C. (1991). The search for meaning following a stroke. Basic and Applied Social Psychology, 12 81-96.

Todis, B. \& Singer, G. (1991). Stress and stress management in families with adopted children who have disabilities. Journal of the Association for Persons with Severe Handicaps, 16, 3-13.

Townley, G., Katz, J., Wandersman, A., Skiles, B., Schillaci, M.J., Timmerman, B.E., \& Mousseau, T.A. (2013). Exploring the role of sense of community in the undergraduate transfer student experience. Journal of Community Psychology, 41(1), 277-290.

Townley, G., Kloos, B., Green, E.P., \& Franco, M.M. (2011). Reconcilable differences? Human diversity, cultural relativity, and sense of community. American Journal of Community Psychology, 47, 69-85.

Tracey, J.B. \& Hinkin, T.R. (1998). Transformational leadership or effective managerial practices? Group and Organizational Management, 23(2), 220-237. 
PERSPECTIVES OF RELIGIOUS LEADERS

Trickett, E.J. (1984). Toward a distinctive community psychology: An ecological metaphor for the conduct of community research and the nature of training. American Journal of Community Psychology, 12(3), 261-279.

Trickett, E.J. (1996). A future for community psychology: The contexts of diversity and the diversity of contexts. American Journal of Community Psychology, 24(2), 209-234.

Tsang, H.W.H., Chan, F. \& Chan, C.C. (2004). Factors influencing occupational therapy students' attitudes toward persons with disabilities: A conjoint analysis. American Journal of Occupational Therapy, 58(4), 426-434.

Tsui, A.S., Egan, T.D. \& O’Reilly, C.A. (1992). Being different: Relational demography and organizational attachment. Administrative Science Quarterly, 37, 549-579.

Tsui, A.S. \& O’Reilly, C.A. (1989). Beyond simple demographic effects: The importance of relational demography in superior-subordinate dyads. Academy of Management Journal, 32, 402-423.

Turkheimer, E., Haley, A., Waldron, M., D’Onofrio, B., \& Gottesman, I. I. (2003). Socioeconomic status modifies heritability of IQ in young children. Psychological Science, 14(6), 623-628.

Turner, S., Hatton, C., Shah, R., Stansfield, J. \& Rahim, N. (2004). Religious expression amongst adults with intellectual disabilities. Journal of Applied Research in Intellectual Disabilities, 17, 161-171.

U.S. Department of Education (n.d.). Promoting educational excellence for all Americans. Retrieved from http://idea.ed.gov/ 
PERSPECTIVES OF RELIGIOUS LEADERS

U.S. Department of Justice, Civil Rights Division (2012). A guide to disability rights

law. Retrieved from www.ada.gov/cguide.htm

United Church of Christ (2010). First congregational: United church of Christ. Retrieved from http://www.uccportland.org/worship

United Methodist Church (2010). First United Methodist Church. Retrieved from http://fumcpdx.org/category/congregational-life/

United Methodist Committee on DisAbility Ministries (2013). Disability Ministries. Retrieved from http://www.umdisabilityministries.org/

United Nations (U.N.; 2007). UN enable: Frequently asked questions (FAQs). Retrieved from www.un.org/esa/socdev/enable/faqs.htm\#definition

United States Conference of Catholic Bishops (1978). Pastoral statement of U.S. catholic bishops on people with disabilities. Retrieved from http://www.ncpd.org/viewsnews-policy/policy/church/bishops/pastoral

Vanderbilt Kennedy Center (2013). Disabilities, religion, and spirituality. Retreived from http://kc.vanderbilt.edu/site/services/disabilityservices/page.aspx?id=20

Vanier, J. (1998). Becoming human. London, UK: Paulist.

Vehmas, S. (1999). Newborn infants and the moral significance of intellectual disabilities. Journal of the Association for Persons with Severe Handicaps, 24(2), 111-121.

Verdonschot, M.M., de Witte, L.P., Reichrath, E., Buntinx, W.H. \& Curfs, L.M. (2009). Community participation of people with an intellectual disability: A review of empirical findings. Journal of Intellectual Disability Research, 53(4), 303-318. 
Vitello, S.J. \& Soskin, R.M. (1985). Mental retardation: Its social and legal context. Englewood Cliffs, NJ: Prentice Hall.

Vogel, J., Polloway, E., \& Smith, J. (2006). Inclusion of people with mental retardation and other developmental disabilities in communities of faith. Mental Retardation, 44(2), 100-111.

Wagner, M., Cadwallader, T. \& Marder, C. (2003). Life outside the classroom for youth with disabilities. A report from the National Longitudinal Transition Study-2 (NLTS2). Menlo Park, CA: SRI International.

Wang, M., Thomas, K.R., Chan, F. \& Cheing, G. (2003). A conjoint analys http://www.ncpd.org/about/serve is of factors influencing American and Taiwanese college students' preferences for people with disabilities. Rehabilitation Psychology, 48(3), 195-201.

Watkins, C. (1995). Beyond status: The Americans with Disabilities Act and the parental rights of people labeled developmentally disabled or mentally retarded. California Law Review, 83(6), 1415-1475.

Watt, K.J., Johnson, P. \& Virji-Babul, N. (2010). The perception of friendship in adults with Down syndrome. Journal of Intellectual Disability Research, 54(11) 10151023.

Weaver, A.J. (1995). Has there been a failure to prepare and support parish-based clergy in their role as front-line community mental health workers? A review. The Journal of Pastoral Care, 49(2), 129-149. 
Weaver, A.J., Revilla, L.A. \& Koenig, H.G. (2002). Counseling families across the stages of life: A handbookfor pastors and other helping professionals. Nashville, TN: Abingdon Press.

Weaver, A.J., Samford, J.A., Kline, A.E., Lucas, L.A., Larson, D.B., \& Koenig, H.G. (1997). What do psychologists know about working with the clergy? An analysis of eight APA journals: 1991-1994. Professional Psychology: Research and Practice, 28(5), 471-474.

Webb-Mitchell, B. (1993). Let the children come: Young people with disabilities in church. The Christian Century, 110(28), 979.

Webb-Mitchell, B. (1994). Unexpected guests at God's banquet: Welcoming people with disabilities in the church. New York, NY: Crossroad.

Wehmeyer, M.L. \& Lee, S.H. (2007). Educating children with intellectual disability. In A. Carr, G. O’Reilly, P. Noonan-Walsh, \& J. McEvoy (Eds.), The handbook of intellectual disability and clinical psychology practice (pp.559-605). London: Brunner-Routledge.

Weiner, B. (1979). A theory of motivation for some classroom experiences. Journal of Education Psychology, 71, 3-25.

Weiner, B. (1986). An attributional theory of motivation and emotion. New York, NY: Springer.

Weiner, B. (1993). On sin versus sickness: A theory of perceived responsibility and social motivation. American Psychologist, 48, 957-965. 
Weiner, B., Perry, R.P. \& Magnusson, J. (1988). An attributional analysis of reactions to stigma. Journal of Personality and Social Psychology, 55(5), 738-748.

Weisner, T.S., Beizer, L., \& Stolze, L. (1991). Religion and families of children with developmental delays. American Journal on Mental Retardation, 95, 647-662.

Werner, P. \& Davidson, M. (2004). Emotional reactions of lay persons to someone with Alzheimer's disease. International Journal of Geriatric Psychiatry, 19, 391-397.

Werner, S., Corrigan, P., Ditchman, N., \& Sokol, K. (2012). Stigma and intellectual disability: A review of related measures and future directions. Research in Developmental Disabilties, 33, 748-675.

Westhead, P. \& Cowling, M. (1998). Family firm research: The need for a methodological rethink. Entrepreneurship Theory and Practice, 23(1), 31-56.

Willow Creek Association (n.d.) Disability Ministries. Retrieved from http://www.willowcreek.org/disabilities

Wolfensberger, W. (2001). The normative lack of Christian communality in local congregations as the central obstacle to a proper relationship with needs members'. Journal of Religion, Disability \& Health, 4(2/3), 111-126.

Wong, D.W., Chan, F., Da Silva Cardoso, E., Lam, C.S. \& Miller, S.M. (2004). Rehabilitation counseling students' attitudes toward people with disabilities in three social contexts: A conjoint analysis. Rehabilitation Counseling Bulletin, 47(4), 194-204.

Woolever, C. \& Bruce, D. (2002). A field guide to U.S. congregations: Who's going where and why. Louisville, KY: Westminister John Knox Press. 
Wooten, T.C., Coker, J.W. \& Elmore, R.C. (2003). Financial control in religious organizations: A status report. Nonprofit Management \& Leadership, 13(4), 343365.

World Health Organization (WHO; 2012). Health Topics: Disabilities. Retrieved from www.who.int/tipics/disabilities/en/

Wright, B.A. (1991). Labeling: The need for greater person-environment individuation. In C.R. Snyder \& D.R. Forsyth (Eds.), Handbook of social and clinical psychology (pp. 469-487). New York, NY: Pergamon Press.

Yazbeck, M., McVilly, K., \& Parmenter, T.R. (2004). Attitudes toward people with intellectual disabilities. Journal of Disability Policy Studies, 15, 97-111.

Yong, A. (2007). Disability, the human condition, and the spirit of the eschatological long run: Toward a pneumatological theology of disability. Journal of Religion, Disability, \& Health, 11, 5-25.

Yuker, H. (1988). The effects of contact on attitudes toward disabled persons: Some empirical generalisations. In H.E. Yuker (Ed.), Attitudes toward people with disabilities (pp. 262-272). New York, NY: Springer.

Yuker, H.E. (1994). Variables that influence attitudes toward people with disabilities: Conclusions from the data. Journal of Social Behavior and Personality, 9, 3-22.

Yuker, H.E., Block, J.R., \& Campbell, W.J. (1960). A scale to measure attitudes toward disabled persons. Albertsons, NY: Human Resources Center.

Yukl, G.A. (2006). Leadership in organizations, $6^{\text {th }}$ ed. Upper Saddle River, NJ: Prentice Hall. 
Yukl, G. \& Fu, P.P. (1999). Determinants of delegation and consultation by managers. Journal of Organizational Behavior, 20, 219-232.

Zimmerman, M.A. (2000). Empowerment theory: Psychological, organizational and community levels of analysis. In J. Rappaport \& E. Seidman (Eds.), Handbook of community psychology (pp. 43-63). New York, NY: Plenum Press.

Zohar, D. \& Tenne-Gazit, O. (2008). Transformational leadership and group interaction as climate antecedents: A social network analysis. Journal of Applied Psychology, 93(4), 744-757.

Zola, I. (1993). Self, identity and the naming question: Reflections on the language of disability. Social Science and Medicine, 36, 167-173. 
Appendix A: Recruitment Letter



DATE

RECIPIENT

ADDRESS

CITY, STATE ZIPCODE

DATE

Dear RECIPIENT,

My name is Mazna Patka, and I am an Applied Social and Community Psychology doctoral student at Portland State University. I am currently working on my dissertation research, under the mentorship of Katherine McDonald, PhD and Eric Mankowski, PhD. My research involves interviewing pastors, parochial vicars, and deacons to understand their views on the participation of individuals with intellectual disabilities within Catholic communities.

I am contacting you because I would like you to consider participating in my study. Your participation in this study is valuable because little is known about the perspectives of Catholic religious leaders toward the participation of individuals with intellectual disabilities in faith communities. By understanding the perceptions of Catholic religious leaders, it is my hope that this research will help the Catholic community better understand the participation of individuals with intellectual disabilities within its community.

Participation in this study involves an interview that will last about 60 to 90 minutes. The interview questions ask about your views on the inclusion of individuals with intellectual disabilities in Catholic faith communities and how the Catholic Church and its teachings influence the meaning of intellectual disabilities. The interview will ask 
questions such as "What do you think about individuals with intellectual disabilities being included within faith communities?" At the end of the interview, I will ask you about your role in church and demographic questions.

I have consulted with Dorothy Coughlin, Director of the Office for People with Disabilities at the Archdiocese of Portland to ensure my study is applicable and of benefit to the Catholic community in Portland. This study has also received approval from the Human Subjects Research Review Committee at Portland State University.

Participation in this interview is completely voluntary. You may choose to skip questions or stop participation at anytime. Your name or your parish's name will not be shared with anyone at any time. The decision to participate in this study is entirely yours.

I have attached the informed consent document and interview questions to this letter for the study to provide you time to consider participation. I will be contacting you by telephone in a few days to tell you more about my research and answer any questions you may have. If you are interested in participating, we can then set up a date, time, and location to meet that is most convenient for you. If you would like to contact me before I call you, please feel free to call me at (971) 340-5550 or email me at mpatka@pdx.edu.

Your participation in this study is extremely important and will help better understand perspectives of religious leaders like yourself on how to include individuals with intellectual disabilities within the Catholic community.

Thank you.

Sincerely,

Mazna Patka, MS

Doctoral Student

Applied Social and Community Psychology

Portland State University, Portland, Oregon 


\section{Appendix B: Telephone Script}

$\mathbf{P}=$ Potential Participant

$\mathbf{I}=$ Interviewer (Mazna Patka)

I: May I please speak to (name of potential participant)?

I: My name is Mazna Patka and I am a doctoral student at Portland State University. I am conducting research on the inclusion of individuals with intellectual disabilities in the Catholic community as part of my dissertation. I am conducting interviews with pastors, parochial vicars, and deacons to understand their views on including individuals with intellectual disabilities in their faith communities.

I recently mailed you a letter about my research, and I wanted to know if you would be interested in learning more about my study. Is this a convenient time?

P: No, could you call back later (agree on a more convenient time for Mazna to call back).

OR

P: Yes.

I: Background information:

- The purpose of my study is to understand how Catholic religious leaders make meaning of intellectual disabilities and their perspectives toward the 
participation of individuals with intellectual disabilities in their faith community.

○ I will be conducting interviews starting on (insert date)

○ The interview questions seek to understand your views on inclusion of persons with intellectual disabilities within the Catholic community.

○ The interviews will last about 60 to 90 minutes hour, and would be arranged at a time and location convenient for you.

○ Participation in this interview is entirely voluntary. The probability of harm or discomfort anticipated is no greater than what you experience in daily life.

○ You may decline to answer any of the interview questions you do not wish to answer and you may terminate the interview at any time.

- I would like to assure you that this study has been reviewed and approved by the Human Subjects Research Review Committee at Portland State University. However, the final decision to participate is yours. 
- After all of the data has been analyzed, you will receive a summary of the research results. You will have the opportunity to provide feedback on the summary.

If you are interested in participating, we can set up a time, date, and location to meet for the interview.

P: Sure

I: What is the best location, time, and date for us to meet? (DECIDE ON TIME). If any questions or concerns arise, please feel free to contact me at (971) 340-5550. Thank you for your time.

\section{OR}

P: No, I am not interested in participating.

I: That is not a problem. May I know why you are not interested in participating?

Thank you for your time.

I: Goodbye.

P: Goodbye. 


\section{Appendix C: Email Template}

\section{Dear [Participant Name],}

My name is Mazna Patka and I am a doctoral student at Portland State University. I am conducting research on the inclusion of individuals with intellectual disabilities in the Catholic community as part of my dissertation. I am conducting interviews with pastors, parochial vicars, and deacons to understand their views on including individuals with intellectual disabilities in their faith communities. I recently mailed you a letter about my research, and I wanted to know if you would be interested in learning more about my study.

I called your office today (date) and you were not available. Your office staff shared your email address with me. I hope that you will consider participating, because your experience as a religious leader is valuable to my study.

The purpose of my study is to understand how Catholic religious leaders make meaning of intellectual disabilities and their perspectives toward the participation of individuals with intellectual disabilities in their faith communities.

I will be conducting interviews starting in February. The interview will last about 60 to 90 minutes, and would be arranged at a time and location convenient for you.

Participation in this interview is entirely voluntary. If you do choose to participate in the interview, you may decline to answer any interview questions you do not which to answer and you may terminate the interview at any time.

Once I complete all of my interviews, all individuals who participate will receive a summary of the research results. You will have the opportunity to provide feedback on the summary.

If you are interested in participating, we can set up a time, date, and location to meet. For example, if you would like, I can reserve a room at Portland State University for us to meet or I can meet with you at [Parish]. If you are interested, would you be able to 
meet with me on [possible dates]? If one of these days does work for you, please let me know as well as the time that works best for you. If one of these days does not work for your schedule, please let me know when you would prefer to meet.

If for any reason you are not interested in participating in my research, it is perfectly okay. The decision to participate is completely yours. However, it would be helpful for me to know why you are not interested in participating.

I look forward to hearing from you.

Sincerely,

Mazna Patka, MS, ABD

Doctoral Candidate

Applied Social and Community Psychology

Portland State University, Portland, Oregon, USA 
Appendix D: Informed Consent

\section{胥 Portland State \\ Informed Consent \\ Individuals with Intellectual Disabilities in Faith Communities: \\ Perspectives of Catholic Religious Leaders}

I, Mazna Patka, am asking you to participate in a research study. This study is being conducted under the guidance of my advisers, Katherine McDonald, PhD and Eric Mankowski, PhD. The purpose of this consent form is to give you the information you will need to help you decide whether or not to be in the study. Please read this form carefully. You may ask questions about the purpose of the research, what I will ask you in the interview, the possible risks and benefits, your rights as a volunteer, and anything else about the research or this form. When all your questions have been answered, you can decide if you want to be in the study.

\section{Purpose of this Study}

I am a doctoral student at Portland State University. For my dissertation, I want to better understand how individuals with intellectual disabilities are included within Catholic faith communities. I am interviewing pastors, parochial vicars, and deacons. I hope to understand their experiences with individuals with intellectual disabilities as well as barriers and successes they have experienced or foresee when including individuals with intellectual disabilities within faith communities. I will also be asking about how Catholicism informs understandings of intellectual disabilities.

\section{Procedures}

If you choose to be in this study, I would like to interview you about your perspectives of the inclusion of individuals with intellectual disabilities within Catholic faith communities. The interview will last about 60 to 90 minutes. The interview will take place at a location you choose such as your work place or at Portland State University. The interview will consist of two parts. The first part will involve asking question about your perceptions followed by questions about yourself like your age and level of education completed. For example, I will ask you:

- How are individuals with intellectual disabilities involved in your faith community?

- Can you describe anything that prevents the inclusion of individuals with intellectual disabilities in faith communities? 
You do not have to answer every question.

With your permission, I would like to audio record your interview so that I can have an accurate record. The audio recording will be saved on a password protected computer. I will transcribe your interview and assign a number to the transcript so it does not have your name or any identifying information. Please indicate below whether or not you give your permission for me to audio record your interview. If you do not give permission to audio record your interview, I will take notes during the interview to document your responses. Only my advisers and I will have access to the research materials (e.g., audio recording, transcriptions, informed consent document).

\section{Possible Risks}

To protect your privacy, your name and any identifying information will not be shared with anyone other than my research advisers. If the results of this study are published or presented, I will not use your name or other identifying information.

You may also feel uncomfortable answering some questions. For example, discussing barriers you may have experienced when trying to include individuals with intellectual disabilities may be difficult. You can choose to not answer any questions and you can decide to stop at any time. If you decide to stop your participation, you will not face any negative repercussions, and I will not be offended or upset.

\section{Benefits of this Study}

You may feel good about helping me learn more about the perspectives of Catholic religious leaders toward the participation of individuals with intellectual disabilities in faith communities. I hope that the results of this study will benefit the Catholic community to better understand the inclusion of individuals with intellectual disabilities. I will share a summary of my findings with the Director of the Office for People with Disabilities at the Archdiocese of Portland in Oregon. The results of the study may potentially provide information on the barriers religious leaders face as well as their successes. It is hoped that this research will help inform interventions that help promote inclusion of individuals with intellectual disabilities. I will provide you a resource list of books and websites concerning the inclusion of individuals with disabilities in faith communities.

\section{Participant Statement}

This study has been explained to me. I volunteer to participate in this research. I have had a chance to ask questions. If I have questions later on about the research, I can ask the investigator, Mazna Patka by calling her at (971) 340-5550, emailing her at 
mpatka@pdx.edu, or writing to her at P.O. Box 751, Department of Psychology, Portland State University, Portland, OR 97207-0751.

If I have questions about my rights as a research participant, I can contact the Portland State University Human Subjects Research Review Committee at (503) 725-4288, (877) $480-4400$, by mail at Portland State University, Market Center Building, $6^{\text {th }}$ Floor, P.O. Box 751, Portland, OR 97207-0751, or by email at hsrrc@pdx.edu.

If I have questions for Mazna Patka's advisers, I can contact Katherine McDonald, PhD at (315) 443-6140, by mail at Syracuse University, David B. Falk College of Sport and Human Dynamics, 426 Ostrom Avenue, Syracuse, NY 13244, or by email at kemcdona@syr.edu, or Eric Mankowski, PhD at (503) 725-3901, by mail at Portland State University, Psychology Department, P.O. Box 751, Portland, OR 97207, or by email at mankowskie@pdx.edu.

I have received a copy of this consent form.

\section{Audio Recording}

I give my permission for the researcher to audio record my interview.

I do not give my permission for the researcher to audio record my interview.

\section{Consent}

I give my consent to be interviewed.

Participant Printed Name

Participant Signature

Date

Investigator Signature

Date 


\section{Appendix E: Interview Guide}

Individuals with Intellectual Disabilities in Faith Communities: Perceptions of Catholic Religious Leaders

This interview consists of two parts. First, I will ask you about your perceptions toward individuals with intellectual disabilities within your faith community, and then I will ask you questions about yourself.

According to the Association on Intellectual and Developmental Disabilities, intellectual disability is defined as the following:

Intellectual disability originates before the age of 18 and is characterized by significant limitations in both intellectual functioning and adaptive behavior. By intellectual functioning, I mean reasoning, learning, and problem solving. Adaptive behavior covers a range of everyday social and practical skills.

For example, Down syndrome and fetal alcohol syndrome are both types of intellectual disabilities. Intellectual disabilities were formerly called mental retardation.

Intellectual disability is a type of developmental disability, but developmental disability includes other disabilities and occurs before the age of 22. Other developmental disabilities that are not intellectual disabilities include autism and blindness.

Do you have any questions about the definition of intellectual disability? 
1. How would you describe your leadership role within your faith community?

This may include:

- Motivating members of the community

- Conveying church mission

- Providing a vision

- Decision making processes

- Mentorship

- Counseling

- Disability specific services

2. How would you describe your faith community?

3. How would you describe your experience with individuals with intellectual disabilities?

This may include:

- Their age

- Life characteristics

- Outside your faith community

- Inside your faith community

- How they are involved in your faith community

- How often you see them 
- Type of relationship (e.g., mentorship, friendship)

- Do you know their name(s)

4. What do you think about individuals with intellectual disabilities being included within faith communities?

5. How are individuals with intellectual disabilities involved in your faith community? Settings may include:

- Weekly Eucharist

- Other Sacraments

- Religious education

- Church social events

- Parish Council

- Ushering

- Care Ministry

- Eucharistic Minister

6. Do you think there are any religious activities individuals with intellectual disabilities should not participate in?

- What are the reasons behind your view?

Probe: Can you elaborate on that? 
7. Can you describe anything that prevents the inclusion of individuals with intellectual disabilities in faith communities?

This may include:

- Communication barriers (e.g. individuals who use sign language or have no formal communication system)

- Physical accessibility

- Attitudes

- Programming (e.g., lack of individualized supports in religious programming)

- Policies

Probe: Can you say more about that?

How might you address these barriers?

8. Do you think individuals with intellectual disabilities should be more included within your faith community?

If yes:

What do you think could contribute to greater inclusion within your faith community?

What might get in the way?

If no: 
PERSPECTIVES OF RELIGIOUS LEADERS

Can you explain why?

Probe: Would you elaborate on that?

We are about halfway through the interview now. I think it is going very well and you are providing important information. How is the process going for you?

9. What resources does the Catholic church use in shaping its understanding of intellectual disabilities?

Probes:

Are there-

Specific passages from the scriptures?

\section{John 9:1-3}

As he went along, he saw a man blind from birth. His disciples asked him, "Rabbi, who sinned, this man or his parents, that he was born blind?" "Neither this man nor his parents sinned," said Jesus "but this happened so that the works of God might be displayed in him."

\section{$\underline{\text { Luke 14:12-14 }}$}

“Then Jesus said to his host, 'When you give a luncheon or dinner, do not invite your friends, your brothers or relatives, or your rich neighbors; if you do, they may invite you back and so you will be repaid. But when you give a banquet, invite the poor, the 
crippled, the lame, and the blind, you will be blessed. Although they cannot repay you, you will be repaid at the resurrection of the righteous."

Stories about the Saints?

Documents from the Vatican?

How do you present them to members of your faith community?

10. What kinds of secular resources do you use to inform your understanding of intellectual disabilities?

11. What is the highest level of education you completed?

Did your educational training include disability issues?

Was it part of your theological training?

What was taught?

What did the training consist of?

Lecture based?

Contact with individuals with disabilities?

I do not have any more questions for Part 1. Is there anything you would like to add?

Next, I will ask you questions about yourself.

12. How long have you been in your current position? 
13. What was your role prior to this position?

Where was your past role?

14. Does your church have a formal administration or management group?

How many people does it consist of?

Are they also religious leaders?

Paid staff?

What are their duties?

15. What is your age?

16. What is your race?

17. What is your ethnicity? 


\section{Appendix F: Interview Guide Short Form}

\section{Individuals with Intellectual Disabilities in Faith Communities: Perceptions of Catholic Religious Leaders}

This interview consists of two parts. First, I will ask you about your perceptions toward individuals with intellectual disabilities within your faith community and then I will ask you questions about yourself.

According to the Association on Intellectual and Developmental Disabilities, intellectual disability is defined as the following:

Intellectual disability originates before the age of 18 and is characterized by significant limitations in both intellectual functioning and adaptive behavior. By intellectual functioning, I mean reasoning, learning, and problem solving. Adaptive behavior covers a range of everyday social and practical skills. For example, Down syndrome and fetal alcohol syndrome are both types of intellectual disabilities. Intellectual disabilities were formerly called mental retardation. Intellectual disability is a type of developmental disability, but developmental disability includes other disabilities and occurs before the age of 22. Other developmental disabilities that are not intellectual disabilities include autism and blindness.

1. How would you describe your leadership role within your faith community?

2. How would you describe your faith community?

3. How would you describe your experience with individuals with intellectual disabilities?

4. What do you think about individuals with intellectual disabilities being included within faith communities?

5. How are individuals with intellectual disabilities involved in your faith community?

6. Do you think there are any religious activities individuals with intellectual disabilities should not participate in?

7. Can you describe anything that prevents the inclusion of individuals with intellectual disabilities in faith communities? 
8. Do you think individuals with intellectual disabilities should be more included within your faith community?

9. What resources does the Catholic church use in shaping its understanding of intellectual disabilities?

10. What kinds of secular resources do you use to inform your understanding of intellectual disabilities?

\section{Demographic Questions}

11. What is the highest level of education you completed?

12. How long have you been in your current position?

13. What was your role prior to this position?

14. Does your church have a formal administration or management group?

15. What is your age?

16. What is your race?

17. What is your ethnicity? 


\section{Appendix G: Resource List}

\section{Disability and Religion Resource List}

This resource guide is provided in case you would like to learn more about disability issues within religious communities. You are also encouraged to contact Dorothy Coughlin, Director of the Office for People with Disabilities at the Archdiocese of Portland. Dorothy's email address is dcoughlin@archpdx.org, and her phone number is 503-223-8399.

\section{Organizations in Oregon}

Interfaith Disabilities Network of Oregon (IDNO)

http://www.interfaithdisabilities.org/

IDNO is a non-profit organization serving people with disabilities and their families, denominational groups, individual congregations, support professionals, and allied service agencies. IDNO engages with faith communities to promote mutually beneficial relationships among people with and without disabilities.

\section{L'Arche Portland}

http://larche-portland.org/

L'Arche communities bring together individuals with and without developmental disabilities to live together in faith-based communities.

\section{Online Resources}

\section{The $3^{\text {rd }}$ Summer Institute on Theology and Disability} http://bethesdainstitute.org/theology

The $3^{\text {rd }}$ Summer Institute on Theology and Disability is a weeklong institute that brings together scholars in the areas of theology and disability with clergy, religious leaders, practitioners, and others interested in inclusive ministries and faith supports. The website has audio presentations from its institutes, which are free of charge.

\section{National Catholic Partnership on Disability (NCPD)}

http://www.ncpd.org/ 
NCPD was established to further the implementation of the 1978 Pastoral Statement of U.S. Catholic Bishops on People with Disabilities, which calls for full inclusion of all individuals with disabilities in church and society. The website posts webinars, toolkits, and articles. It also has a section specifically on the inclusion of individuals with intellectual and developmental disabilities (http://www.ncpd.org/ministriesprograms/specific/intellectual).

\section{Network of Inclusive Catholic Educators (NICE)}

http://ipi.udayton.edu/nice.htm

NICE is a support network and resource for individuals with disabilities and their families. They provide DVD and print resources, workshops, and networking opportunities.

\section{National Apostolate for Inclusion Ministry (NAFIM)}

http://www.nafim.org/

NAFIM's mission is to answer the call of Catholic Bishops to embrace all people with disabilities through awareness, identifying and promoting opportunities for individuals with disabilities, foster spiritual development among individuals with disabilities, and encourage appropriate pastoral care for individuals with disabilities.

\section{Vanderbilt Kennedy Center - Tips Sheets and Resources}

http://kc.vanderbilt.edu/site/services/disabilityservices/tipsheets.aspx

The Vanderbilt Kennedy Center has a list of tip sheets and resources in PDF format for anyone interested in learning more about disability related topics. It has a section on religion and spirituality covering topics such as a tip sheet for religious leaders on the inclusion of people with disabilities.

\section{National Association of Pastoral Musicians (NPM)}

http://www.npm.org/pastoral_music/archives.html

NPM provides free volumes of Pastoral Music from 1976 to 2009. Its June-July 2006 volume is on Accessible Worship (http://www.npm.org/pastoral_music/issues/PM\%20Vol\%2030-5.pdf), and has an article by Dorothy Coughlin (Director of the Office for People with Disabilities at the Archdiocese in Portland) titled "Adapted Liturgies, Integral People."

Institute on Community Integration - University Center for Excellence in Developmental Disabilities 
http://ici.umn.edu/products/newsletters.html

The Institute on Community Integration offers a free subscription mailing list for Impact, which is a newsletter that provides practical information for individuals in a variety of fields interested in disability issues.

Resource Packet on Disability, Spirituality, and Healing

http://thechp.syr.edu/spirituality.html

The Disability, Spirituality, and Healing resource has documents on topics including Changing Attitudes, Creating Awareness, and Disability Awareness: An Empowering Ministry.

\section{Joni and Friends}

http://www.joniandfriends.org/

Joni and Friends is an organization that aims to promote Christian ministry in the disability community. Its website includes information on disability resources and its ministries. It has an office in Southern Oregon

(http://www.joniandfriends.org/southern-oregon/) that works with local churches to form outreach programs for individuals with disabilities and their families.

\section{Disability Concerns - Christian Reformed Church}

http://www.crcna.org/pages/disability.cfm

Disability Concerns helps churches become more inclusive by promoting connectedness of individuals with disabilities and their families. Disability Concerns provides a free handbook called Inclusion Handbook: Everybody Belongs Everybody Serves to provide church leadership the tools to encourage friendship and inclusion.

\section{Congregational Accessibility Network (CAN)}

http://www.accessibilitynetwork.net/Home

CAN promotes inclusion of persons with disabilities in faith communities by providing tools for individuals with disabilities, families, friends, advocates, and faith communities. CAN provides a checklist for congregations to determine whether their community is accessible.

Church Access for Persons with Disabilities: Catholic Teachings, Practical Suggestions, and Resources

http://www.catholicdisabilityteachings.com/ 
This website provides Catholic teachings and suggestions that congregations can integrate to promote inclusion.

\section{Friendship Program Guide}

www.friendship.org

This is a resource for leaders who are beginning programs of inclusion within their congregation. It includes information on getting organized, choosing materials, defining volunteer roles, and more.

\section{Allies in Self-Advocacy}

http://alliesinselfadvocacy.org/accessible-meetings-presentations/

This website links to resources that provide information on working with groups and networks on meetings and conferences include individuals with disabilities. Resources include a manual on how to create meaningful partnerships with individuals with disabilities and creating accessible conferences and meetings.

\section{Faith and Light}

www.faithandlight.org

Faith and Light is an organization of international groups and are part of the Christian tradition. Its mission is to reveal each persons gift in beauty in Church and society. Groups made up of people with and without intellectual disabilities come together at least once a month for a gathering of friendship, sharing, prayer, and celebration.

\section{$\underline{\text { Books }}$}

General

Opening Doors to People with Disabilities (Volumes I \& II) Published by the National Catholic Partnership on Disability

Welcoming People with Disabilities: Do's and Don't for Parish Ministers by the National Pastoral Life Center 
Including People with Disabilities in Faith Communities: A Guide for Service Providers, Families, and Congregations by Erik Carter

From Barriers to Bridges: A Community Action Guide for Congregations by Ginny Thornburgh

Worship and Sacraments

Awakening Spiritual Dimensions: Prayer Services with Persons with Severe Disabilities by Fr. William Gillum

Expressing Faith in Jesus: Church Membership for People with Cognitive Impairments by Ronald C. Vredeveld

Prayer for People who Can't Till by William Tenny Brittain

That All May Worship: An Interfaith Handbook to Assist Congregations in Welcoming People with Disabilities by the Religion and Disability Program of the National Organization on Disability

Access to Sacraments of Institution and Reconciliation for Developmentally Disabled Persons by Cardinal Joseph Bernardin

A Place for Me in God's Family by the International Bible Society

Toward Inclusive Worshipping Communities by Disability Awareness Commission, Archdiocese of Portland

In Heaven There Are No Thunderstorms: Celebrating the Liturgy with Developmentally Disabled People by Gijs Okuijsen and Cees van Opzeeland

Sacramental Preparation Booklets on Eucharist, Baptism, Confirmation, and Reconciliation by the Center for Ministry with People with Disabilities.

Guidelines for Celebrating of the Sacraments with Persons with Disabilities by the National Catholic Partnership on Disability

Pastoral Ministry with Disabled Persons by Walter Kern 
Appendix H: Member Check

\author{
舟 Portland State \\ Department of Psychology \\ P.O. Box 751 \\ Portland, OR 97207-0751
}

RECIPIENT

ADDRESS

CITY, STATE ZIPCODE

DATE

Dear RECIPIENT,

Thank you for participating in my research study titled "Individuals with Intellectual Disabilities in Faith Communities: Perspectives of Catholic Religious Leaders." I appreciate you taking the time to meet with me and share your experiences as a religious leader. I am writing to share with you a summary of my preliminary findings.

I am interested in your reaction to this summary. For example:

- Is the summary missing any important ideas that you have about the topic?

- Do the findings surprise you? Why or why not?

- What could these findings mean for you, your parishioners, and the Diocese?

I will be contacting you in about a week to learn about your reaction, questions, and/or concerns. If you prefer, you can contact me through email at mpatka@pdx.edu or by phone at 971-340-5550.

Thank you again for participating in the individual interview. I appreciate your contribution.

Sincerely,

Mazna Patka, MS, ABD

Doctoral Student, Applied Social and Community Psychology

Portland State University

mpatka@pdx.edu

971-340-5550 
Appendix I: Summary

INDIVIDUALS WITH INTELLECTUAL DISABILITIES IN FAITH COMMUNITIES: PERSPECTIVES OF CATHOLIC RELIGIOUS LEADERS

Mazna Patka, Portland State University

mpatka@pdx.edu, 971-340-5550

May 30,2013

\section{PURPOSE}

The aim of this study was to understand the perspectives of Catholic pastors, parochial vicars, and deacons toward the inclusion of individuals with intellectual disabilities, including how they understand intellectual disabilities. To understand these perspectives, I conducted 12 interviews, which included five pastors, four parochial vicars, and three deacons in the Portland area in parishes that do and do not host adaptive liturgy.

\section{SUMMARY OF FINDINGS}

Disability Training \& Experience

Participating religious leaders who received disability specific training in post-graduate education:

- 5 No Training

- 3 Some Information within the Classroom

- 3 Fieldwork/Practicum

- 1 Mental Illness Focus

4 Participating religious leaders were familiar with the Pastoral Statement of U.S. Bishops

1 Participating religious leader was familiar with documents from the Second Vatican Council

Participating religious leaders reported a variety of disabilities present in their parishes.

\section{Responsibilities \& Priorities}

All participating religious leaders reported engaging within their parish in multiple ways. Like most participants, one individual described his role as "hatching, matching, and dispatching" which involves baptizing, marrying, and burying individuals. When considering priorities, there were varying levels of support for allocating resources to disability issues. Two participating religious leaders stressed the importance and role of the Office for People with Disabilities at the Archdiocese of Portland and both leaders made inclusion for people with disabilities a priority. However, even within the same parish there were differences in opinion. Two participating religious leaders stressed that, in their opinion, disability issues are not a priority within their parish. 
Knowledge of Resources to Understand Intellectual Disabilities

- 2 participating religious leaders did not know of any resources within the Catholic community.

- 8 participating religious leaders know about the Office for People with Disabilities at the Archdiocese of Portland.

- 1 participating religious leader knew religious leaders engaged in adaptive liturgy, Catholics with disabilities, and lay people working in the area of disabilities.

\section{Meaning of Intellectual Disabilities}

-Some described individuals with intellectual disabilities as children in adult bodies or "innocent children."

- In the context of confession, one participant questioned whether individuals with intellectual disabilities are capable of committing sin.

"I don't know how much conscious this person might have of this being something bad, or really wanting to do this...many times there's no malice in the action, you know, there's no evil will or anything."

- In contrast, one individual stated, "to not allow them to grow up in your mind is a disservice to them, 'cause they're growing up in their mind....and they want to be selfsufficient. If you're going label them as children, you never really allow them to be as selfsufficient as they can be."

Participation of Individuals with Intellectual Disabilities in Parish Life

One individual knew of persons with intellectual disabilities being present for mainstream Sunday mass, but was not aware of their participation in any other way. Participating as ushers and greeters were two common ways in which individuals with intellectual disabilities have engaged in the participating parishes.

\section{Eucharistic Ministers}

- One religious leader knew of an individual with intellectual disabilities who was a Eucharistic minister.

- One participating religious leader indicated he would need to assess whether an individual with intellectual disabilities understands the Eucharist by asking questions and making sure they can physically engage in the role. Five participating religious leaders stated that they would not be concerned with assessing knowledge but the individual must be able to

"You know, who of us truly understands? Does a second grader that's receiving the Eucharist understand what they're receiving? It's something we grow an understanding of...I don't think that's nearly important as... the person's desire to serve." 
physically engage in the role.

\section{Support to Expand Participation}

One individual described an experience where he conducted a baptism and first communion that was tailored to promote the participation of an individual with intellectual disabilities.

Specifically, the individual with intellectual disabilities had a sibling who had already been confirmed and was able to serve as a representative for the person with intellectual disabilities for the process. The sibling went through the process for the person with intellectual disabilities. The person with intellectual disabilities

"She wanted to be baptized and then..confirmed. She also didn't like water...she was afraid of anybody but her parents and her brother...so they let me know all of this and this was going to happen, and this is going to be really difficult but she wants it." was present and communicated with the sibling throughout the process.

\section{Friendships}

Two participating religious leaders stated that they did not know of adults with intellectual disabilities having close friendships within the parish. In contrast, one participant stated that an individual with intellectual disabilities made connections within the community where other parishioners provided the person with intellectual disability transportation to and from events. Another participant described a parishioner with intellectual disabilities who connected with others where members without disabilities knew his name and personal information such as his occupation.

Impact of People with Intellectual Disabilities Present in Faith Communities Three participants discussed the importance of the presence of individuals with intellectual disabilities because of the impact it can have on the community. One individual stated that parents "feel it's good for their kids and also them to see that, just remember how blessed you are." Thus, this may suggest that some adhere to the idea that individuals with intellectual disabilities live a poor quality of life. Because of the disability, it may be assumed the lives of people with intellectual disabilities are not normal, unsatisfactory, and full of suffering.

\section{Adaptive Liturgy}

Two participants reported having direct experiences with the adaptive liturgy, and 10 participants were familiar with adaptive liturgy but have not had direct experience with it. Four participants described the purpose of the adaptive mass as connecting families with individuals with disabilities and serving the specific needs of the disability community. It was reported that family members of individuals with
"Families of those people...with intellectual disabilities and other disabilities...have told me that you have no idea how hard it is on us to sit through a regular mass when they feel like they're being judged" 
disabilities, not people with disabilities, have advocated for the adaptive liturgy.

Some participants were asked about their thoughts on integrating components of the adaptive liturgy into mainstream mass. One individual expressed that "some of them [individuals attending the adaptive mass] are handicapped enough where they would not want to do that [attend a mainstream mass]." Another individual said that the adaptive liturgy is a resource that serves the needs of people with disabilities, which a mainstream mass would not do. The individual believed that for people with disabilities to be integrated within the mainstream mass, they would need to have an advocate without a disability within the parish.

In contrast, four participating religious leaders stated that they wanted individuals with intellectual disabilities to be part of the mainstream mass. For example, one individual stated, "Well, I think you know it's like anything, um the whole idea you know and theologically the ideal community is an inclusive community...The primary purpose is to gather...that's true with people with intellectual disabilities...they should be able to be comfortable in...the mainstream 9 o'clock mass at their local parish...but at the same time there is something to be said for having liturgies that on occasion anyhow that address the specific kinds of experiences that people in that category might have as opposed to people in another." One individual shared it would be best to only have a mainstream mass because "sometimes it's hard because you know in the preparation, just the ordinary preparation for Sunday Eucharist, you know for all the people I takes a lot of effort and time. It's very hard to create something just for disabled people, I think. It's better if we can bring them into the community and that could help them."

\section{Conclusion}

The present summary provides an overview of the findings of interviews with Catholic religious leaders about their views on the participation of individuals with intellectual disabilities within faith communities. In general, a range of views and experiences exist, and many religious leaders believe people with intellectual disabilities should participate within their faith community in some way.

Caveats

It is important to note this summary includes a small group of Catholic religious leaders. Those who did not participate may have different experiences and perspectives. 


\section{Appendix J: Codebook}

\section{Model I: Close to God}

Language Used to Describe People with Disabilities: Language used by religious leaders to describe people with intellectual disabilities

Descriptors: Ways in which people with intellectual disabilities are described or labels used to describe them

Suffering: Describing the experience of intellectual disabilities as unpleasant, harmful, or suggesting constant pain

P: he suffered from an intellectual disability

Relationship with Persons with Disabilities Outside of Parish Life: The relationships religious leaders have with individuals outside of their parish life such as family members and friends

Extended Family Member: Relationship with an individual who is not part of ones immediate family but is part of ones extended family (e.g., cousin)

P: I'm a little familiar 'cause my uh my cousin is disabled...the only on-going relationship I have is with my cousin.

Positive Relationship: Positive experiences with individuals with disabilities based on the description of experiences

P: the only on-going relationship I have is with my cousin...I mean, it's incredible.

Disability Related Training: Training or professional development that involves disability issues through mediums such as lecture and fieldwork

Working with Individuals with Disabilities as a Seminarian: Work participating religious leaders had engaged in that involved working alongside individuals with disabilities while training to be a priest

P: I think in our MDiv program. Um in terms of looking at all of the pastoral issues around a community. Um yes there was some acknowledgement. Probably not much. But there was some um field education pieces about people with disabilities and also going to live with. Like I lived in a place in [city], during the summer time with people with intellectual disabilities. 
Secular Resources to Educate Parish Staff: Secular resources religious leaders have utilized to build upon their knowledge of disability issues and how to better serve people with disabilities

Independently Sought Funding: Attained secular resources by seeking out financial support for funding

P: I had um, after a couple of years of being here I asked a psychiatrist, I had gotten a little grant, the psychiatrist that I met to come in and do some educational things for our staff...At the end of it, he said to us, now look you guys, you guys have two things to offer, faith and community. And he said that is what people are looking for.

Beliefs About How Religious Leaders Can Help People with Disabilities: Beliefs held by religious leaders about what they can do to help people with disabilities to be part of their faith community

Building Community: The belief that religious leaders can offer individuals with disabilities membership in a community, which is the parish

P: people with all kinds of disabilities, emotional, and uh physical, and uh mental, that you know our neighborhood, the big killer in the neighborhood is loneliness, so and social isolation...so I would say you know all of our programming is geared to folks who are most marginalized in society.

Reaction of Parishioners toward Individuals with Disabilities: Reactions of parishioners without disabilities toward people with disabilities

Negative (e.g., stigmatizing) Reactions with People with Disabilities: Reactions on the part of parishioners that are negative such as fear and stereotypical beliefs

Nature of Disabilities: Stigmatizing beliefs about the inherent nature of individuals with disabilities

P: You know it's always astonishing to me about how people think...mental disability is contagious. Or um that that somehow its going to wear off on them somehow.

Initial Reactions to People with Disabilities: The reactions of parishioners without disabilities when they first encounter people with disabilities in the parish.

P: People fear it. People fear that sense of loss when they are confronted with anyone different than them. So, whether or not it is a disability um or it's a poverty that when 
people are confronted with somebody who has that sense or cultural sense of loss, they are so afraid that that loss can also be in them....That's the place in which we build the community. Um. So I think we need to name those fears, we need to confront those fears, and walk through those things together.

Parishioners without Disabilities Accepting People with Disabilities:

The reaction of parishioners without disabilities toward people with disabilities in the parish. This is the reaction of parishioners who consistently attend a parish.

P1: There is no fight against the way somebody smells or the way somebody acts or the way somebody comes to mass.

P1: He's [man with intellectual disabilities] always first in line, and the whole community knows that. They expect that. They receive that. They honor that.

Acceptance Dependent Upon Parishioner Characteristics: The contrast between ethnic and linguistic groups that demonstrate different attitudes toward people with disabilities

P: we have one family who comes to mass...they have a son who's um, I actually don't even know the extent of what his issue is, but he's physically disabled, he's got mental disabilities, he's got all sort of disabilities, then he calls out during mass...that family is totally welcome [at a Spanish mass]...but I would know, if they were to try to come to our earlier morning mass where people expect quiet or something like that, I would have somebody coming to talk and argue with me.

Raising Awareness Among Parishioners: Actions religious leaders have taken to promote an understanding of disability issues

Parish Mission: Parish missions that explicitly focus on the inclusion of individuals with various types of disabilities and its application on a dayto-day basis

P: We're kind of the last place to be for people...its important to for us to realize that what we do here, we are, we are not a nonprofit organization that you know, we are a religious community that opens our doors to build community and use our faith to build community with the marginalized.

Workshops/Retreats: Training geared for parishioners to learn about disability issues 
P: trying to help educate people about what we do here and about homelessness, mental illness, uh addictions and those kinds of issues in particular.

Acting Upon Parishioner Reactions: The ways in which religious leaders take action based on the attitudes and behaviors of parishioners without disabilities when considering parish level issues

P: I will [preach] as soon as I get wind of...something that has the capacity to grow to become a little bit larger presence, that's when I will do a bulletin article, that's when I will tell a story, I will create a parable of you know where we first find Christ in this situation, stuff like that to challenge, challenge, challenge.

Decision Making without Parishioner Support: Instances where decisions were made that may not be popular or in alignment with what parishioners may want or are used to

P: we're not going to change things because somebody feels uncomfortable. There are other places. We are what we are. And intentionally, deliberately. And uh, people who come here, with one exception so far in my life, like it.

Beliefs About Inclusion of People with Intellectual Disabilities in Parish Life: Beliefs held by religious leaders about the participation of individuals with intellectual disabilities in sacraments, volunteer positions, service, etc

Parish Life Open To All: The belief that all people should be included in the life of the parish regardless of life situation

P: We don't judge, we don't discriminate, and by that I don't mean in terms of coming in the door or not. I mean between how we relate to people. Uh, we meet them where they are and try to lead them on.

Positive Past Experiences: Positive experiences with individuals with intellectual disabilities in the context of parish life

P: Uhh, I used to say mass for them [L'Arche communities] occasionally...that's the really only hands on uh thing that I had there...It was just sheer joy to uh, to go and be with them and celebrate mass with them and stuff, yeah, it was just, they're just delightful to be around.

Mainstream versus Integrated Settings: Beliefs about whether inclusion should be in segregated settings, mainstream settings, or a mixture of both 
Proponents for Inclusion in Mainstream Mass: Religious leader belief that inclusion should be within the mainstream life of the parish rather than a segregated setting that is tailored for people with disabilities

P: I think we become a better church if they're there...this is their home, this is their place for prayer

P: for the people who want to be exclusionary, I just I don't, it does not make pastoral sense to me, because how can I speak, how can I ever be effective, I mean of course we have to go out. I have to be present outside, but I mean, unless they're there to share the word with them, to share sacraments with them, how can we expect them to have that moment and that relationship with God in order to experience that desire to know God better

What Participation Can Involve/Look Like: Descriptions of the ways in which individuals with intellectual disabilities participate in parish life which can span from initiating participation or volunteering for a role to the actual participation within a role

Initiating Participation: What needs to be done and by whom for participation to take place

Initiated by Parishioners: Participation initiated by parishioners for a role within the parish

P: They can do whatever they want to do if they articulate it and we can ask them to do things that they would be able to do

Initiated by Religious Leader: Participation initiated by the religious leader for a role within the parish

P: I asked him if he would be willing to handout the bulletins at the end of mass...he's the bulletin hander-outer.

Desire: The belief that individuals need only to have a desire to participate in the life of their religion

P: In worship, in the learning process, in volunteering, and service. Uh, just the same way anybody else would be but at their chosen uh level.

Training/Mentoring: Training or mentoring provided for participation in roles

P: If she asked to be Eucharistic Minister, we would certainly work with her. Not just say, okay, go do it, but there's a training anyway. 
Participation in Specific Roles: Descriptions of specific roles that individuals with intellectual disabilities have participated in within their parish

Volunteer: Volunteer positions that people with intellectual disabilities engage in within the parish

P: The other day she volunteered, the orange juice.

Communion: Participation of individuals with intellectual disabilities in Holy Communion

P: Well first of all he's been coming here to mass, every mass, for thirty years. And everyday he brings up the gifts...Everyday he receives communion first.

Eucharistic Ministers: Participation of individuals with intellectual disabilities as a Eucharistic Minister during mass

P: We do have uh people various disabilities and illnesses who are Eucharistic Ministers.

Promoting Inclusion of People with Intellectual Disabilities in Sacraments: Action taken by religious leaders to include people with intellectual disabilities in sacraments

Including People Excluded in Other Faith Communities: Including people with disabilities who have been excluded from religious participation in another parish

P: This mother came to me and this gentleman and um he um suffered from an intellectual disability... she said to me um that she had tried to bring him to almost every Catholic parish in the [city] area, and no priest would give him communion. And so I said to her, you know, that's no problem. We'll work together...The first person to receive the Eucharist, uh, at my first mass was [gentleman's name].

Training/Mentoring: Training/mentoring provided to parishioners to promote success in participation

P: You know, a lot of our people who live on the streets can certainly volunteer but they are mentored. Um. They are assigned a person. For example... we try our best to have everyone be successful here. So we don't let anybody not be in, so yes, we do an awful lot of mentoring. 
Communication: Promoting participation through communication involving simple language

P: And uh, um, her understanding is is is very um third gradish, if you you will in terms of religion...so we have to walk her through that and affirm like you would with a third grader that well, you know, it it is and it isn't...it's a little tougher concepts and abstract thought, of course.

P: I go to a lot of parishes over the course of a year and so often they'll go 'how do you do mass, father?' It's the wrong question for me. I say, 'no, how do you do it? I'm here to help you pray, and you've been doing it'... some guys they go well, okay, I'm gonna show them the right way. Uhhh, no [laughing]. You know, it's how do they, how does that local community do it, including how does the local, how the does the L'Arche community do it?

Utilizing Resources within Community: Working with resources such as the Archdiocese to help promote inclusion

P: Yeah, parents and if we come up short with the parents for some reason, like you know we're coming up with uh a hard situation, we definitely will contact the office at the Archdiocese for support, and they're fantastic.

Collaborating with Family Members: Working with family members to understand what can be done to promote inclusion

P: we can work with you, lets find the way...so far it's been really a no brainer, very easy to do, uh because typically the families... know more than we do and what the needs are, and so its basically just plugging ourselves in with the needs.

Accommodating through Segregated Settings: Accommodating individuals through a setting that is tailored for people with disabilities that allows for inclusion within the larger faith community but not in a mainstream setting

Attitude toward Segregated Settings: Religious leader attitudes toward the use of segregated settings as a way to include people with disabilities

Mixed Feelings: Religious leaders expressing feeling conflicted about the differing wants of stakeholder groups like parents of children with disabilities 
P: families...have told me that you have no idea of how hard it is on us to sit in a regular mass when they feel like they're being judged or the person with the disability themselves can't handle crowds. So it's like if we don't do this [adaptive liturgy], you know for a lot of those families its pretty much the one mass they go to a month, "cause we only do it once a month. So I'm conflicted there. You know, because I understand that but you know, so what is the answer?

Physical Accessibility: Descriptions of the parish that concern the extent to which the parish is physically accessible

P: just changed the confessional because...there is an option to sit in front of the priest or a kneeler, and the kneeler was sticking out in the doorway, so a wheelchair couldn't get in there...We took the carpeting out of the chapel...so that wheelchairs could get in without, you know not, that the wheels wouldn't get tied up in strings of the old carpeting.

Needed Accommodations within Mainstream Mass: Accommodations that religious leaders think should be present for inclusion within their parish

P: What needs to happen around that it is um you know the family or the community itself also interpreting... not just by words but by action...Again that's a piece of breaking down the barrier, but also empowering you know a family or the extended community around the person to also help translate and articulate.

P: They may need to have a discussion, on-going discussion about... what the homily meant, where Father was going later on in the day. Wouldn't it be awesome if everybody kept digging into and throughout the rest of the day and didn't just leave it when they got in the car after going to mass? So I mean we have to find ways. We have to make sure that they're there.

Presence of Individuals with Intellectual Disabilities Impacting Others: Beliefs about the impact people with intellectual disabilities have on others within a setting

P: for them to be an instrument of grace in the community by simply being present. I have found that's just been incredibly powerful. To let people be exposed to the, to peoples' honesty. To be able to see life in sometimes articulated in the simple expressions, that is a powerful gift for a community. So to make sure that people are visible and honored and a part of a family, and not separated out from the family, because the family is also us. 
Beliefs About the Nature of People with Intellectual Disabilities: Beliefs held by religious leaders about the inherent nature (e.g. personality, character) of individuals with intellectual disabilities

Exhibiting Exceptional Skill/Knowledge: The description of individuals with intellectual disabilities demonstrating behavior or knowledge that is viewed to be in excess of what is considered normal

P: It's just, it's almost savant. You know, I don't know if that would be accurate, but yeah it's amazing how he's managed to do that or in a relatively short period of time

Closer to God: The description of individuals with intellectual disabilities being closer to God due to their disability. The descriptions make people with intellectual disabilities appear God-like. The disability is not viewed to be a gift but their presence is as though it is a gift for others.

P: 'cause I think people in the L'Arche, I think they had a deeper, you know they I mean they didn't have all this uh, you know don't have all the prejudice and the and you know who's in and who's out, and you know all of those kinds of things, you know its just a very kind of raw uh simple approach to it.

Not Gift: The belief disability is not described as a gift

P: I don't want to be arrogant and just enough to say it's a gift to be disabled. You know, I might get smacked in the head by some people to say that, you know and I'm not one of those people to say it's a it's, you've been given a gift to be given this illness, this cross to carry, I don't speak in that language.

Cause of Intellectual Disability: Beliefs about the cause of intellectual disabilities

Attitude Toward Fixing: Beliefs about whether people require fixing

P: I think that's one of the really big problems with any kind of emotional or mental disability is that other people think they should be fixed or that they can be fixed. One of the biggest gifts that I've received here is the realization from not only social workers, psychiatrists, and faith leaders in this particular community, but one of the things that I've really really really really learned is that um we cannot fix people. And so that realization in that there is no medication that is going to solve somebody's problem. The only thing that is going to help is community and relationships. That's the healing presence that people are looking for. 
Resources to Understand Intellectual Disabilities: Resources participating religious leaders would use to understand the nature and cause of intellectual disabilities and intellectual disability related issues. These resources are not relied on to provide service but rather help religious leaders and parish staff in working with individuals with intellectual disabilities.

Secular Resources: Resources like medical doctors and social workers that have been used to understand disabilities and disability related issues

P: That psychiatrist, the social workers that we're in contact with

\section{Model II: Conformity}

Leadership Role: Responsibilities and experiences related to ones leadership role within the parish

General Concerns for the Church: Broad concerns religious leaders have that relate to their duties

P: Um and then these days, such a litigious society, trying to keep us out of trouble, keeping people from falling, and then having some disability because they've fallen.

Limitations to One's Authority: Beliefs about the authority a religious leader has in relation to parishioners

P: Um in church law I have an immense amount of authority, but as with most authority, you only have it if you have people with you... Otherwise you're charging ahead and there's nobody behind. And then what is that?...I have immense power yet my parpowers, authority, and, they're limited by what the people give me

Priorities of Larger Church: Religious leaders beliefs about the priorities of the larger Catholic church

P: This is a huge archdiocese and there are many parishes, and you know the pedophilia, the bankruptcy, and all the things we do and so this is not at the top of the list. You know?

P: maybe in the seminary now...but it's probably not as crushing pressure as uh, I think Hispanic community...it's more numbers.

Parish Priorities: Priorities of religious leaders at the parish level 
P: You know [woman with disability] has so many needs, you know for our sake, can someone pick her up and take her to the bus...truthfully, I didn't have the time or energy or ability to do much for her...the priest wants certain things done, and helping somebody to the bus and getting in, you know that's not part of it. [laughing]

Language Used to Describe People with Disabilities: Language used by religious leaders to describe people with intellectual disabilities

Descriptors: Ways in which people with intellectual disabilities are described or labels used to describe them

P: handicapped person

P: down syndrome person.

P: So we had all normal kids and [name of person with intellectual disabilities]

Training: A broad range of experiences relating to training as a seminarian and religious leader

Limitations in Training: Experiences and beliefs about the limitations to seminary training

P: there's a shortage. Whatever mentoring you need to get, you need to get because you're only going to have a short time before you're responsible. And I don't think that's good. Because a certain amount of this you learn by osmosis.

Preference for Specific Parishioner Groups: The preference or liking of particular groups within society as parishioners

Preference Based on Ethnicity: An expressed liking of parishioners who are of particular national groups that stereotypically work in positions requiring high levels of education

P: they're [national groups from Asia] very um, they do well in computers...they're not like the Hispanic community...fixing up uh hotel beds, doing those service things...they tend to do well in uh, computers and...I find them very gracious... when I'm with them, you know heaven's gonna be like this

Preference Based on Socio Economic Status and Education: An expressed liking of parishioners who are of a higher socio economic status and educational background 
P: I am really lucky. I've had, i've had tougher parishes. I have a parish here that is very bright, well educated. I would say 95\% have bachelor's degrees, and probably $75 \%$ masters or more, here. You know I can use big words and they understand. So it's kind of fun preaching. They're well read. They go to movies you know. Go to the opera, symphony...They have a lot of abilities, er capabilities, possibilities that people in [specific area within the city] don't have.

Preference Based on Type of Disability: An expressed preference for people with certain types of disabilities

P: I think that down syndrome type have been easier people.

Beliefs About the Nature of People with Intellectual Disabilities: Beliefs held by religious leaders about the inherent nature (e.g. personality, character) of individuals with intellectual disabilities

Lacking Complexity: Beliefs about individuals with intellectual disabilities lacking complexity and without worries. It implies individuals with intellectual disabilities have inability to experience negative emotions and are easy to please.

P: He lived there [L'Arche] for a while. But so he was in the youth group down there, you know. And I was the youth group leader. So we had all normal kids and [name]... [laughing] He was always happy. You know, if the Oregon Ducks won that day, he was really happy... he was simple, life was simple, some of the other kids, normal kids they got stressed out by work and stuff like that.

P: You know, they're not complicated, they like hugs, you know, those kinds of things

Nature Around Issues of Rights: Beliefs about the character of individuals with intellectual disabilities when they are denied access

P: And sometimes people with uh uh, handicap around rights can be aggressive too. Um and angry.

Resources to Understand Intellectual Disabilities: Resources participating religious leaders would use to understand the nature and cause of intellectual disabilities and intellectual disability related issues. These resources are not relied on to provide service but rather help religious leaders and parish staff in working with individuals with intellectual disabilities.

Secular Resources: Resources like medical doctors and social workers that have been used to understand disabilities and disability related issues 
P: Being here at [university], I have any number of professors and things...I suspect they would be willing to help. You know so. Now there's [county] and all their agencies that can, so.

Relationship with Persons with Disabilities Outside of Parish Life: The relationships religious leaders have with individuals outside of their parish life such as family members and friends

Immediate Family Member: Relationships with individuals who are part of ones immediate family

P: Our oldest one um, you know might have Asperger's or autism or he has a hard time getting initiative...now our second son is very gifted. He might be a doctor, he has a girlfriend, he's charging ahead in life...For years I've asked him [son with possible disability], what's your excitement? What's your passion? It's kind of flat line

Extended Family Member: Relationships with individuals who are not part of ones immediate family but is part of ones extended family (e.g., cousin)

Isolation: The experience of isolation experienced by family members of individuals with disabilities

P: you know their two sons will live them, with them forever. They don't get out much. They can't go take him into social environments 'cause they might go off, you know.

Purpose of Individuals with Intellectual Disabilities: Beliefs about the reason for why people with intellectual disabilities exist or the purpose of their existence in relation to others without disabilities

Parents: Beliefs about the purpose individuals with intellectual disabilities serve as children for parents

P: has taught us so much about love. We are more loving family, because of this child. You know, they're not complicated, they like hugs, you know, those kinds of things...And so, what the handicapped do for us, in our own little selfish worlds, is they draw us out of ourselves.

General Parishioners: Beliefs about the purpose individuals with intellectual disabilities serve for general members of the parish

P: So these handicapped people, God places there...to give us an opportunity...to expand our hearts and to hear another's journey and to look through their eyes and that 
might be a very saving grace actually, if they actually do that. 'Cause if we just stay within ourselves, and selfish, you know, that's kind of the definition of hell, is to be with yourself forever.

\section{Beliefs About Inclusion of People with Intellectual Disabilities in Parish Life:}

Beliefs held by religious leaders about the participation of individuals with intellectual disabilities in sacraments, volunteer positions, service, etc

Mainstream versus Segregated Settings: Beliefs about whether inclusion should be in segregated settings, mainstream settings, or a mixture of both

Proponent for Segregated Settings: The belief that inclusion should be in the form of a segregated setting tailored for people with disabilities

P: The environment is too intellectual for them, they would need a translator. [laughing] Like you see for the deaf or something like that. Or somebody by their side, you know, which is probably generally their parents or something. They've been doing it all their life, translating for them.

P: normal people are just going so fast, things that we do that I feel that they're probably left to the side. Um, unless somebody can slow down and say hello to them...I guess an extended sense they're not productive, you know, what good are they? They're in the aisle, they're in the way.

Beliefs About How Religious Leaders Can Help People with Disabilities: Beliefs held by religious leaders about what they can do to help people with disabilities to be part of their faith community

Referring Individuals with Intellectual Disabilities: The act of referring individuals with intellectual disabilities to a professional working in the area of disability because religious leaders do not believe they can work with individuals with intellectual disabilities

P: I kind of refer, it's not like I can necessarily become um, the expert on uh uh, handicapped or uh, adaptive uh, accommodations here. But maybe somebody on the community that's more, lives in that, can do that.

Employment of Persons with Intellectual Disabilities: Descriptions of individuals with disabilities who work at the parish level and experiences relating to the employees

Parish Staff with Disabilities: A description of staff members who have disabilities 
P: I have a man who is going to be ordained as a priest this year, [name]. [seminarian's name] has [physical disabilities].

Staff with Intellectual Disabilities: Description of staff member with intellectual disabilities

P: Yeah, I'm hiring [name]. Down syndrome. Forty something... she's very bright, and has her own little apartment she takes care of. And she takes care of her accounts and all of that...does her own shopping and uh.

Decision to Hire Person with Intellectual Disabilities: The reason why the participating religious leader chose to hire the woman with intellectual disabilities

P: Her mother and I had lunch recently...she said she's all upset 'cause...she's going to lose her job... she needs to be productive and feel productive...I described what I might need, and she said that would just be perfect for [woman with down syndrome], and said you know her, she'll be great.

Employment Responsibilities: Roles the person with intellectual disabilities will engage in as a staff member

P: Has small small jobs like filing. Little secretarial kind of an office, greeting people...we're going to have her be here two days a week

View Toward Role of Employees with Intellectual Disabilities: The way in which religious leaders describe the employment role of people with intellectual disabilities

P: 'cause her one little job she had

What Participation Can Involve/Look Like: Descriptions of the ways in which individuals with intellectual disabilities participate in parish life which can span from initiating participation or volunteering for a role to the actual participation within a role

Relationships with Parishioners with Disabilities: The types of relationships religious leaders have with parishioners with disabilities

P: I see them in wheelchairs or that...I say hi and I'm kind to them, but uh, I kind of also walk by because there's there people that are walking and you know I'm working with them, and um. So uh, it makes me think you know, uh, well they're in a wheelchair, should I know anything more than that? [laughing] That kind of thing. 
P: I'm a minister but at coffee and donuts, as human beings are, they kind of know who their friends are, so most every Sunday they're sitting with the same friends...I think we're kind and we do well

Initiating Participation: What needs to be done and by whom for participation to take place

Initiated by Parishioners: Participation initiated by parishioners for a role within the parish

P: I can't be calling people and say why didn't you call me. They have to have initiatives.

Proposing Change: Ways in which religious leaders work with proposals for change that are initiated by parishioners

P: I have to listen to them, uh, and understand what they're saying...understand it in my mind, and then I need to propose it to Father...sometimes I let the people talk directly to him because I'd just be in the middle and they need to talk to each other. In other times I need to translate what they're saying and ask to a language that he'll understand, 'cause he doesn't want to be bothered by all these things

Initiated by Religious Leader: Participation initiated by the religious leader for a role within the parish

P: In terms of um, proactively thinking about disabilities, I guess not here.

Eligibility for Participation in Parish Life: Information religious leaders utilize to determine whether individuals can or cannot participate in specific roles

Denied Participation: Experiences with people with disabilities where the religious leader denied participation of a person with disabilities within parish life.

P: Not that I know of. Um. When [man with disability] wanted to read and [woman with disability] wanted to give out communion, um, uh Father has concerns, safety concerns. Um, logistically, how do we do this? Well, uh, for [man with disability] we have to assign somebody else to, how's that gonna work? Who's gonna walk him up to the amble? So uh, number of things that had to be taken care of and decided, and you know, who's gonna work on this?

P: Uh. So like mainstreaming people in classrooms or schools or something. Uh. I think it's a great if they're not totally disruptive, you know. 
Advocacy at Parish Level: Belief that an advocate without a disability is needed at the parish level in order for individuals with intellectual disabilities to participate in parish life

P: the ones that are not handicapped can yell louder or get in your face...they're kind of just pushed to the side... unless you have a special advocate for them in the parish.

Physical Accessibility: Descriptions of the parish that concern the extent to which the parish is physically accessible

P: The church here is a very small, tiny old church that is absolutely unfriendly to anyone with a physical disability, particularly. Stairs all over the place. You know, narrow aisles um.

Requirements for Eucharistic Minister: Information religious leaders utilize to determine whether individuals with intellectual disabilities can engage as a Eucharistic minister

P: Well, I mean they understand for us it's the blood and body of the Lord, and that's the person you're giving. You're not giving bread. You're not giving wine. Pretty simple...And obviously physically are you able to walk up the steps, are you able to hold the cup. Not drop it you know. You know, have enough motor skills to make it work. To do it.

P: I probably wouldn't, um. Or um excuse me, maybe I have them meet with the person who does religious formation and see, you know. Kind of work and see if it's possible...They're just sort of basic kind of expectations of everyone.

Participation in Specific Roles: Descriptions of specific roles that individuals with intellectual disabilities have participated in within their parish

Parish Council: Beliefs about the inability of individuals with intellectual disabilities to be a member of parish council

Not Suitable for Participation: The belief that people with intellectual disabilities should not participate in parish council because of beliefs what it means to have an intellectual disability

P: And and there's an agenda happening or politicking or whatever. Um, and in a blessed sense these people may uh, not catch that at all. Which and you know, I wish I wouldn't either, you know. [laughing] You know, you know, there's no hidden agendas for them [laughing] which is just refreshing. I guess in some way I wish I could be like that, you 
know. I wish we could offer a more like that, but we sometimes are very smart and you know, we're pushing this or that one or whatever. Um, [laughing] so maybe they should come and teach us how to relate [laughing]. 


\section{Model III: Unfortunate Innocent Children}

Language Used to Describe People with Disabilities: Language used by religious leaders to describe people with intellectual disabilities

Descriptors: Ways in which people with intellectual disabilities are described or labels used to describe them

P: who are are uh, dumb

$\mathrm{P}$ : person is intellectually disabled

Beliefs About the Nature of People with Intellectual Disabilities: Beliefs held by religious leaders about the inherent nature (e.g. personality, character) of individuals with intellectual disabilities

Fortune: Beliefs about how unfortunate (i.e., unfavored, ill fated) people with disabilities are which is expressed by contrasting them with people without disabilities

P: They'd just go thinking about how fortunate they are, and their life, and how thankful they are for being there to help those people

Innocent Children: Beliefs about individuals with intellectual disabilities ceasing development at childhood and therefore not adults. Individuals with intellectual disabilities are also viewed as not being able to commit sin or any wrongdoing.

P: there is this huge crucifix above the alter and you know Christ's head was tipped down, and it was like it was looking out over their, the people there, and he was saying, these are my innocent children...these people even though they were adults, mentally they were still children.

P: there's a girl with down syndrome...but he would come and I'm of course always hear her confession and give her absolution, but the question that I have most of the time is how much of this is really a sin for her, you know? How much of this, like she's like really willfully doing and knows that it's wrong and another condition for something to be a sin is that you know that something is wrong and that you are, then you still want to do it and that it's grave matter, and so many times I, with kids once they reach the age of reason, they more or less know when they got into a fight with their brother, sister. They know that's wrong and but sometimes with them I, like my heart goes out to them 'cause I think there's such an innocence in this person that I don't know how much of this is a sin but I give them absolution and all the same...no she doesn't understand that it's a sin, 
or she thinks it's a sin because she's there in confession. I don't know myself if that is really a sin for her...just because of the innocence of the person.

Purpose of Individuals with Intellectual Disabilities: Beliefs about the reason for why people with intellectual disabilities exist or the purpose of their existence in relation to others without disabilities

Child with a Disability: Beliefs about the purpose individuals with intellectual disabilities serve as children with intellectual disabilities

P: may not be the perfect human being, but that child will change you, if you just keep loving that child and helping that child. God's doing the work needed for you through your child. Um. And I believe that.

What Participation Can Involve/Look Like: Descriptions of the ways in which individuals with intellectual disabilities participate in parish life which can span from initiating participation or volunteering for a role to the actual participation within a role

Eligibility for Participation in Parish Life: Information religious leaders utilize to determine whether individuals can or cannot participate in specific roles

P: I don't think we need to promote inclusion in that specific area that you know, it that it might not be for people with disabilities. I don't think we need to include them in that, that we that we say that maybe it's not for them. But I think many times we need to find ways of including them in other areas...so inclusion doesn't mean that everyone needs to have access to everything, you know because that's not true of the world either [laughing], you know. And uh, so understanding inclusion in the right way, I think that no, there's like very clear processes and and uh, of course some things are for some people, some things are for men, some things are for women, some things are for different ages, you know the sacraments and like so many things are, so many things are ruled in that way. You know, what things are for whom, stuff like that, but I don't think in a discriminatory way. But in a respectful way, because it's only to help the person um have a good development in that role and also help the whole community, and so.

Participation Contingent Upon Factors Such As Responsibility: The belief that the roles individuals with intellectual disabilities may be limited due to the level of responsibility required in certain positions

P: For example, the priesthood, if any person is intellectually disabled, and that's such a problem for the person to read, that's the priest, because as a priest you need to be a father and you need um, well there's many things that you need to have... it is not for many people, not with intellectual disabilities... It doesn't mean you're not good for life 
either. There's many good, hard things you could do, um but maybe not this one because of the responsibility you have before people.

Approach to Interacting with Persons with Intellectual Disabilities: Beliefs about what is needed on the part of religious leaders to interact with people with intellectual disabilities

Patience: The belief that patience is required when working with people with intellectual disabilities

P: I had to have a lot of patience uh to be present to them, because they tended to keep repeating things and repeating things, and they would ask questions and I would answer them...you just have to have patience.

Love: The belief that people need to express love toward people with intellectual disabilities

P: Just patience and love. And willingness to give 'em a hug and you know that kind of stuff.

Protection from Harm: Religious leaders feeling the need to protect individuals with intellectual disabilities from others and the general context/environment

P: two young people that came to my young adult group meetings, and uh when [man's name] started to act a little peculiar...I would just kinda go over and say, hey, hey [man's name] lets go get a drink of water or something...it's trying to protect them...But I was always making sure that I was present so that when other people were trying to help and do the wrong thing, trying to help, they don't make it worse. And so, that's where I, that's why I keep saying safety and responsibility.

Promoting Inclusion of People with Intellectual Disabilities in Sacraments: Action taken by religious leaders to include people with intellectual disabilities in sacraments

Training/Mentoring: Training/mentoring provided to parishioners to promote success in participation

P: Gotta see them around. And you can show them and be right with them, almost doing it yourself, but letting them know that they're actually doing it.

Challenges with Accommodations: Challenges religious leaders experience when trying to include people with disabilities in the parish 
Attitudes toward Creating Accommodations: Beliefs held by religious leaders about making changes for accessibility that require changes to the physical structure of a parish

P: And and it its not really an option to modify that or build a ramp or anything, because because we cannot change the façade of the church because it's a, because the church is so old and so from the outside, person I think that you can change.

\section{Beliefs About Inclusion of People with Intellectual Disabilities in Parish Life:}

Beliefs held by religious leaders about the participation of individuals with intellectual disabilities in sacraments, volunteer positions, service, etc

Mainstream versus Segregated Settings: Beliefs about whether inclusion should be in segregated settings, mainstream settings, or a mixture of both

Proponents for Inclusion in Mainstream Mass: Religious leader belief that inclusion should be within the mainstream life of the parish rather than a segregated setting that is tailored for people with disabilities

Resources: Reasons for integration due to the amount of resources (e.g., time) required to create a segregated setting

P: Sometimes its hard because you know in the preparation, just the ordinary preparation for Sunday Eucharist, you know for all the people it takes a lot of effort and time. It's very hard to create something just for disabled people, I think. It's better if we can bring them into the community and that could help them. 


\section{Model IV: Deficiency}

Language Used to Describe People with Disabilities: Language used by religious leaders to describe people with intellectual disabilities

Descriptors: Ways in which people with intellectual disabilities are described or labels used to describe them

P: those who are disabled

P: she's intellectually impaired

General Opinion of Disabilities: Broad beliefs about disabilities in comparison to not having a disability

P: There is something they're not able to do which in the normal daily course of life you would expect people to be able to do. People talk about differently abled, well or the argument about the deaf who you know there are some people in the deaf community who oppose cochlear implants. If I were deaf, I'd kill to get one of those things. It's better to be able to hear than not to hear. Now that doesn't mean that people who don't have hearing who either never had it or who lose it, you know are bad people or that they are sinners, or that they are inferior in some way. But it's better to hear than not be able to hear. Uh, it's better to see than not be able to see.

Beliefs About the Nature of People with Intellectual Disabilities: Beliefs held by religious leaders about the inherent nature (e.g. personality, character) of individuals with intellectual disabilities

Cause: Beliefs about the cause of intellectual disabilities

P: Whether it was a result of his sin or or his parents sin, he said neither. You know, because the reality is, sometimes things just are what they are, why does so and so get cancer and so and so doesn't? Sometimes its just in our DNA, sometimes we're just in the wrong place at the wrong time

Nature: Beliefs about the inherent nature of individuals with intellectual disabilities

P: There is something they're not able to do which in the normal daily course of life you would expect people to be able to do

Blessed: Beliefs about people with disabilities being blessed more than people without disabilities 
P: Um, people who are every bit as beloved of God as you are, in some respects more precisely because they needed more. Um, so yeah, I don't see that at all as patronizing.

Innocent Children: Beliefs about individuals with intellectual disabilities ceasing development at childhood and therefore not adults. Individuals with intellectual disabilities are also viewed as not being able to commit sin or any wrongdoing.

P: It's not bad but do we want to keep them children? Can we let them grow up? You know it's uh, I think it's a disservice to people to say aren't they cute, you know and I think there is that, and especially with down syndrome people, they are cute. They're lovable, they're you know they're open their vulnerable, they're you know, can be taken advantage of pretty easily, but I think not to allow them to grow up in your own mind is a disservice to them. 'Cause they're growing up in their mind, whatever that might mean to them, but I mean um yeah, yeah it's uh, and they want to be self-sufficient. I think if you're gonna, if you're gonna label them as children, you never really allow them to be as self-sufficient as they can be.

prayer

Healing: Beliefs about the possibility of disabilities being healed through

P: It's like I'll pray for healing for certain things, but you want to be careful to avoid creating unnecessary expectations for people. On the other hand, I do know of cases where people have been healed of paralysis. And you know, people have been healed just the way you look at this and say, "Woah!"

Cause: Beliefs about the cause of intellectual disabilities

P: I know there is a lot of scientific evidence that forgiveness makes a huge difference in a persons physical bodily health... Maybe the person was so bound by his resentment that it caused a physical ailment that causes paralysis. I don't know.

P: some of them, who knows, maybe if they had happier lives, freer lives, maybe the dementia wouldn't have set in so early. I have no way to know that. Not my kinda job. [Talking about disabilities generally]

Resources to Understand Intellectual Disabilities: Resources participating religious leaders would use to understand the nature and cause of intellectual disabilities and intellectual disability related issues. These resources are not 
relied on to provide service but rather help religious leaders and parish staff in working with individuals with intellectual disabilities.

P: Uh, but resources in terms of understanding you know what what the uh, you know the documents of the second Vatican Council talk about dealing with people with disabilities across the board, you know from economic to physical to emotional to intellectual.

What Participation Can Involve/Look Like: Descriptions of the ways in which individuals with intellectual disabilities participate in parish life which can span from initiating participation or volunteering for a role to the actual participation within a role

Physical Accessibility: Descriptions of the parish that concern the extent to which the parish is physically accessible

P: Now we're looking at from the perspective of a physical disability, people in wheelchairs or people with walkers. Uh, how do we do that? So, it's a very expensive proposition to put in wheelchair lifts, ramps, and those kinds of things. We do have a wheelchair access on the side of the building here, but that when that was put in, there was code, today I think it's, the code requires a lesser gradient ramp than the one we have on the side.

Promoting Inclusion of People with Intellectual Disabilities in Sacraments: Action taken by religious leaders to include people with intellectual disabilities in sacraments

Communication: Promoting participation through communication involving simple language

P: Part of it was just where each person was, and in what way I could connect with them. So that took a little bit of a while just to, I would watch a lot and make mental notes, so okay, this person will ask, will answer questions, and this person will always be excited so be careful about asking too many rhetorical questions because they'll override everybody else. So then if I give somebody's name, I'd say [name] what do you think? Or look at directly at somebody else and say, ask a question, and that way I allow more people opportunity to participate. And then picking on things um, often times they will react to things that they see and things being acted out.

Reaction of Parishioners toward Individuals with Disabilities: Reactions of parishioners without disabilities toward people with disabilities 
Parishioners without Disabilities Accepting People with Disabilities: The reaction of parishioners without disabilities toward people with disabilities in the parish. This is the reaction of parishioners who consistently attend a parish.

P: People just understood. Once it became the norm, that once a month that this mass, these people, there would be 2 of them, people just understood that's how. If you go to one of them, this is how, this is how they're gonna do it. And we explain to folks uh, first the first couple of times that they did it, and then after that people said, 'oh okay fine.' They got on to it. They were told that this has to work here and they adjusted fine.

Acting Upon Parishioner Reactions: The ways in which religious leaders take action based on the attitudes and behaviors of parishioners without disabilities when considering parish level issues

P: If they have that problem then I would say why, I would like to have a conversation, why why do you see that as problematic? P12: A lot of times its fear, ungrounded fear that people have. But you have to deal with that, in those cases.

\section{Beliefs About Inclusion of People with Intellectual Disabilities in Parish Life:}

Beliefs held by religious leaders about the participation of individuals with intellectual disabilities in sacraments, volunteer positions, service, etc

Parish Life Open To All: The belief that all people should be included in the life of the parish regardless of life situation

P: But to the degree that people can and you know, we want people, we'd like people to try and do that because in that sense they get a sense of belonging to something bigger. You know you're part of this larger family so to speak, all these people and you're a part of this too. P12: So that they have that sense of experience and it's not just looking at other people with their kinds of disabilities and never seeing much beyond that.

Mainstream versus Segregated Settings: Beliefs about whether inclusion should be in segregated settings, mainstream settings, or a mixture of both

Both: Preference for both segregated and integrated settings within parishes

P: Well, I think each has its strengths and its weaknesses. In a in a separate adapted liturgy, you can really focus on the particular needs of the people there, so its like having a children's mass. So when you have a mass for children or younger children, you can really preach differently, you can relate to them differently, the whole focus is different, in a way it's really the, the focus is on them very specifically. When you do a like a Sunday mass, I've got people and they're all across the spectrum in intellectual abilities, 
in terms of their spiritual lives and so on. So, that situation's a lot harder to do a one size fits all. Now I can see that working like Christmas and Easter and those kinds of things which are major celebrations and so to me it's more of a mix and match thing where sometimes, you know for the families who come here

Proponents for Inclusion in Mainstream Mass: Religious leader belief that inclusion should be within the mainstream life of the parish rather than a segregated setting that is tailored for people with disabilities

P: Theologically the ideal community is an inclusive community where people are there because they want to be and they choose to be there and what their strengths or weaknesses or abilities or disabilities may be are irrelevant, what their ethnic background um, gender or any of these kinds of things would be uh secondary. The primary purpose is to gather, and I think that's true with people with intellectual disabilities as well as any other kinds of things, they should be able to be comfortable in you know the mainstream 9 o'clock mass at their local parish, okay, but at the same time there is something to be said for having liturgies that on occasion that address the specific kinds of experiences that people in that category might have as opposed to people in another...I think the ideas would be to integrate the community so that everybody feels a part of the community, I don't like the idea that this group meets here, and this group meets there, and this other group meets over here, they should, that's okay on occasion and for special celebrations, but the ideal would be that they all meet together.

Proponents for Segregated Settings: Reasons for having a segregated setting for people with disabilities

P: Um. Sure. It's two different levels of intellectual capability and so the people in the uh, the people of one intellectual ability would want to be doing things at their intellectual level...they would have to make a commitment to doing some care taking in addition...they get off of work at the end of the day, it's Wednesday night, they wanna, they're tired, but they grab a quick bite to eat and now they're gonna go out and be with their group, and uh, it and you know they're able to relax in the group. 


\section{Model V: Human Diversity}

Language Used to Describe People with Disabilities: Language used by religious leaders to describe people with intellectual disabilities

People First: Language that is people first when talking about people with disabilities

P: People with disabilities

Awareness About Terminology: Awareness that people with disabilities prefer certain language to describe people with disabilities

P: So you would say that to a typical person, you could I think in the same way, uh, help another uh person that was, what's the word, it's not typical, it's..people with disabilities

Relationship with Persons with Disabilities Outside of Parish Life: The relationships religious leaders have with individuals outside of their parish life such as family members and friends

Extended Family Member: Relationships with individuals who are not part of ones immediate family but is part of ones extended family (e.g., cousin)

Included in Familial Activities: Experiences where extended family member were included in activities with family members without disabilities

P: In my family I grew up with a cousin who uh, had severe down syndrome and um, she was part of our life, so it was kind of a typical thing in our family so we didn't have.

Beliefs About the Nature of People with Intellectual Disabilities: Beliefs held by religious leaders about the inherent nature (e.g. personality, character) of individuals with intellectual disabilities

Paralleling Diversity in Other Segments of Society: The belief that people with intellectual disabilities are part of the natural diversity seen among people without disabilities

P: Just as we get used to in any society. There are many characters that you know, the guy who is always negative about whatever you do or whatever the process is, the guy that's judgmental, or the woman that's angry. So these are just other characters that uh, are unique to the community. 
Resources to Understand Intellectual Disabilities: Resources participating religious leaders would use to understand the nature and cause of intellectual disabilities and intellectual disability related issues. These resources are not relied on to provide service but rather help religious leaders and parish staff in working with individuals with intellectual disabilities.

Religious Resources: Resources that within the Catholic faith community that can aid in understanding intellectual disability and intellectual disability issues

P: I think uh, the people who are doing, are the greatest resource, who are doing adaptive liturgy

Secular Resources: Resources like medical doctors and social workers that have been used to understand disabilities and disability related issues

Professionals: Individuals working in the field of disability

P: who work uh, the lay people who already work in the area

Individuals with Disabilities: Individuals who have disabilities

P: with people who that have special needs of any type [cough] uh, are our best resources.

Disability within the Context of the Bible: Beliefs that passages in the bible that appear to be disability related may not actually concern people within intellectual disabilities

P5: You know, I'm I'm trying to see specially when we're talking about intellectual disabilities, I'm not sure that that that is that is as recognized in first century Palestine...But what we do see is a prejudice that Jesus interrupts to the leper, to people who had what we might say, and this would be controversial in some circles, so the demons that are expelled. Well is that someone with an intellectual disability? Is that somebody that has a psychosis?...Christian psychotherapist would probably say yeah, what he was doing was working with people more that had either mental illness or they had, you know, something was going on.

Difference within a Biblical Context: The way in which differences are perceived in first century Palestine 
P: Um, but um, so it's a little more difficult in first century Palestinian um uh culture and in a culture of honor and shame to, to get to that. Clearly in that culture um, anyone that was not typical was seen as somebody that must have been a sinner.

What Participation Can Involve/Look Like: Descriptions of the ways in which individuals with intellectual disabilities participate in parish life which can span from initiating participation or volunteering for a role to the actual participation within a role

Eligibility for Participation in Parish Life: Information religious leaders utilize to determine whether individuals can or cannot participate in specific roles

Desire: The belief that individuals need only to have a desire to participate in the life of their religion

P: Now there are some priests who are ignorant who would say, uh, in a strict reading of the law, uh, that they have to have certain amounts of information knowledge, but uh what the what the documents actually say is that they need a desire.

\section{Promoting Inclusion of People with Intellectual Disabilities in Sacraments:}

Action taken by religious leaders to include people with intellectual disabilities in sacraments

Communication: Promoting participation through communication involving simple language

P: stop, slow down, and engage, explain yourself and then re-explain yourself when that explanation didn't work. And then finally move to story telling or even simple diagrams or whatever you need to do to help the individual.

Collaborating with Family Members: Working with family members to understand what can be done to promote inclusion

P: she was somehow communicating through the parents who were much more articulate, certainly uh, or not articulate, much more uh, able to sense direction. Um. That um, while she wanted it, she did not want water, you know, on her.

Finding a Fit for Individuals and Roles: The consideration of what an individual is able to do and matching ability to possible roles within the parish

P: And and you know, you, one needs to be prudent because it's it's not helpful to put somebody in a situation where they're going to be the brunt of jokes or the their going to be, because of, because you know, they're picking their nose and trying to give out 
communion. You know, because they don't, they can't distinguish. That seems to me to be a cruel thing to do to them. So, trying to and working hard to match up the skills and the abilities of an individual to a particular ministry and their desire... making sure that you're matching skills that um, you know if they're some kind of palsy it would be you know, stupid to give them a cup full of wine. You'd make them fail. That doesn't make any sense to me!

Utilizing Resources within Community: Working with resources such as the Archdiocese or others who have specific skills to help promote inclusion

P: Um. There was one guy who um, I'm not sure what his issues were but a accompanying his, his disability was, he had um epilepsy. So, he'd be up doing a reading and all of a sudden he'd be behind the ally, he'd disappear. You know, you could go over there and he was having a seizure and you know, we have people, nurses and doctors, and all of their needs. So people helped him, but he's, there were consequences.

Approach to Interacting with Persons with Intellectual Disabilities: Beliefs about what is needed on the part of religious leaders to interact with people with intellectual disabilities

Openness: Being flexible and okay with unexpected occurrences when working with diverse groups

P: Like, somebody just kind of acting out or getting up and starting yelling and the most of our people that had some special needs were uh, specifically going to a liturgy because they got to know people... I guess, to that kind of openness. Um, but they're not horrible consequences, they're just sometimes their shocking, sometimes if you're not ready, if you're from another, if you're not from the parish and you're either visiting you'd be like 'What was that!

Reaction of Parishioners toward Individuals with Disabilities: Reactions of parishioners without disabilities toward people with disabilities

Parishioners without Disabilities Accepting People with Disabilities: The reaction of parishioners without disabilities toward people with disabilities in the parish. This is the reaction of parishioners who consistently attend a parish.

P: So, I think people heard that kind of um, um, engagement from them and built on that themselves and that, it really interesting, it was, it was, people who were typical were just kind of going 'what, well of course we're not going to isolate those two people away from here.' You know, I think we kind of started to build consensus in the opposite 
direction, or in the direction of more inclusive. So in the end we decided not to do or have something that would separate anyone from the community.

Relationship with Persons with Disabilities Outside of Parish Life: The relationships religious leaders have with individuals outside of their parish life such as family members and friends

Reflection of Experience: The person experience of being with individuals with intellectual and developmental disabilities

P: I had a great experience with my friend, [name], who I told you about when I went to [center]. The first time I went up there, um, uh, you know I thought well this is going to be fine, I'm thinking. But I walked in and halfway down the hall, and all these kids are various states of, you know, deformity and and consciousness, and I mean it's overwhelming. And I remember I simply froze. Now, I'm a pretty capable individual, I instantly froze.

Fear: Fear of working with individuals with intellectual disabilities based on ones own perceived inability

P: And [name] goes, come here, hold him. My first thought was I'm gonna break that thing, that child, I'm going to do something to it, its head is going to go some way and die or something. So it was much more uh, there was no fear of or prejudice, it was the fear I might break this thing, this child, is, I'm going to hold or that I might do some damage or that I'm going to cross a boundary or, you know, it was those kinds of things. So I think that's probably more the issue for people... But primarily I think people are mostly um, overcome by fear because they just have not been educated.

Overcoming Fear: The experience of overcoming fear through education and interaction

And once [name] educated me, once I could actually hold a baby, and rock in a chair with this baby, it was dying basically. Um, you know then it was okay, 'cause I had done it. I had kind of crossed that boundary of fear.

\section{Beliefs About Inclusion of People with Intellectual Disabilities in Sacraments:}

Beliefs held by religious leaders about the participation of individuals with intellectual disabilities in sacraments

P: Yeah the sacraments should be, well the sacraments are available, that's not an issue.

Segregated versus Integrated Settings: Beliefs about whether segregated settings should be created for people with disabilities 


\author{
Both: Preference for both segregated and integrated settings within \\ parishes
}

P: We had a, the gay and lesbian community down there wanted wanted to have a group. And um, we said okay, well we'll start a group...I think there might have been twelve or thirteen gay and lesbian people and then their parents and family and friends who just said you know what, why are we isolating ourself in a group from the community who is not, who is not, who has made a place for us, who has accepted us, why are we doing this? Because I'd much rather go to the fish fry than sit there in this room and be with everybody else. So, their own choice was to do, to disband that thing and become a regular part of the community, as an example. So I think that there might be stages, and that people need to have the sense and the safety of of um um of an adaptive liturgy.

P5: But I think people necessarily, I don't think either one is the silver bullet. You know, for a family, you really really have it, it's where you're at a particular time. My guess though would that inevitably what a family really wants and what people really want is to be part of something that is typical, that everybody is doing, that is bigger than themselves. That's my gut. I don't know if I'm right or wrong, but that's my gut reaction.

People with Disabilities: Perspectives of people with disabilities in regard to mainstream and segregated settings

Proponents for Integration in Mainstream Mass: Experiences where people with disabilities have advocated for participation in mainstream mass

P: Well, two of the people who were uh, I don't know, I would suspect one might have been a down syndrome young man and then a young woman who I think, and if my memory serves me right, had been in an accident and had damaged her brain. So these two people had a lot of limitations and um, but they were both serving at mass. No one prompted them, they got up and go 'I don't want to leave my mass!' You know so there was that kind of, you know they were very vocal about it.

Parents: Perspectives of parents in regard to mainstream and segregated settings

Stigma: Experience of stigma in mainstream settings

P: So we had this one woman who was kind of facilitating the discussion, and um, one mother got up and said we just, you know, we really need a place, I don't feel welcomed, I want something where I don't have to feel that I am looked at strangely because I come 
in late and my child had, I think the child had um a very severe Asperger's, something, and I think a couple others serious issues...

P: With families with people with disabilities, we had people working and in our liturgies that um had some kind of limitation or disability...So we had this group of parents who wanted a special kind of thing. Uh because they didn't want to be looked at strangely when they came in with their child who had whatever it was who had was aspirating half way through or screaming out in the middle of the liturgy, frightening people or, they just said they were exhausted by I think their experience of a community that either somebody would turn around and look at them strangely or whatever 